\title{
The periaqueductal gray and defensive behaviour : new clues from an old concept
}

Citation for published version (APA):

Lim, L. W. (2009). The periaqueductal gray and defensive behaviour : new clues from an old concept. [Doctoral Thesis, Maastricht University]. Datawyse / Universitaire Pers Maastricht.

https://doi.org/10.26481/dis.20090205ll

Document status and date:

Published: 01/01/2009

DOI:

10.26481/dis.20090205II

Document Version:

Publisher's PDF, also known as Version of record

\section{Please check the document version of this publication:}

- A submitted manuscript is the version of the article upon submission and before peer-review. There can be important differences between the submitted version and the official published version of record.

People interested in the research are advised to contact the author for the final version of the publication, or visit the DOI to the publisher's website.

- The final author version and the galley proof are versions of the publication after peer review.

- The final published version features the final layout of the paper including the volume, issue and page numbers.

Link to publication

\footnotetext{
General rights rights.

- You may freely distribute the URL identifying the publication in the public portal. please follow below link for the End User Agreement:

www.umlib.nl/taverne-license

Take down policy

If you believe that this document breaches copyright please contact us at:

repository@maastrichtuniversity.nl

providing details and we will investigate your claim.
}

Copyright and moral rights for the publications made accessible in the public portal are retained by the authors and/or other copyright owners and it is a condition of accessing publications that users recognise and abide by the legal requirements associated with these

- Users may download and print one copy of any publication from the public portal for the purpose of private study or research.

- You may not further distribute the material or use it for any profit-making activity or commercial gain

If the publication is distributed under the terms of Article $25 \mathrm{fa}$ of the Dutch Copyright Act, indicated by the "Taverne" license above, 


\section{The Periaqueductal Gray and Defensive Behaviour: New Clues from an Old Concept}

LEE WEI LIM 
The cover design was based on "The Scream" (Skrik, 1893-1910), a seminal series of expressionist paintings by the Norwegian artist Edvard Munch, depicting a blood red sky.

"I was walking along a path with two friends, the sun was setting, suddenly the sky turned blood red; I paused, feeling exhausted, and leaned on the fence, there was blood and tongues of fire above the blueblack fjord and the city, my friends walked on, and I stood there trembling with anxiety, and I sensed an infinite scream passing through nature".

Typesetting: Lee Wei Lim

Copyright: (C) Lee Wei Lim, Maastricht 2008

All rights reserved. No part of this book may be reproduced in any form or by any electronic means, including information, storage and retrieval systems, without permission in writing from copyright holder.

ISBN: 978-90-9023955-2

Printed in the Netherlands

Universitaire Pers Maastricht 


\title{
The Periaqueductal Gray and Defensive Behaviour: New Clues from an Old Concept
}

\author{
Proefschrift \\ Ter verkrijging van de graad van doctor aan \\ de Universiteit Maastricht, op gezag van \\ de Rector Magnificus, Prof. Mr. G.P.M.F. Mols \\ volgens het besluit van het College van Decanen, \\ in het openbaar te verdedigen op
}

Donderdag 5 Februari 2009 om 16.00 uur

door

Lee Wei Lim

Geboren op 10 September 1980 te Maleisië 


\section{Promoters}

Prof. Dr. H. W. M. Steinbusch

Prof. Dr. V. Visser-Vandewalle

\section{Co-promoters}

Dr. Y. Temel

Dr. A. Blokland

\section{Evaluation Committee}

Prof. Dr. J. J. van Overbeeke (Chairman)

Prof. Dr. J. S. H. Vles

Prof. Dr. M. De Baets

Dr. K. Schruers 


\section{"S.ience is the attempt to make the chaotic diversity of our sense experience correspond to a logically uniform system of thought."}

Albert Einstein (1879-1955)

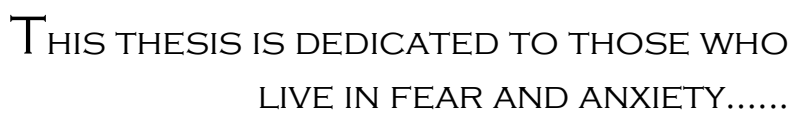





\section{CONTENTS}

Chhatpitien 11: General Introduction

Chliapitier 2: $\quad$ The Periaqueductal Gray: from longitudinal $\quad 17$ column to defensive behaviour

Submitted

Chlalpitere 3: $\quad$ Fos immunoreactivity in the rat forebrain induced by electrical stimulation of the dorsolateral periaqueductal gray

J Chem Neuroanat. (In press)

Chlialpitere 4 s: $\quad$ Effect of buspirone on the behavioural regulation of rats in low versus high anxiety conditions Arzneimittelforschung (Drug Res) 58:6 (2008) 269-276

Chlatpitiers 5; $\quad$ High-frequency stimulation of the dorsolateral periaqueductal gray and ventromedial hypothalamus fails to inhibit panic-like behaviour Behav Brain Res193 (2008) 197-203

Chlialpitere 6: $\quad$ Buspirone induced acute and chronic changes of neural activation in the periaqueductal gray of rats Neuroscience 155 (2008) 164-173

Chianpitien $\bar{y}$; $\quad$ Electrical stimulation of the dorsolateral periaqueductal gray evokes escape response followed by fear behaviour in rats: reversal by SSRI treatment

Submitted

Chlialpitiers 8: $\quad$ Conclusion

Acknowledgement

Biography

List of Publications 


\section{$(C H[A] P) T[E] \mathbb{R} \Perp$}

\section{GENERAL INTRODUCTION}

Periaqueductal Gray and Defensive Behaviour:

New Clues from an Old Concept 


\section{General Introduction}

"F ear produces an agony and anxiety about the heart not to be described; and it may be said to paralyze the soul in such a manner, that it becomes insensible to everything but to its own misery.....When the effects of fear operate powerfully, without any mixture of hope, these passive impressions are predominant but where there is a possibility of escape, the mind reacts with wonderful energy...enabling the sufferer to precipitate his flight, by exertions that would have been impracticable in a more composed state of mind"

T. Cogan, On the Passions (1802)

Defensive behaviour is a form of behavioural and neuropsychological response to fear or anxiety condition due to avoidable and unavoidable threat stimuli. It plays an important role to protect an organism from potentially dangerous conditions where animals learn to escape from and avoid places where they have been attacked or hurt (Blanchard and Blanchard 1972; Panksepp 1998). The characteristic of stimuli is based on the presence of elements of either fear and/or threat, which may be real or perceived to be a threat stimulus as defined in both human and animal studies (Anders et al 2008; LeDoux 1993). Defensive behaviour is commonly categorized into flight, fight, and freeze responses. In rodents, subjects usually fear of high-illuminated areas and the smell of potential predators such as cat odor (Blanchard et al 1990; Dielenberg et al 1999). In humans defensive behaviour is associated with a number of complicated cognitive and emotional states including anxiety, horror, panic, and fearful sensation (Goossens et al 2007; Lobue and DeLoache 2008; Teachman et al 2008). Different types of fear can be observed across different animal species. The fear response is initiated and controlled by the defense system, which runs from the cortex to the periaqueductal gray (PAG) (Davis 1996; LeDoux 1993; McNaughton and Corr 2004).

Studies using electrical deep brain stimulation (DBS) to explore the function of brain areas have revealed the existence of a coherent operating fear system in the brain. When this system is activated by an internal stimulus such as electrical stimulation of the PAG, animals show a variety of defensive behaviours, ranging from a freezing response to escape (flight) reactions (Carrive 1993; Jenck et al 1995; Lim et al 2008a). These reflect the different types of fear responses which are similar to the behaviour of animals that have perceived a predator at a far or near distance. Even though animals show escape reaction when this fear system is stimulated, they cannot learn to avoid the electrical brain stimulation induced fearful behaviour (Bandler and Shipley 1994; Bittencourt et al 2005; Jenck et al 1995). It is noteworthy that electrical stimulation of the dorsolateral PAG (dlPAG) evokes a typical reaction which is generally regarded as escape or defensive behaviour (Bandler and Shipley 1994; De Oca et al 1998). This behaviour consists of a spontaneous flight reaction characterized by wild running, galloping, and 
jumping accompanied by hypertension, tachycardia, tachypnoea, freezing, and fear-like responses (Bittencourt et al 2005; Hogg et al 2006; Lim et al 2008a). In humans, it has been reported that electrical stimulation of the PAG can produce intense emotional fear sensation, with remarkable autonomic changes, which are features of a typical panic attack (PA) (Amano et al 1978; Mobbs et al 2007; Nashold et al 1969).

\section{CURRENT PROBLEM}

Panic disorder (PD) is one of the most frequently encountered anxiety disorder, and one out of every seventy five people worldwide experiences a panic attack (PA) once in their lives (NIH 1991). PAs are characterized by an acute moment of intense fear or psychologically distress with a sudden onset rapidly building to a peak level and are usually accompanied by somatic and psychological symptoms associated with a sense of impending danger and an urge to escape from the susceptible risk condition (Craske and Waters 2005; Griez and Schruers 1998; Klerman et al 1993). PA is recognized as a disabling condition and its treatment includes pharmacologic and behavioural therapies as well as combinations of these strategies (American-Psychiatric-Association. 2000; Barlow et al 2000; Goisman et al 1999). In some cases, patients do not respond to these treatments and experience a chronic course of disease burden, usually together with their families (Fleet et al 1996; Reiman et al 1984; Roy-Byrne et al 1999).

Besides, many clinical reports have demonstrated that PD is closely associated with agoraphobia, a distinguishing feature of fear in having a PA at a place from which escape is difficult (Kessler et al 2006; Marchand et al 2008; Roberge et al 2008). This psychopathology is generally followed by agoraphobia which develops from an intrinsic mechanism after a person has experienced an episode or several series of PAs (Kessler et al 2006; Marchand et al 2008; Roberge et al 2008). Such a person usually associates the panic with the location or environment where it occurred, and therefore this place is considered no longer secure. Patients usually experience this as a high state of anxiety with fear of losing control and social embarrassment (Goisman et al 1994; Vincelli et al 2000; Wittchen et al 2008).

Many studies in which the effects of the PAG stimulation have been investigated in combination with psychopharmacological challenge showed that the PAG is involved in panic or anxiety-like behaviour. Thus, the use of electrical stimulation of the PAG as an animal model can be used in the development of novel panicolytic, anxiolytic, and phobiolytic drugs. 


\section{AIM OF THE PRESENT STUDY}

Investigating the defensive behaviour induced by electrical stimulation of the dIPAG is one of the main topics of this thesis. We have specifically chosen this animal model to gain more knowledge about the functional anatomy and behavioural phenotype of defensive behaviour. At present, we are still in the early stages of understanding fearful emotion and cognitive behaviour and the exact role of the PAG in these behaviours. Nevertheless, recent developments in neuroscience will gradually reveal the nature and complexities of emotionality of defensive behaviour in our phylogenetically old brain structure - the PAG.

The aim of the studies presented in this thesis was to investigate the possibilities to modulate the activity of the dIPAG in order to induce or attenuate fear responses in the rat. This modulation was achieved by state-of-art deep brain stimulation (DBS) of the dIPAG and treatment with serotonin (5-HT) drugs. The purposes and results of experiments are described in the following chapters.

In Chapter 2, we provide an extensive review on the histology, anatomy, and chemistry of the PAG. In addition, we outline the involvement of different PAG parts in different behaviours. In Chapter 3, we present an overview of the neural activation (cFos immunoreactivity) in the different neuroanatomical structures following escape behaviour induced by electrical stimulation of the dIPAG. Chapter 4 aims to find a behavioural model with high and low fear in which we could test the effects of dIPAG stimulation. This study provides further evidence of the effects of buspirone on different levels of anxiety which were evaluated in two different conditions of the open-field. Following this, Chapter 5 tests the hypothesis that electrical stimulation of the dIPAG at higher frequencies $(>100 \mathrm{~Hz})$ could be used to inhibit escape or panic-like behaviour. This was based on findings in which high frequency DBS of the subthalamic nucleus inhibited the output of this structure. Likewise, we would expect an inhibition of the output of the dIPAG which may prevent the fear response. In Chapter 6, we investigate the change in neuronal activities within the different regions of the PAG using buspirone (a 5-HT1A partial agonist) in the treatment of generalized anxiety disorder. Chapter 7 addresses the main hypothesis whether the fear-like behaviour could be attenuated by acute and chronic administration of buspirone or the SSRI escitalopram. Additionally, the levels of blood corticosterone were also explored with respect to the different experimental conditions. Finally, in Chapter $\boldsymbol{8}$, we provide an overall conclusion of our experimental findings and translate this to the clinical setting. 


\section{References}

Amano K, Tanikawa T, Iseki H, Kawabatake phobias, and generalized anxiety disorder. Annu Rev Clin Psychol 1:197-225.

Davis M (1996): Fear-potentiated startle in the study of animal and human emotion. In emotion: An interdisciplinary approach (R. Kavanaugh, B Zimmerberg, \& S. FIne, eds), pp. 61-89. Hillsdale, N.J.: Lawrence Erlbaum.

De Oca BM, DeCola JP, Maren S, Fanselow MS (1998): Distinct regions of the periaqueductal gray are involved in the acquisition and expression of defensive responses. $J$ Neurosci 18:3426-3432.

Dielenberg RA, Arnold JC, McGregor IS (1999): Low-dose midazolam attenuates predatory odor avoidance in rats. Pharmacol Biochem Behav 62:197-201.

Fleet RP, Dupuis G, Marchand A, Burelle D, Arsenault A, Beitman BD (1996): Panic disorder in emergency department chest pain patients: prevalence, comorbidity, suicidal ideation, and physician recognition. Am J Med 101:371-380.

Goisman RM, Warshaw MG, Keller MB (1999): Psychosocial treatment prescriptions for generalized anxiety disorder, panic disorder, and social phobia, 1991- H, Notani M, Kawamura H, et al (1978): Single neuron analysis of the human midbrain tegmentum. Rostral mecencephalic reticulotomy for pain relief. Appl Neurophysiol 41:66-78.

American-Psychiatric-Association. (2000): Diagnostic and statistical manual of mental disorders. 4th ed., text revision. Washington, D.C.: American Psychiatric Association.

Anders S, Eippert F, Weiskopf N, Veit R (2008): The human amygdala is sensitive to the valence of pictures and sounds irrespective of arousal: an fMRI study. Soc Cogn Affect Neurosci 3:233-243.

Bandler R, Shipley MT (1994): Columnar organization in the midbrain periaqueductal gray: modules for emotional expression? Trends Neurosci 17:379-389.

Barlow DH, Gorman JM, Shear MK, Woods SW (2000): Cognitive-behavioural therapy, imipramine, or their combination for panic disorder: A randomized controlled trial. Jama 283:2529-2536.

Bittencourt AS, Nakamura-Palacios EM, Mauad H, Tufik S, Schenberg LC (2005): Organization of electrically and chemically evoked defensive behaviours within the deeper collicular layers as compared to the periaqueductal gray matter of the rat. Neuroscience 133:873-892.

Blanchard DC, Blanchard RJ (1972): Innate and conditioned reactions to threat in rats with amygdaloid lesions. J Comp Physiol Psychol 81:281-290.

Blanchard RJ, Blanchard DC, Weiss SM, Meyer S (1990): The effects of ethanol and diazepam on reactions to predatory odors. Pharmacol Biochem Behav 35:775-780.

Carrive P (1993): The periaqueductal gray and defensive behaviour: functional representation and neuronal organization. Behav Brain Res 58:27-47.

Craske MG, Waters AM (2005): Panic disorder, 1996. Am J Psychiatry 156:1819-1821.

Goisman RM, Warshaw MG, Peterson LG, Rogers MP, Cuneo P, Hunt MF, et al (1994): Panic, agoraphobia, and panic disorder with agoraphobia. Data from a multicenter anxiety disorders study. J Nerv Ment Dis 182:72-79.

Goossens L, Sunaert S, Peeters R, Griez EJ, Schruers KR (2007): Amygdala hyperfunction in phobic fear normalizes after exposure. Biol Psychiatry 62:1119-1125.

Griez E, Schruers K (1998): Experimental pathophysiology of panic. J Psychosom Res 45:493-503.

Hogg S, Michan L, Jessa M (2006): Prediction of anti-panic properties of escitalopram in the dorsal periaqueductal grey model of panic anxiety. Neuropharmacology 51:141-145.

Jenck F, Moreau JL, Martin JR (1995): Dorsal periaqueductal gray-induced aversion as a simulation of panic anxiety: elements of face and predictive validity. Psychiatry Res 57:181-191.

Kessler RC, Chiu WT, Jin R, Ruscio AM, Shear K, Walters EE (2006): The epidemiology of panic attacks, panic disorder, and agoraphobia in the National Comorbidity Survey Replication. Arch Gen Psychiatry 63:415-424.

Klerman GL, Hirschfeld RMA, Weissman MM (1993): Panic Anxiety and Its Treatments: Report of the World Psychiatric Association Presidential Educational Program Task Force. American Psychiatric Association:pp 44. 
LeDoux JE (1993): Emotional networks in the brain. In Handbook of emotions (M. Lewis \&J. M. Haviland, eds.) New York: Guilford Press:109-118.

Lim LW, Blokland A, Visser-Vandewalle V, Vlamings R, Sesia T, Steinbusch H, et al (2008): Highfrequency stimulation of the dorsolateral periaqueductal gray and ventromedial hypothalamus fails to inhibit panic-like behaviour. Behav Brain Res 193:197-203.

Lobue V, DeLoache JS (2008): Detecting the snake in the grass: attention to fear-relevant stimuli by adults and young children. Psychol Sci 19:284-289.

Marchand A, Coutu MF, Dupuis G, Fleet R, Borgeat F, Todorov C, et al (2008): Treatment of Panic Disorder with Agoraphobia: Randomized Placebo-Controlled Trial of Four Psychosocial Treatments Combined with Imipramine or Placebo. Cogn Behav Ther:1-14.

McNaughton N, Corr PJ (2004): A two-dimensional neuropsychology of defense: fear/anxiety and defensive distance. Neurosci Biobehav Rev 28:285-305.

Mobbs D, Petrovic P, Marchant JL, Hassabis D, Weiskopf N, Seymour B, et al (2007): When fear is near: threat imminence elicits prefrontal-periaqueductal gray shifts in humans. Science 317:1079-1083.

Nashold BS, Jr., Wilson WP, Slaughter DG (1969): Sensations evoked by stimulation in the midbrain of man. J Neurosurg 30:14-24.

NIH NIoH (1991): Treatment of Panic Disorder. NIH Consens Statement 9(2):1-24.

Panksepp J (1998): Affective Neuroscience: The foundations of human and animal emotions. Oxford University Press:206-222.

Reiman EM, Raichle ME, Butler FK, Herscovitch P, Robins E (1984): A focal brain abnormality in panic disorder, a severe form of anxiety. Nature 310:683-685.

Roberge P, Marchand A, Reinharz D, Savard P (2008): Cognitive-behavioural treatment for panic disorder with agoraphobia: a randomized, controlled trial and cost-effectiveness analysis. Behav Modif 32:333-351.

Roy-Byrne PP, Stein MB, Russo J, Mercier E, Thomas R, McQuaid J, et al (1999): Panic disorder in the primary care setting: comorbidity, disability, service utilization, and treatment. J Clin Psychiatry 60:492-499; quiz 500.

Teachman BA, Stefanucci JK, Clerkin EM, Cody MW, Proffitt DR (2008): A new mode of fear expression: perceptual bias in height fear. Emotion 8:296-301.

Vincelli F, Choi YH, Molinari E, Wiederhold B, Riva G (2000): Experiential cognitive therapy for the treatment of panic disorders with agoraphobia: definition of a clinical protocol. Mary Ann Liebert Inc Publishers.

Wittchen HU, Nocon A, Beesdo K, Pine DS, Hofler M, Lieb R, et al (2008): Agoraphobia and panic. Prospective-longitudinal relations suggest a rethinking of diagnostic concepts. Psychother Psychosom 77:147-157. 
16 


\title{
CHHAPPTCIER $\underline{2}$
}

\section{The Periaqueductal Gray: From longitudinal columns to defensive behaviour}

\author{
Lee Wei Lim, Arjan Blokland, Veerle Visser-Vandewalle,
} Harry Steinbusch, and Yasin Temel

\begin{abstract}
Recent findings on the different functional properties of the neuroanatomical columnar subdivision of the Periaqueductal Gray (PAG) have provided a fundamental understanding for the pathophysiology of panic and anxiety disorder. In this review, we focus mainly on the prominent role of the PAG in defensive behaviour by combining both the behavioural and neuroanatomical data. We have applied the theoretical model of the "two dimensional defence system" by McNaughton and Corr (2004), and thereby constituted an organizational structure on the neuronal circuitry of the different brain regions in relation with this panic- and fear-like behaviour. It has become clear that the dorsal and lateral PAG are involved in the active emotional coping (fight and flight reaction), whereas the ventrolateral PAG is responsible for the passive emotional coping (quiescence/freezing). In this regard, the PAG and other related brain structures are working in concert with different neurotransmitters providing animals with defensive strategies in response to predatory threats. The functional roles of the PAG in these behaviours as characterized in animals warrants further translational studies in humans which may eventually lead to novel approaches in anxiety- and panic-related disorders.
\end{abstract}

(Submitted) 


\section{Table of contents}

1. Introduction

1.1 Background

1.2 Organisation of the review

2. Organisation of the PAG

2.1 Cell types

2.2 Longitudinal columns

2.3 Regional anatomy of the PAG

3. Functional connections of the PAG

3.1 Upstream connections

3.1.1. Amygdala

3.1.2. Hypothalamus

3.1.2.1 Anterior hypothalamus

3.1.2.2 Medial part of the Posterior Hypothalamic area

3.1.2.3 Paraventricular Hypothalamic Nucleus

3.1.2.4 Lateral Hypothalamic area

3.1.3 Thalamus

3.1.4 Raphe nuclei and reticular formation

3.1.5 Substantia nigra and ventral tegmental area

3.1.6 Cortical connections

3.2 Downstream connections

3.2.1 Pons and medulla oblongata

3.2.2 Spinal cord

4. Neurochemistry of the PAG

4.1 Monoamines and amino acids

4.1.1 Serotonin

4.1.2 Dopamine

4.1.3 Noradrenalin

4.1.4 Glutamate

4.1.5 GABA

4.2 Neuropeptides and opioid receptors

4.2.1 Substance P

4.2.2 Cholecystokinin

4.2.3 Enkephalin

5. Discussion

4.2.4 Opioid receptors

5.1 The defence circuit of the PAG

5.2 Summary

5.3 Perspectives 


\section{Introduction}

\subsection{Background}

Panic attack is characterized by an acute moment of intense fear and psychological distress with a sudden onset and rapidly building to a peak level. It is frequently followed by somatic and psychological symptoms associated with a sense of impending danger and an urge to escape from the susceptible risk condition (Griez and Schruers 1998; Griez et al 2001). Besides, panic attack is regarded as the central pathological feature of panic disorder with physical symptoms such as shortness of breath, sweating, palpitations, trembling, feeling of choking, chest pain or discomfort, nausea or abdominal distress, feeling dizzy or unsteady, derealisation, fear of losing control, fear of dying, paresthesia, and chills or hot flushes (American-Psychiatric-Association 2000). The percentage of lifetime prevalence of panic attack in the United States range 3-5.6\% and 1.5-5\% for panic disorder (American-Psychiatric-Association 1998 May); and in Europe, the prevalence has been reported as $1.8 \%$ for panic disorder (Goodwin et al 2005). This disorder does not only cause functional disability but also affects the quality of life and related socio-economic conditions and interpersonal relationships (Abbar 1996; Klerman et al 1991; Wittchen 1988).

To study the neurobiology underlying panic animal models have been developed in which animals display panic-like behaviour. A widely used and highly reproducible rodent model for panic and related behaviours is the electrical stimulation of the periaqueductal gray (PAG). This technique involves the implantation of an electrode to stimulate specific parts of the PAG. Electrical PAG stimulation evokes a typical escape behaviour, which is also referred as defensive behaviour or panic-like behaviour. This behaviour is characterized by fight, flight \& freezing responses involving increased locomotor activity, galloping and jumps (Bandler et al 1985b; Brandao et al 1999; Brandao et al 1982; Brandao et al 2003). The defensive behaviour has been proposed to reflect aversive responses since they are very similar to escape reactions induced by natural aversive stimuli, such as the exposure to a proximal predator (Blanchard et al 1988; Blanchard and Blanchard 1989a; Blanchard and Blanchard 1989b). Interestingly, two types of behaviour can be observed during electrical stimulation of the PAG. It has been found that sub-threshold stimulation resulted in freezing and stimulation at the threshold or above induced escape reaction. Following the post-stimulation period, the animals displayed highly immobile, indicative of fear response (Lim et al 2008a; Vianna et al 2001c). 
In humans, stimulation of the PAG was originally applied for pain relief (Richardson and Akil 1977a; Richardson and Akil 1977b; Young et al 1985). Some studies also reported other findings after PAG stimulation. For example, in 1915 it was described by Brown that the PAG was a site for eliciting vocalization or "laughter" when stimulated with electrical current (Brown 1915). Twenty years later, Kabat and coworkers demonstrated that PAG stimulation increased the respiratory rate and blood pressure (Kabat et al 1935). Many other studies have demonstrated that PAG stimulation produced intense emotional fear sensation, impending death with remarkable autonomic changes as characterized by the typical feature of panic attack (Amano et al 1978; Mobbs et al 2007; Nashold et al 1969). Recently, clinical reports have also shown that the reduction of pain and blood pressure were achieved by stimulating the rostral PAG and this is possibly mediated by a reduction in the central sympathetic system (Green et al 2007; Green et al 2006).

In the search for novel drugs and surgical therapies in panic disorders the PAG seems to be an interesting target. In 1990 Depaulis and Bandler provided an overview of the anatomical and neurochemical properties of the PAG and its role in defensive behaviour. In this review, we have applied the theoretical model of the "two dimensional defence system" by McNaughton and Corr (McNaughton and Corr 2004) and constituted an organizational structure for PAG regions in relation with this defensive behaviour. The two dimensional defensive behaviour is categorized into "defensive direction" and "defensive distance" based on the concept of Gray's "Neuropsychology of Anxiety" (Gray 1982). The first dimension describes the two systems of defensive behaviour associated particularly with the PAG in controlling defensive avoidance (fear) and defensive approach (anxiety) (See Figure 1 and 2). The second dimension illustrates an important hierarchical neural organization of defensive behaviour with respect to the different levels of neuroanatomical structures. 


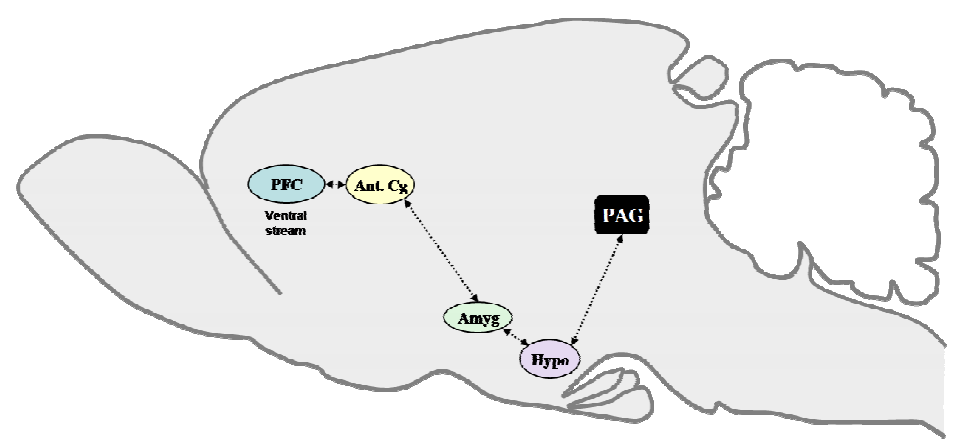

Figure 1, Schematic illustration of the main upstream connections of the PAG based on the McNaughton and Corr's two-dimensional defence system of "defensive avoidance" for panic and fear behaviour (McNaughton and Corr 2004). $\mathrm{PFC}=$ Prefrontal cortex (ventral stream), Ant. $\mathrm{Cg}=$ Anterior Cingulate, $\mathrm{Amyg}=$ nuclei of Amygdaloid complex, $\mathrm{Hypo}=$ Hypothalamus, and $\mathrm{PAG}=$ Periaqueductal Gray.

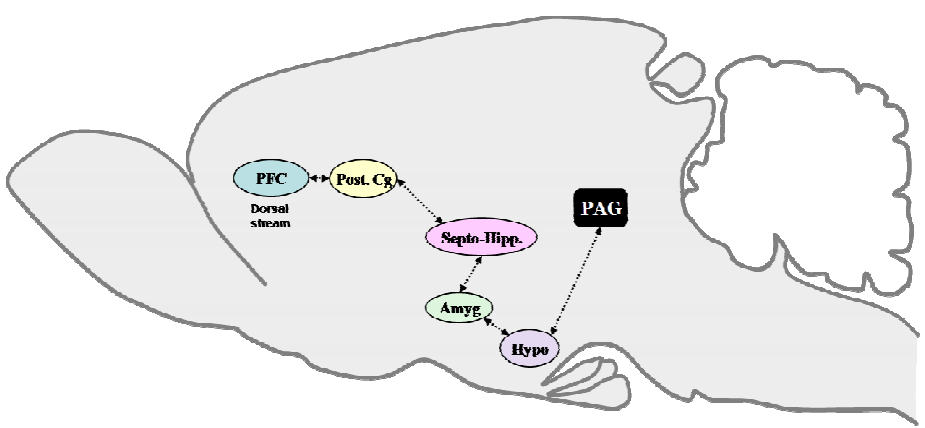

Figure 2, Schematic illustration of the main upstream connections of the PAG based on the McNaughton and Corr's two-dimensional defence system of "defensive approach" for anxiety related behaviour (McNaughton and Corr 2004). PFC= Prefrontal cortex, Post. $\mathrm{Cg}=$ Posterior Cingulate, Amyg= nuclei of Amygdaloid complex, Septo-Hipp= Septo-Hippocampal system, $\mathrm{Hypo}=$ Hypothalamus, and $\mathrm{PAG}=$ Periaqueductal Gray. 


\subsection{Organisation of the review}

We will first describe the intrinsic organization of the PAG including the specific cell types and the anatomical and functional separation into longitudinal columns, followed by a brief description of the regional anatomy in Section 2. In Section 3, the upstream and downstream connections of the PAG and its subdivisions will be discussed in detail. We will mainly focus on the functional and anatomical interconnections. Subsequently, in Section 4 we will review the neurochemical properties of the PAG including their behaviour correlates. In Section 5, we will discuss the role of the PAG in defensive behaviour in the light of behavioural and neuroanatomical data. Finally, we will discuss the use of animal models in which the PAG is stimulated and how this research may contribute to a promising future in treating neuropsychiatric disorders.

\section{Intrinsic organization of the PAG}

The PAG, also called the "substantia grisea centralis" or "central gray", surrounds the cerebral aqueduct of Sylvius from the midbrain to the brain stem. At the level of individual cells, three main types of neurons can be found. At the level of the PAG structure, cells are organized in longitudinal columns.

\subsection{Cell types}

Examination at the cellular level shows that the PAG consists of diffuse collection of neurons and fibers surrounding the cerebral aqueduct and the reticular formation, which are both important relay centers for ascending and descending sensorimotor pathways to and from the spinal cord (Jordan et al 1992; Zieglgansberger and Puil 1973). The morphology of the population of the majority of the neurons in the PAG comprises three major cell types: vertical cells, stellate cells, and horizontal cells (Laemle 1979). In general, the neurons of the PAG are all relatively small, ranging in size from 8 to $30 \mu \mathrm{m}$ in diameter. Based on the Golgi-Cos study, these neurons can be divided into three different types, Class I (Ia \& Ib), II and III cells (IIIa, IIIb, IIIc, and IIId), according to their size and cytological characteristic (Hamilton 1973a; Hamilton 1973b; Liu and Hamilton 1980).

(a) Class I ( Ia \& Ib) neurons are approximately $18 \mu \mathrm{m}$ in length and $8 \mu \mathrm{m}$ in diameter. They are the smallest of the three types and have the shape of spindle bipolar neurons with one straight dendritic process. The nucleus is rather large, oval in shape and stains slightly lighter than the surrounding cytoplasm with the Nissl staining. The cells are generally darkly stained and have typically axons projecting from one end of the cell. The nucleus is located in the center and takes up the entire width of the cell. Nissl substances are uniformly distributed and are not found in clumps. Class I neurons are 
usually found in the medial regions of the PAG. The type Ia is smaller than the type $\mathrm{Ib}$ and they are found particularly in the medial PAG.

(b) Class II neurons are approximately $11 \mu \mathrm{m}$ in length and $12 \mu \mathrm{m}$ in diameter and are slightly larger with a fusiform or spherical shape. Triangular shaped neurons can also be found and have an apical dendrite that traverses a long distance within the PAG. The nucleus in this cell type is usually irregularly shaped. The axons of these cells are located in the central region, not at a pole as in class I neurons. Class II neurons generally have several dendrites. The Nissl substance is arranged in clumps which are evenly distributed in the cytoplasm. Class II neurons can be found in the area just dorsal to the cerebral aqueduct (the dorsal parts of the PAG) along with a large number of glial cells.

(c) Class III (IIIa, IIIb, IIIc, and IIId) neurons are pleomorphic multipolar neurons, approximately $19 \mu \mathrm{m}$ in length and $15 \mu \mathrm{m}$ in diameter. They are the largest of the three types with a fusiform, spherical, or triangular shape and have a sparse amount of Nissl substance in their cytoplasm. In Golgi staining, type IIIa has a rhomboid-shaped soma and dichotomically branching dendrites, whereas type IIIb has a spheroidal soma and short axons. Type IIIc has a piriform soma and spiny dendrites, while the type IIId has the largest soma and structure resembles an undifferentiated motor neuron of the CNS. Due to the latter, these cells stain very lightly and usually only axons and dendrites can be identified. The nucleus is large in class III neurons, it is round, centrally located, and darkly staining. These cells (types IIIc and IIId) are found only in the lateral parts of the PAG along with a large number of glial cells. Axons of the types IIIa and IIId with strong branching characteristic are axonal projecting in nature, whereas the other types are found mostly in the lateral and dorsal parts of the PAG.

\subsection{Longitudinal columns}

The most frequently used subdivision system of the PAG is the separation into four major longitudinal columns according to their cytoarchitectural features (Figs. 3a, 3b, $3 \mathrm{c}, 3 \mathrm{~d}$, and 3e; and Fig. 4). These subdivisions are cell-rich and serve as distinct anatomical modules for specific functions. They are generally classified as the dorsomedial- (dmPAG), dorsolateral- (dlPAG), lateral- (lPAG) and ventrolateral (vlPAG) PAG (Bandler and Shipley 1994; Carrive and Bandler 1991; Herrera et al 1987; Olszewki and Baxter 1954). The functions of these major subdivisions are discussed later. In addition, the intermediate part of the IPAG (ilPAG), which is a minor subdivision, has been found to contain dense NOS-staining fibers without NOS-staining neurons. This region in particular is thought to play a role in the modulation of cardiovascular functions including systemic arterial blood pressure and heart rate (Wang et al 2001). 


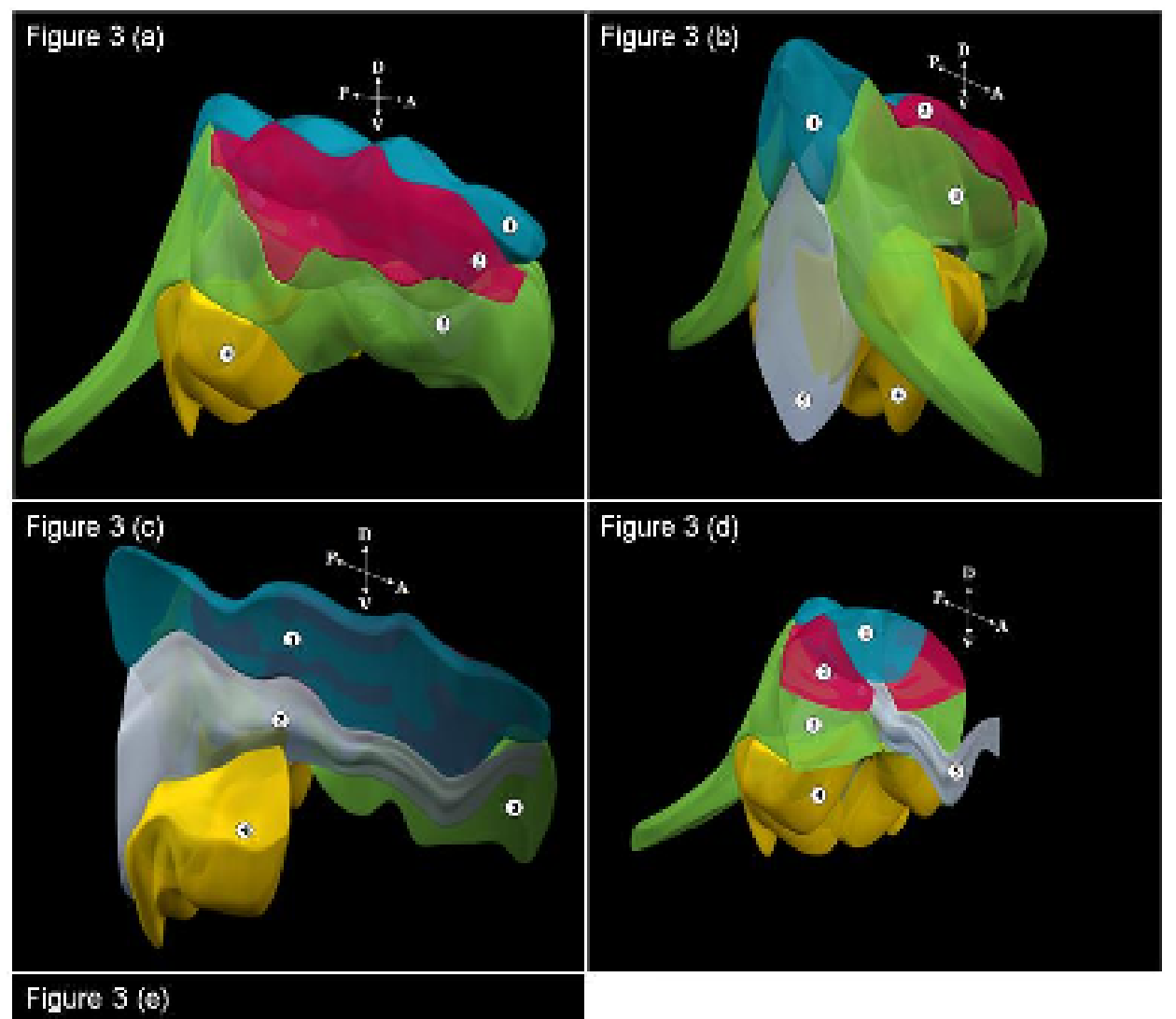

Figure 3, A: lateral view, B: posterior-oblique vi ew, C: internal sagittal view, D: coronal section view - rostral PAG, and E: coronal section view. These 3-D reconstructions of the subdivisions of the PAG longitudinal columns were created based on the 1998 George Paxinos and Charles Watson rat's Atlas $4^{\text {th }}$ Edition (from Bregma $-4.80 \mathrm{~mm}$ till $-8.80 \mathrm{~mm}$ ) using the Computer Aided Design (CAD) Environment software (Ontario, Canada) according to the anatomical and functional differentiation. Abbreviations: $1=$ dorsomedial PAG, 2= dorsolateral PAG, 3=lateral PAG, 4= ventrolateral $\mathrm{PAG}$, and $5=$ aqueduct. $\mathrm{A}=$ anterior, $\mathrm{P}=$ posterior, $\mathrm{D}=$ dorsal, and $\mathrm{V}=$ ventral. 


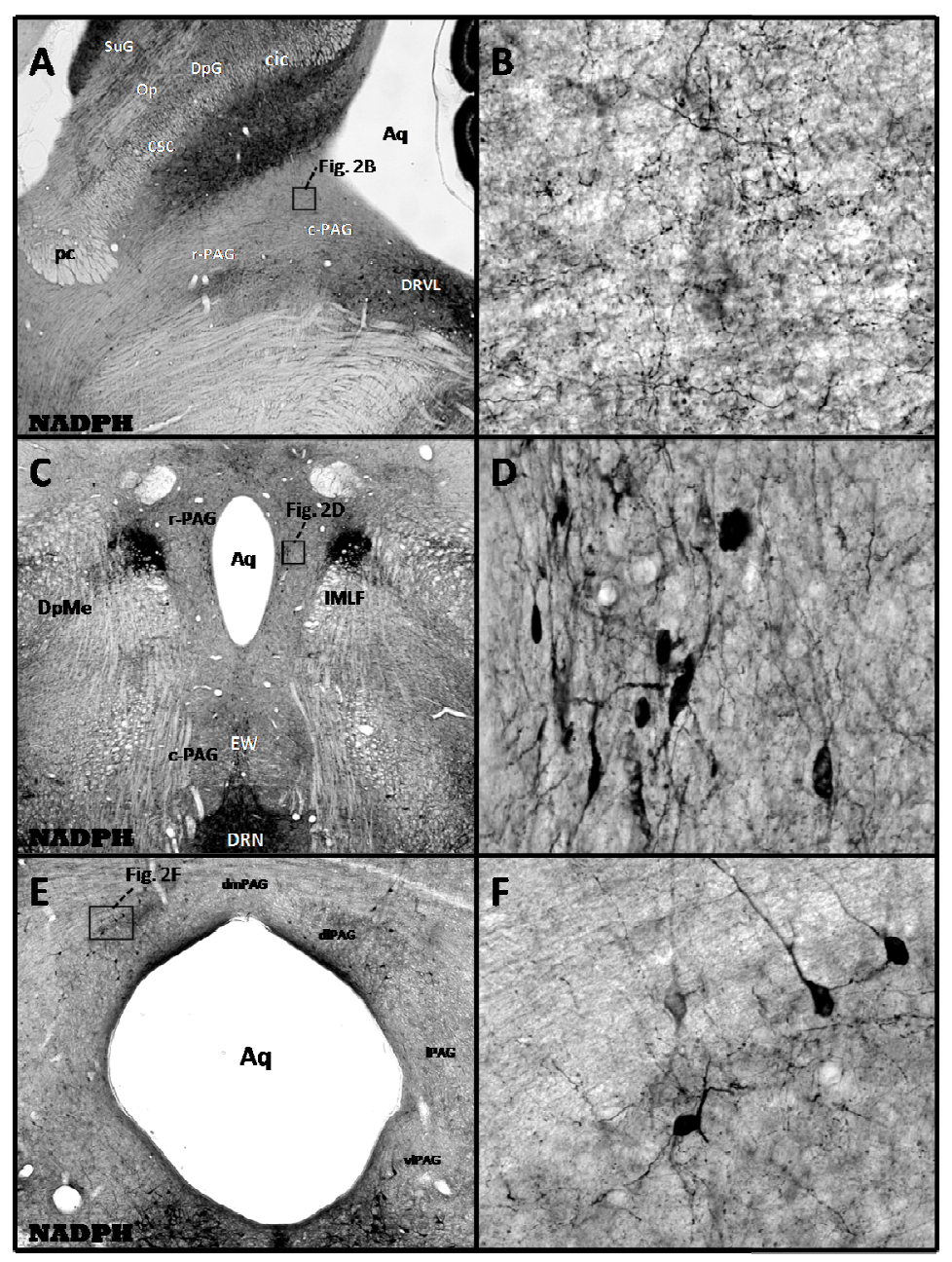

Figure 4, Bright-field photomicrographs showing a low-magnification overview of the PAG in sagittal section (Fig. 4A), horizontal section (Fig. 4C), and coronal section (Fig. 4E), stained by NADPH-diaphorase histochemistry and visualized with DAB-immunohistochemistry in the normal rat brain. The detailed information of the boxed areas in $\mathrm{A}, \mathrm{C}$, and $\mathrm{E}$ are shown in $40 \mathrm{X}$ highmagnification photomicrographs of $\mathrm{B}, \mathrm{D}$, and $\mathrm{F}$, respectively. Abbreviations: $\mathrm{Aq}=$ Aqueduct, $\mathrm{cic}=$ commissure of the inferior colliculus, $\mathrm{csc}=$ commissure of the superior colliculus, $\mathrm{c}-\mathrm{PAG}=$ caudal periaqueductal gray, $\mathrm{dlPAG}=$ dorsolateral periaqueductal gray, $\mathrm{dmPAG}=$ dorsomedial periaqueductal gray, $\mathrm{DpG}=$ deep gray layer of the superior colliculus, $\mathrm{DpMe}=$ deep mesencephalic nucleus, $\mathrm{DRN}=$ dorsal raphe nucleus, $\mathrm{DRVL}=$ dorsal raphe ventrolateral, $\mathrm{EW}=$ Edinger Westphal nucleus, $\mathrm{IMLF}=$ interstitial nucleus of the medial longitudinal fasciculus, $1 \mathrm{PAG}=$ lateral periaqueductal gray, $\mathrm{NADPH}=$ nicotinamide adenine dinucleotide phosphate-oxidase, 5-HT= 5hydroxytryptamine, $\mathrm{Op}=$ optic nerve layer of the superior colliculus, $\mathrm{pc}=$ posterior commissure, $\mathrm{r}$ $\mathrm{PAG}=$ rostral periaqueductal gray, and $\mathrm{SuG}=$ superficial gray layer of the superior colliculus. $\mathrm{vlPAG}=$ ventrolateral periaqueductal gray. 
The dIPAG has a wedge-shaped form located most part in the rostral and intermediate two thirds region of the PAG. The dmPAG is located medially to the dorsolateral columns and is separated by an imaginary midline. The regions of IPAG and vlPAG columns are located in between the anterior boundaries of the dIPAG and the border of dorsal raphe nucleus (DRN). The boundary between the lateral and ventrolateral columns has been inferred from functional and connectional studies. There is no known specific histochemical marker that can be used to distinguish IPAG from vIPAG columns. However, a constant and useful identifying feature of the vIPAG is the presence of a number of prominent blood vessels (Bandler and Keay 1996; Bandler and Shipley 1994; Bandler and Tork 1987; Clement et al 1996).

\subsection{Regional anatomy of the $P A G$}

The PAG is located inferiorly to the reticular formation and its inferior border is bounded by the tegmentum (back of the pons), the nucleus fastigius of the cerebellum and medulla's reticular area. Ventral to the PAG, close to the midline, is located the oculomotor nucleus (and associated Edinger-Westphal nucleus), and the medial longitudinal fasciculus. The medial lemniscus is located at anterior-laterally of the PAG and more lateral to the medial longitudinal fasciculus. Further ventrally lies the large red nucleus (nucleus ruber) and close to the red nucleus is the substantia nigra (SN) (Herrera et al 1987). 


\section{Functional connections of the PAG}

The PAG receives input from and projects to a variety of higher and lower centers. The organization of the projections differs per subdivision. Most of the data presented here are derived from rodent and non-human primate studies. In general, the connections of the PAG share three different characteristics. Firstly, monosynaptic connections (e.g. from the vlPAG neurons to the locus coeruleus) (Bajic et al 2000). Secondly, these connections are implicated only in the mediation of somatic defensive behaviour such as flight, fight and freezing responses. The third characteristic is that the connections are unequally distributed between PAG subdivisions (Vianna and Brandao 2003).

\subsection{Upstream connections}

The PAG is interconnected with several upstream brain regions. The majority of the fibers leaving the PAG usually terminate in the parabrachial nuclei, reticular formation, trigeminal motor nucleus and nucleus ambiguus. The main afferents are from the amygdala, nucleus stria terminalis, hypothalamus, midline thalamus, periventricular gray, the dorsolateral and ventrolateral midbrain tegmentum (Jurgens and Pratt 1979). In addition, several structures in the CNS receive dopaminergic inputs from the PAG, including the lateral bed nucleus of the stria terminalis, central amygdaloid nucleus (Hasue and Shammah-Lagnado 2002), nucleus accumbens (Stratford and Wirtshafter 1990), striatum (Descarries et al 1986), lateral habenula (Li et al 1993), hippocampus (Pohle et al 1984), magnocellular basal forebrain (Semba et al 1988), lateral septum and medial prefrontal cortex (Stratford and Wirtshafter 1990). Different subdivisions are connected with different brain regions. These will be discussed in more detail in the next paragraphs.

\subsubsection{Amygdala}

The amygdala sends broad projections to the rostral midbrain including the PAG, the deep layers of the superior colliculus, and the lateral mesencephalic reticular formation (Fendt et al 1994; Meloni and Davis 1999). It has been suggested that amygdala and the PAG, together with the medial hypothalamus, constitute an integrated circuitry in the brain that commands defensive behaviour and elaborates aversive emotional and motivational states (McNaughton and Corr 2004). The amygdala's function is most likely to make distinction and response to the various stimulus inputs from the environment and then sending message to the PAG according to the degree of threat occurring within an organism. The PAG would be in charge of selecting, organizing and commanding the appropriate behaviour and neurovegetative defensive reactions (Fanselow 1991). Studies using electrical stimulation to evoke defensive behaviours in awake animals have led to the conclusion that a pathway originating in the amygdala, projecting to the hypothalamus and from there to the PAG is essential for the 
expression of these responses (Clemente and Chase 1973; Fonberg 1972; Kaada 1967; Siegel and Edinger 1981).

The central amygdaloid nucleus has an essential link in the pathway mediating the autonomic and behaviour symptoms of conditioned fear. It is possible to disrupt the conditioned fear responses by destroying areas to which the central amygdaloid nucleus project. Studies over the past years have provided detailed descriptions of the efferent targets of the central nucleus in a number of mammalian species (Cassell et al 1986; Price and Amaral 1981; Saper 1979; Schwaber et al 1982; van der Kooy et al 1984). It has been shown that lesions of the lateral hypothalamic area interfere with autonomic, but not behaviour conditioned responses; whereas lesions of the midbrain dorsal PAG region interfere with behaviour, but not autonomic conditioned responses. However, lesions of the amygdala in the fear-conditioning pathway disrupt both the behaviour and autonomic responses (Iwata et al 1986; LeDoux et al 1984). Therefore, it was suggested that the pathways mediating autonomic and conditioned fear responses diverge after the amygdala with projections to the lateral hypothalamic area and PAG.

Further evidence for an amygdala-PAG interaction is derived from studies in which experimental lesions of the rostra1 dorsal PAG, a target of the central amygdaloid nucleus, disrupted the conditioned freezing response, but did not affect the arterial pressure conditioned response (LeDoux 1994 ). In contrast, neither the freezing nor arterial pressure responses were affected by ibotenic acid lesions of the rostral PAG. The observation that lesions of the rostral PAG disrupts behaviour and cardiovascular conditioned responses indicate that the projection from the forebrain mediating the behaviour conditioned responses passes through, but does not synapse in, the rostra1 PAG. Nevertheless, injection of ibotenic acid into the caudal PAG region has significantly reduced the duration of conditioned freezing but did not affect the conditioned arterial pressure response. Thus, the intrinsic neurons in caudal PAG contribute to the conditioned freezing, but not to the conditioned arterial pressure response (LeDoux 1994; LeDoux et al 1988).

The midbrain PAG region possesses locomotor functions and receives projections from various limbic forebrain areas, including the central amygdala, and projects to spinal motor neurons. PAG has been considered as an interface between the limbic forebrain and spinal cord in the expression of fear behaviour. Lesions of the PAG would disconnect spinal motor systems from the amygdala. Processes mediated by the amygdala would thus be deprived of access to final common pathways controlling emotional behaviour when neurons in the caudal PAG are destroyed (Swanson et al 1984).

Immunohistochemistry experiments have confirmed the chemical nature of PAG projections to the central amygdaloid nucleus. Robust projections from the PAG and DRN to the lateral bed nucleus of the stria terminalis, central amygdaloid nucleus have been documented with retrograde (Rizvi et al 1991; Shammah-Lagnado et al 2001) and 
anterograde tracing techniques (Cameron et al 1995a; Cameron et al 1995b; Rizvi et al 1991; Vertes 1991). Some of these projecting neurons were found to be cholecystokinin(Seroogy and Fallon 1989), serotonin (5-HT)- (Li et al 1990), vasoactive intestinal polypeptide- (Kozicz et al 1998; Petit et al 1995) and TH-immunoreactive (A10dc group). The latter mainly contributes to the dopaminergic innervation of the central amygdaloid nucleus. In addition, these small TH-immunoreactive periaqueductal neurons are frequently co-localised with cholecystokinin (Seroogy and Fallon 1989).

The amygdala and PAG receive their input mainly from the innervation of 5-HTcontaining fibers originating from the DRN. The axons that project to the amygdala follow the DRN -forebrain tract, while those that go to the PAG run through the DRN periventricular tract. Most of the nerve fibers that originate in the DRN are thin and have small varicosities that make preferential contact with 5-HT2A/2C receptors (Azmitia and Segal 1978; Mamounas et al 1991; McTavish and Heel 1992).

The different parts of the midbrain are involved in mediating different measures of conditioned fear, namely fear-potentiated startle and freezing, both of which are dependent on the amygdala. The study by Zhao and co-workers showed that fearpotentiated startle in rats is mediated by neurons in the deep layers of the superior colliculus/deep mesencephalic nucleus of the rostral midbrain through the glutamate nonNMDA receptors whereas the dIPAG was responsible for freezing (Zhao and Davis 2004). In another study, it was shown that microinjection of glutamate in the dorsal PAG area produced freezing behaviour (Krieger and Graeff 1985) and microinjection of GABA receptor blockers or GABA inhibitors of glutamic acid decarboxylase (GAD) produced fear-like behaviour with a delay of action about 7 min (Brandao et al 1982; Brandao et al 1986; Schmitt et al 1985). Lesions of the ventral PAG disrupted the conditioned freezing response but did not change the dorsal PAG electrical stimulation or chemical stimulation-induced freezing and escape responses (Vianna et al 2001a; Vianna et al 2001b). These findings suggest that freezing and escape responses induced by dorsal PAG stimulation do not depend on the integrity of the ventral PAG.

\subsubsection{Hypothalamus}

The hypothalamic projections to the PAG can be divided into four subregions: anterior hypothalamus, the paraventricular nucleus, the posterior hypothalamus and the lateral hypothalamus (Fig. 5a, and 5b). Bandler and colleagues showed in 1982 \& 1985 that electrical stimulation of the medial hypothalamus evoked defensive behaviour or "defensive rage" whereas stimulation with excitatory amino acid failed to evoke such behaviour (Bandler 1982; Bandler and McCulloch 1984). In the PAG, both electrical and chemical stimulation evokes defensive behaviour. Sun and Guyenet reported that both electrical and chemical stimulation of the lateral hypothalamus increased the systemic arterial pressure, increased lumbar sympathetic nerve discharge, and produced excitation in sympathetic premotor neurons in the rostral ventral lateral medulla (Sun and Guyenet 1986). They also provided evidence that the descending pathway from the lateral 
hypothalamus was glutamatergic. This finding was contradicted by Hilton and Redfern as there was no sympathetic arousal as observed in the cardiovascular defensive response evoked by electrical or chemical stimulation of the hypothalamus (Hilton and Redfern 1986). Furthermore, Hilton and associates demonstrated that sympathoexcitatory responses characteristic of the defence reaction were readily evoked by both electrical and chemical PAG stimulation (Hilton and Redfern 1986; Yardley and Hilton 1986). Electrical stimulation in animals of the areas from which defensive behaviour is evoked produced a pattern of sympathetic excitation characteristically evoked by threatening stimuli. Thus, electrical stimulation of sites in the amygdala, hypothalamus, and PAG evoke cardiovascular and defensive responses (Hilton 1975; Hilton and Zbrozyna 1963; Thornton et al 2002; Yang and Coote 1998).

\subsubsection{Anterior Hypothalamus}

Neurons located in the medial area of the anterior hypothalamus project strongly to the vlPAG (Snowball et al 2000) as well as the dIPAG (Semenenko and Lumb 1992), the dorsal and superior central raphe nuclei in the pontine tegmentum, to the nucleus raphe magnus (NRM), nucleus raphe pallidus (NRP), to the ventral part of the upper medullary medial tegmental field via the medial forebrain bundle, and the dorsal longitudinal fasciculus (Holstege 1987).

Preoptic regions are considered to be part of the anterior hypothalamus. The median preoptic neurons are activated by warmth exposure and project to the rostral PAG. These neurons influence thermoregulatory skin vasodilatation. It has been shown that activation of rostral PAG neurons produced skin vasodilatation, and activation of neurons slightly caudal to this region suppressed vasodilatation in response to local warming of the preoptic area (Zhang et al 1995). These findings also suggested that it is quite probable that the rostral PAG and caudal PAG play some role in thermoregulation during environmental thermal stimuli as well as during local preoptic warming. 

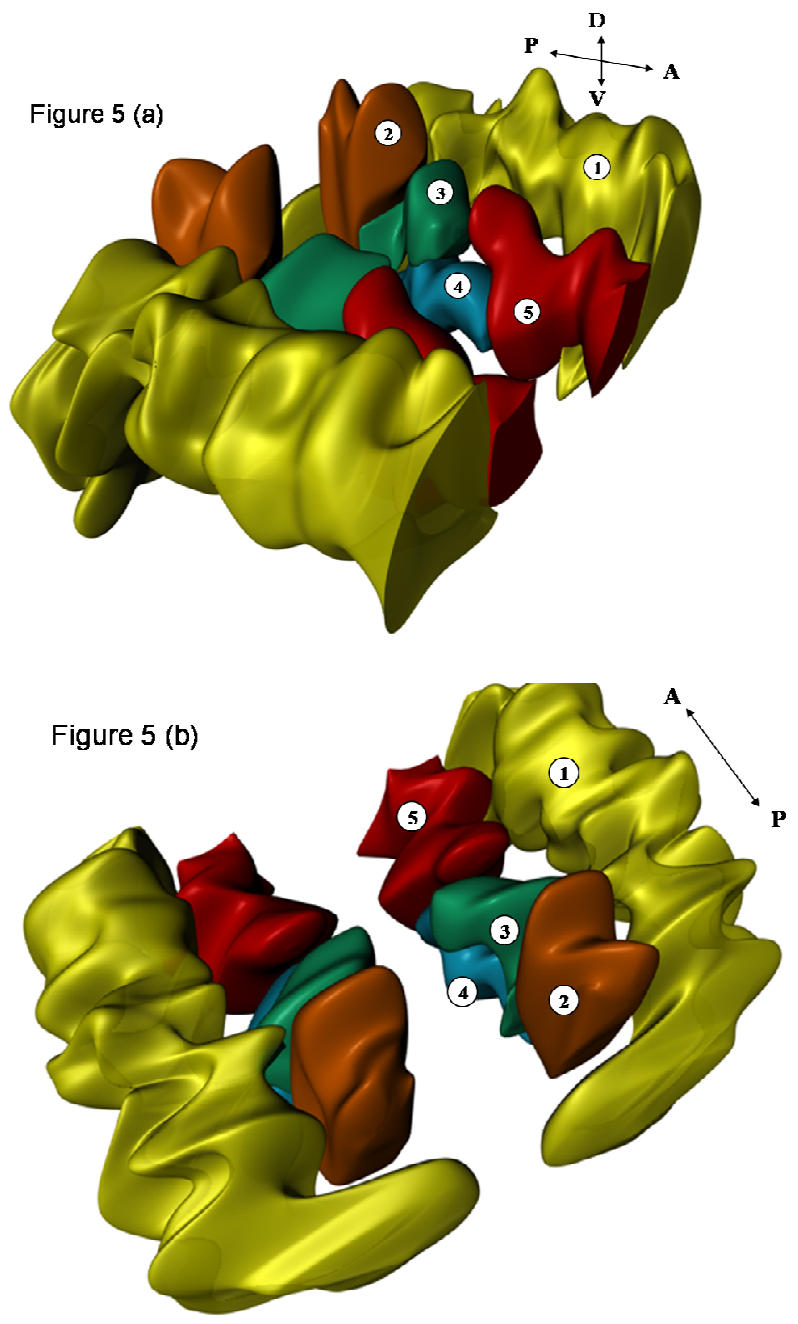

Figure 5, A: Superior oblique view, from anterior to posterior direction, and B: Superior oblique view, from posterior to anterior direction. These 3-D reconstructions of the subdivision of the hypothalamus were created based on the 1998 George Paxinos and Charles Watson rat's Atlas $4^{\text {th }}$ Edition (from Bregma $-1.30 \mathrm{~mm}$ till $-4.80 \mathrm{~mm}$ ) using the Computer Aided Design (CAD) Environment software (Ontario, Canada). Abbreviations: 1=, Lateral hypothalamus, $2=$ Posterior hypothalamus, $3=$ Dorsomedial hypothalamic nucleus, $4=$ Ventromedial hypothalamic nucleus, and 5= Anterior hypothalamic nucleus. $\mathrm{A}=$ anterior, $\mathrm{P}=$ posterior, $\mathrm{D}=$ dorsal, and $\mathrm{V}=$ ventral. 


\subsubsection{Medial Hypothalamus}

The medial hypothalamus sends axons to the dIPAG of the midbrain via the dorsal longitudinal fasciculus (Arnault and Roger 1987). Electrical stimulation of this area produces affective aggression, and lesions of the PAG can subsequently disrupt this behaviour (Canteras et al 2001). Immunohistochemical analysis revealed the presence of 5-HT axons and preterminals throughout the PAG, and in particular, in its dorsolateral aspect which receives major inputs from the medial hypothalamus. This projection has been implicated in defensive rage behaviour and is mediated by $5-\mathrm{HT}_{1 \mathrm{~A}}$ and $5-\mathrm{HT}_{2 / 1 \mathrm{C}}$ receptors (Shaikh et al 1997).

\subsubsection{Paraventricular Hypothalamic Nucleus}

The paraventricular hypothalamic nucleus $(\mathrm{PVH})$ projects to the caudal brainstem and spinal cord via the medial forebrain bundle, the mammillotegmental tract and the dorsal longitudinal fasciculus. The fibers continue through the lateral part of the mesencephalon and upper pons, along this way, some fibers project to the nucleus raphe magnus, rostral nucleus raphe pallidus and adjoining reticular formation and specific parts of the medullary lateral tegmental field (Holstege 1987). The PVH contains a large number of neurotransmitter substances such as oxytocin, vasopressin, somatostatin, dopamine, met-enkephalin, leu-enkephalin, neurotensin, cholecystokinin, dynorphin, substance $\mathrm{P}$, glucogen, renin and corticotrophin releasing factor (Swanson and Sawchenko 1983). The latter provides a clear evidence of neuroactive substances involved in the PVH-caudal brainstem or spinal pathway (Hermes et al 1988). More importantly, the retrograde study of the transportation of the neuroanatomical tracer cholera toxin-b from both the autonomic and endocrine components of the PVH showed neuronal activation and projection to the visceromotor (infralimbic) cortex, median preoptic nucleus, ventromedial preoptic area, bed nucleus of the stria terminalis, parabrachial nucleus, vlPAG, ventrolateral medulla, and nucleus of the solitary tract (Elmquist and Saper 1996).

\subsubsection{Lateral Hypothalamic area}

Tracing and autoradiographic studies showed that the lateral hypothalamus sends fibers to the vlPAG (Behbehani et al 1988) and IPAG (Bianchi et al 1998), the cuneiform nucleus, parabrachial nuclei, nucleus Kolliker-Fuse, nucleus subcoeruleus, the locus coeruleus, the caudal pontine and medullary medial reticular formation (Holstege 1988). Anatomical studies using injection of anterograde tracer Phaseolus vulgaris leucoagglutinin into the lateral hypothalamus showed an extensive projection to the ventromedial and the vlPAG and a less dense projection to the medial and dorsal parts of this region (Behbehani et al 1988). There was a strong correlation between the response of PAG cells to electrical stimulation and injection of glutamic acid into the lateral hypothalamus and their response to pressure-injected neurotensin (Behbehani 1995). 


\subsubsection{Thalamus}

The topographic organization studies by Velayos \& Reinoso clearly revealed the brainstem afferents of the mediodorsal (MD) thalamic nucleus (Velayos and ReinosoSuarez 1982). After injection of the retrograde tracer horseradish peroxidase (HRP) in the medial part of the MD thalamic nucleus, labelled neurons were observed at the level of the interpeduncular nucleus, ventral tegmental area and SN. Injections of HRP in the intermediate part of the mediodorsal nucleus revealed labelled cells in the interpeduncular nucleus, SN, dorsal and central superior raphe nuclei, dorsal tegmental nucleus and coeruleus complex. After injections in the lateral part of MD thalamic nucleus, labelled neurons were observed in the deep layers of the superior colliculus, lateral and vlPAG, oral paramedian pontine reticular tegmentum, interpeduncular nucleus, $\mathrm{SN}$, locus coeruleus, dorsal tegmental nucleus, cuneiform area, and the mesencephalic reticular formation (Velayos and Reinoso-Suarez 1982). Krout and Loewy observed that PAG projections to the thalamus are predominantly from the IPAG and vlPAG, innervating medial and intralaminar thalamic nuclei (Krout et al 2002; Krout and Loewy 2000). In addition, the anterograde and retrograde lectin tracing techniques showed that the rostral reticular thalamic nucleus received inputs not only from the cingulate, orbital and infralimbic cortices, but also from the vlPAG, mesencephalic reticular formation, laterodorsal tegmental nucleus, pedunculopontine nucleus, medial pretectum and ventral tegmental area (Cornwall et al 1990).

\subsubsection{Raphe nuclei and reticular formation}

The median raphe nucleus and the DRN are localized in the midbrain and contain cell bodies of 5-HT neurons that project to the forebrain and midbrain including the PAG (Azmitia and Segal 1978). The connection of raphe nuclei with the PAG has been shown to play a role in the pathophysiology of generalized anxiety disorder and panic disorder (Abrams et al 2004; Chaouloff 2000). In this respect, the activation of the DRNperiventricular 5-HT pathway, which also innervates the dorsal PAG, inhibited the fight or flight reactions in response to proximal danger, behaviour reactions that have been related to panic (Blanchard et al 2001a; Blanchard et al 2003; Graeff 2002; McNaughton and Gray 2000). Furthermore, the neural connectivity of raphe nuclei and PAG has been investigated using the elevated T-maze, the inhibitory avoidance and one-way escape (Pobbe and Zangrossi 2005). This study showed that, intra-DRN injection of the $5-\mathrm{HT}_{1 \mathrm{~A}}$ receptor antagonist WAY-100635 had consistently affected the performance of these two behaviours. On the other hand, the dorsal PAG local administration of WAY-100635 had by itself no effect, but blocked the effect of intra-DRN injection of WAY-100635 on oneway escape in the elevated T-maze. In contrast to WAY-100635, intra-dorsal PAG injection of the 5- $\mathrm{HT}_{2 \mathrm{~A}}$ receptor antagonist ketanserin blocked all behaviour effects of intra-DRN injection of WAY-100635 (Pobbe and Zangrossi 2005).

A retrograde labelling study from the nucleus raphe magnus and adjoining reticular formation showed considerable numbers of labelled neurons in the lateral PAG, vlPAG, dmPAG, except for the dlPAG (Mantyh 1983a; Mantyh 1983b). At the caudal 
pontine levels, the PAG fibers gradually shift ventrally and medially to terminate in the ventral part of the medullary medial reticular formation and in the nucleus raphe magnus (Holstege 1988; Jurgens and Pratt 1979). The caudal vlPAG and the ventrally adjoining mesencephalic tegmentum send fibers to the nucleus raphe pallidus. The neurons in the dmPAG projects strongly to the medially located nucleus raphe magnus while the lateral PAG and the laterally adjoining mesencephalic tegmentum project mainly laterally to the ventral part of the caudal pontine and upper medullary medical reticular formation with virtually no projections to the nucleus raphe magnus (Holstege 1988).

\subsubsection{Substantia nigra and ventral tegmental area}

The connection between the SN/ventral tegmental area and the vlPAG has been identified as the pathway to modulate cardiovascular physiology and nociception (Kirouac and Pittman 2000). This functional link has been demonstrated by stimulation studies of the SN/ventral tegmental area which produced significant cardiovascular responses and pain modulation that were mediated by a pathway to the vIPAG and DRN (Altier and Stewart 1998; Kirouac and Pittman 2000). However, there is no evidence at presence that antinociception elicited by activation of neurons in the $\mathrm{SN} /$ ventral tegmental area is mediated by a projection to the vlPAG. A retrograde tracing study has clearly shown that the vlPAG receives substantial input from the SN/ventral tegmental area (Coffield et al 2004; Comoli et al 2003). This projection does not appear to use dopamine as neurotransmitter, but is thought to be GABAergic (Kirouac et al 2004).

\subsubsection{Cortical connections}

A number of cortical projections in the medial prefrontal areas such as the infralimbic, prelimbic, anterior cingulate, and precentral areas and lateral areas along the rhinal sulcus (the anterior and posterior insular areas, and the perirhinal areas) project axons that terminate focally within the rostrocaudal columns of the PAG (Bandler et al 1985b; Illing and Graybiel 1986; Neafsey et al 1986; Shipley et al 1991).

The neural projections from the prefrontal cortical region to the PAG arise primarily from the medial prefrontal areas 25,32 , and $10 \mathrm{~m}$, anterior cingulate, and dorsomedial areas $24 \mathrm{~b}$ and 9, selected orbital areas 14c, 13a, Iai, 12o, and caudal 121, and ventrolateral area $6 \mathrm{v}$ (An et al 1998). In addition, the caudal parts of the prefrontal cortex also project to the PAG. These projections come from the posterior cingulate cortex, the dorsal dysgranular, and granular parts of the temporal polar cortex, the ventral insula, and the dorsal bank of the superior temporal sulcus. The projections from the medial prefrontal areas $10 \mathrm{~m}, 25$, and 32 terminate predominantly in the bilateral dlPAG columns. Fibers from orbital areas 13a, Iai, 12o, and caudal 121 terminate primarily in the vlPAG column, whereas fibers from dorsomedial areas 9 and $24 \mathrm{~b}$ terminate mainly in the lateral column (An et al 1998).

Several studies have shown that the medial prefrontal network is subdivided into three main circuits (An et al 1998; Bernard and Bandler 1998; Ongur et al 1998). These 
three subdivisions are based on the projections to the specific columns of the PAG. The first circuit originates from the orbital areas within the medial prefrontal network (areas 13a, Iai, $12 \mathrm{o}$ and caudal 121) and project selectively to the vlPAG and to the lateral hypothalamus. The second circuit runs from the medial wall areas $(10 \mathrm{~m}, 25$, and 32$)$ to the dIPAG and to the medial and lateral hypothalamus. The third circuit has its origin at the level of the dorsomedial areas $24 \mathrm{~b}$ and 9 and project predominantly to the IPAG, with additional projections to the dlPAG, vlPAG and to the dorsal hypothalamus (An et al 1998; Bernard and Bandler 1998; Ongur et al 1998).

In summary, (1) dorsal PAG: receives information from the caudodorsal part of the medial wall which includes anterior cingulate dorsal, anterior cingulate ventral, and the caudal parts of the prelimbic area and infralimbic area; (2) vlPAG: (a) projections from the rostroventral part of the medial wall specifically rostral portions of prelimbic and infralimbic areas, (b) from the adjacent medial orbital cortex which includes medial orbital, ventral orbital, and the medial part of ventrolateral orbital, and (c) from the lateral orbital and agranular insular cortical areas including dorsolateral orbital cortex, dorsal agranular insular cortex, and posterior agranular insular cortex; (3) lPAG: receives input from the rostral prelimbic cortex, caudal prelimbic cortex, anterior cingulate dorsal, dorsolateral orbital cortex, and dorsal agranular insular cortex; (4) dIPAG, vlPAG, dmPAG IPAG: all receive projections from the perirhinal cortex

The medial prefrontal wall region is divided into the infralimbic, prelimbic, and medial frontal polar areas. The infralimbic area (IL) corresponds to Brodmann area 25. The prelimbic area (PL) corresponds to Brodmann area 32 and possesses a well-defined lamination. The frontal polar area (FP) occupies medial (FPm) and lateral (FPl) parts of the frontal pole. The dorsomedial convexity includes anterior cingulate and precentral areas. The anterior cingulate cortex, which corresponds to Brodmann area 24, can be distinguished from the prelimbic cortex by a broader and less densely packed layer $\mathrm{V}$. The anterior cingulate cortex was further divided into dorsal (ACd) and ventral (ACv) divisions. The precentral area is divided into precentral medial $(\mathrm{PrCm})$ and precentral lateral $(\mathrm{PrCl})$ areas. Although the whole of the orbital region is agranular, it can be divided into medial orbital (MO), ventral orbital (VO), ventrolateral orbital (VLO), lateral orbital (LO) and dorsolateral orbital (DLO) areas. Agranular insular cortex lies more caudally, superficial to the claustrum. It was subdivided into dorsal (AId), ventral (AIv) and posterior (AIp) areas. Dysgranular (DI) and granular (GI) insular cortices were also distinguished (Krettek and Price 1977a; Krettek and Price 1977b; Ray and Price 1992).

In the rat, primary motor areas of forelimbs, hind limbs and trunk project exclusively to the IPAG and vlPAG, while primary auditory and secondary visual cortex innervate the dIPAG. Perirhinal, anterior cingulate and agranular lateral retrosplenial cortex project to the dIPAG. The vlPAG receives projection from medial, ventral, dorsal and ventrolateral cortex, dorsolateral orbital and posterior insular agranular cortex. The 
prelimbic and infralimbic cortex are connected to rostroventral portion of vlPAG and dorsocaudal portion of dIPAG (Vianna and Brandao 2003).

\subsection{Downstream connections}

\subsubsection{Pons and medulla oblongata}

The caudal PAG neurons send projections to the nucleus retroambiguus, a structure located in the lateral portion of the most caudal part of the medulla oblongata. This structure in turn projects to the motor neurons innervating the pharynx, soft palate, larynx, intercostals and abdominal muscles; which may account for the vocalization responses during lateral PAG stimulation in animals (Holstege 1987; Jurgens and Ploog 1970).

The PAG projections to the pontine lateral tegmentum or paralemniscal cell group is considered to mediate the antinociceptive action, which does not completely disappear after blocking the nucleus raphe magnus and adjacent reticular formation (Guimaraes and Prado 1999). This finding corresponds with dorsal PAG stimulation induced analgesia after physiological blockage of the nucleus raphe magnus and adjacent reticular formation (Gebhart et al 1983; Guimaraes and Prado 1999; Sandkuhler and Gebhart 1984).

The rostroventrolateral medulla (RVLM) receives input from neurons from the raphe obscurus, raphe pallidus, raphe magnus, DRN, and also from the ventrolateral, lateral and ventral regions of the PAG, as shown by a double-labelling study with Cholera toxin subunit B (Bago et al 2002). Cholera toxin B positive neurons were located in all PAG regions and these cells were also 5-HT-positive. The majority of the 5-HT containing cells are located in the vlPAG, a few in the IPAG and ventral PAG, and none in the dorsolateral and dorsal PAG regions (Bago et al 2002). However, the attenuation of the cardiovascular components of a defence response evoked from the dorsal PAG, which involves 5-HT in the rostroventrolateral medulla neurons, could probably be initiated via a direct or indirect pathway from the vlPAG (Lovick 1992). Furthermore, the sympathetic components of an active defence response are also mediated through the rostroventrolateral medulla during the activation of dorsal PAG neurons (Lovick 1991). The hypotensive response evoked by the sympathoexcitatory region of rostroventrolateral medulla neurons has been shown to receive some projections from the neurons located in the vlPAG (Carrive and Bandler 1991; Chen and Aston-Jones 1995).

The vlPAG-rostroventrolateral medulla pathway is also involved in the mediation of the sympatho-inhibition during the response to severe haemorrhage. This sympathoinhibitory response to haemorrhage depends upon the integrity of neurons in the caudal midline raphe neurons, which may be activated during haemorrhage by input from the vlPAG (Henderson et al 1998). In addition, 5-HT projections to the rostroventrolateral 
medulla play a modulatory role at sympatho-excitory neurons via the baroreceptor, and chemoreceptor (Miyawaki et al 2001).

\subsubsection{Spinal Cord}

Some neurons in the IPAG send fibers through the ipsilateral ventral funiculus of the cervical spinal cord to terminate in laminae VIII and the adjoining part of VII (Martin et al 1979). A few fibers descend ipsilaterally in the lateral funiculus to terminate in the T1-T2 intermediolateral cell column (Holstege 1988). The neural projection to the medial part of intermediate zone in the cervical cord is involved in the head movement and not in nociception. In addition, the descending IPAG projections to the nucleus raphe pallidus, caudal pontine medial reticular formation continues to the axial muscle motorneurons in the spinal cord (Mouton et al 2005). This projection may be responsible for the medullary reticulospinal activation of axial muscle electromyogram (EMG) and lateral vestibulospinal activation of back muscle EMG in the rat after lateral PAG stimulation (Cottingham et al 1987; Cottingham and Pfaff 1987). 


\section{Neurochemistry of the PAG}

\subsection{Monoamines and amino acids}

\subsubsection{Serotonin}

In the PAG, as in the other structures of the CNS, 5-HT plays a major role in the regulation of anxiety and panic disorders (Abrams et al 2004; Chaouloff 2000) (Deakin 1991b). This is based on the distribution of 5-HT-immunoreactive fibers and DRN projections to the substantia nigra, striatum, amygdala and frontal cortex (Imai et al 1986; Steinbusch 1981; van der Kooy and Hattori 1980). 5-HT-like immunoreactive cell bodies have been found in the ventrolateral and ventromedial regions of the caudal PAG and 5HT-like immunoreactive processes throughout the PAG (Please see Fig. 6) (Clements et al 2004). The dorsal PAG also contains $5-\mathrm{HT}_{1 \mathrm{~A}}$ and 5- $\mathrm{HT}_{2 \mathrm{~A}}$ receptors (Pobbe and Zangrossi 2005).

Moreover, the DRN has long been considered as a centre for coordination of behaviour activation and modulation of cardiovascular and respiratory activity. In line with this, stimulation of the PAG causes changes of behaviour, cardiovascular and respiratory function. These findings suggest that the effect of PAG stimulation on panicanxiety, aversion and avoidance behaviour might involve the DRN. Furthermore, the PAG and DRN are interconnected (Fuxe 1965; Lindvall et al 1974; Petrov et al 1992; Peyron et al 1996; Tanaka et al 1994).

Further studies have shown that the nucleus raphe magnus receives not only 5-HT input but also glutamatergic, cholinergic and peptidergic (NT, Substance P, Leu- and Met-enkephalin) from adjacent reticular nucleus cuneiformis and PAG (Basbaum and Fields 1984; Behbehani and Zemlan 1986; Richter and Behbehani 1991). It is important to note that microinjection of the 5-HT1 receptor agonist (5-methoxy-N,Ndimethyltryptamine; 5-MeODMT) into the dorsal PAG increased the escape threshold, whereas microinjection of $5-\mathrm{HT}_{2 \mathrm{~A}}$ receptor antagonists (metergoline or ketanserin) induced aversive reaction (Schutz et al 1985). Interestingly, Nogueira and Graeff showed that intra-PAG administration of the 5-HT1A receptor agonists (8-hydroxy-2-di-npropylaminotetralin hydrobromide; 8-OH-DPAT and BAY-R-1532) decreased the escape threshold during PAG stimulation (Nogueira and Graeff 1995). On the other hand, Jenck et al. (1989), Beckett and Marsden (1997) showed the opposite effects with systemic injection of 5-OH-DPAT (Beckett and Marsden 1997; Jenck et al 1989) in comparison with other neurochemical substances. 


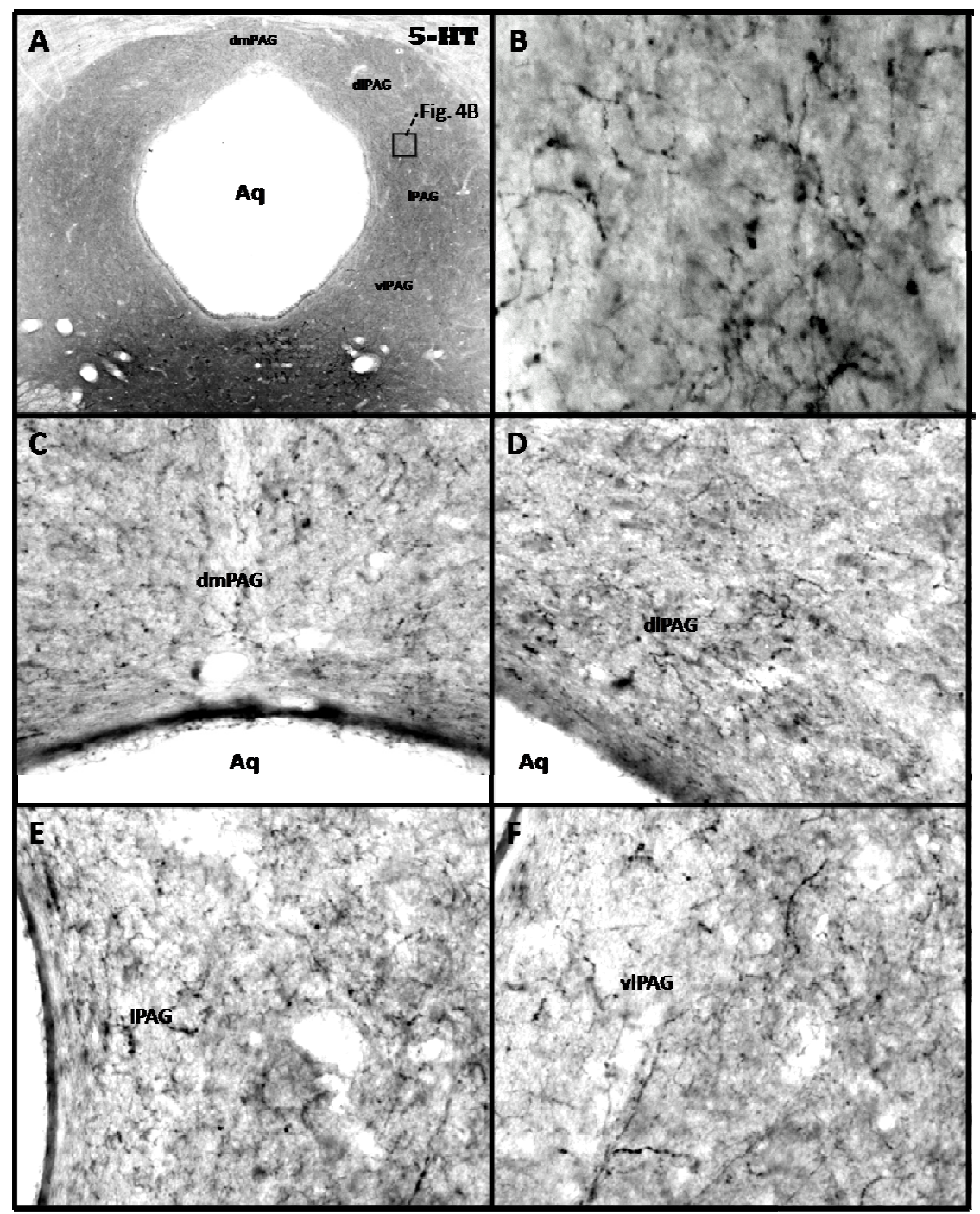

Figure 6, Bright-field photomicrographs showing a coronal section (Fig. 6A) of a normal rat brain processed for serotonin (5-HT) immunohistochemical staining to illustrate the widespread, diffuse innervation pattern of serotonergic fibers throughout the entire PAG region. Boxed area in Fig. $6 \mathrm{~A}$ is shown in a 100X high-magnification photomicrograph in Fig. 6B. Illustrative images of 5-HT immunoreactivity in the dmPAG (Fig. 6C), dIPAG (Fig. 6D), IPAG (Fig. 6E), and vlPAG (Fig. 6F) areas are shown with 40X high-magnification. 


\subsubsection{Dopamine}

Immunohistochemical staining for tyrosine-hydroxylase $(\mathrm{TH})$ revealed that $\mathrm{TH}-$ positive neurons can be found throughout the IPAG and vlPAG (See Fig. 7) (Han et al 2003). These cells are classified microscopically into two groups depending on their size and location, (i) large size cells: TH-positive neurons with $30-40 \mathrm{~mm}$ in diameter, located in the lateral region of the PAG, with a multipolar morphology, and giving rise to abundant TH-positive fibers; and (ii) small size cells: rounded neurons of $10-15 \mathrm{~mm}$ in diameter located adjacent to the aqueduct of Sylvius surface in the vlPAG. Numerous TH-positive fibers are scattered within the vlPAG, with regularly spaced varicosities (asterisks). Both types of cells are thought to be neurons because they have shown to express the NeuN neuronal marker (Flores et al 2004). It has been observed that the small TH-immunoreactive PAG neurons contain cholecystokinin (Seroogy et al 1989). Large dopaminergic neurons of the PAG appear to participate in the supraspinal modulation of opiate-induced analgesia, but spinal nociceptive pain reactions, as measured by the tailimmersion reaction, seem not to be affected after PAG dopaminergic neuron manipulation. The dopaminergic network of the PAG (See Fig. 8) has been included into the dorsocaudal A10 group as described by Hokfelt (A10dc group, 1984), and it is considered as a dorsal part of the dopaminergic periventricular system (Lindvall et al 1974; Moore et al 1978; Moore 1978; Moore and Bloom 1978).

Both D1 and D2 receptors are expressed by PAG neurons (Martin-Ruiz et al 2001) and colocalization of D1 and D2 receptors is rare in the central nervous system (Missale et al 1998). However, PAG neurons that are involved in the modulation of opiate-induced analgesia express D1 rather than D2 dopamine receptors. The neuronal pathways underlying these analgesic effects are largely unknown at present. 


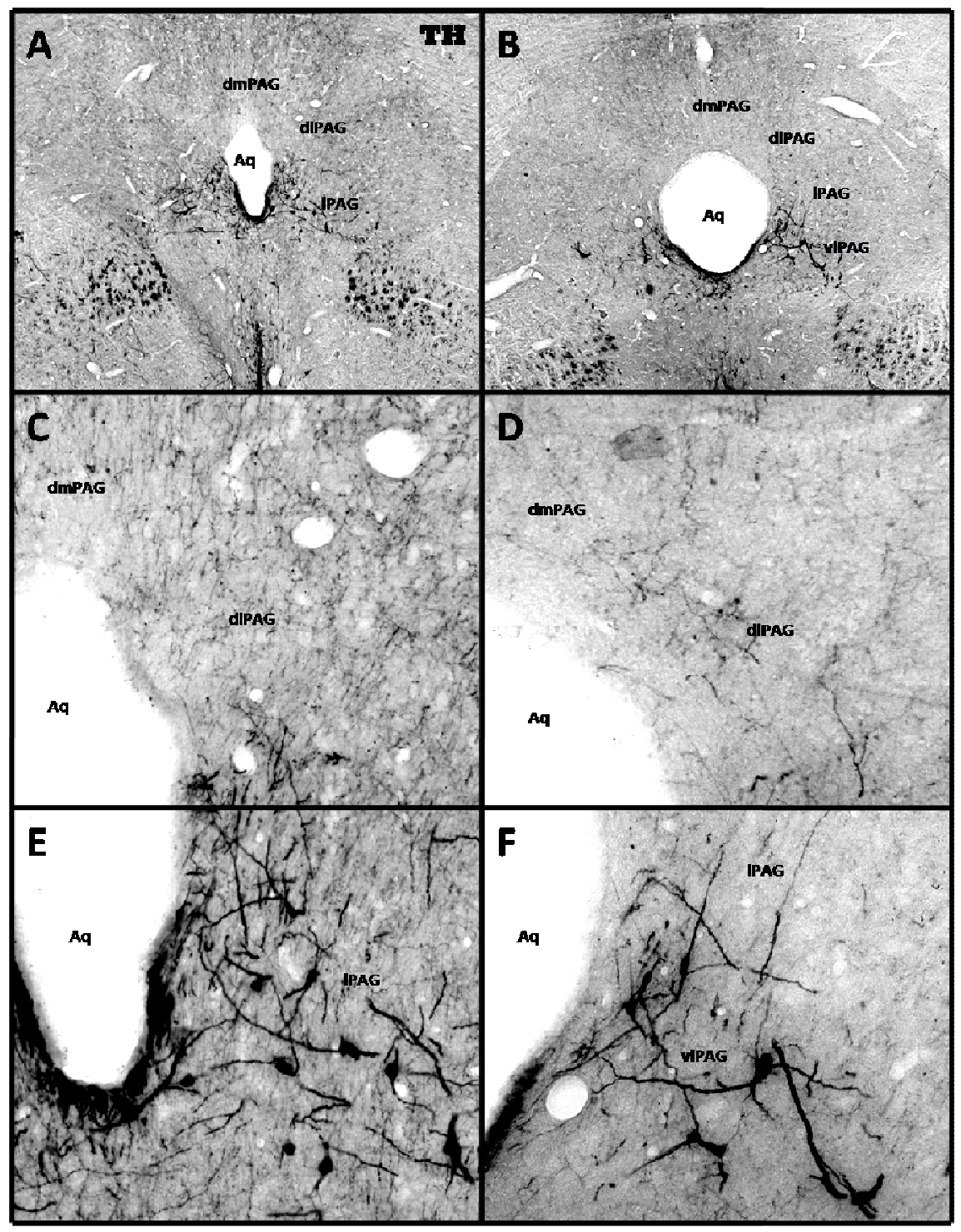

Figure 7, Bright-field photomicrographs showing a coronal section of the rostral (Fig. 7A) and caudal (Fig. 7B) PAG regions containing tyrosine hydroxylase (TH) visualized with immunohistochemistry to illustrate the specific localization of TH neurons in the IPAG and vlPAG regions. Illustrative images of the rostral and caudal regions are shown with 20X magnification photomicrograph in $\mathrm{C}$ and $\mathrm{E}$; and $\mathrm{D}$ and $\mathrm{F}$. 


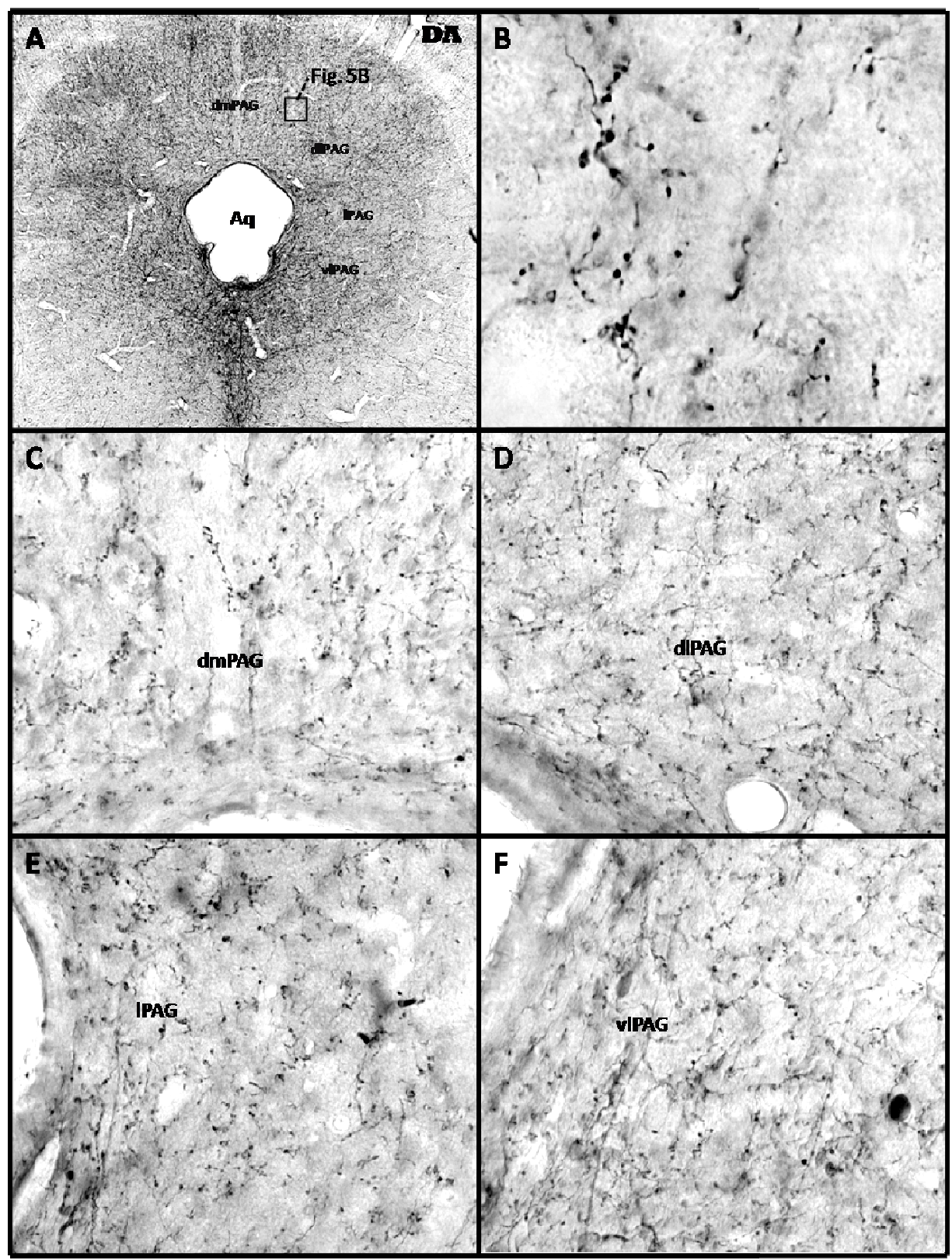

Figure 8, Bright-field photomicrographs showing a coronal section (Fig. 8A) of a normal rat brain processed for dopamine (DA) immunohistochemical staining to illustrate the widespread, diffuse innervation pattern of dopaminergic fibers throughout the entire PAG region. Boxed area in Fig. 8A is shown in a 100X high-magnification photomicrograph in Fig. 8B. Illustrative images of DA immunoreactivity in the dmPAG (Fig. 8A), dIPAG (Fig. 8B), IPAG (Fig. 8C), and vlPAG (Fig. 8D) areas are shown with $40 \mathrm{X}$ high-magnification. 


\subsubsection{Noradrenaline}

Noradrenaline (NA) belongs to the category of catecholamines and plays an important role in the central cardiovascular regulation. The PAG is densely innervated by catecholamine-containing terminals (Herbert and Saper 1992) and NA is highly concentrated in the midbrain, including the PAG (Versteeg et al 1976a; Versteeg et al 1976b). A study based on the injection of anterograde tracer biotinylated dextran amine (BDA) into the vlPAG found labelled noradrenergic neurons in the dorsolateral and ventrolateral pontine tegmentum. The PAG contains a dense network of adrenergic and noradrenergic fibres which consists of ascending fibres from the caudal and rostral ventrolateral medulla to the ventral and dorsal parts of the PAG (Hebert and Saper 1992).

Microinjection of NA into the rostral, medial and caudal portions of the dorsal PAG evoked pressor responses. The pressor response is based on the basal mean arterial pressure and heart rate of the rats. The magnitude or degree of the pressor responses varied according to the location of the injection site along the dorsal PAG column. This response is usually accompanied by bradycardia and no gross behaviour change. The pressor response was significantly higher when NA was injected into the rostral portion of the dorsal PAG and decreased when injections were performed at the caudal parts (Pelosi and Correa 2005). The stimulation of the hypothalamus elicits predatory attack in which the mean current strength of predatory attack can be diminished by microinjection of noradrenaline into the dorsal PAG. This indicates that hypothalamus-induced aggressive responses involve beta adrenoceptive mechanisms located in the dorsal PAG (Saha et al 2004).

\subsubsection{Glutamate}

The distribution of glutamate-like immunoreactive neurons has been observed in the PAG with the majority of the stained neurons being in the ventrolateral and dorsal PAG subdivisions. Aspartate-like immunoreactive neurons also exhibit a similar distribution pattern. These neurons are usually fusiform or triangular in shape and predominantly localized in the dorsolateral and ventrolateral subdivisions of the PAG. The numbers of aspartate-like immunoreactive neurons are documented less than the numbers of glutamate-like immunoreactive neurons (Clements et al 1987).

Immunohistochemical staining methods have shown the presence and distribution of glutamate receptors in cell bodies located in the dorsal parts of the PAG. The glutamatergic system in the PAG has been associated with the expression of defensive rage responses (Beitz 1989; Carobrez 2003; Lima et al 2007). Injections of the NMDA receptor antagonist AP7 into the dorsal PAG induced anti-aversive effects in animal models of anxiety, such as in the elevated plus maze (Guimaraes et al 1991) or the Vogel punished licking test (Molchanov and Guimaraes 1999). In other studies, microinjection of NMDA into the PAG induced seizures followed by generalized clonic convulsions 
(N'Gouemo and Faingold 1999; Peterson et al 2000; Raisinghani and Faingold 2003). The apparent convulsive behaviour was confirmed as seizure activity from EEG recordings (Peterson et al 2000).

One of the glutamate-receptors that plays an important role in defensive responses is the kainate receptor. These receptors participate in excitatory neurotransmission by activating post-synaptic receptors and also bind to kainate and acts as a cation channel. They also modulate the release of inhibitory neurotransmitter GABA through a presynaptic mechanism. There are five types of kainate receptor subunits, GluR5, GluR6, GluR7, KA1 and KA2, which are similar to AMPA and NMDA receptor subunits. Kainate receptors play a role in both pre- and postsynaptic neurons (Huettner 2003). They have a limited distribution in the brain when compared to AMPA and NMDA receptors. In the PAG, prominent mRNA has been found of GluR-A, -B, and NR1. In adult rats, kainate triggers a full range of behaviour and autonomic defensive responses (Bandler and Depaulis 1988). Administration of kainate receptor antagonist into the PAG induces anxiolytic-like effects in the elevated plus maze (Matheus and Guimaraes 1997). The pretreatment with AMPA/kainate or NMDA glutamate receptor antagonists also attenuated the defensive reactions (flight reactions characterized by running and jumping) induced by an NO donor in the dlPAG (Moreira et al 2004).

Injection of kainic acid into the DRN significantly increased the 5-HT release in the amygdala and the dorsal PAG (Adell et al 1991). In line with this, Viana and co-workers (Viana et al 1997) found that the 5-HT release in both structures enhanced inhibitory avoidance and impaired one-way escape in the elevated T-maze which is in accordance with Deakin \& Graeff's suggestion that release of 5-HT in the amygdala enhances conditioned fear (inhibitory avoidance) while the release of 5-HT in the dorsal PAG decreases unconditioned fear (escape) (Deakin 1991a; Viana et al 1997).

Local infusion of the non-NMDA, AMPA/kainate glutamate receptor antagonist 2,3-dihydroxy-6-nitro-7-sulfamoylbenzo( $F)$-quinoxaline (NBQX) into the dorsal/lateral PAG, the lateral mesencephalic reticular formation, or the superficial superior colliculus did not affect the fear-potentiated startle. But the NBQX tended to reduce contextual freezing when infused into the dorsal/lateral PAG. However, the same dose of NBQX infused into the deep layers of the superior colliculus/deep mesencephalic nucleus (deep $\mathrm{SC} / \mathrm{DpMe}$ ) blocked fear potentiated startle. This suggests that the deep SC/DpMe, but not the ventral PAG, is critical for fear-potentiated startle but not freezing; whereas the PAG, but not the deep SC/DpMe, is critical for freezing (Zhao and Davis 2004). 


\subsubsection{GABA}

Gamma-amino butyric acid (GABA) is the most ubiquitous inhibitory transmitter with two major subtype receptors, GABA-A and GABA-B receptors. The GABA-A receptor is an ionotropic receptor that gates a chloride channel and GABA-B receptor is metabotropic, activating a second messenger cascade that activates a potassium channel. Immunohistochemical studies have shown that GABAergic neurons are widely distributed throughout the whole brain and are the major source of synaptic inhibition in the central nervous system. The precursor for GABA is glutamate and the key synthesizing enzyme is glutamic acid decarboxylase (GAD) which is a relatively good marker for GABAergic neurons (Bear et al 2001; Brodal 2004; Kandel et al 1995).

The GABA immunoreactive neurons are sparsely scattered throughout the PAG, but high numbers are present particularly in the dorsal and ventrolateral subdivisions (Borelli et al 2005a; Vianna et al 2003a). The post-embedding double-immunogold electron microscopic method of labeling provides better visualization of the subcellular morphological structures and permits quantification of the GABA and enkephalin neurotransmitters. This method has shown that there are 247 vesicle-containing axon terminals and 165 dendrites which are classified as GABA in the vlPAG (Renno et al 1999). The enkephalin- and/or GABA-labelled terminals in this PAG area contain densely packed round or pleomorphic, small, agranular vesicles and form mainly symmetrical pre- and postsynaptic density contacts with enkephalin-labelled dendrites (Renno et al 1999). An autoradiography study has shown that both GABA-A and GABA$B$ receptors exist in the PAG which indicates that many of the GABA-responsive PAG neurons have both subtypes of GABA receptors (Bowery et al 1987). With regard to this, the next finding by Reichling and associates in 1990, the short intrinsic circuit in the PAG, identified the GABAergic presypnaptic fibers in the dIPAG (Reichling and Basbaum 1990; Tredici et al 1983).

Injection of GABA into the midbrain PAG activates medullary neurons that are involved in pain inhibition and potentate morphine-induced analgesia (Levy and Proudfit 1979; Moreau and Fields 1986; Morgan et al 2003). GABAergic mechanisms in the PAG modulate the descending pain inhibitory system (Behbehani et al 1990). Electrophysiological studies have suggested that activation of $\mu$-opioid receptors inhibits GABA neurons, thereby allowing the off-cells of the PAG to activate neurons in the nucleus raphe magnus, ultimately producing analgesia (Fields et al 1991). This suggests that GABAergic neurons are involved in the modulation of antinociception effects of opiates at the level of PAG. 


\subsection{Neuropeptides}

\subsubsection{Substance $P$}

Substance $\mathrm{P}$ is a short-chain neuropeptide that functions as a neurotransmitter. It belongs to the tachykinin neuropeptide family. In the central nervous system, substance $P$ has been associated in the regulation of mood disorders, anxiety, stress, reinforcement, neurogenesis, respiratory rhythm, neurotoxicity, nausea/emesis and pain (Harrison and Geppetti 2001). Substance $P$ is particularly concentrated in the amygdala and other regions that regulate affective behaviour and neurochemical responses to stress. The PAG also contains substance P-positive, medium-sized fibers with multiple varicosities (Kramer et al 1998; Maubach et al 1999; Renoldi and Invernizzi 2006).

\subsubsection{Cholecystokinin}

Cholecystokinin (CCK)-immunoreactive fibers are ranged from small to medium size with regular varicosities and its receptors are widely distributed within the gut and the brain (Moran et al 1986; Zarbin et al 1983). The immunohistochemical studies have shown that the CCK-like immunoreactive fibers and terminals are present throughout the rostrocaudal levels of the PAG and are more heavily distributed in the caudal two-thirds area. It was also demonstrated that a higher concentration of CCK immunoreactivity fibers and terminals was found in the dlPAG as compared with the dmPAG (Liu et al 1994).

Recently, systemic administration of $\mathrm{CCK}_{2}$ receptor agonist has been shown to trigger panic attacks in human (Bourin et al 1991; Bradwejn and Koszycki 2001). This effect seems to involve the dPAG since systemic administration of the latter drug induced Fos immunoreactivity in this area (Singewald and Sharp 2000). Further evidence for the involvement of CCK in panic is that intra-dPAG or systemic injection of CCK-8s induced escape or panic-like reaction in rats (Zanoveli et al 2004). This finding was also in consistent with previous reports that intra-dlPAG injection with $\mathrm{CCK}_{2}$ receptor agonist CCK-4 facilitated escape behaviour when the animals were tested in the elevated T-maze (Bertoglio et al 2006; Bertoglio and Zangrossi 2005) and in the bowl-shape cage (Bertoglio et al 2007). On the other hand, the treatment with $\mathrm{CCK}_{2}$ receptor antagonist LY225910 had significantly inhibited the escape reaction in the elevated T-maze, indicative of panicolytic-like action (Bertoglio and Zangrossi 2005). In view of these behavioural and immunohistochemical studies, among other factors, they support strongly that the regulatory site for panic-related behaviour is probably located in the dIPAG. 


\subsubsection{Enkephalin}

In1979, Gramsch and co-workers detected $\beta$-endophin and met-enkephalin in the PAG (Gramsch et al 1979). Several investigations showed that enkephalin neurons especially in the vlPAG play a role in pain modulation (Budai and Fields 1998; Williams et al 1995). Enkephalinergic terminals synapse on GABA containing dendrites in the PAG.

The enkephalinergic system in the PAG is also involved in the modulation of hypothalamus-induced predatory attack behaviour (Siegel et al 1997). The predatory attack was elicited by electrical stimulation of lateral hypothalamus in the rat and it was completely suppressed by injections of delta-alanine methionine enkephaline in the dorsal PAG (Bhatia et al 1997). The injection of delta-alanine methionine enkephaline into the dPAG also completely suppressed the somatomotor components of predatory attack behaviour (Manchanda et al 1995). The administration of naloxone facilitated the hypothalamus-induced attack behaviour and cancelled the inhibitory effect of deltaalanine methionine enkephaline (Bhatia et al 1997; Brutus and Siegel 1989; Manchanda et al 1995; Weiner et al 1991).

\subsubsection{Opioid receptors}

Opioid peptides are derived from proenkephalin A, and are found in very high levels in the PAG (Pittius et al 1984). Opioid peptides act on their receptors. These are the $\mu-, \delta$-, and $\kappa$-opiate receptors. Binding sites of these receptors have been localized in the PAG and possess excitatory effects and play a critical role in the activation of descending pain systems (Pfeiffer et al 1982a; Pfeiffer and Herz 1982; Pfeiffer et al 1982b). Opiates typically exert inhibitory effects on neurons in the central nervous system except for PAG neurons (Gent and Wolstencroft 1976). Opioid effects in the PAG are mimicked by glutamate receptor agonists including NMDA and electrical stimulation (Jacquet and Squires 1988; Jensen and Yaksh 1989) and all drive PAG output. Numbers of neurons expressing c-Fos immunoreactivity after opioid withdrawal in both awake and anesthetized rats were elevated in the lateral and ventrolateral subdivisions of the PAG, predominantly in the caudal areas of the vlPAG (Chieng et al 1995).

Stimulation of opioid receptors within the PAG activates the descending inhibitory pathways and suppresses nociception (Bellgowan and Helmstetter 1998; Rossi et al 1994). In addition, vlPAG stimulation in opioid-naive animals with excitatory amino acids produces quiescence, hyporeactivity, hypotension, bradycardia, and opioid-mediated analgesia (Keay et al 1997). Many vlPAG neurons that descend to the rostral ventromedial medulla, the excitation of which is thought to be crucial for analgesia, have immunolabelling for $\mu$-opioid receptors (Commons et al 2000). The PAG also mediates several behaviour reactions such as freezing and defensive immobility, which are partly under opioid control (Fanselow et al 1991). 
The $\mu$-opioid receptor immunoreactivity is present in both subpopulations of GABAergic vlPAG neurons and vlPAG neurons that project to the rostral ventromedial medulla (Commons et al 2000).

The $\kappa$-opioid receptor was previously known for its ability to cause strange psychoactive effects which have been called 'hallucinogenic'. Pharmaceutical companies looking for novel analgesics investigated kappa-opioid agonists and discovered that they caused unwanted side effects in humans which made them non-applicable as pain medications. The kappa opioid agonist, enadoline significantly increased measures of sedation, confusion and dizziness, produced visual distortions and feelings of depersonalization, and increased urinary output. The highest dose $(160 \mu \mathrm{g} / 70 \mathrm{~kg})$ was not tolerated and led to psychotomimetic effects (Walsh et al 2001). When rats are given the kappa opioid receptor agonist U50,488 during the first 3 post-natal weeks, they exhibited an increase in ultrasonic vocalization production and in contrast with adult rats showed no behaviour activation (Carden et al 1994; Kehoe and Boylan 1994). Kappa opioid receptors are also expressed in the PAG as early as the first postnatal week (Kitchen et al 1990). 


\section{Discussion}

\subsection{The defence circuit of the $P A G$}

According to the two-dimensional neuropsychology of defence proposed by McNaughton \& Corr and in agreement with previous evidence, PAG and its connections control the alterations of circulation, respiration, pain perception, behaviour and automatic movements in response to threatening or novel stimuli (McNaughton and Corr 2004). As for the PAG efferents, the majority of the fibers leaving the PAG usually terminate in the parabrachial nuclei, reticular formation, trigeminal motor nucleus and nucleus ambiguus. The PAG also receives afferents from the following structures such as the amygdala, nucleus stria terminalis, hypothalamus, thalamus, periventricular gray, the dorsolateral and ventrolateral midbrain tegmentum (Jurgens and Pratt 1979). Besides, several structures in the CNS receive dopaminergic (TH-ir) inputs from the DR/PAG, including the lateral bed nucleus of the stria terminalis, central amygdaloid nucleus (Hasue and Shammah-Lagnado 2002), accumbens (Stratford and Wirtshafter 1990), caudate-putamen (Descarries et al 1986), lateral habenula (Li et al 1993), hippocampus (Pohle et al 1984), magnocellular basal forebrain (Semba et al 1988), lateral septum and medial prefrontal cortex (Stratford and Wirtshafter 1990; Yoshida et al 1989).

The medial hypothalamic area, including the anterior hypothalamus, dorsomedial part of the ventromedial hypothalamus (VMHdm), and dorsal premammillary nucleus (PMd), which together form a defensive system (Canteras 2002; Canteras et al 2001), shows a strong activation to conditioned fear (e.g. cat odor, as well as a live cat) (Canteras et al 1997; Dielenberg et al 2001a; Dielenberg et al 2001b; Dielenberg and McGregor 2001). The bed nucleus of the stria terminalis, ventral part of the lateral septum, and PAG are also activated during cat odor exposure. Keay \& Bandler illustrated the axons of medial prefrontal cortex densely targeted the ventromedial hypothalamic nucleus and anterior hypothalamic area and terminated within the dlPAG (Canteras 2002; Vianna and Brandao 2003). On the other hand, the orbital and anterior insular prefrontal cortex areas selectively targeted the lateral hypothalamus and projected only to the vlPAG. As for the IPAG, the dorsomedial prefrontal cortex convexity and anterior cingulate cortex (area 24) firstly project its fiber to the dorsal hypothalamic areas and finally terminated in the $\mathrm{PAG}$ column.

It is interesting to note that the functional significance of the parallel projection from the prefrontal cortex to the different parts of hypothalamus finally terminate in specific columns of the PAG. Recent data have shown that the amygdala and the PAG, together with the medial hypothalamus, constitute an integrated circuitry in the brain that commands defensive behaviour and elaborates aversive emotional and motivational states. The function of the amygdala would be to synthesize the various stimulus inputs from the 
environment and then signal to the PAG according to the degree of threat represented to the organism (LeDoux 1994 ; LeDoux et al 1988; McNaughton and Corr 2004).

A series of retrograde studies revealed that the projections to the PAG arise predominantly from the medial prefrontal cortex wall and a few selected orbital/anterior insular prefrontal cortex regions (Floyd et al 2000; Reep and Winans 1982). In addition, injections of anterograde tracers into each PAG-projecting prefrontal region revealed distinct columnar patterns in the PAG. The medial prefrontal cortex projects densely to the dlPAG; whereas vlPAG received an exclusive robust input from the orbital and anterior insular areas $(12 \mathrm{o}, 12 \mathrm{l}, 13 \mathrm{a}, 14 \mathrm{c}$, Iai) and weaker input from the medial and dorsomedial prefrontal areas (Floyd et al 2000; Floyd et al 2001; Jasmin et al 2004). In addition, the dorsomedial prefrontal cortex (areas $9 \& 24$ ) was found to project robustly to the IPAG column, which indicates that different types of defensive behaviour are resulting from different columnar organization of the PAG (Gabbott 2003; Gabbott et al 2003; Jasmin et al 2004; Yasui et al 1991).

In line with McNaughton and Corr's defensive system, Keay and Bandler (2001) divided emotional coping strategies of different types of stress into active and passive strategies. The active coping is regarded as the activation of either the dorsolateral or lateral PAG columns; whereas passive emotional coping strategy is triggered by activation of the ventromedial PAG column. This behaviour was observed during the microinjection of excitatory amino acid into the rostral dIPAG or IPAG which evoked a confrontational defensive reaction, while microinjection at the caudal dIPAG or IPAG evoked a response of escape or flight reaction (Keay and Bandler 2001). In addition, hypertension and tachycardia were noticed during the rostral dIPAG or IPAG (confrontational defence system) stimulation with decreased blood flow to skeletal muscle and viscera, but increased extracranial flow. Meanwhile, stimulation of the caudal dIPAG and IPAG evoked only the hypertension which was accompanied by increased blood flow to the skeletal muscle but decreased blood circulation in the visceral and oral facial region. In contrast to the stimulation of dIPAG or $1 \mathrm{PAG}$, microinjection of excitatory amino acid into the vlPAG produced a passive reaction of quiescence/immobility, decreased vigilance and hyporeactivity with hypotension and bradycardia, not responding to any external environmental stimuli. The similar effect of hypotensive responses without significant heart rate changes was also observed during the stimulation in the dmPAG (See Table 2) (Pajolla and de Aguiar Correa 2004; Pajolla et al 2005). 
Table 1, Definition of different types of defensive behaviour associated with periaqueductal gray stimulation either by electrical or chemical compounds.

\begin{tabular}{|c|c|}
\hline TERMS & DEFINITION \\
\hline $\begin{array}{l}\text { Affective defense } \\
\text { behaviour }\end{array}$ & $\begin{array}{l}\text { It is characterized by an aggressive response based on the presence of } \\
\text { elements of either fear and/or threat, which may be real or perceived to be a } \\
\text { threat stimulus as defined in both human and animal studies. In rodents, the } \\
\text { behavioural response includes a flattening of the ears, a shrinking or } \\
\text { lowering of the body, drawing in of the head, piloerection, hissing, and } \\
\text { pupillary dilatation. }\end{array}$ \\
\hline Conditioned fear & $\begin{array}{l}\text { Behavioural inhibition with neurovegetative changes such as raised fur, } \\
\text { defecation, urination, and teeth clattering which is associated with previous } \\
\text { experience of aversive stimulus. }\end{array}$ \\
\hline Defecation & $\begin{array}{l}\text { Discharge of feces during emotional distress or normal physiological } \\
\text { function. }\end{array}$ \\
\hline Defensive behaviour & $\begin{array}{l}\text { Behavioural and neuropsychological reaction in response to fear or anxiety } \\
\text { condition with respect to avoidable and unavoidable threat stimuli. It is } \\
\text { commonly categorized into flight, fight, and freezing response in the } \\
\text { laboratory animal studies. }\end{array}$ \\
\hline Defensi & $\begin{array}{l}\text { It is a form of aggressive behaviour that characterized by remarkable } \\
\text { sympathetic activation with behavioural signs such as arching of the back, } \\
\text { pupillary dilatation, piloerection, retraction of the ears, growling, hissing, } \\
\text { and paw striking at a moving object. }\end{array}$ \\
\hline Exopht & $\begin{array}{l}\text { Eyeball protrusion and wide opened eyelids (contraction of orbital and tarsal } \\
\text { sympathetic muscles, respectively). The eyes take on a spherical shape and } \\
\text { brilliant appearance suggestive of an increased entrance of light. }\end{array}$ \\
\hline Flight & $\begin{array}{l}\text { It is a general model of predation defense behaviour to avoid or flee the } \\
\text { animals from the attack of predator. In rats, the behaviour comprises the } \\
\text { running (trotting or galloping) and/or jumping responses. }\end{array}$ \\
\hline Fight & $\begin{array}{l}\text { It is a form of aggressive behaviour to defend the animals against any attack } \\
\text { from predators that the prey may fight back ferociously. Sometimes, it can be } \\
\text { defending for a territory, food, shelter and mates. }\end{array}$ \\
\hline Freezing & $\begin{array}{l}\text { Most prey animals will avoid fights with predators, in general they will } \\
\text { display a posture of tense immobility accompanied by exophthalmus, } \\
\text { mystacioplegia and, quite often, defecation and micturition, accompanied by } \\
\text { hypertension, hypervigilance and increased autonomic function. }\end{array}$ \\
\hline Gallopir & $\begin{array}{l}\text { Fast running alternating stance and swing movements of anterior and } \\
\text { posterior limb pairs. }\end{array}$ \\
\hline Grooming & $\begin{array}{l}\text { Self-directed behaviours consisting of the repetitive manipulation of the fur } \\
\text { of the head and trunk as well as the manipulation and/or licking of the } \\
\text { genitals. The rat displays a 'sitting' posture (upright posture on flexed hind } \\
\text { limbs). }\end{array}$ \\
\hline Immobile behaviour & The animals remain on a location usually with four paws on the ground. \\
\hline Jumping & Upward leaps directed to the border of the open arena. \\
\hline Micturition & $\begin{array}{l}\text { Discharge of urine during aversive response or normal physiological } \\
\text { function. }\end{array}$ \\
\hline Mystacioplegia & s of ongoing vibrissae movements. \\
\hline
\end{tabular}




\begin{tabular}{|l|l|}
\hline \multicolumn{1}{|c|}{ TERMS } & \multicolumn{1}{|c|}{ DEFINITION } \\
\hline $\begin{array}{l}\text { Panic-like } \\
\text { symptoms }\end{array}$ & $\begin{array}{l}\text { Palpitation, blushing of face and neck and respiratory arrest or } \\
\text { hyperventilation, feelings of terror or impending death, and desire to flee. } \\
\text { The behaviour mimics defensive and escape behaviour. }\end{array}$ \\
\hline Predatory attack & $\begin{array}{l}\text { Aggressive behaviour specifically triggered by the presence of a prey object } \\
\text { within the visual field of the predator that consists of a purposeful and goal- } \\
\text { directed attack with absence of sympathetic arousal. }\end{array}$ \\
\hline Rearing & $\begin{array}{l}\text { Upright posture with extended hind limbs and forelegs lean against the wall } \\
\text { or an object. }\end{array}$ \\
\hline Resting & $\begin{array}{l}\text { Quiescent horizontal posture with open or half-open eyes, reduced sniffing } \\
\text { activity and muscle relaxation as suggested by the flexion of the limbs and } \\
\text { lowering of trunk and tail. The head may be raised and the rat displays a } \\
\text { 'sphinx' like posture. }\end{array}$ \\
\hline Running & $\begin{array}{l}\text { Increased locomotor activity with rapid movement of fore- \& hind-limb } \\
\text { toward or away from aversive stimuli. }\end{array}$ \\
\hline Sleeping & $\begin{array}{l}\text { Quiescent horizontal posture with closed eyes, no sniffing activity and } \\
\text { overall muscle relaxation as suggested by the flexion of the limbs and } \\
\text { lowering of the trunk, head, neck \& tail. }\end{array}$ \\
\hline Trotting & $\begin{array}{l}\text { Overall behavioural arrest accompanied by an increased muscle tonus as } \\
\text { suggested by the extension of the neck and:or limbs and raising of head, } \\
\text { trunk and/or tail. Except for the visible tachypnoea, the rat looks like a } \\
\text { 'statue' for periods lasting from } 10 \mathrm{~s} \text { to the end of the stimulus }(60 \text { s). }\end{array}$ \\
\hline Walking & $\begin{array}{l}\text { Running keeping the same pattern of walking } \\
\text { the contralateral limbs. }\end{array}$ \\
\hline
\end{tabular}




\subsection{Summary}

In this review, we have outlined the general neuroanatomy and neurochemical properties of the PAG. The PAG has been considered a key structure to coordinate behaviour in response to threatening stimuli and pain regulation. It has been demonstrated that stimulation of this area in rats initiate different defensive behaviours such as fight, flight and freeze in response to aversive external and internal stimuli. Besides, it also eliminates the perception of pain by stimulation which is called stimulation produced analgesia. Several physiological changes have been observed in the alteration of blood circulation, respiration, pain perception, autonomic movement and postural adjustment with complex behaviour during and after the stimulation or lesions of the PAG. In addition, the PAG also modulates several biological functions such as reproductive or sexual behaviour, maternal behaviour, vocalization, anxiety, cardiovascular, and respiratory activities.

The finding that the PAG is composed of different anatomical columns has contributed to the understanding of its functional differentiation. It consists of several columnar groups of neurons, each differing with regard to their connections. More specifically, it has become clear that the dorsal and lateral PAG are involved in the active emotional coping (fight and flight reaction), whereas the ventrolateral PAG is responsible for the passive emotional coping (quiescence/freezing). Several behaviours are coordinated through these columns by means of efferent connections to the reticular formation, raphe nuclei, cuneiform nucleus, and thalamus. The main afferent connections consist predominantly of projections from the sensory cortex, prefrontal cortex, cingulate cortex, motor cortex, insular cortex via the hypothalamus, amygdala, dorsal and median raphe nuclei. Such connectivity of different neuroanatomical structures presents a picture of neural systems in controlling the fundamental basis for defensive reactions. In view of these, the neuropsychology of defence also requires different interaction of neurochemical properties in concert with their morphological structures to achieve the optimal condition for defensive functions.

\subsection{Perspectives}

The history of PAG investigation dated almost a century old (See Table 2) and the future research should focus on the neurobiology aspect of its pathogenesis using the state-of-art technology of electrophysiological investigation. The precise relationship between the experimentally induced panic and naturally occurring panic attack share many similar clinical features in humans. However, the exact relationship of the underlying pathogenesis between these two remains largely unknown. Many studies in which the effects of the PAG stimulation have been investigated in combination with psychopharmacological challenge showed that the PAG is involved in panic or anxietylike behaviour. Thus, electrical stimulation of the PAG in animals would be a promising future direction in the aspect of neuropsychiatric disorders for developing potential 
panicolytic and anxiolytic drugs. Besides, the anatomical structure and functional roles of the PAG in the animal brain have been studied extensively, whereas the human PAG is still poorly understood. It will be essential to conduct some fundamental investigations on the translational studies from the experimental rodent findings into human subjects. Further, electrical stimulation of the PAG has been shown to produce analgesic effect and lowering the blood pressure. These findings suggest a possible mechanism in the therapeutic approach to modify the pathological states of neuronal condition as well as their firing patterns. Such potential approach in normalizing the mechanism of dysfunctional neurons and its connectivity may possibly contribute to future neuropsychiatry surgery in terms of normalizing its neuronal firing patterns. Though, many hypotheses have been proposed to explain on how deep brain stimulation exerts its therapeutic effects, but still there is no well-established theories underlying its working mechanism (Lozano and Eltahawy 2004; Montgomery and Gale 2007). More importantly, addressing the application of these electrophysiological modulation techniques and a careful assessment during the intervention is required to explore these possible future therapies.

\section{Acknowledgement}

This research was supported by a grant from the FP6 Marie Curie Fellowship (MEST-CT-2005-020589). 
Table 2, The table presents the major milestones in the history of PAG research. The following dates and events were gathered chronologically from several sources based on the scientific published data dated since 1915 .

\begin{tabular}{|c|c|}
\hline Years & Chronological Events \\
\hline 1915 & $\begin{array}{l}\text { Brown made the first observation of the central gray in phonation. He stimulated } \\
\text { the cut surface of the transected brain stem of rostral PAG and obtained a sound } \\
\text { 'resembling laughter'. }\end{array}$ \\
\hline 1935 & $\begin{array}{l}\text { Kabat et al. demonstrated that central gray stimulation increases the respiratory } \\
\text { rate and blood pressure. }\end{array}$ \\
\hline 1937 & $\begin{array}{l}\text { Magoun et al. demonstrated that stimulation of rostral PAG yielded species- } \\
\text { specific calls. }\end{array}$ \\
\hline 1944 & $\begin{array}{l}\text { Bailey and Davis described the central gray has been implicated in rage and fear } \\
\text { reactions. }\end{array}$ \\
\hline 1954 & $\begin{array}{l}\text { Olszewski and Baxter subdivided the human PAG into a region adjacent to the } \\
\text { mesencephalic aqueduct termed the subnucleus medialis, lateralis and dorsalis. }\end{array}$ \\
\hline 1954 & $\begin{array}{l}\text { Delgado et al. stimulated the dorsal PAG with observation of laboratory animals } \\
\text { easily learned to switch off the experimental electrical stimulation. }\end{array}$ \\
\hline 1956 & $\begin{array}{l}\text { Hunsperger conducted electrical stimulation of the dorsal PAG in laboratory } \\
\text { animals which induced defensive reactions, such as vigorous flight or defensive } \\
\text { aggression. }\end{array}$ \\
\hline 1958 & $\begin{array}{l}\text { Nauta's limbic system-midbrain circuit proposed that limbic system has robust } \\
\text { connenctions with mesencephalic structures such as PAG \& tegmentum. }\end{array}$ \\
\hline 1963 & $\begin{array}{l}\text { Skultety demonstrated that many autonomic reactions can be elicited by } \\
\text { stimulation or lesions of the central gray. }\end{array}$ \\
\hline 1969 & $\begin{array}{l}\text { Reynolds discovered that electrical stimulation of the periaqueductal gray } \\
\text { induce profound analgesia. }\end{array}$ \\
\hline 1969 & $\begin{array}{l}\text { Nashold et al. demonstrated that during stimulation of human central gray } \\
\text { produces feeling of intense fear. }\end{array}$ \\
\hline 1972 & $\begin{array}{l}\text { Wise et al. elaborated the theoretical model on serotomin with anxiety and } \\
\text { expected the facilitation of serotonin in the escape behaviour. }\end{array}$ \\
\hline 1972 & $\begin{array}{l}\text { Kiser et al. }(1972,1975,1978,1980) \text { showed the different ways of increasing 5- } \\
\text { HT activity in the dorsal PAG had an anti-aversive effect, whereas 5-HT } \\
\text { depletion resulted in the facilitation of escape from dorsal PAG electrical } \\
\text { stimulation. }\end{array}$ \\
\hline 1973 & $\begin{array}{l}\text { Nobin and Bjorklund were the first to describe scattered neurons displaying } \\
\text { catecholamine fluorescence lying ventrolateral to the aqueduct in the human } \\
\text { fetal midbrain. Serotonin-containing cells were first identified in the human } \\
\text { ventrolateral and ventral central gray using the Falck-Hillarp histochemical } \\
\text { technique. }\end{array}$ \\
\hline 1973 & Hamilton conducted a study on the cytoarchitechture of the PAG subdivisions. \\
\hline 1975 & $\begin{array}{l}\text { Kiser and Lebovitz demonstrated that the stimulation of the dorsal central gray } \\
\text { induces aversive behaviour in animals which might serve as animal model for } \\
\text { anxiety. }\end{array}$ \\
\hline
\end{tabular}




\begin{tabular}{|c|c|}
\hline 1977 & $\begin{array}{l}\text { Jurgens and Muller-Preuss emphasized the importance of direct descending } \\
\text { limbic system input to the primate central gray. }\end{array}$ \\
\hline 1977 & $\begin{array}{l}\text { Hosobuchi et al., Richardson and Akil showed preliminary results on } \\
\text { stimulation of the PAG was effective in reducing intractable pain. }\end{array}$ \\
\hline 1978 & $\begin{array}{l}\text { Schenberg \& Graeff demonstarted that Benzodiazepines diminishes the } \\
\text { aversive behaviour induced by central gray stimulation. }\end{array}$ \\
\hline 1979 & $\begin{array}{l}\text { Laemle described the vertical and horizontal cell in central gray, stellate cells } \\
\text { with } 4 \text { randomly oriented primary dendrites and reported the neuronal axons } \\
\text { arise from soma ascend and descend in the central gray. }\end{array}$ \\
\hline 1979 & $\begin{array}{l}\text { Holstege mapped the central gray cells projecting to the spinal cord, raphe } \\
\text { magnus/ pallidus and adjacent reticular formation of the cat. }\end{array}$ \\
\hline 1979 & $\begin{array}{l}\text { Gramsch et al. detected moderate amount of both } \beta \text {-endorphin \& met- } \\
\text { enkephalin in human central gray. }\end{array}$ \\
\hline 1979 & $\begin{array}{l}\text { Sakuma and Pfaff described the central gray has been implicated in sexual } \\
\text { behaviour. }\end{array}$ \\
\hline 1979 & $\begin{array}{l}\text { Rose demonstrated electrophysiologically the presence of neurons in the primate } \\
\text { central gray which respond to genital, rectal, innoculous somatosensory and } \\
\text { various forms of noxious stimulation. }\end{array}$ \\
\hline 1980 & $\begin{array}{l}\text { Kesner and Calder described the central gray has been implicated in the } \\
\text { memory storage. }\end{array}$ \\
\hline 1981 & $\begin{array}{l}\text { Hardy and Leichnetz demonstrated that the prefrontal cortex of the monkey } \\
\text { projects predominantly to the lateral dorsal subdivision of the central gray. }\end{array}$ \\
\hline 1981 & $\begin{array}{l}\text { Morato de Carvalho et al. carried out an experiment using electrical } \\
\text { stimulation of the dorsal PAG as a punishing stimulus and showed that the } \\
\text { neural substrate of dorsal PAG delivered punishment seems to be different from } \\
\text { that of peripherally applied punishment as compared with Graeff } 1974 \text { electrical } \\
\text { foot shock punishment. }\end{array}$ \\
\hline 1982 & $\begin{array}{l}\text { Pfeiffer et al. identified the localization of } \mu-, \delta-\text {, and } \kappa \text {-opiate receptor binding } \\
\text { sites it the human PAG and possess the excitatory effects in the periaqueductal } \\
\text { gray which play a critical role in the opiate activation of the descending pain } \\
\text { modulatory systems as opioid-induced analgesia }\end{array}$ \\
\hline 1982 & $\begin{array}{l}\text { Mantyh investigated the hypothalamus with greatest descending input to the } \\
\text { primate central gray, described the fusiform neuron in the monkey central gray, } \\
\text { multipolar neurons and stellate cells. }\end{array}$ \\
\hline 1982 & $\begin{array}{l}\text { Brandao et al. concluded that the GABAergic terminals tonically inhibit the } \\
\text { neurons of the dorsal PAG that control defensive behaviour and serotonergic } \\
\text { fibers seem to exert a phasic inhibition of aversion. }\end{array}$ \\
\hline 1983 & $\begin{array}{l}\text { Palacios et al. concluded that serotonin receptors are present in the human } \\
\text { central gray. }\end{array}$ \\
\hline 1983 & $\begin{array}{l}\text { Pearson et al. described tyrosine hydroxylase immunoreactive fibers in the } \\
\text { ventral and ventrolateral PAG. }\end{array}$ \\
\hline 1984 & $\begin{array}{l}\text { Cortes et al. identified the human central gray contains a high density of } \\
\text { muscarinic receptors especially in the dorsolateral subdivision. }\end{array}$ \\
\hline 1985 & $\begin{array}{l}\text { Kirzinger and Jurgens suggested that stimulation of caudolateral involved in } \\
\text { vocal motor control. }\end{array}$ \\
\hline 1986 & ne distribution of serotonergic neurons. \\
\hline
\end{tabular}




\begin{tabular}{|c|c|}
\hline 1987 & $\begin{array}{l}\text { Pazos et al. identified the serotonin- } 1 \& \text { serotonin- } 2 \text { receptors are present in } \\
\text { human central gray. }\end{array}$ \\
\hline 1987 & $\begin{array}{l}\text { Clements et al. identified the distribution of glutamate-like immunoreactive } \\
\text { neurons in ventrolateral and dorsal subdivisions of central gray. }\end{array}$ \\
\hline 1988 & $\begin{array}{l}\text { Beitz et al. provided the first detailed analysis of the interaction of central gray } \\
\text { descending projections with bulbospinal neurons in the rat. }\end{array}$ \\
\hline 1989 & $\begin{array}{l}\text { Jenck et al. reported that 5-HT1A-receptor agonist enhanced escape from } \\
\text { DPAG electrical stimulation. }\end{array}$ \\
\hline 1990 & $\begin{array}{l}\text { Graeff et al. concluded that the amygdala, the medial hypothalamus and the } \\
\text { PAG constitute a set of interrelated structures, brain aversive system (BAS) that } \\
\text { includes the dorsal PAG (Graeff 1981) act together to produce response } \\
\text { suppression, emotional and motivational states. }\end{array}$ \\
\hline 1994 & $\begin{array}{l}\text { Bandler \& Shipley described the columnar organization in the midbrain } \\
\text { periaqueductal gray with } 4 \text { subdivisions as the dorsomedial, dorsolateral, lateral } \\
\text { and ventrolateral PAG. }\end{array}$ \\
\hline 1995 & $\begin{array}{l}\text { Nogueira and Graeff explored the roles of serotonin receptors subtypes 5- } \\
\text { HT1A and 5-HT2A/2C in the regulation of aversion in the dorsal PAG. }\end{array}$ \\
\hline 1996 & $\begin{array}{l}\text { Reddy et al. identified the neurotransmitter receptors: nicotinic, muscarinic, } \\
\text { serotoninergic, opiod, and kainate receptors in the middle gestational period of } \\
\text { fetal development in the human PAG. }\end{array}$ \\
\hline 1999 & $\begin{array}{l}\text { Renno et al. confirmed the colocalization of GABA and enkephalin in the } \\
\text { ventrocaudal periaqueductal gray. }\end{array}$ \\
\hline 1999 & $\begin{array}{l}\text { Brandao et al. regarded the } \mathrm{dPAG} \text { contained fear neural substrates, with } \\
\text { previous experimental evidence (see Brandao et al., 1982). }\end{array}$ \\
\hline 2000 & $\begin{array}{l}\text { Kirouac \& Pittman showed a projection from the ventral tegmental area to the } \\
\text { periaqueductal gray involved in cardiovascular regulation. }\end{array}$ \\
\hline 2004 & $\begin{array}{l}\text { McNaughton and Corr present a two-dimensional neuropsychology of } \\
\text { defense: fear/anxiety and defensive distance }\end{array}$ \\
\hline 2004 & $\begin{array}{l}\text { Zhao \& Davis confirmed that fear-potentiated startle is mediated by neurons in } \\
\text { the deep layers of the superior colliculus/deep mesencephalic nucleus whereas } \\
\text { the dorsal/lateral PAG responsible for freezing. }\end{array}$ \\
\hline 2005 & $\begin{array}{l}\text { Yoshida et al. concluded that the rostral PAG receives warm signals from the } \\
\text { median preoptic nucleus and the caudal PAG receives cold signals from the } \\
\text { dorsomedial hypothalamus/dorsal hypothalamic area. }\end{array}$ \\
\hline 2006 & $\begin{array}{l}\text { Maekawa et al. confirmed that the ventromedial hypothalamus are connected to } \\
\text { the PAG. }\end{array}$ \\
\hline
\end{tabular}




\section{References}

Abbar M (1996): [Panic disorder and panic attack]. Encephale 22 Spec No 5:13-18.

Abrams JK, Johnson PL, Hollis JH, Lowry CA (2004): Anatomic and functional topography of the dorsal raphe nucleus. Ann N Y Acad Sci 1018:46-57.

Adell A, Carceller A, Artigas F (1991): Regional distribution of extracellular 5-hydroxytryptamine and 5hydroxyindoleacetic acid in the brain of freely moving rats. J Neurochem 56:709-712.

Altier N, Stewart J (1998): Dopamine receptor antagonists in the nucleus accumbens attenuate analgesia induced by ventral tegmental area substance $\mathrm{P}$ or morphine and by nucleus accumbens amphetamine. J Pharmacol Exp Ther 285:208-215.

Amano K, Tanikawa T, Iseki H, Kawabatake H, Notani M, Kawamura H, et al (1978): Single neuron analysis of the human midbrain tegmentum. Rostral mecencephalic reticulotomy for pain relief. Appl Neurophysiol 41:66-78.

American-Psychiatric-Association (1998 May): Practice guideline for the treatment of patients with panic disorder. Work Group on Panic Disorder. Am J Psychiatry 155(5 Suppl):1-34.

American-Psychiatric-Association (2000): Diagnostic and Statistical Manual of Mental Disorders. Fourth Edition:Text Revision. Washington, DC: American Psychiatric Press.

An X, Bandler R, Ongur D, Price JL (1998): Prefrontal cortical projections to longitudinal columns in the midbrain periaqueductal gray in macaque monkeys. J Comp Neurol 401:455-479.

Arnault P, Roger M (1987): The connections of the peripeduncular area studied by retrograde and anterograde transport in the rat. J Comp Neurol 258:463-476.

Azmitia EC, Segal M (1978): An autoradiographic analysis of the differential ascending projections of the dorsal and median raphe nuclei in the rat. J Comp Neurol 179:641-667.

Bago M, Marson L, Dean C (2002): Serotonergic projections to the rostroventrolateral medulla from midbrain and raphe nuclei. Brain Res 945:249-258.

Bajic D, Proudfit HK, Van Bockstaele EJ (2000): Periaqueductal gray neurons monosynaptically innervate extranuclear noradrenergic dendrites in the rat pericoerulear region. J Comp Neurol 427:649-662.

Bandler R (1982): Induction of 'rage' following microinjections of glutamate into midbrain but not hypothalamus of cats. Neurosci Lett 30:183-188.

Bandler R, Depaulis A (1988): Elicitation of intraspecific defence reactions in the rat from midbrain periaqueductal grey by microinjection of kainic acid, without neurotoxic effects. Neurosci Lett 88:291-296.

Bandler R, Keay KA (1996): Columnar organization in the midbrain periaqueductal gray and the integration of emotional expression. Prog Brain Res 107:285-300.

Bandler R, McCulloch T (1984): Afferents to a midbrain periaqueductal grey region involved in the 'defense reaction' in the cat as revealed by horseradish peroxidase. II. The diencephalon. Behav Brain Res 13:279-285.

Bandler R, McCulloch T, Dreher B (1985): Afferents to a midbrain periaqueductal grey region involved in the 'defence reaction' in the cat as revealed by horseradish peroxidase. I. The telencephalon. Brain Res 330:109-119.

Bandler R, Shipley MT (1994): Columnar organization in the midbrain periaqueductal gray: modules for emotional expression? Trends Neurosci 17:379-389.

Bandler R, Tork I (1987): Midbrain periaqueductal grey region in the cat has afferent and efferent connections with solitary tract nuclei. Neurosci Lett 74:1-6.

Basbaum AI, Fields HL (1984): Endogenous pain control systems: brainstem spinal pathways and endorphin circuitry. Annu Rev Neurosci 7:309-338.

Bear MF, Connors BW, Paradiso MA (2001): Neuroscience, exploring the brain 2nd edition. . Lippincott Williams \& Wilkins 107, 131-153.

Beckett S, Marsden CA (1997): The effect of central and systemic injection of the 5-HT1A receptor agonist 8-OHDPAT and the 5-HT1A receptor antagonist WAY100635 on periaqueductal greyinduced defence behaviour. $J$ Psychopharmacol 11:35-40. 
Behbehani MM (1995): Functional characteristics of the midbrain periaqueductal gray. Prog Neurobiol 46:575-605.

Behbehani MM, Jiang MR, Chandler SD, Ennis M (1990): The effect of GABA and its antagonists on midbrain periaqueductal gray neurons in the rat. Pain 40:195-204.

Behbehani MM, Park MR, Clement ME (1988): Interactions between the lateral hypothalamus and the periaqueductal gray. $J$ Neurosci 8:2780-2787.

Behbehani MM, Zemlan FP (1986): Response of nucleus raphe magnus neurons to electrical stimulation of nucleus cuneiformis: role of acetylcholine. Brain Res 369:110-118.

Beitz AJ (1989): Possible origin of glutamatergic projections to the midbrain periaqueductal gray and deep layer of the superior colliculus of the rat. Brain Res Bull 23:25-35.

Bellgowan PS, Helmstetter FJ (1998): The role of mu and kappa opioid receptors within the periaqueductal gray in the expression of conditional hypoalgesia. Brain Res 791:83-89.

Bernard JF, Bandler R (1998): Parallel circuits for emotional coping behaviour: new pieces in the puzzle. J Comp Neurol 401:429-436.

Bertoglio LJ, de Bortoli VC, Zangrossi H, Jr. (2007): Cholecystokinin-2 receptors modulate freezing and escape behaviours evoked by the electrical stimulation of the rat dorsolateral periaqueductal gray. Brain Res 1156:133-138.

Bertoglio LJ, Guimaraes FS, Zangrossi H, Jr. (2006): Lack of interaction between NMDA and cholecystokinin-2 receptor-mediated neurotransmission in the dorsolateral periaqueductal gray in the regulation of rat defensive behaviours. Life Sci 79:2238-2244.

Bertoglio LJ, Zangrossi H, Jr. (2005): Involvement of dorsolateral periaqueductal gray cholecystokinin-2 receptors in the regulation of a panic-related behaviour in rats. Brain Res 1059:46-51.

Bhatia SC, Saha SN, Manchanda SK, Nayar U (1997): Enkephalinergic mechanisms in midbrain (dPAG) in modulation of hypothalamically-induced predatory attack behaviour. Indian J Exp Biol 35:438442.

Bianchi R, Corsetti G, Rodella L, Tredici G, Gioia M (1998): Supraspinal connections and termination patterns of the parabrachial complex determined by the biocytin anterograde tract-tracing technique in the rat. $J$ Anat 193 ( $\mathrm{Pt}$ 3):417-430.

Blanchard DC, Griebel G, Blanchard RJ (2001): Mouse defensive behaviours: pharmacological and behavioural assays for anxiety and panic. Neurosci Biobehav Rev 25:205-218.

Blanchard DC, Griebel G, Blanchard RJ (2003): The Mouse Defense Test Battery: pharmacological and behavioural assays for anxiety and panic. Eur J Pharmacol 463:97-116.

Blanchard DC, Rodgers RJ, Hendrie CA, Hori K (1988): 'Taming' of wild rats (Rattus rattus) by 5HT1A agonists buspirone and gepirone. Pharmacol Biochem Behav 31:269-278.

Blanchard RJ, Blanchard DC (1989a): Antipredator defensive behaviours in a visible burrow system. $J$ Comp Psychol 103:70-82.

Blanchard RJ, Blanchard DC (1989b): Attack and defense in rodents as ethoexperimental models for the study of emotion. Prog Neuropsychopharmacol Biol Psychiatry 13 Suppl:S3-14.

Borelli KG, Ferreira-Netto C, Coimbra NC, Brandao ML (2005): Fos-like immunoreactivity in the brain associated with freezing or escape induced by inhibition of either glutamic acid decarboxylase or GABAA receptors in the dorsal periaqueductal gray. Brain Res 1051:100-111.

Bourin M, Bradwejn J, Koszycki D (1991): [Is cholecystokinin a biological support in panic attacks?]. Encephale 17:475-479.

Bowery NG, Hudson AL, Price GW (1987): GABAA and GABAB receptor site distribution in the rat central nervous system. Neuroscience 20:365-383.

Bradwejn J, Koszycki D (2001): Cholecystokinin and panic disorder: past and future clinical research strategies. Scand J Clin Lab Invest Suppl 234:19-27.

Brandao ML, Anseloni VZ, Pandossio JE, De Araujo JE, Castilho VM (1999): Neurochemical mechanisms of the defensive behaviour in the dorsal midbrain. Neurosci Biobehav Rev 23:863875.

Brandao ML, de Aguiar JC, Graeff FG (1982): GABA mediation of the anti-aversive action of minor tranquilizers. Pharmacol Biochem Behav 16:397-402. 
Brandao ML, Di Scala G, Bouchet MJ, Schmitt P (1986): Escape behaviour produced by the blockade of glutamic acid decarboxylase (GAD) in mesencephalic central gray or medial hypothalamus. Pharmacol Biochem Behav 24:497-501.

Brandao ML, Vianna DM, Masson S, Santos J (2003): [Neural organization of different types of fear: implications for the understanding of anxiety]. Rev Bras Psiquiatr 25 Suppl 2:36-41.

Brodal P (2004): The central nervous system, structure and function 3rd edition. Oxford University Press 48-56.

Brown TG (1915): Note on the physiology of the basal ganglia and mid-brain of the anthropoid ape, especially in reference to the act of laughter. J Physiol 49:195-207.

Brutus M, Siegel A (1989): Effects of the opiate antagonist naloxone upon hypothalamically elicited affective defense behaviour in the cat. Behav Brain Res 33:23-32.

Budai D, Fields HL (1998): Endogenous opioid peptides acting at mu-opioid receptors in the dorsal horn contribute to midbrain modulation of spinal nociceptive neurons. J Neurophysiol 79:677-687.

Cameron AA, Khan IA, Westlund KN, Cliffer KD, Willis WD (1995a): The efferent projections of the periaqueductal gray in the rat: a Phaseolus vulgaris-leucoagglutinin study. I. Ascending projections. J Comp Neurol 351:568-584.

Cameron AA, Khan IA, Westlund KN, Willis WD (1995b): The efferent projections of the periaqueductal gray in the rat: a Phaseolus vulgaris-leucoagglutinin study. II. Descending projections. J Comp Neurol 351:585-601.

Canteras NS (2002): The medial hypothalamic defensive system: hodological organization and functional implications. Pharmacol Biochem Behav 71:481-491.

Canteras NS, Chiavegatto S, Valle LE, Swanson LW (1997): Severe reduction of rat defensive behaviour to a predator by discrete hypothalamic chemical lesions. Brain Res Bull 44:297-305.

Canteras NS, Ribeiro-Barbosa ER, Comoli E (2001): Tracing from the dorsal premammillary nucleus prosencephalic systems involved in the organization of innate fear responses. Neurosci Biobehav Rev 25:661-668.

Carden SE, Davachi L, Hofer MA (1994): U50,488 increases ultrasonic vocalizations in 3-, 10-, and 18day-old rat pups in isolation and the home cage. Dev Psychobiol 27:65-83.

Carobrez AP (2003): [Glutamatergic neurotransmission as molecular target in anxiety]. Rev Bras Psiquiatr 25 Suppl 2:52-58.

Carrive P, Bandler R (1991): Viscerotopic organization of neurons subserving hypotensive reactions within the midbrain periaqueductal grey: a correlative functional and anatomical study. Brain Res 541:206-215.

Cassell MD, Gray TS, Kiss JZ (1986): Neuronal architecture in the rat central nucleus of the amygdala: a cytological, hodological, and immunocytochemical study. J Comp Neurol 246:478-499.

Chaouloff F (2000): Serotonin, stress and corticoids. J Psychopharmacol 14:139-151.

Chen S, Aston-Jones G (1995): Anatomical evidence for inputs to ventrolateral medullary catecholaminergic neurons from the midbrain periaqueductal gray of the rat. Neurosci Lett 195:140-144.

Chieng B, Keay KA, Christie MJ (1995): Increased fos-like immunoreactivity in the periaqueductal gray of anaesthetised rats during opiate withdrawal. Neurosci Lett 183:79-82.

Clement CI, Keay KA, Owler BK, Bandler R (1996): Common patterns of increased and decreased fos expression in midbrain and pons evoked by noxious deep somatic and noxious visceral manipulations in the rat. J Comp Neurol 366:495-515.

Clemente CD, Chase MH (1973): Neurological substrates of aggressive behaviour. Annu Rev Physiol 35:329-356.

Clements JR, Beitz AJ, Fletcher TF, M.A M (2004): Immunocytochemical localization of serotonin in the rat periaqueductal gray: A quantitative light and electron microscopic study The Journal of Comparative Neurology 236:60 - 70.

Clements JR, Madl JE, Johnson RL, Larson AA, Beitz AJ (1987): Localization of glutamate, glutaminase, aspartate and aspartate aminotransferase in the rat midbrain periaqueductal gray. Exp Brain Res 67:594-602. 
Coffield JA, Bowen KK, Miletic V (2004): Retrograde tracing of projections between the nucleus submedius, the ventrolateral orbital cortex, and the midbrain in the rat. The Journal of Comparative Neurology 321:488 - 499.

Commons KG, Aicher SA, Kow LM, Pfaff DW (2000): Presynaptic and postsynaptic relations of muopioid receptors to gamma-aminobutyric acid-immunoreactive and medullary-projecting periaqueductal gray neurons. J Comp Neurol 419:532-542.

Comoli E, Coizet V, Boyes J, Bolam JP, Canteras NS, Quirk RH, et al (2003): A direct projection from superior colliculus to substantia nigra for detecting salient visual events. Nat Neurosci 6:974-980.

Cornwall J, Cooper JD, Phillipson OT (1990): Projections to the rostral reticular thalamic nucleus in the rat. Exp Brain Res 80:157-171.

Cottingham SL, Femano PA, Pfaff DW (1987): Electrical stimulation of the midbrain central gray facilitates reticulospinal activation of axial muscle EMG. Exp Neurol 97:704-724.

Cottingham SL, Pfaff DW (1987): Electrical stimulation of the midbrain central gray facilitates lateral vestibulospinal activation of back muscle EMG in the rat. Brain Res 421:397-400.

Deakin JF (1991a): Depression and 5HT. Int Clin Psychopharmacol 6 Suppl 3:23-28; discussion 29-31.

Deakin JFG, F.G. (1991b): 5-HT and mechanisms of defense. J Psychopharmacol 5:305-315.

Descarries L, Berthelet F, Garcia S, Beaudet A (1986): Dopaminergic projection from nucleus raphe dorsalis to neostriatum in the rat. J Comp Neurol 249:511-520, 484-515.

Dielenberg RA, Carrive P, McGregor IS (2001a): The cardiovascular and behavioural response to cat odor in rats: unconditioned and conditioned effects. Brain Res 897:228-237.

Dielenberg RA, Hunt GE, McGregor IS (2001b): "When a rat smells a cat": the distribution of Fos immunoreactivity in rat brain following exposure to a predatory odor. Neuroscience 104:10851097.

Dielenberg RA, McGregor IS (2001): Defensive behaviour in rats towards predatory odors: a review. Neurosci Biobehav Rev 25:597-609.

Elmquist JK, Saper CB (1996): Activation of neurons projecting to the paraventricular hypothalamic nucleus by intravenous lipopolysaccharide. J Comp Neurol 374:315-331.

Fanselow MS (1991): The midbrain periaqueductal gray as coordinator of action in response to fear and anxiety. In: DePaulis A, Bandler R (eds) The midbrain periaqueductal gray matter: functional, anatomical and immunohistochemical organization. Plenum Press, New York, pp 151-173.

Fanselow MS, Kim JJ, Young SL, Calcagnetti DJ, DeCola JP, Helmstetter FJ, et al (1991): Differential effects of selective opioid peptide antagonists on the acquisition of pavlovian fear conditioning. Peptides 12:1033-1037.

Fendt M, Koch M, Schnitzler HU (1994): Amygdaloid noradrenaline is involved in the sensitization of the acoustic startle response in rats. Pharmacol Biochem Behav 48:307-314.

Fields HL, Heinricher MM, Mason P (1991): Neurotransmitters in nociceptive modulatory circuits. Annu Rev Neurosci 14:219-245.

Flores JA, El Banoua F, Galan-Rodriguez B, Fernandez-Espejo E (2004): Opiate anti-nociception is attenuated following lesion of large dopamine neurons of the periaqueductal grey: critical role for D1 (not D2) dopamine receptors. Pain 110:205-214.

Floyd NS, Price JL, Ferry AT, Keay KA, Bandler R (2000): Orbitomedial prefrontal cortical projections to distinct longitudinal columns of the periaqueductal gray in the rat. $J$ Comp Neurol 422:556-578.

Floyd NS, Price JL, Ferry AT, Keay KA, Bandler R (2001): Orbitomedial prefrontal cortical projections to hypothalamus in the rat. J Comp Neurol 432:307-328.

Fonberg E (1972): Control of emotional behaviour through the hypothalamus and amygdaloid complex. In Physiology, Emotion, and Psychosomatic Illness. Ciba Foundation Symposium8, Elsevier, Amsterdam:13 1-1 50.

Fuxe K (1965): Evidence for the Existence of Monoamine Neurons in the Central Nervous System. Iv. Distribution of Monoamine Nerve Terminals in the Central Nervous System. Acta Physiol Scand Suppl:SUPPL 247:237+.

Gabbott PL (2003): Radial organisation of neurons and dendrites in human cortical areas 25, 32, and 32'. Brain Res 992:298-304.

Gabbott PL, Warner TA, Jays PR, Bacon SJ (2003): Areal and synaptic interconnectivity of prelimbic (area 32), infralimbic (area 25) and insular cortices in the rat. Brain Res 993:59-71. 
Gebhart GF, Sandkuhler J, Thalhammer JG, Zimmermann M (1983): Quantitative comparison of inhibition in spinal cord of nociceptive information by stimulation in periaqueductal gray or nucleus raphe magnus of the cat. $J$ Neurophysiol 50:1433-1445.

Gent JP, Wolstencroft JH (1976): Effects of methionine-enkephalin and leucine-enkephalin compared with those of morphine on brainstem neurones in cat. Nature 261:426-427.

Goodwin RD, Faravelli C, Rosi S, Cosci F, Truglia E, de Graaf R, et al (2005): The epidemiology of panic disorder and agoraphobia in Europe. Eur Neuropsychopharmacol 15:435-443.

Graeff FG (2002): On serotonin and experimental anxiety. Psychopharmacology (Berl) 163:467-476.

Gramsch C, Hollt V, Mehraein P, Pasi A, Herz A (1979): Regional distribution of methionine-enkephalinand beta-endorphin-like immunoreactivity in human brain and pituitary. Brain Res 171:261-270.

Gray JA (1982): The Neuropsychology of Anxiety: an enquiry into functions of the septo-hippocampal system, 1st ed. Oxford University Press.

Green AL, Wang S, Bittar RG, Owen SL, Paterson DJ, Stein JF, et al (2007): Deep brain stimulation: a new treatment for hypertension? J Clin Neurosci 14:592-595.

Green AL, Wang S, Owen SL, Xie K, Bittar RG, Stein JF, et al (2006): Stimulating the human midbrain to reveal the link between pain and blood pressure. Pain 124:349-359.

Griez E, Schruers K (1998): Experimental pathophysiology of panic. J Psychosom Res 45:493-503.

Griez EJL, Faravelli C, Nutt D, Zohar J (2001 ): Anxiety Disorders: An Introduction to Clinical Management and Research

Guimaraes AP, Prado WA (1999): Pharmacological evidence for a periaqueductal gray-nucleus raphe magnus connection mediating the antinociception induced by microinjecting carbachol into the dorsal periaqueductal gray of rats. Brain Res 827:152-159.

Guimaraes FS, Carobrez AP, De Aguiar JC, Graeff FG (1991): Anxiolytic effect in the elevated plus-maze of the NMDA receptor antagonist AP7 microinjected into the dorsal periaqueductal grey. Psychopharmacology (Berl) 103:91-94.

Hamilton BL (1973a): Cytoarchitectural subdivisions of the periaqueductal gray matter in the cat. J Comp Neurol 149:1-27.

Hamilton BL (1973b): Projections of the nuclei of the periaqueductal gray matter in the cat. $J$ Comp Neurol 152:45-58.

Han F, Zhang YF, Li YQ (2003): Fos expression in tyrosine hydroxylase-containing neurons in rat brainstem after visceral noxious stimulation: an immunohistochemical study. World $J$ Gastroenterol 9:1045-1050.

Harrison S, Geppetti P (2001): Substance p. Int J Biochem Cell Biol 33:555-576.

Hasue RH, Shammah-Lagnado SJ (2002): Origin of the dopaminergic innervation of the central extended amygdala and accumbens shell: a combined retrograde tracing and immunohistochemical study in the rat. J Comp Neurol 454:15-33.

Hebert H, Saper CB (1992 ): Organization of medullary adrenergic and noradrenergic projections to the periaqueductal gray matter in the rat. J Comp Neurol 315:34-52.

Henderson LA, Keay KA, Bandler R (1998): The ventrolateral periaqueductal gray projects to caudal brainstem depressor regions: a functional-anatomical and physiological study. Neuroscience $82: 201-221$

Herbert H, Saper CB (1992): Organization of medullary adrenergic and noradrenergic projections to the periaqueductal gray matter in the rat. J Comp Neurol 315:34-52.

Hermes ML, Buijs RM, Masson-Pevet M, Pevet P (1988): Oxytocinergic innervation of the brain of the garden dormouse (Eliomys quercinus L.). J Comp Neurol 273:252-262.

Herrera M, Sanchez del Campo F, Smith-Agreda V (1987): The commissural nucleus of the inferior colliculus in the rabbit. A morphological study. J Hirnforsch 28:671-683.

Hilton SM (1975): Ways of viewing the central nervous control of the circulation--old and new. Brain Res 87:213-219.

Hilton SM, Redfern WS (1986): A search for brain stem cell groups integrating the defence reaction in the rat. J Physiol 378:213-228.

Hilton SM, Zbrozyna AW (1963): Amygdaloid region for defence reactions and its efferent pathway to the brain stem. $J$ Physiol 165:160-173. 
Holstege G (1987): Some anatomical observations on the projections from the hypothalamus to brainstem and spinal cord: an HRP and autoradiographic tracing study in the cat. J Comp Neurol 260:98-126.

Holstege G (1988): Anatomical evidence for a strong ventral parabrachial projection to nucleus raphe magnus and adjacent tegmental field. Brain Res 447:154-158.

Huettner JE (2003): Kainate receptors and synaptic transmission. Prog Neurobiol 70:387-407.

Illing RB, Graybiel AM (1986): Complementary and non-matching afferent compartments in the cat's superior colliculus: innervation of the acetylcholinesterase-poor domain of the intermediate gray layer. Neuroscience 18:373-394.

Imai H, Steindler DA, Kitai ST (1986): The organization of divergent axonal projections from the midbrain raphe nuclei in the rat. $J$ Comp Neurol 243:363-380.

Iwata J, LeDoux JE, Meeley MP, Arneric S, Reis DJ (1986): Intrinsic neurons in the amygdaloid field projected to by the medial geniculate body mediate emotional responses conditioned to acoustic stimuli. Brain Res 383:195-214.

Jacquet YF, Squires RF (1988): Excitatory amino acids: role in morphine excitation in rat periaqueductal gray. Behav Brain Res 31:85-88.

Jasmin L, Burkey AR, Granato A, Ohara PT (2004): Rostral agranular insular cortex and pain areas of the central nervous system: a tract-tracing study in the rat. J Comp Neurol 468:425-440.

Jenck F, Broekkamp CL, Van Delft AM (1989): Effects of serotonin receptor antagonists on PAG stimulation induced aversion: different contributions of 5HT1, 5HT2 and 5HT3 receptors. Psychopharmacology (Berl) 97:489-495.

Jensen TS, Yaksh TL (1989): Comparison of the antinociceptive effect of morphine and glutamate at coincidental sites in the periaqueductal gray and medial medulla in rats. Brain Res 476:1-9.

Jordan LM, Brownstone RM, Noga BR (1992): Control of functional systems in the brainstem and spinal cord. Curr Opin Neurobiol 2:794-801.

Jurgens U, Ploog D (1970): Cerebral representation of vocalization in the squirrel monkey. Exp Brain Res 10:532-554.

Jurgens U, Pratt R (1979): Role of the periaqueductal grey in vocal expression of emotion. Brain Res 167:367-378.

Kaada B (1967): Brain mechanisms related to aggressive behaviour. UCLA Forum Med Sci 7:95-133.

Kabat H, Magoun HW, Ranson SW (1935): Electrical stimulation of points in the forebrain and midbrain. The resultant alteration in blood pressure, . Arch Neurol Psychiat (Chicago) 34 931-955.

Kandel ER, Schwartz JH, Jessel TM (1995): Essentials of neural science and behaviour. Prentice Hall International, INC 234-237, 297.

Keay KA, Bandler R (2001): Parallel circuits mediating distinct emotional coping reactions to different types of stress. Neurosci Biobehav Rev 25:669-678.

Keay KA, Crowfoot LJ, Floyd NS, Henderson LA, Christie MJ, Bandler R (1997): Cardiovascular effects of microinjections of opioid agonists into the 'Depressor Region' of the ventrolateral periaqueductal gray region. Brain Res 762:61-71.

Kehoe P, Boylan CB (1994): Behavioural effects of kappa-opioid-receptor stimulation on neonatal rats. Behav Neurosci 108:418-423.

Kirouac GJ, Li S, Mabrouk G (2004): GABAergic projection from the ventral tegmental area and substantia nigra to the periaqueductal gray region and the dorsal raphe nucleus. $J$ Comp Neurol 469:170-184.

Kirouac GJ, Pittman QJ (2000): A projection from the ventral tegmental area to the periaqueductal gray involved in cardiovascular regulation. Am J Physiol Regul Integr Comp Physiol 278:R1643-1650.

Kitchen I, Kelly M, Viveros MP (1990): Ontogenesis of kappa-opioid receptors in rat brain using [3H]U69593 as a binding ligand. Eur J Pharmacol 175:93-96.

Klerman GL, Weissman MM, Ouellette R, Johnson J, Greenwald S (1991): Panic attacks in the community. Social morbidity and health care utilization. Jama 265:742-746.

Kozicz T, Vigh S, Arimura A (1998): The source of origin of PACAP- and VIP-immunoreactive fibers in the laterodorsal division of the bed nucleus of the stria terminalis in the rat. Brain Res 810:211219.

Kramer MS, Cutler N, Feighner J, Shrivastava R, Carman J, Sramek JJ, et al (1998): Distinct mechanism for antidepressant activity by blockade of central substance P receptors. Science 281:1640-1645. 
Krettek JE, Price JL (1977a): The cortical projections of the mediodorsal nucleus and adjacent thalamic nuclei in the rat. J Comp Neurol 171:157-191.

Krettek JE, Price JL (1977b): Projections from the amygdaloid complex to the cerebral cortex and thalamus in the rat and cat. J Comp Neurol 172:687-722.

Krieger JE, Graeff FG (1985): Defensive behaviour and hypertension induced by glutamate in the midbrain central gray of the rat. Braz J Med Biol Res 18:61-67.

Krout KE, Belzer RE, Loewy AD (2002): Brainstem projections to midline and intralaminar thalamic nuclei of the rat. J Comp Neurol 448:53-101.

Krout KE, Loewy AD (2000): Periaqueductal gray matter projections to midline and intralaminar thalamic nuclei of the rat. J Comp Neurol 424:111-141.

Laemle LK (1979): Neuronal populations of the human periaqueductal gray, nucleus lateralis. J Comp Neurol 186:93-107.

LeDoux JE (1994 ): The amygdala: Contributions to fear and stress. Seminal Neuroscience 6:231-237.

LeDoux JE, Iwata J, Cicchetti P, Reis DJ (1988): Different projections of the central amygdaloid nucleus mediate autonomic and behavioural correlates of conditioned fear. J Neurosci 8:2517-2529.

LeDoux JE, Sakaguchi A, Reis DJ (1984): Subcortical efferent projections of the medial geniculate nucleus mediate emotional responses conditioned to acoustic stimuli. J Neurosci 4:683-698.

Levy RA, Proudfit HK (1979): Analgesia produced by microinjection of baclofen and morphine at brain stem sites. Eur J Pharmacol 57:43-55.

Li YQ, Jia HG, Rao ZR, Shi JW (1990): Serotonin-, substance P- or leucine-enkephalin-containing neurons in the midbrain periaqueductal gray and nucleus raphe dorsalis send projection fibers to the central amygdaloid nucleus in the rat. Neurosci Lett 120:124-127.

Li YQ, Takada M, Mizuno N (1993): Demonstration of habenular neurons which receive afferent fibers from the nucleus accumbens and send their axons to the midbrain periaqueductal gray. Neurosci Lett 158:55-58.

Lim LW, Blokland A, Visser-Vandewalle V, Vlamings R, Sesia T, Steinbusch H, et al (2008): Highfrequency stimulation of the dorsolateral periaqueductal gray and ventromedial hypothalamus fails to inhibit panic-like behaviour. Behav Brain Res 193:197-203.

Lima VC, Molchanov ML, Aguiar DC, Campos AC, Guimaraes FS (2007): Modulation of defensive responses and anxiety-like behaviours by group I metabotropic glutamate receptors located in the dorsolateral periaqueductal gray. Prog Neuropsychopharmacol Biol Psychiatry.

Lindvall O, Bjorklund A, Moore RY, Stenevi U (1974): Mesencephalic dopamine neurons projecting to neocortex. Brain Res 81:325-331.

Liu H, Chandler S, Beitz AJ, Shipley MT, Behbehani MM (1994): Characterization of the effect of cholecystokinin (CCK) on neurons in the periaqueductal gray of the rat: immunocytochemical and in vivo and in vitro electrophysiological studies. Brain Res 642:83-94.

Liu RP, Hamilton BL (1980): Neurons of the periaqueductal gray matter as revealed by Golgi study. $J$ Comp Neurol 189:403-418.

Lovick TA (1991): Central nervous system integration of pain control and autonomic function. NIPS 6:8286.

Lovick TA (1992): Midbrain influences on ventrolateral medullo-spinal neurones in the rat. Exp Brain Res 90:147-152.

Lozano AM, Eltahawy H (2004): How does DBS work? Suppl Clin Neurophysiol 57:733-736.

Mamounas LA, Mullen CA, O'Hearn E, Molliver ME (1991): Dual serotoninergic projections to forebrain in the rat: morphologically distinct 5 -HT axon terminals exhibit differential vulnerability to neurotoxic amphetamine derivatives. J Comp Neurol 314:558-586.

Manchanda SK, Poddar A, Saha S, Bhatia SC, Kumar VM, Nayar U (1995): Predatory aggression induced by hypothalamic stimulation: modulation by midbrain periaqueductal gray (PAG). Neurobiology (Bp) 3:405-417.

Mantyh PW (1983a): Connections of midbrain periaqueductal gray in the monkey. I. Ascending efferent projections. J Neurophysiol 49:567-581.

Mantyh PW (1983b): Connections of midbrain periaqueductal gray in the monkey. II. Descending efferent projections. J Neurophysiol 49:582-594. 
Martin-Ruiz R, Puig MV, Celada P, Shapiro DA, Roth BL, Mengod G, et al (2001): Control of serotonergic function in medial prefrontal cortex by serotonin-2A receptors through a glutamatedependent mechanism. J Neurosci 21:9856-9866.

Martin GF, Humbertson AO, Jr., Laxson LC, Panneton WM, Tschismadia I (1979): Spinal projections from the mesencephalic and pontine reticular formation in the North American Opossum: a study using axonal transport techniques. J Comp Neurol 187:373-399.

Matheus MG, Guimaraes FS (1997): Antagonism of non-NMDA receptors in the dorsal periaqueductal grey induces anxiolytic effect in the elevated plus maze. Psychopharmacology (Berl) 132:14-18.

Maubach KA, Rupniak NM, Kramer MS, Hill RG (1999): Novel strategies for pharmacotherapy of depression. Curr Opin Chem Biol 3:481-488.

McNaughton N, Corr PJ (2004): A two-dimensional neuropsychology of defense: fear/anxiety and defensive distance. Neurosci Biobehav Rev 28:285-305.

McNaughton N, Gray JA (2000): Anxiolytic action on the behavioural inhibition system implies multiple types of arousal contribute to anxiety. $J$ Affect Disord 61:161-176.

McTavish D, Heel RC (1992): Dexfenfluramine. A review of its pharmacological properties and therapeutic potential in obesity. Drugs 43:713-733.

Meloni EG, Davis M (1999): Muscimol in the deep layers of the superior colliculus/mesencephalic reticular formation blocks expression but not acquisition of fear-potentiated startle in rats. Behav Neurosci 113:1152-1160.

Missale C, Nash SR, Robinson SW, Jaber M, Caron MG (1998): Dopamine receptors: from structure to function. Physiol Rev 78:189-225.

Miyawaki T, Goodchild AK, Pilowsky PM (2001): Rostral ventral medulla 5-HT1A receptors selectively inhibit the somatosympathetic reflex. Am J Physiol Regul Integr Comp Physiol 280:R1261-1268.

Mobbs D, Petrovic P, Marchant JL, Hassabis D, Weiskopf N, Seymour B, et al (2007): When fear is near: threat imminence elicits prefrontal-periaqueductal gray shifts in humans. Science 317:1079-1083.

Molchanov ML, Guimaraes FS (1999): Defense reaction induced by a metabotropic glutamate receptor agonist microinjected into the dorsal periaqueductal gray of rats. Braz J Med Biol Res 32:15331537.

Montgomery EB, Jr., Gale JT (2007): Mechanisms of action of deep brain stimulation (DBS). Neurosci Biobehav Rev.

Moore KE, Annunziato L, Gudelsky GA (1978): Studies on tuberoinfundibular dopamine neurons. Adv Biochem Psychopharmacol 19:193-204.

Moore RY (1978): Catecholamin innervation of the basal forebrain. I. The septal area. J Comp Neurol 177:665-684.

Moore RY, Bloom FE (1978): Central catecholamine neuron systems: anatomy and physiology of the dopamine systems. Annu Rev Neurosci 1:129-169.

Moran TH, Robinson PH, Goldrich MS, McHugh PR (1986): Two brain cholecystokinin receptors: implications for behavioural actions. Brain Res 362:175-179.

Moreau JL, Fields HL (1986): Evidence for GABA involvement in midbrain control of medullary neurons that modulate nociceptive transmission. Brain Res 397:37-46.

Moreira FA, Molchanov ML, Guimaraes FS (2004): Ionotropic glutamate-receptor antagonists inhibit the aversive effects of nitric oxide donor injected into the dorsolateral periaqueductal gray of rats. Psychopharmacology (Berl) 171:199-203.

Morgan MM, Clayton CC, Lane DA (2003): Behavioural evidence linking opioid-sensitive GABAergic neurons in the ventrolateral periaqueductal gray to morphine tolerance. Neuroscience 118:227232.

Mouton LJ, Klop EM, Holstege G (2005): C1-C3 spinal cord projections to periaqueductal gray and thalamus: a quantitative retrograde tracing study in cat. Brain Res 1043:87-94.

N'Gouemo P, Faingold CL (1999): The periaqueductal grey is a critical site in the neuronal network for audiogenic seizures: modulation by GABA(A), NMDA and opioid receptors. Epilepsy Res 35:3946.

Nashold BS, Jr., Wilson WP, Slaughter DG (1969): Sensations evoked by stimulation in the midbrain of man. J Neurosurg 30:14-24. 
Neafsey EJ, Bold EL, Haas G, Hurley-Gius KM, Quirk G, Sievert CF, et al (1986): The organization of the rat motor cortex: a microstimulation mapping study. Brain Res 396:77-96.

Nogueira RL, Graeff FG (1995): Role of 5-HT receptor subtypes in the modulation of dorsal periaqueductal gray generated aversion. Pharmacol Biochem Behav 52:1-6.

Olszewki J, Baxter D (1954): Cytoarchitecture of the Human Brainstem. . Philadelphia: J B Lippincott.

Ongur D, An X, Price JL (1998): Prefrontal cortical projections to the hypothalamus in macaque monkeys. J Comp Neurol 401:480-505.

Pajolla GP, de Aguiar Correa FM (2004): Cardiovascular responses to the injection of L-glutamate in the lateral hypothalamus of unanesthetized or anesthetized rats. Auton Neurosci 116:19-29.

Pajolla GP, Tavares RF, Pelosi GG, Correa FM (2005): Involvement of the periaqueductal gray in the hypotensive response evoked by L-glutamate microinjection in the lateral hypothalamus of unanesthetized rats. Auton Neurosci 122:84-93.

Pelosi GG, Correa FM (2005): Cardiovascular effects of noradrenaline microinjected into the dorsal periaqueductal gray area of unanaesthetized rats. Eur J Neurosci 22:3188-3194.

Peterson SL, Armstrong JJ, Walker MK (2000): Focal microinjection of carbachol into the periaqueductal gray induces seizures in the forebrain of the rat. Epilepsy Res 42:169-181.

Petit JM, Luppi PH, Peyron C, Rampon C, Jouvet M (1995): VIP-like immunoreactive projections from the dorsal raphe and caudal linear raphe nuclei to the bed nucleus of the stria terminalis demonstrated by a double immunohistochemical method in the rat. Neurosci Lett 193:77-80.

Petrov T, Jhamandas JH, Krukoff TL (1992): Characterization of peptidergic efferents from the lateral parabrachial nucleus to identified neurons in the rat dorsal raphe nucleus. $J$ Chem Neuroanat 5:367-373.

Peyron C, Luppi PH, Fort P, Rampon C, Jouvet M (1996): Lower brainstem catecholamine afferents to the rat dorsal raphe nucleus. J Comp Neurol 364:402-413.

Pfeiffer A, Feuerstein G, Faden A, Kopin IJ (1982a): Evidence for an involvement of mu-, but not deltaor kappa-opiate receptors in sympathetically and parasympathetically mediated cardiovascular responses to opiates upon anterior hypothalamic injection. Life Sci 31:1279-1282.

Pfeiffer A, Herz A (1982): Different types of opiate agonists interact distinguishably with mu, delta and kappa opiate binding sites. Life Sci 31:1355-1358.

Pfeiffer A, Pasi A, Mehraein P, Herz A (1982b): Opiate receptor binding sites in human brain. Brain Res 248:87-96.

Pittius CW, Seizinger BR, Pasi A, Mehraein P, Herz A (1984): Distribution and characterization of opioid peptides derived from proenkephalin A in human and rat central nervous system. Brain Res 304:127-136.

Pobbe RL, Zangrossi H, Jr. (2005): 5-HT(1A) and 5-HT(2A) receptors in the rat dorsal periaqueductal gray mediate the antipanic-like effect induced by the stimulation of serotonergic neurons in the dorsal raphe nucleus. Psychopharmacology (Berl) 183:314-321.

Pohle W, Ott T, Muller-Welde P (1984): Identification of neurons of origin providing the dopaminergic innervation of the hippocampus. J Hirnforsch 25:1-10.

Price JL, Amaral DG (1981): An autoradiographic study of the projections of the central nucleus of the monkey amygdala. J Neurosci 1:1242-1259.

Raisinghani M, Faingold CL (2003): Identification of the requisite brain sites in the neuronal network subserving generalized clonic audiogenic seizures. Brain Res 967:113-122.

Ray JP, Price JL (1992): The organization of the thalamocortical connections of the mediodorsal thalamic nucleus in the rat, related to the ventral forebrain-prefrontal cortex topography. J Comp Neurol 323:167-197.

Reep RL, Winans SS (1982): Efferent connections of dorsal and ventral agranular insular cortex in the hamster, Mesocricetus auratus. Neuroscience 7:2609-2635.

Reichling DB, Basbaum AI (1990): Contribution of brainstem GABAergic circuitry to descending antinociceptive controls: I. GABA-immunoreactive projection neurons in the periaqueductal gray and nucleus raphe magnus. J Comp Neurol 302:370-377.

Renno WM, Mahmoud MS, Hamdi A, Beitz AJ (1999): Quantitative immunoelectron microscopic colocalization of GABA and enkephalin in the ventrocaudal periaqueductal gray of the rat. Synapse 31:216-228. 
Renoldi G, Invernizzi RW (2006): Blockade of tachykinin NK1 receptors attenuates stress-induced rise of extracellular noradrenaline and dopamine in the rat and gerbil medial prefrontal cortex. $J$ Neurosci Res 84:961-968.

Richardson DE, Akil H (1977a): Pain reduction by electrical brain stimulation in man. Part 1: Acute administration in periaqueductal and periventricular sites. J Neurosurg 47:178-183.

Richardson DE, Akil H (1977b): Pain reduction by electrical brain stimulation in man. Part 2: Chronic self-administration in the periventricular gray matter. $J$ Neurosurg 47:184-194.

Richter RC, Behbehani MM (1991): Evidence for glutamic acid as a possible neurotransmitter between the mesencephalic nucleus cuneiformis and the medullary nucleus raphe magnus in the lightly anesthetized rat. Brain Res 544:279-286.

Rizvi TA, Ennis M, Behbehani MM, Shipley MT (1991): Connections between the central nucleus of the amygdala and the midbrain periaqueductal gray: topography and reciprocity. J Comp Neurol 303:121-131.

Rossi GC, Pasternak GW, Bodnar RJ (1994): Mu and delta opioid synergy between the periaqueductal gray and the rostro-ventral medulla. Brain Res 665:85-93.

Saha SN, Bhatia SC, Nayar U (2004): Adrenergic involvement in the locus ceruleus and adjoining regions in the facilitation of predatory attack behaviour as induced by hypothalamic stimulation in cats. Indian J Physiol Pharmacol 48:51-58.

Sandkuhler J, Gebhart GF (1984): Characterization of inhibition of a spinal nociceptive reflex by stimulation medially and laterally in the midbrain and medulla in the pentobarbital-anesthetized rat. Brain Res 305:67-76.

Saper CB (1979): Anatomical substrates for the hypothalamic control of the autonomic nervous system. In Integrative Functions of the Autonomic Nervous System, C. McBrooks, K. Loizumi, and A. Sato, eds. U. Tokyo Press, Tokyo. .333-341.

Schmitt P, Di Scala G, Brandao ML, Karli P (1985): Behavioural effects of microinjections of SR 95103, a new GABA-A antagonist, into the medial hypothalamus or the mesencephalic central gray. Eur $J$ Pharmacol 117:149-158.

Schutz MT, de Aguiar JC, Graeff FG (1985): Anti-aversive role of serotonin in the dorsal periaqueductal grey matter. Psychopharmacology (Berl) 85:340-345.

Schwaber JS, Kapp BS, Higgins GA, Rapp PR (1982): Amygdaloid and basal forebrain direct connections with the nucleus of the solitary tract and the dorsal motor nucleus. . J Neurosci 2: 14241438:1424-1438.

Semba K, Reiner PB, McGeer EG, Fibiger HC (1988): Brainstem afferents to the magnocellular basal forebrain studied by axonal transport, immunohistochemistry, and electrophysiology in the rat. $J$ Comp Neurol 267:433-453.

Semenenko FM, Lumb BM (1992): Projections of anterior hypothalamic neurones to the dorsal and ventral periaqueductal grey in the rat. Brain Res 582:237-245.

Seroogy KB, Dangaran K, Lim S, Haycock JW, Fallon JH (1989): Ventral mesencephalic neurons containing both cholecystokinin- and tyrosine hydroxylase-like immunoreactivities project to forebrain regions. J Comp Neurol 279:397-414.

Seroogy KB, Fallon JH (1989): Forebrain projections from cholecystokininlike-immunoreactive neurons in the rat midbrain. $J$ Comp Neurol 279:415-435.

Shaikh MB, De Lanerolle NC, Siegel A (1997): Serotonin 5-HT1A and 5-HT2/1C receptors in the midbrain periaqueductal gray differentially modulate defensive rage behaviour elicited from the medial hypothalamus of the cat. Brain Res 765:198-207.

Shammah-Lagnado SJ, Alheid GF, Heimer L (2001): Striatal and central extended amygdala parts of the interstitial nucleus of the posterior limb of the anterior commissure: evidence from tract-tracing techniques in the rat. J Comp Neurol 439:104-126.

Shipley MT, Ennis M, Rizvi TA, Behbehani MM (1991): Topographical specificity of forebrain inputs to the midbrain periaqueductal gray: Evidence for discrete longitudinally organized input columns. In A. Depaulis and R. Bandler (eds): The Midbrain Periaqueductal Gray Matter. New York: Plenum, :417-448. 
Siegel A, Edinger H, ; pp. , (1981): Neural control of aggression and rage behaviour. In Handbook of the Hypothalamus, vol. 3: Behavioural Studies of the Hypothalamus, P.J. Morgane and J. Panksevv, eds. Dekker, New York.203-240.

Siegel A, Schubert KL, Shaikh MB (1997): Neurotransmitters regulating defensive rage behaviour in the cat. Neurosci Biobehav Rev 21:733-742.

Singewald N, Sharp T (2000): Neuroanatomical targets of anxiogenic drugs in the hindbrain as revealed by Fos immunocytochemistry. Neuroscience 98:759-770.

Snowball RK, Semenenko FM, Lumb BM (2000): Visceral inputs to neurons in the anterior hypothalamus including those that project to the periaqueductal gray: a functional anatomical and electrophysiological study. Neuroscience 99:351-361.

Steinbusch HW (1981): Distribution of serotonin-immunoreactivity in the central nervous system of the rat-cell bodies and terminals. Neuroscience 6:557-618.

Stratford TR, Wirtshafter D (1990): Ascending dopaminergic projections from the dorsal raphe nucleus in the rat. Brain Res 511:173-176.

Sun MK, Guyenet PG (1986): Hypothalamic glutamatergic input to medullary sympathoexcitatory neurons in rats. Am J Physiol 251:R798-810.

Swanson LW, Mogenson GJ, Gerfen CR, Robinson P (1984): Evidence for a projection from the lateral preoptic area and substantia innominata to the 'mesencephalic locomotor region' in the rat. Brain Res 295:161-178.

Swanson LW, Sawchenko PE (1983): Hypothalamic integration: organization of the paraventricular and supraoptic nuclei. Annu Rev Neurosci 6:269-324.

Tanaka M, Okamura H, Tamada Y, Nagatsu I, Tanaka Y, Ibata Y (1994): Catecholaminergic input to spinally projecting serotonin neurons in the rostral ventromedial medulla oblongata of the rat. Brain Res Bull 35:23-30.

Thornton JM, Aziz T, Schlugman D, Paterson DJ (2002): Electrical stimulation of the midbrain increases heart rate and arterial blood pressure in awake humans. J Physiol 539:615-621.

Tredici G, Bianchi R, Gioia M (1983): Short intrinsic circuit in the periaqueductal gray matter of the cat. Neurosci Lett 39:131-136.

van der Kooy D, Hattori T (1980): Dorsal raphe cells with collateral projections to the caudate-putamen and substantia nigra: a fluorescent retrograde double labeling study in the rat. Brain Res 186:1-7.

van der Kooy D, Koda LY, McGinty JF, Gerfen CR, Bloom FE (1984): The organization of projections from the cortex, amygdala, and hypothalamus to the nucleus of the solitary tract in rat. $J$ Comp Neurol 224:1-24.

Velayos JL, Reinoso-Suarez F (1982): Topographic organization of the brainstem afferents to the mediodorsal thalamic nucleus. J Comp Neurol 206:17-27.

Versteeg DH, Palkovits M, Van der Gugten J, Wijnen HL, Smeets GW, de Jong W (1976a): Catecholamine content of individual brain regions of spontaneously hypertensive rats (SH-rats). Brain Res 112:429-434.

Versteeg DH, Van Der Gugten J, De Jong W, Palkovits M (1976b): Regional concentrations of noradrenaline and dopamine in rat brain. Brain Res 113:563-574.

Vertes RP (1991): A PHA-L analysis of ascending projections of the dorsal raphe nucleus in the rat. $J$ Comp Neurol 313:643-668.

Viana MB, Graeff FG, Loschmann PA (1997): Kainate microinjection into the dorsal raphe nucleus induces 5-HT release in the amygdala and periaqueductal gray. Pharmacol Biochem Behav $58: 167-172$.

Vianna DM, Borelli KG, Ferreira-Netto C, Macedo CE, Brandao ML (2003): Fos-like immunoreactive neurons following electrical stimulation of the dorsal periaqueductal gray at freezing and escape thresholds. Brain Res Bull 62:179-189.

Vianna DM, Brandao ML (2003): Anatomical connections of the periaqueductal gray: specific neural substrates for different kinds of fear. Braz J Med Biol Res 36:557-566.

Vianna DM, Graeff FG, Brandao ML, Landeira-Fernandez J (2001a): Defensive freezing evoked by electrical stimulation of the periaqueductal gray: comparison between dorsolateral and ventrolateral regions. Neuroreport 12:4109-4112. 
Vianna DM, Graeff FG, Landeira-Fernandez J, Brandao ML (2001b): Lesion of the ventral periaqueductal gray reduces conditioned fear but does not change freezing induced by stimulation of the dorsal periaqueductal gray. Learn Mem 8:164-169.

Vianna DM, Landeira-Fernandez J, Brandao ML (2001c): Dorsolateral and ventral regions of the periaqueductal gray matter are involved in distinct types of fear. Neurosci Biobehav Rev 25:711719.

Walsh SL, Geter-Douglas B, Strain EC, Bigelow GE (2001): Enadoline and butorphanol: evaluation of kappa-agonists on cocaine pharmacodynamics and cocaine self-administration in humans. $J$ Pharmacol Exp Ther 299:147-158.

Wang MR, Kuo JS, Chai CY (2001): Nitric oxide produces different actions in different areas of the periaqueductal grey in cats. Neurosci Lett 309:57-61.

Weiner S, Shaikh MB, Shaikh AB, Siegel A (1991): Enkephalinergic involvement in periaqueductal gray control of hypothalamically elicited predatory attack in the cat. Physiol Behav 49:1099-1105.

Williams FG, Mullet MA, Beitz AJ (1995): Basal release of Met-enkephalin and neurotensin in the ventrolateral periaqueductal gray matter of the rat: a microdialysis study of antinociceptive circuits. Brain Res 690:207-216.

Wittchen HU (1988): Natural course and spontaneous remissions of untreated anxiety disorders-results of the Munich follow-up study (MFS). In: I. Hand and H.U. Wittchen, Editors, Panic and Phobias: 2. Treatments and Variables Affecting Course and Outcome, Springer, Berlin 3-17.

Yang Z, Coote JH (1998): Influence of the hypothalamic paraventricular nucleus on cardiovascular neurones in the rostral ventrolateral medulla of the rat. $J$ Physiol 513 ( Pt 2):521-530.

Yardley CP, Hilton SM (1986): The hypothalamic and brainstem areas from which the cardiovascular and behavioural components of the defence reaction are elicited in the rat. J Auton Nerv Syst 15:227244.

Yasui Y, Itoh K, Kaneko T, Shigemoto R, Mizuno N (1991): Topographical projections from the cerebral cortex to the nucleus of the solitary tract in the cat. Exp Brain Res 85:75-84.

Yoshida M, Shirouzu M, Tanaka M, Semba K, Fibiger HC (1989): Dopaminergic neurons in the nucleus raphe dorsalis innervate the prefrontal cortex in the rat: a combined retrograde tracing and immunohistochemical study using anti-dopamine serum. Brain Res 496:373-376.

Young RF, Kroening R, Fulton W, Feldman RA, Chambi I (1985): Electrical stimulation of the brain in treatment of chronic pain. Experience over 5 years. J Neurosurg 62:389-396.

Zanoveli JM, Netto CF, Guimaraes FS, Zangrossi H, Jr. (2004): Systemic and intra-dorsal periaqueductal gray injections of cholecystokinin sulfated octapeptide (CCK-8s) induce a panic-like response in rats submitted to the elevated T-maze. Peptides 25:1935-1941.

Zarbin MA, Innis RB, Wamsley JK, Snyder SH, Kuhar MJ (1983): Autoradiographic localization of cholecystokinin receptors in rodent brain. J Neurosci 3:877-906.

Zhang YH, Yanase-Fujiwara M, Hosono T, Kanosue K (1995): Warm and cold signals from the preoptic area: which contribute more to the control of shivering in rats? J Physiol 485 ( Pt 1):195-202.

Zhao Z, Davis M (2004): Fear-potentiated startle in rats is mediated by neurons in the deep layers of the superior colliculus/deep mesencephalic nucleus of the rostral midbrain through the glutamate nonNMDA receptors. $J$ Neurosci 24:10326-10334.

Zieglgansberger W, Puil EA (1973): Actions of glutamic acid on spinal neurones. Exp Brain Res 17:35-49. 


\title{
Fos immunoreactivity in the rat forebrain induced by electrical stimulation of the dorsolateral periaqueductal gray matter
} Lee Wei Lim, Yasin Temel, Veerle Visser-Vandewall,
Arjan Blokland, and Harry Steinbusch

\begin{abstract}
Electrical stimulation of the dorsolateral periaqueductal gray (dlPAG) matter induces panic- or fear-like responses with intense emotional distress and severe anxiety. In this study, we evoked this panic-like behaviour by dlPAG stimulation and evaluated the effects on neuronal activation in different brain regions. The number of c-Fos immunoreactive (c-Fos-ir) cells was measured semi-quantitatively through series of stained rat brain sections. Our results demonstrate strong neural activation in the medial prefrontal cortex, orbital cortex, anterior olfactory nuclei, secondary motor cortex, and the somatosensory cortex. A significant moderate increase in the number of c-Fos-ir cells was also detected in various regions, including the hypothalamus, amygdala, striatum, and frontal cortex. Additionally, there was mild expression of positive c-Fos-ir cells in the hippocampus, thalamus, and habenular regions. In conclusion, we have shown that electrical stimulation of the dIPAG produced a distinctive pattern of neuronal activation across forebrain regions as compared to the sham and control animals. Interestingly, the pattern of activation matched the defence system as described by McNaughton and Corr.
\end{abstract}

J Chem Neuroanat. (In press) 


\section{Introduction}

Electrical stimulation of the dorsolateral periaqueductal gray (dlPAG) evokes a typical reaction which is generally seen as escape or defensive behaviour (Bandler and Shipley 1994; De Oca et al 1998). This behaviour consists of a spontaneous flight reaction characterized by wild running, galloping, and jumping accompanied by hypertension, tachycardia, tachypnoea, freezing, and fear-like responses (Bittencourt et al 2005; Hogg et al 2006; Lim et al 2008a). It is now widely accepted that this escape behaviour has similarities with panic-like symptoms in humans (Deakin and Graeff 1991; Nashold et al 1969; Schenberg et al 1998). In clinical practice, panic attack occurs spontaneously and produces intense emotional distress with significant changes in autonomic and neurological functions including palpitation, chest strains, sweating, dyspnoe, feeling of choking, trembling, nausea, dizziness, paresthesia, chills or hot flushes, depersonalization or derealization, and fear of dying or losing control (AmericanPsychiatric-Association 1994; Cassano and Savino 1993). Importantly, the clinical and pre-clinical neuropsychological data have demonstrated a similar pattern of emotional changes of fear or panic-like behaviour during stimulation of the dorsal parts of the PAG (Hogg et al 2006; Hunsperger 1956; Nashold et al 1969).

Numerous studies have been conducted to understand the pathophysiology of fear and panic processes within the PAG, and still not much is known about the mechanisms involved, most probably due to complicated neuroanatomy and neurochemistry (Borelli et al 2005b; de Bortoli et al 2006; Lim et al 2008a). This type of fear-like behaviour is rather complex and requires some higher cortical connections to process the acquired defensive information of external threats. In considering the neuronal structures for fear and panic-like reaction, there is evidence confirming that the PAG is involved in the coordination of defensive behaviour (Maren and Quirk 2004; Mobbs et al 2007). Recent preclinical studies have demonstrated that electrical stimulation of the dIPAG at the escape threshold led to a significant increase in the number of c-Fos immunoreactive (cFos-ir) cells in specific neuroanatomical structures (Borelli et al 2005b; Lim et al 2008a). This neural activation is thought to reflect an extended neuroanatomical network controlling defensive behaviour (Coimbra et al 2006; McNaughton and Corr 2004; Vianna and Brăndao 2003). For instance, electrical or chemical stimulation of the dIPAG induced significant c-Fos expression in the ventromedial hypothalamus, dorsal premammillary nucleus, local coeruleus, amygdala and prefrontal cortex (Coimbra et al 2006; McNaughton and Corr 2004; Vianna et al 2003b). Nevertheless, a systematic analysis of the effects of dIPAG stimulation on c-Fos expression is lacking. Such information would unravel which brain regions are directly or indirectly involved in defensive behaviour. In this experiment, we systematically analyzed the neuronal activation in different forebrain regions associated with electrical stimulation of the dlPAG. The number of c-Fos immunoreactive (c-Fos-ir) cells was measured semiquantitatively through consecutive series of immunohistochemically stained rat brain sections. 


\section{Material and Methods}

\section{Subjects}

Subjects were male albino Wistar rats $(N=16,12$ weeks old, bred and housed at the Central Animal Facility of Maastricht University, Maastricht, the Netherlands). Rats had an average body weight of 300-350 g at the time of surgery. They were housed individually in standard cages on sawdust bedding in an air-conditioned room (about 20 ${ }^{\circ} \mathrm{C}$ ) under a 12/12-h reversed light/dark cycle. Food, standard laboratory chow (Hopefarms, Woerden, the Netherlands) and water were available ad libitum. All experimental procedures were approved by the Animal Experiments and Ethics Committee of Maastricht University, the Netherlands.

\section{Surgical procedure}

A detailed description of the surgical procedure and the electrodes has been provided previously (Lim et al 2008a; Temel et al 2007). In brief, the rats were anesthetized throughout the entire surgical procedure using a combination of ketamine $(90 \mathrm{mg} / \mathrm{kg}$ s.c.) and xylazine $(10 \mathrm{mg} / \mathrm{kg}$ s.c.). Rats were placed in a stereotactic apparatus (Stoelting, Wood Dale, USA; model 51653). After making burr holes in the skull, rats of group $\mathrm{A}$ and $\mathrm{B}$ received implantation of the electrodes at the level of the dIPAG (coordinates from Bregma: AP, -7.6; ML, 0.7; and V, -4.8; approached with a coronal angle of $10^{\circ}$ ). A construction of one gold-plated needle-like electrodes with an inner wire of a platinum-iridium combination (Technomed, Beek, The Netherlands), with a tip diameter of $50 \mu \mathrm{m}$ and a shaft diameter of $250 \mu \mathrm{m}$, was employed in this experiment. The electrode was fixed in position using dental cement (Heraeus Kulzer, Hanau, Germany). After the operation, rats were injected with Temgesic $(0.1 \mathrm{mg} / \mathrm{kg}$, s.c.) and received twoweek recovery and animal handling periods. Rats of group $\mathrm{C}$ (control) received no surgery.

\section{Deep brain stimulation}

The stimulation procedures were performed by two researchers. All animals had a preliminary stimulation session to determine the escape threshold. The stimulation amplitudes were gradually increased until the escape behaviour was observed. At each step, stimulation duration was $15 \mathrm{sec}$ followed by stimulation off period of $45 \mathrm{~s}$. The stimulation frequency was set at $50 \mathrm{~Hz}$, and pulse width at $0.1 \mathrm{~ms}$ based on previous experiments that variation in pulse width did not influence the behavioural performance (Desbonnet et al 2004). A World Precision Instruments digital stimulator (DS8000, WPI, Berlin, Germany) and a stimulus isolator (DLS100, WPI, Berlin, Germany) were used to deliver the stimuli. Real time verification of the parameters applied during stimulation 
was obtained using a digital oscilloscope (Agilent 54622D oscilloscope, Agilent Technologies, Amstelveen, the Netherlands). After confirming the current amplitudes necessary to evoke escape behaviour, all rats had a two-week stimulation off period before the final stimulation session was performed at the lowest threshold of escape reaction.

\section{Behavioural evaluation}

Rats were placed in the open-field (OF) arena (square: $100 \mathrm{~cm} \times 100 \mathrm{~cm}$, and height: $40 \mathrm{~cm}$ ), clear Plexiglas box with an open top and a dark floor (Lim et al 2008e). The apparatus was located in a dimly red lit condition (15-20 lux) based on the recommendation of the guide for light intensity in animal rooms (UFAW 1999; Van Zutphen et al 2006). All testing was conducted in the same room and the apparatus was cleaned after each experimental procedure with ethanol. Rats were connected with an external stimulator through externalized leads. The stimulation started approximately 1 min after the rat was placed in the OF arena. We observed three different types of behaviour during the experimental procedure, consisting of 'no effect', 'freezing' behaviour characterized by piloerection, micturition/defaecation, and immobility, and 'escape behaviour' characterized by rigorous and aimlessly running. Behavioural changes during this procedure were observed by two researchers. Freezing behaviour was consistently characterized by immobility (without body movement) accompanied by two distinctive symptoms of increased alertness (head scanning) and piloerection. After cessation of stimulation, freezing disappeared and animals began to move again. Animals with escape thresholds above $100 \mu \mathrm{A}$ were discarded from analysis. All the testing condition and experimental paradigm were ensured to be similar in all animals in order to avoid differences in activation due to factors other than the stimulation.

\section{Experimental groups}

These procedures resulted in three experimental groups: A. dIPAG stimulation $(n=7$,$) B. dlPAG sham (n=2)$, and C. control $(n=5)$. The sham (operated) and control animals (non-operated) were tested similarly with those of electrical stimulation group. The sham group consisted of two rats who were originally in group A, but showed malfunction of the electrode and have therefore been treated as a separate, sham stimulated group. 


\section{Histological processing}

Two hours after the final electrical stimulation procedure, rats were placed under generalized anesthesia with Nembutal $(75 \mathrm{mg} / \mathrm{kg})$ and perfused transcardially with Tyrode $(0.1 \mathrm{M})$ and fixative containing $4 \%$ paraformaldehyde, $15 \%$ picric acid and $0.05 \%$ glutaraldehyde in $0.1 \mathrm{M}$ phosphate buffer $(\mathrm{pH} 7.6)$. The rat brains have been postfixed for 2 hours in the same fixative used for perfusion. Hereafter, the brains have been cryprotected by overnight sucrose treatment at $4{ }^{\circ} \mathrm{C}$. Brain tissue was then quickly frozen with $\mathrm{CO}_{2}$ and stored at $-80^{\circ} \mathrm{C}$. Subsequently, the forebrain regions were cut serially (10 series) on a cryostat (MICROM, Germany) into $30 \mu \mathrm{m}$ frontal sections and again stored at $-80^{\circ} \mathrm{C}$. One from the ten series was taken for c-Fos immunohistochemistry which was carried out by using an anti-c-Fos rabbit polyclonal antibody (Santa Cruz Biotechnology Inc., Santa Cruz, CA) (diluted 1:20,000 in 0.1\% Bovine Serum Albumin (BSA) and Tris Buffered Solution (TBS)-Triton (TBS-T) solution) which was used as the primary antibody. After overnight incubation at room temperature on a constant shaker with this primary anitibody, sections were rinsed with TBS-T, then TBS, and then TBS-T again. They were then incubated with the secondary antibody (diluted 1: 400 in biotinylated donkey anti-rabbit biotine; Jackson Immunoresearch Laboratories Inc., Westgrove, USA) for $90 \mathrm{~min}$. Subsequently, the sections were incubated with an avidinbiotin-peroxidase complex (diluted 1:800 in Elite ABC-kit, Vectastatin; Burlingame, USA) for $2 \mathrm{~h}$. In between steps, sections were washed with TBS and TBS-T. To visualize the immune complex of Horseradish Peroxide (HRP) reaction product, sections were incubated with 3,3'-diaminobenzidine tetrahydrochloride (DAB)/ Nickel Chloride $\left(\mathrm{NiCL}_{2}\right)$ solution $\left(5 \mathrm{ml} \mathrm{DAB}\right.$ solution, $5 \mathrm{ml}$ Tris $/ \mathrm{HCl}, 50 \mu 1 \mathrm{NiCL}_{2}$, and $3.35 \mu 1$ hydrogen peroxide). This reaction was stopped after $10 \mathrm{~min}$ by rinsing thoroughly all the sections with TBS. All sections were then mounted on gelatin-coated glasses. After dehydrating, all sections were cover-slipped with Pertex (HistolabProducts ab, Goteborg, Sweden). Additionally, another sequence of sections per animal was stained with standard hematoxylin-eosin (Merck, Darmstadt, Germany) to examine the localization of the electrode tips.

\section{Semi-quantitative evaluation of c-Fos immunoreactive cells}

Photographs of the areas of interest were taken at $4 \mathrm{X}$ magnification using an Olympus DP70 camera connected to an Olympus AX70 bright-field microscope (analySIS; Imaging System, Münster, Germany). The semi-quantitative assessment was similar to a previously reported method, with minor modifications (Nguyen et al 2006). The nomenclature and selected boundaries for semi-quantitative evaluation of the areas of interest were analyzed according to the rat brain atlas of Paxinos and Watson (Paxinos and Watson 1998) and based on the following coordinates according to bregma (mm, anteroposterior levels): $3.70,3.20,2.70,2.20,1.70,1.20,0.70,0.48,0.20,-1.80,-1.88$, $2.12,-2.80,-3.14,-3.30,-3.80,-4.16$, and -4.30 . Sections after bregma levels $-4.52 \mathrm{~mm}$ 
were not taken into evaluation because they were stained with standard hematoxylineosin (Merck, Darmstadt, Germany) for evaluation of electrode tip localization. The areas of evaluation were based on histological criteria. The number of positive c-Fos-ir cells was semi-quantitatively graded with the following scores as: negative $(-)$, weak $(+/-)$ mild $(+)$, moderate $(++)$, and strong $(+++)$, a method used previously (Nguyen et al 2006). The determination of scores was based on the number of positive c-Fos-ir cells with consideration of the areas' size of interest in comparison with the control $(\mathrm{n}=5)$ and sham $(n=2)$ groups. The procedures of grading were performed twice for each animal and the average of the scores was used as the final grade. The same light intensity and threshold conditions were employed for all sections. In addition, artifacts (dust debris) and nature of the c-Fos cells in the sections were taken into consideration to ensure the accuracy of measurements. An inter-rater reliability assessment was used to assess the consistency of a measure involving a comparison of the dIPAG DBS group with the control and sham groups.

\section{Statistical analysis}

Behavioural data are presented as mean \pm S.E.M using one-sample T-test. The cFos-ir cells were assessed semi-quantitatively, as explained earlier. The inter-rater reliability was approximately $90 \%$ for c-Fos ratings.

\section{Results}

\section{Histological evaluation of the electrode localization}

In two rats electrode tips were not located in the dIPAG and in these rats the escape threshold was $>100 \mu \mathrm{A}$. These rats were discarded from analysis. The localizations of the electrode tips in the dIPAG are illustrated in Fig. 1. Based on the histological staining with hematoxylin and eosin, no gross neuronal damage was observed except for the electrode trajectory. 


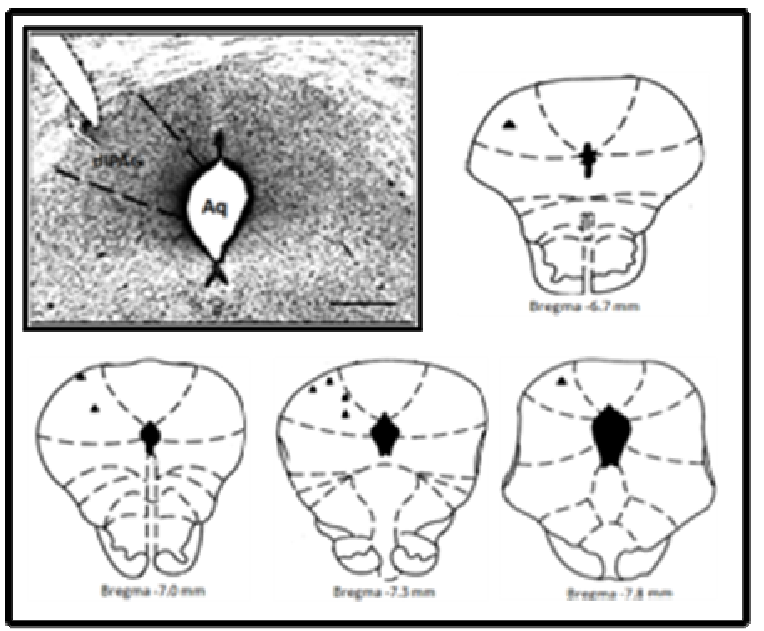

Figure 1. Representative low-power photomicrographs of a $30 \mu \mathrm{m}$-thick coronal section from the brain of a rat subjected to stereotactic implantation of concentric bipolar electrode to stimulate the dIPAG (Fig. A, scale bar $=250 \mu \mathrm{m}$ ) are shown. Fig. B, Schematic representation of the electrode sites in the dIPAG according to the Paxinos and Watson atlas, respectively. The symbol $(\boldsymbol{\Delta})$ indicates the electrode localization in the dIPAG. Abbreviation: $\mathrm{Aq}=$ aquaduct of Sylvius, $\mathrm{dlPAG}=$ dorsolateral periaqueductal gray.

\section{Behavioural effects on stimulation}

The current intensity applied to the dIPAG was based on the lowest threshold to induce escape behaviour. The mean current amplitude necessary for inducing 'freezing behaviour' was $78.57 \pm 4.04 \mu \mathrm{A}$, and $85.71 \pm 5.05 \mu \mathrm{A}$ for 'escape behaviour' (Fig. 2).

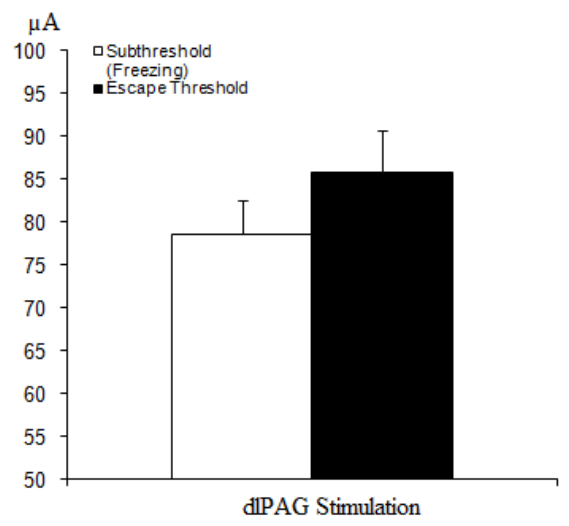

Figure 2. This figure shows the current amplitudes $(\mu \mathrm{A})$ necessary to induce escape reaction. Data represent means \pm S.E.M. of dIPAG group. 


\section{Distribution of c-Fos immunoreactive cells}

High numbers of c-Fos-ir cells were observed in the medial prefrontal cortex, orbital cortex, anterior olfactory nuclei, secondary motor cortex, and the somatosensory cortex in rats with dIPAG stimulation as compared to rats without dIPAG stimulation. In addition, moderate numbers of c-Fos-ir cells were detected in various regions, including the hypothalamus, amygdala, striatum, and frontal cortex. Furthermore, there was mild expression of c-Fos-ir cells in the hippocampus, thalamus, and habenular regions. Tables 1,2 , and 3 provide more detailed information concerning the pattern of c-Fos-ir cells in different areas of the brain resulting from dIPAG stimulation.

\section{Cortical Regions}

Electrical stimulation of the dIPAG increased the number of c-Fos-ir cells in the frontal cortical areas such as the cingulate gyrus $(\mathrm{Cg} 1 \& \mathrm{Cg} 2)$, prelimbic $(\mathrm{PrL})$, infralimbic (IL), and motor cortex 2 (M2), but not in the motor cortex 1 (M1) (Figs. 3 AF). Other cortical regions, for instance the piriform cortex (Pir), dorsal and ventral parts of agranular insular cortex (AID and AIV), claustrum (Cl), ventral and lateral part of orbital cortex (VO and LO) (Figs. 4 A-F), retrosplenial agranular (RSA), retrospenial agranular a and b cortex (RSGa and RSGb), primary somatosensory cortex (S1), and secondary somatosensory cortex (S2) (Figs. 5 A-F), showed a strong increase in the number of c-Fos-ir cells. Interestingly, we noted that dIPAG stimulation induced c-Fos expression in the $5^{\text {th }}$ and $6^{\text {th }}$ cortical layers of the granular insular cortex (GI), dysgranular insular cortex (DI), and the posterior part of agranular insular cortex (AIP), but not in the $1^{\text {st }}-4^{\text {th }}$ cortical layers (Figs. 6A, B, C, and D).

\section{Thalamus, hypothalamus, and habenula}

Moderate numbers of c-Fos-ir cells were observed in the dorsomedial part of laterodorsal thalamic nucleus (LDDM), and the paraventricular thalamic nuclei (PV); while the central thalamic nucleus (CM) only showed mild significant difference, in dIPAG-stimulated animals. No remarkable changes were detected in other parts of the thalamic nuclei (Figs. 7A, B, C, and D). Similarly, the habenular nuclei were also less affected except for the medial part of the lateral habenular nucleus (LH) which showed a mild increase in c-Fos-ir cells (Figs. 7A and B). However, dlPAG DBS caused a pronounced increase in the number of c-Fos-ir cells in different parts of the hypothalamus, particularly in the lateral hypothalamic area (LH), posterior part of anterior hypothalamic area (AHP), ventromedial hypothalamus (VMH), and periventricular hypothalamic nucleus (Pe) (Figs. 7E and F). 


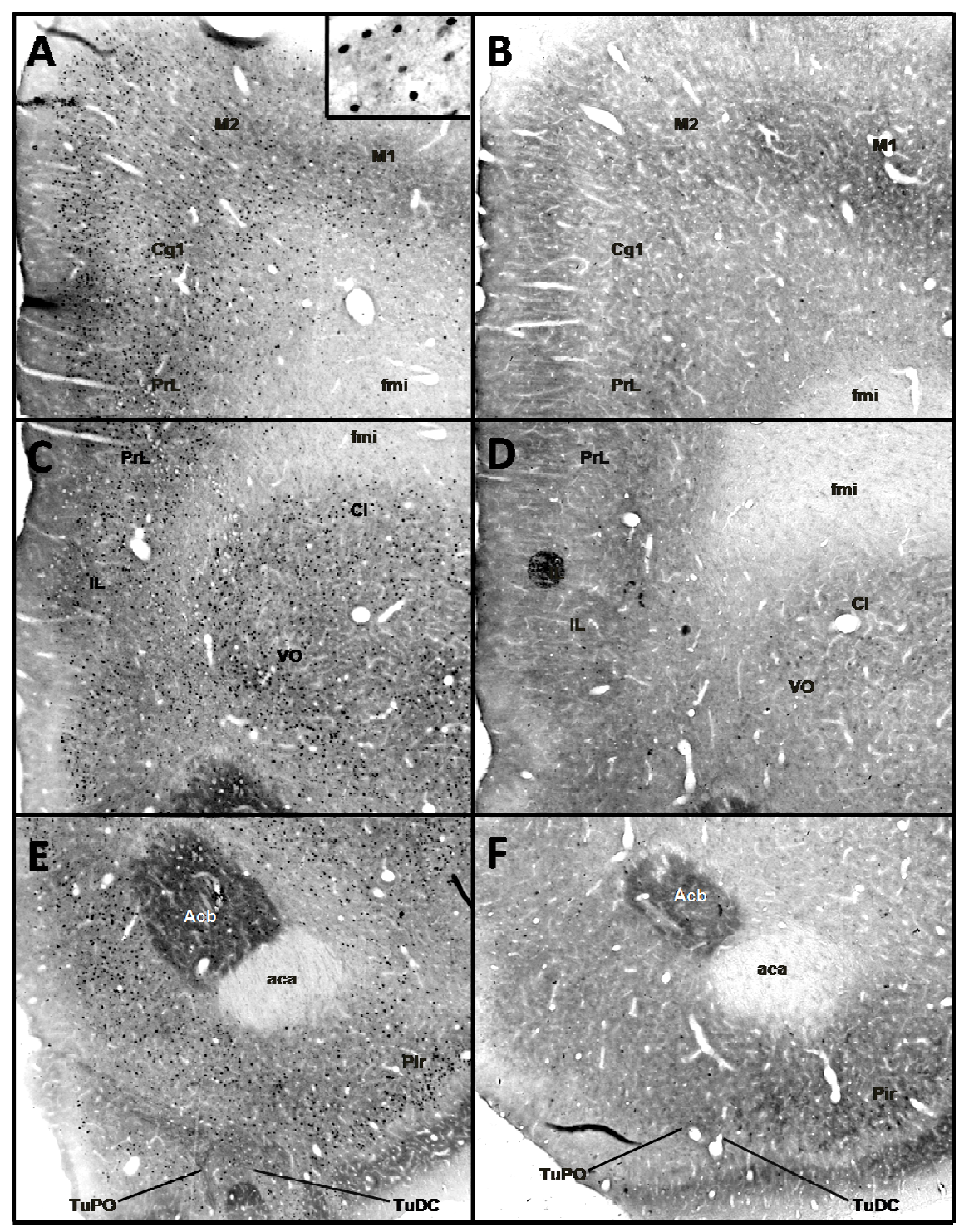

Figure 3. Representative photomicrographs of a $30 \mu \mathrm{m}$-thick coronal section from brain regions of the frontal cortical areas at the bregma level of $2.20 \mathrm{~mm}$. Figures. A, C, and E show the c-Fos-ir cells in animals with the dIPAG DBS as compared to the control animals (Figs. B, D, and F). The small dark dots represent c-Fos-ir cells at $4 \mathrm{X}$ magnification power. The inset in A shows a representative high-power photomicrograph of a c-Fos-ir cell. Abbreviations: Cg1 (cingulate gyrus 1), M1 (motor cortex 1), M2 (motor cortex 2), PrL (prelimbic cortex), IL (infralimbic cortex), fmi (forceps minor of the corpus callosum), $\mathrm{Cl}$ (claustrum), VO (ventral orbital cortex), Acb (nucleus accumbens), aca (anterior commissure, anterior part), TuPO (olfactory tubercle plexiform), and TuDC (olfactory tubercle densocellular layer). 


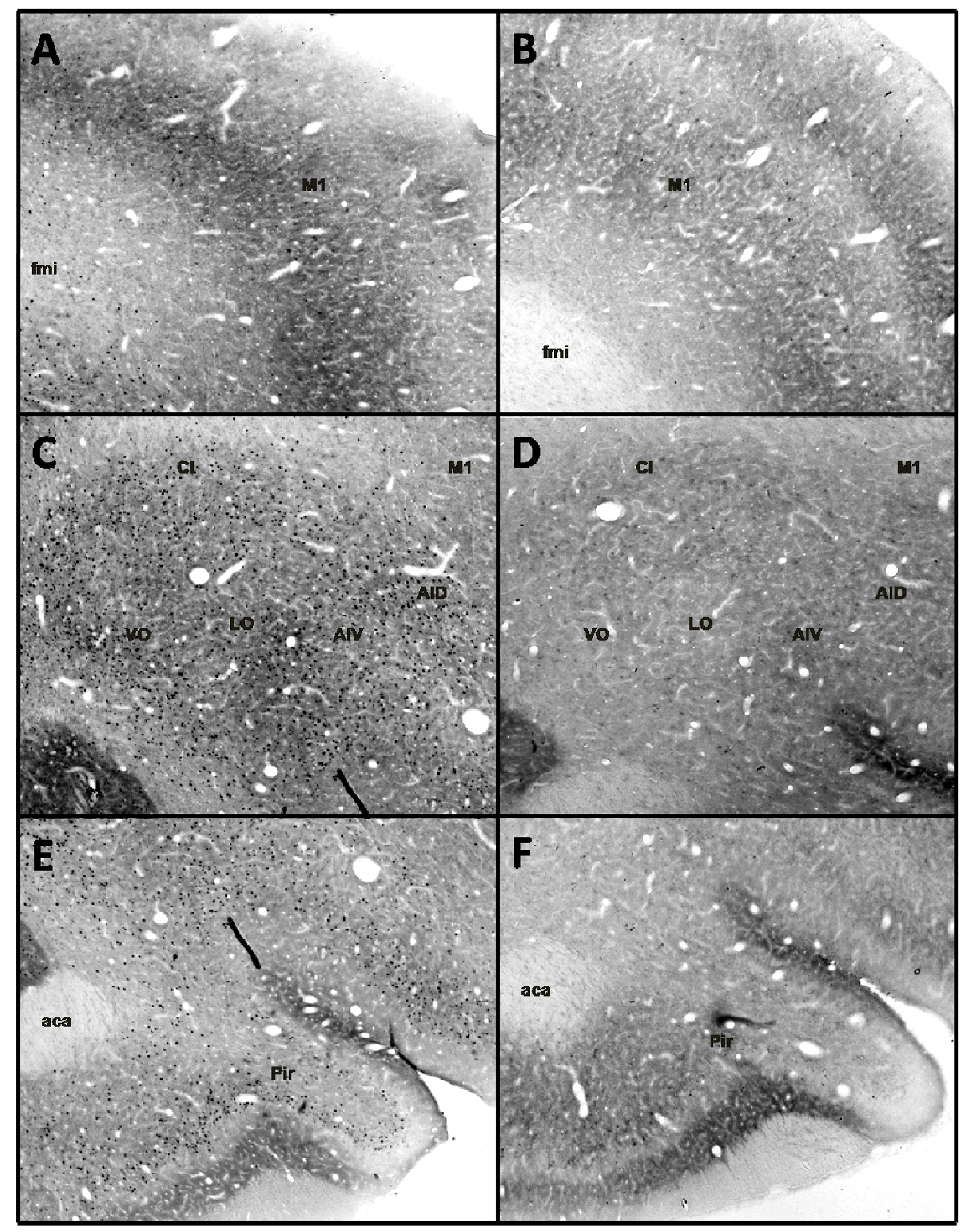

Figure 4. Representative photomicrographs of a $30 \mu \mathrm{m}$-thick coronal section from brain regions of the frontal cortical areas at the bregma level of $2.20 \mathrm{~mm}$. Figs. A, C, and E show the c-Fos-ir cells in animals with the dIPAG DBS as compared to the control animals (Figs. B, D, and F). The small dark dots represent c-Fos-ir cells at $4 \mathrm{X}$ magnification power. Abbreviations: M1 (motor cortex 1), fmi (forceps minor of the corpus callosum), $\mathrm{Cl}$ (claustrum), VO (ventral orbital cortex), LO (lateral orbital cortex), AIV (agranular insular cortex, ventral part), AID (agranular insular cortex, dorsal part), aca (anterior commissure, anterior part), and Pir (piriform cortex). 


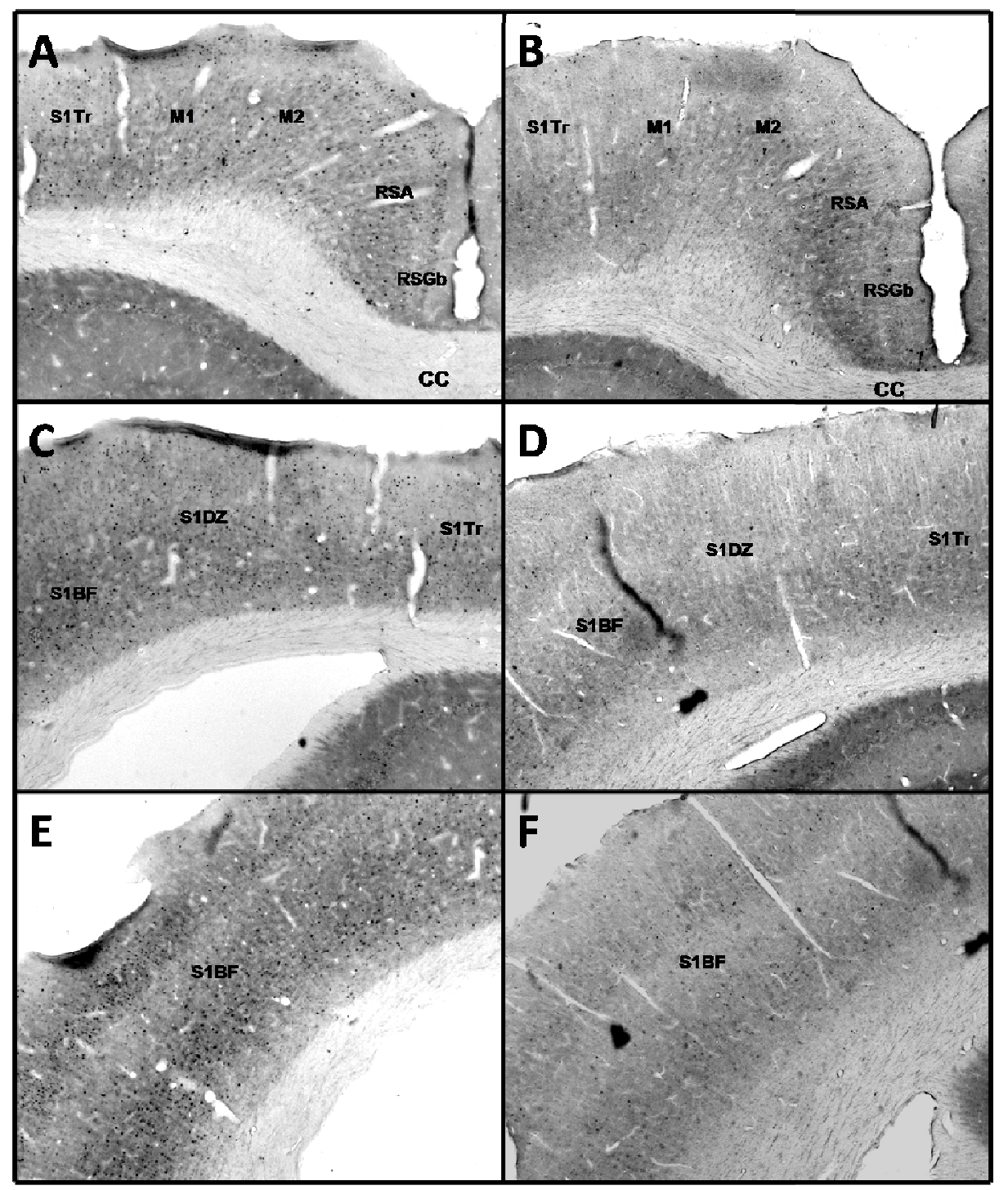

Figure 5. Representative photomicrographs of a $30 \mu \mathrm{m}$-thick coronal section from brain regions of the cortical areas at the bregma level of $-2.3 \mathrm{~mm}$. Figs. A, C, and E show the c-Fos-ir cells in animals with the dlPAG DBS as compared to the control animals (Figs. B, D, and F). Abbreviations: RSGb (retrosplenial granular b cortex), RSA (retrosplenial agranular cortex), M1 (motor cortex 1), M2 (motor cortex 2), S1 Tr (primary somatosensory cortex, trunk region), S1Dz (primary somatosensory cortex, dysgranular region), S1BF (primary somatosensory cortex, barrel field), and cc (corpus callosum). 


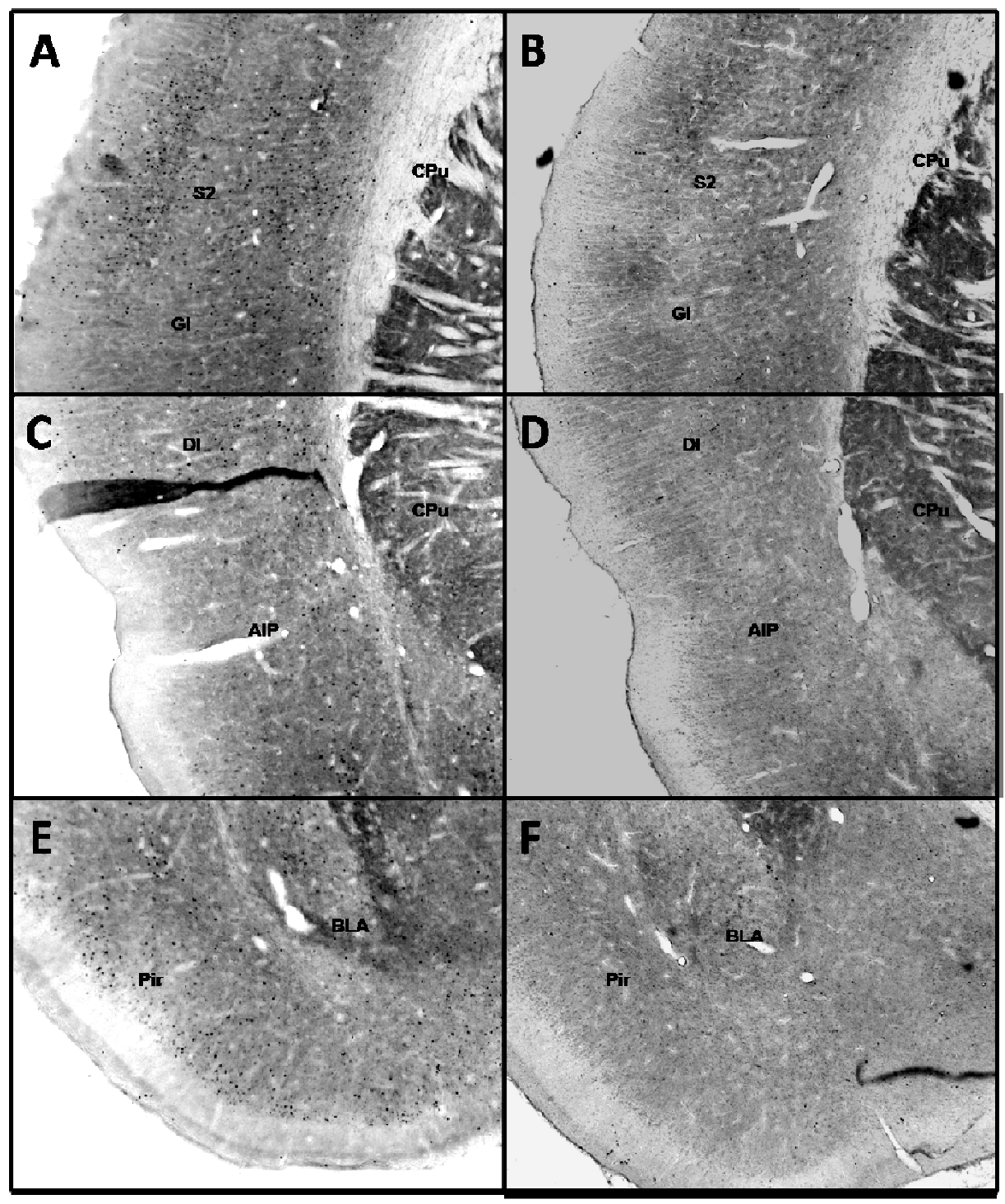

Figure 6. Representative photomicrographs of a $30 \mu \mathrm{m}$-thick coronal section from brain regions of the cortical areas at the bregma level of $-2.3 \mathrm{~mm}$. Figs. A, C, and E show the c-Fos-ir cells in animals with the dIPAG DBS as compared to the control animals (Figs. B, D, and F). Abbreviations: S2 (secondary somatosensory cortex), GI (granular insular cortex), DI (dysgranular insular cortex), AIP (agranular insular cortex, posterior part), $\mathrm{CPu}$ (caudate-putamen), Pir (piriform cortex), BLA (basolateral amygdaloid nucleus, anterior part). 


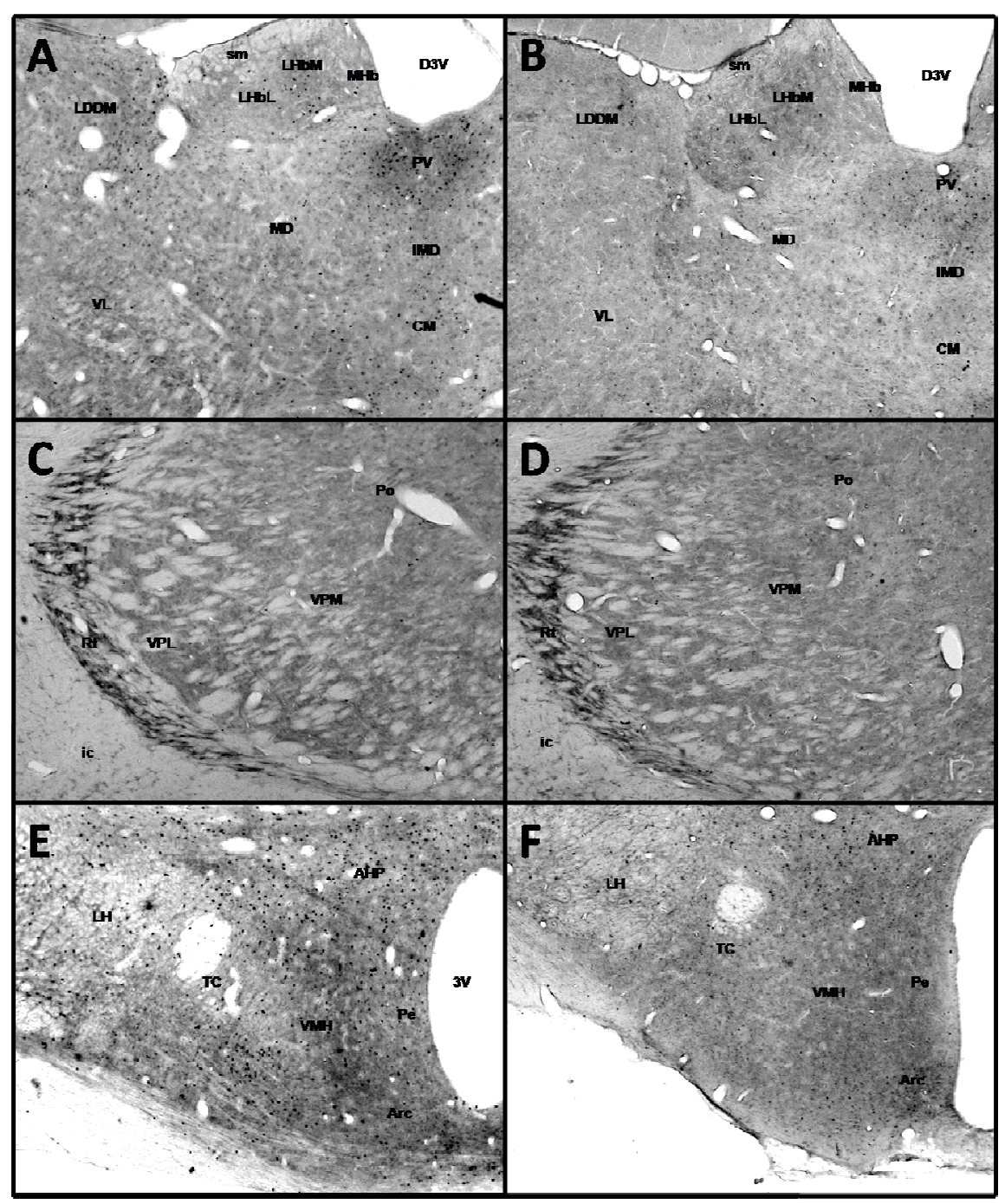

Figure 7. Representative photomicrographs of a $30 \mu \mathrm{m}$-thick coronal section from brain regions of the epithalamic nuclei and thalamic nuclei (Figs. A, B, C \& D), and hypothalamic nuclei (Figs. E \& F) at the bregma level of $-3.14 \mathrm{~mm}$. Figs. A, C, and E show the c-Fos-ir cells in animals with the dlPAG DBS as compared to the control animals (Figs. B, D, and F). Abbreviations: LDDM (laterodorsal thalamic nucleus, dorsomedial part), sm (stria medullaris of the thalamus), LHbL (lateral habenular nucleus, lateral part), LHbM (lateral habenular nucleus, medial part), MHb (medial habenular nucleus), MD (mediodorsal thalamic nucleus), VL (ventrolateral thalamic nucleus), PV (paraventricular thalamic nucleus), IMD (intermediadorsal thalamic nucleus), CM (central medial thalamic nucleus), D3V (dorsal $3^{\text {rd }}$ ventricle), ic (interna capsule), Rt (reticular thalamic nucleus), VPL (ventral posterolateral thalamic nucleus), VPM (ventral posteromedial thalamic nucleus), Po (posterior thalamic nuclear group), LH (lateral hypothalamic area), TC (tuber cinereum area), AHP (anterior hypothalamic area, posterior part), VMH (ventromedial hypothalamic nucleus), Pe (periventricular hupothalamic nucleus), Arc (arcuate hypothalamic nucleus), and $3 \mathrm{~V}$ ( $3^{\text {rd }}$ ventricle). 


\begin{tabular}{|c|c|c|c|c|c|c|c|c|c|}
\hline \multirow{2}{*}{ Brain Regions } & \multicolumn{9}{|c|}{ Coordinates of Bregma (mm) } \\
\hline & 3.70 & 3.20 & 2.70 & 2.20 & 1.70 & 1.20 & 0.70 & 0.48 & 0.20 \\
\hline \multicolumn{10}{|l|}{ Medial Prefrontal Cortex } \\
\hline $\mathrm{Cg} 1$ & $+H$ & $+H$ & + & $H$ & $H$ & $+H$ & $+H$ & $H+$ & $H+$ \\
\hline $\mathrm{Cg} 2$ & N/A & $\mathrm{N} / \mathrm{A}$ & N/A & N/A & ++ & ++ & ++ & +4 & +++ \\
\hline PrL & ++ & ++ & + & ++ & $\mathrm{N} / \mathrm{A}$ & N/A & N/A & $\mathrm{N} / \mathrm{A}$ & N/A \\
\hline IL & N/A & $H$ & $H$ & $H$ & N/A & N/A & $\mathrm{N} / \mathrm{A}$ & $\mathrm{N} / \mathrm{A}$ & $\mathrm{N} / \mathrm{A}$ \\
\hline $\mathrm{DP}$ & $\mathrm{N} / \mathrm{A}$ & ++ & + & + & $\mathrm{N} / \mathrm{A}$ & N/A & $\mathrm{N} / \mathrm{A}$ & $\mathrm{N} / \mathrm{A}$ & N/A \\
\hline \multicolumn{10}{|l|}{ Orbital Cortex } \\
\hline MO & ++ & $\mathrm{N} / \mathrm{A}$ & $\mathrm{N} / \mathrm{A}$ & $\mathrm{N} / \mathrm{A}$ & $\mathrm{N} / \mathrm{A}$ & $\mathrm{N} / \mathrm{A}$ & N/A & $\mathrm{N} / \mathrm{A}$ & $\mathrm{N} / \mathrm{A}$ \\
\hline vo & ++ & ++ & ++ & ++ & $\mathrm{N} / \mathrm{A}$ & N/A & N/A & N/A & N/A \\
\hline LO & ++ & ++ & ++ & $\mathrm{N} / \mathrm{A}$ & $\mathrm{N} / \mathrm{A}$ & $\mathrm{N} / \mathrm{A}$ & $\mathrm{N} / \mathrm{A}$ & $\mathrm{N} / \mathrm{A}$ & $\mathrm{N} / \mathrm{A}$ \\
\hline \multicolumn{10}{|l|}{ Agranular Insula Cortex } \\
\hline $\mathrm{AI}$ & + & $\mathrm{N} / \mathrm{A}$ & $\mathrm{N} / \mathrm{A}$ & $\mathrm{N} / \mathrm{A}$ & $\mathrm{N} / \mathrm{A}$ & $\mathrm{N} / \mathrm{A}$ & $\mathrm{N} / \mathrm{A}$ & N/A & N/A \\
\hline AID & $\mathrm{N} / \mathrm{A}$ & + & + & + & + & + & + & + & + \\
\hline AIV & N/A & + & + & + & + & + & + & + & + \\
\hline AIP & $\mathrm{N} / \mathrm{A}$ & $\mathrm{N} / \mathrm{A}$ & $\mathrm{N} / \mathrm{A}$ & $\mathrm{N} / \mathrm{A}$ & $\mathrm{N} / \mathrm{A}$ & N/A & $\mathrm{N} / \mathrm{A}$ & $\mathrm{N} / \mathrm{A}$ & + \\
\hline \multicolumn{10}{|l|}{ Somatosensory Cortex } \\
\hline $\mathrm{S} 1 \mathrm{~J}$ & N/A & N/A & + & $H$ & $H+$ & $H+$ & $H$ & $+H$ & H+ \\
\hline S1FL & N/A & $\mathrm{N} / \mathrm{A}$ & N/A & N/A & $\mathrm{N} / \mathrm{A}$ & ++ & ++ & ++ & ++ \\
\hline S1JO & $\mathrm{N} / \mathrm{A}$ & $\mathrm{N} / \mathrm{A}$ & $\mathrm{N} / \mathrm{A}$ & $\mathrm{N} / \mathrm{A}$ & $\mathrm{N} / \mathrm{A}$ & $+H$ & ++ & ++ & H+ \\
\hline S1DZ & $\mathrm{N} / \mathrm{A}$ & $\mathrm{N} / \mathrm{A}$ & $\mathrm{N} / \mathrm{A}$ & $\mathrm{N} / \mathrm{A}$ & $\mathrm{N} / \mathrm{A}$ & $+H$ & $+H$ & ++ & H+H \\
\hline S1ULp & $\mathrm{N} / \mathrm{A}$ & $\mathrm{N} / \mathrm{A}$ & $\mathrm{N} / \mathrm{A}$ & N/A & $\mathrm{N} / \mathrm{A}$ & ++ & ++ & ++ & ++ \\
\hline \multicolumn{10}{|l|}{ Olfactory Areas } \\
\hline $\mathrm{AOM}$ & ++ & $\mathrm{N} / \mathrm{A}$ & N/A & N/A & $\mathrm{N} / \mathrm{A}$ & $\mathrm{N} / \mathrm{A}$ & $\mathrm{N} / \mathrm{A}$ & N/A & N/A \\
\hline $\mathrm{AOV}$ & ++ & N/A & $\mathrm{N} / \mathrm{A}$ & $\mathrm{N} / \mathrm{A}$ & $\mathrm{N} / \mathrm{A}$ & $\mathrm{N} / \mathrm{A}$ & N/A & $\mathrm{N} / \mathrm{A}$ & $\mathrm{N} / \mathrm{A}$ \\
\hline $\mathrm{AOP}$ & $\mathrm{N} / \mathrm{A}$ & ++ & ++ & N/A & $\mathrm{N} / \mathrm{A}$ & $\mathrm{N} / \mathrm{A}$ & $\mathrm{N} / \mathrm{A}$ & $\mathrm{N} / \mathrm{A}$ & N/A \\
\hline $\mathrm{Tu}$ & N/A & + & N/A & + & + & + & + & + & + \\
\hline TuDC & N/A & $\mathrm{N} / \mathrm{A}$ & + & $\mathrm{N} / \mathrm{A}$ & N/A & N/A & N/A & N/A & N/A \\
\hline TuPO & $\mathrm{N} / \mathrm{A}$ & $\mathrm{N} / \mathrm{A}$ & + & $\mathrm{N} / \mathrm{A}$ & $\mathrm{N} / \mathrm{A}$ & N/A & N/A & $\mathrm{N} / \mathrm{A}$ & N/A \\
\hline TuPI & N/A & $\mathrm{N} / \mathrm{A}$ & + & N/A & N/A & N/A & $\mathrm{N} / \mathrm{A}$ & N/A & $\mathrm{N} / \mathrm{A}$ \\
\hline \multicolumn{10}{|l|}{ Other Areas } \\
\hline M1 & - & - & - & - & - & - & - & - & - \\
\hline M2 & ++ & ++ & ++ & ++ & ++ & ++ & ++ & ++ & H+ \\
\hline GI & N/A & + & + & + & + & + & + & + & + \\
\hline DI & $\mathrm{N} / \mathrm{A}$ & N/A & $\mathrm{N} / \mathrm{A}$ & N/A & ++ & +++ & $+H$ & ++ & $+H$ \\
\hline $\mathrm{Cl}$ & ++ & $+H$ & ++ & $+H$ & $+1+$ & ++ & $+H$ & ++ & $+H$ \\
\hline Pir & ++ & ++ & ++ & $+1+$ & ++ & ++ & ++ & ++ & $+H$ \\
\hline DEn & + & + & + & + & + & + & + & + & + \\
\hline $\mathrm{Acb}$ & $\mathrm{N} / \mathrm{A}$ & $\mathrm{N} / \mathrm{A}$ & + & + & + & + & + & + & + \\
\hline $\mathrm{CPu}$ & N/A & $\mathrm{N} / \mathrm{A}$ & $\mathrm{N} / \mathrm{A}$ & + & + & + & + & + & + \\
\hline $\mathrm{SHi}$ & N/A & $\mathrm{N} / \mathrm{A}$ & $\mathrm{N} / \mathrm{A}$ & N/A & N/A & + & + & + & + \\
\hline LSI & N/A & N/A & N/A & N/A & + & + & + & + & + \\
\hline $\mathrm{Ld}$ & N/A & $\mathrm{N} / \mathrm{A}$ & N/A & N/A & N/A & + & + & + & + \\
\hline MS & N/A & N/A & N/A & N/A & N/A & + & + & + & + \\
\hline VDB & $\mathrm{N} / \mathrm{A}$ & $\mathrm{N} / \mathrm{A}$ & $\mathrm{N} / \mathrm{A}$ & $\mathrm{N} / \mathrm{A}$ & + & + & + & + & + \\
\hline VTT & $+/-$ & $+/-$ & N/A & N/A & N/A & N/A & N/A & $\mathrm{N} / \mathrm{A}$ & N/A \\
\hline DTT & $+/-$ & $+/-$ & $+/-$ & $+/-$ & $\mathrm{N} / \mathrm{A}$ & N/A & $\mathrm{N} / \mathrm{A}$ & $\mathrm{N} / \mathrm{A}$ & N/A \\
\hline $\mathrm{HDB}$ & $\mathrm{N} / \mathrm{A}$ & N/A & $\mathrm{N} / \mathrm{A}$ & N/A & $\mathrm{N} / \mathrm{A}$ & + & + & + & + \\
\hline fmi & - & - & - & - & - & - & - & - & - \\
\hline aca & - & - & - & - & - & - & - & - & - \\
\hline aci & - & N/A & $\mathrm{N} / \mathrm{A}$ & N/A & N/A & N/A & N/A & N/A & N/A \\
\hline $\mathrm{mfba}$ & N/A & $+/-$ & $+/-$ & $+/-$ & $+/-$ & $+/-$ & $+/-$ & $+/-$ & $+/-$ \\
\hline
\end{tabular}

Table 1. Overview of the effects of electrical stimulation of the dIPAG on c-Fos-ir cells expression in brain regions of medial prefrontal cortex, orbital cortex, agranular insular cortex, somatosensory cortex, olfactory areas, and other areas (bregma coordinates from $3.70 \mathrm{~mm}$ till $0.20 \mathrm{~mm}$ ). Semi-quantitative scores of positive cFos-ir cells: - , negative; +/-, weak, but definite; +, mild; ++, moderate; +++, strong; N/A, brain structure not available in the mentioned bregma coordinates. 


\begin{tabular}{|c|c|c|c|c|c|c|c|c|c|}
\hline \multirow{2}{*}{ Brain Regions } & \multicolumn{9}{|c|}{ Coordinates of Bregma (mm) } \\
\hline & -1.80 & -1.88 & -2.12 & -2.80 & -3.14 & -3.30 & -3.80 & -4.16 & -4.30 \\
\hline \multicolumn{10}{|l|}{ Cortical Areas } \\
\hline $\mathrm{RSGb}$ & + & + & + & + & + & + & + & + & + \\
\hline RSA & + & + & + & + & + & + & + & + & + \\
\hline M2 & + & + & + & + & + & + & $\mathrm{N} / \mathrm{A}$ & $\mathrm{N} / \mathrm{A}$ & N/A \\
\hline M1 & + & + & + & + & + & + & $\mathrm{N} / \mathrm{A}$ & $\mathrm{N} / \mathrm{A}$ & N/A \\
\hline PtA & $\mathrm{N} / \mathrm{A}$ & N/A & $\mathrm{N} / \mathrm{A}$ & N/A & N/A & N/A & + & + & + \\
\hline $\mathrm{S} 1 \mathrm{Tr}$ & $\mathrm{N} / \mathrm{A}$ & $\mathrm{N} / \mathrm{A}$ & $\mathrm{N} / \mathrm{A}$ & ++ & ++ & ++ & $\mathrm{N} / \mathrm{A}$ & $\mathrm{N} / \mathrm{A}$ & N/A \\
\hline S1HL & ++ & ++ & ++ & N/A & N/A & N/A & N/A & N/A & N/A \\
\hline $\mathrm{S} 1 \mathrm{FL}$ & $+H$ & $H+$ & $+H$ & N/A & N/A & $\mathrm{N} / \mathrm{A}$ & $\mathrm{N} / \mathrm{A}$ & N/A & N/A \\
\hline S1DZ & ++ & ++ & ++ & $+H$ & $+H$ & $+1+$ & $\mathrm{N} / \mathrm{A}$ & $\mathrm{N} / \mathrm{A}$ & N/A \\
\hline S1BF & ++ & $H+$ & $+H$ & $+H$ & $+H$ & $+H$ & $+H$ & ++ & N/A \\
\hline S1 & ++ & $H+$ & ++ & N/A & $\mathrm{N} / \mathrm{A}$ & $\mathrm{N} / \mathrm{A}$ & $\mathrm{N} / \mathrm{A}$ & $\mathrm{N} / \mathrm{A}$ & ++ \\
\hline $\mathrm{S} 2$ & $H$ & $+H$ & ++ & $+H$ & $+H$ & $+H$ & $\mathrm{~N} / \mathrm{A}$ & N/A & N/A \\
\hline GI & + & + & + & + & + & + & $\mathrm{N} / \mathrm{A}$ & N/A & N/A \\
\hline DI & + & + & + & + & + & + & N/A & N/A & N/A \\
\hline Ect & N/A & N/A & $\mathrm{N} / \mathrm{A}$ & N/A & + & + & + & + & + \\
\hline PRh & $\mathrm{N} / \mathrm{A}$ & N/A & $\mathrm{N} / \mathrm{A}$ & N/A & + & + & + & + & + \\
\hline AuD & $\mathrm{N} / \mathrm{A}$ & N/A & N/A & N/A & + & + & + & + & + \\
\hline Au1 & N/A & N/A & $\mathrm{N} / \mathrm{A}$ & N/A & N/A & + & + & + & + \\
\hline $\mathrm{AuV}$ & N/A & N/A & $\mathrm{N} / \mathrm{A}$ & N/A & + & + & + & + & + \\
\hline $\mathrm{TeA}$ & N/A & N/A & $\mathrm{N} / \mathrm{A}$ & N/A & $\mathrm{N} / \mathrm{A}$ & $\mathrm{N} / \mathrm{A}$ & + & + & + \\
\hline LEnt & N/A & N/A & N/A & + & + & + & + & + & + \\
\hline AIP & $+H$ & $+H$ & ++ & ++ & N/A & $\mathrm{N} / \mathrm{A}$ & $\mathrm{N} / \mathrm{A}$ & $\mathrm{N} / \mathrm{A}$ & N/A \\
\hline Pir & + & + & + & + & + & + & + & + & + \\
\hline \multicolumn{10}{|l|}{ Amygdala } \\
\hline $\mathrm{CeA}$ & + & + & + & + & + & + & N/A & N/A & N/A \\
\hline BLA & + & + & + & + & + & + & + & + & + \\
\hline BMA & + & + & + & + & + & + & + & $\mathrm{N} / \mathrm{A}$ & N/A \\
\hline MeA & + & + & + & + & + & + & + & $\mathrm{N} / \mathrm{A}$ & N/A \\
\hline $\mathrm{ACo}$ & + & + & + & + & $\mathrm{N} / \mathrm{A}$ & $\mathrm{N} / \mathrm{A}$ & N/A & $\mathrm{N} / \mathrm{A}$ & N/A \\
\hline LA & $\mathrm{N} / \mathrm{A}$ & N/A & + & + & + & + & + & + & N/A \\
\hline PLCo & N/A & $\mathrm{N} / \mathrm{A}$ & N/A & + & + & + & + & + & + \\
\hline \multicolumn{10}{|l|}{ Basal Ganglia } \\
\hline $\mathrm{CPu}$ & + & H & + & + & + & + & + & $\mathrm{N} / \mathrm{A}$ & N/A \\
\hline LGP & - & - & - & - & - & - & $\mathrm{N} / \mathrm{A}$ & N/A & N/A \\
\hline MGP & N/A & N/A & - & - & - & - & $\mathrm{N} / \mathrm{A}$ & $\mathrm{N} / \mathrm{A}$ & N/A \\
\hline STN & $\mathrm{N} / \mathrm{A}$ & $\mathrm{N} / \mathrm{A}$ & N/A & $\mathrm{N} / \mathrm{A}$ & N/A & N/A & + & + & + \\
\hline ic & - & - & - & - & - & - & - & - & - \\
\hline \multicolumn{10}{|l|}{ Hippocampus } \\
\hline DG & + & + & + & + & + & + & + & + & + \\
\hline CA1 & $\mathrm{N} / \mathrm{A}$ & N/A & $\mathrm{N} / \mathrm{A}$ & + & + & + & + & + & + \\
\hline $\mathrm{CA} 3$ & $\mathrm{~N} / \mathrm{A}$ & - & - & - & - & - & - & - & - \\
\hline Hilus & $\mathrm{N} / \mathrm{A}$ & N/A & N/A & - & - & - & - & - & - \\
\hline
\end{tabular}

Table 2. Overview of the effects of electrical stimulation of the dIPAG on c-Fos-ir cells expression in brain regions of cortical areas, amygdala, basal ganglia, and hippocampus (bregma coordinates from $-1.80 \mathrm{~mm}$ till $4.30 \mathrm{~mm}$ ). Semi-quantitative scores of positive c-Fos-ir cells: - , negative; +/-, weak, but definite; +, mild; ++, moderate; +++, strong; N/A, brain structure not available in the mentioned bregma coordinates. 


\begin{tabular}{|c|c|c|c|c|c|c|c|c|c|}
\hline \multirow{2}{*}{ Brain Regions } & \multicolumn{9}{|c|}{ Coordinates of Bregma (mm) } \\
\hline & -1.80 & -1.88 & -2.12 & -2.80 & -3.14 & -3.30 & -3.80 & -4.16 & -4.30 \\
\hline \multicolumn{10}{|l|}{ Habenular } \\
\hline $\mathrm{MHb}$ & - & - & - & - & - & - & - & - & - \\
\hline $\mathrm{LHbM}$ & $\mathrm{N} / \mathrm{A}$ & $\mathrm{N} / \mathrm{A}$ & $\mathrm{N} / \mathrm{A}$ & $\mathrm{N} / \mathrm{A}$ & + & + & + & + & $\mathrm{N} / \mathrm{A}$ \\
\hline LHBL & - & - & - & - & - & - & - & - & - \\
\hline \multicolumn{10}{|l|}{ Thalamus } \\
\hline Rt & $+/-$ & $+/-$ & $+/-$ & $+/-$ & $+/-$ & $+/-$ & $+/-$ & $+/-$ & $\mathrm{N} / \mathrm{A}$ \\
\hline VA & - & - & - & $\mathrm{N} / \mathrm{A}$ & $\mathrm{N} / \mathrm{A}$ & $\mathrm{N} / \mathrm{A}$ & $\mathrm{N} / \mathrm{A}$ & $\mathrm{N} / \mathrm{A}$ & $\mathrm{N} / \mathrm{A}$ \\
\hline $\mathrm{VM}$ & - & - & - & - & - & - & - & N/A & N/A \\
\hline VL & $\mathrm{N} / \mathrm{A}$ & N/A & - & - & - & - & $\mathrm{N} / \mathrm{A}$ & $\mathrm{N} / \mathrm{A}$ & N/A \\
\hline VPL & $\mathrm{N} / \mathrm{A}$ & N/A & - & - & - & - & - & - & - \\
\hline VPM & N/A & N/A & N/A & - & - & - & - & - & - \\
\hline $\mathrm{CM}$ & + & + & + & + & + & + & + & $\mathrm{N} / \mathrm{A}$ & N/A \\
\hline IMD & - & - & - & - & - & - & - & N/A & N/A \\
\hline AV th & - & - & - & $\mathrm{N} / \mathrm{A}$ & $\mathrm{N} / \mathrm{A}$ & $\mathrm{N} / \mathrm{A}$ & $\mathrm{N} / \mathrm{A}$ & N/A & $\mathrm{N} / \mathrm{A}$ \\
\hline $\mathrm{MD}$ & - & - & - & - & - & - & - & N/A & N/A \\
\hline $\mathrm{AD}$ & - & - & - & $\mathrm{N} / \mathrm{A}$ & N/A & N/A & $\mathrm{N} / \mathrm{A}$ & $\mathrm{N} / \mathrm{A}$ & N/A \\
\hline PT & - & - & N/A & $\mathrm{N} / \mathrm{A}$ & $\mathrm{N} / \mathrm{A}$ & $\mathrm{N} / \mathrm{A}$ & N/A & N/A & N/A \\
\hline PC & - & - & - & - & - & - & $\mathrm{N} / \mathrm{A}$ & N/A & N/A \\
\hline LDDM & N/A & N/A & + & + & + & N/A & N/A & $\mathrm{N} / \mathrm{A}$ & N/A \\
\hline LDDL & - & - & - & - & - & - & $\mathrm{N} / \mathrm{A}$ & N/A & N/A \\
\hline LPMR & $\mathrm{N} / \mathrm{A}$ & N/A & $\mathrm{N} / \mathrm{A}$ & $\mathrm{N} / \mathrm{A}$ & - & - & - & - & - \\
\hline LPLR & $\mathrm{N} / \mathrm{A}$ & N/A & N/A & $\mathrm{N} / \mathrm{A}$ & N/A & $\mathrm{N} / \mathrm{A}$ & - & - & - \\
\hline DLG & N/A & N/A & N/A & N/A & N/A & N/A & - & - & - \\
\hline PVA & + & + & + & $\mathrm{N} / \mathrm{A}$ & N/A & N/A & $\mathrm{N} / \mathrm{A}$ & $\mathrm{N} / \mathrm{A}$ & $\mathrm{N} / \mathrm{A}$ \\
\hline PV & N/A & N/A & N/A & + & + & N/A & $\mathrm{N} / \mathrm{A}$ & N/A & N/A \\
\hline PVP & N/A & N/A & $\mathrm{N} / \mathrm{A}$ & $\mathrm{N} / \mathrm{A}$ & $\mathrm{N} / \mathrm{A}$ & + & + & + & + \\
\hline $\mathrm{Rh}$ & - & - & - & - & - & N/A & N/A & N/A & N/A \\
\hline $\operatorname{Re}$ & - & - & - & - & - & - & $\mathrm{N} / \mathrm{A}$ & $\mathrm{N} / \mathrm{A}$ & $\mathrm{N} / \mathrm{A}$ \\
\hline \multicolumn{10}{|l|}{ Hypothalamus } \\
\hline LH & + & + & + & + & + & + & + & + & + \\
\hline $\mathrm{AHC}$ & + & + & + & $\mathrm{N} / \mathrm{A}$ & $\mathrm{N} / \mathrm{A}$ & $\mathrm{N} / \mathrm{A}$ & $\mathrm{N} / \mathrm{A}$ & $\mathrm{N} / \mathrm{A}$ & $\mathrm{N} / \mathrm{A}$ \\
\hline AHP & + & + & + & $\mathrm{N} / \mathrm{A}$ & $\mathrm{N} / \mathrm{A}$ & $\mathrm{N} / \mathrm{A}$ & $\mathrm{N} / \mathrm{A}$ & $\mathrm{N} / \mathrm{A}$ & $\mathrm{N} / \mathrm{A}$ \\
\hline VMH & $\mathrm{N} / \mathrm{A}$ & $\mathrm{N} / \mathrm{A}$ & + & + & + & + & $\mathrm{N} / \mathrm{A}$ & $\mathrm{N} / \mathrm{A}$ & $\mathrm{N} / \mathrm{A}$ \\
\hline $\mathrm{DMD}$ & $\mathrm{N} / \mathrm{A}$ & $\mathrm{N} / \mathrm{A}$ & $\mathrm{N} / \mathrm{A}$ & + & H & + & $\mathrm{N} / \mathrm{A}$ & $\mathrm{N} / \mathrm{A}$ & $\mathrm{N} / \mathrm{A}$ \\
\hline $\mathrm{Pe}$ & + & H & + & H & H & H & $\mathrm{N} / \mathrm{A}$ & $\mathrm{N} / \mathrm{A}$ & $\mathrm{N} / \mathrm{A}$ \\
\hline $\mathrm{Pa}$ & H & + & + & $\mathrm{N} / \mathrm{A}$ & $\mathrm{N} / \mathrm{A}$ & $\mathrm{N} / \mathrm{A}$ & N/A & N/A & N/A \\
\hline
\end{tabular}

Table 3. Overview of the effects of electrical stimulation of the dIPAG on c-Fos-ir cells expression in brain regions of habenular, thalamus, and hypothalamus (bregma coordinates from $-1.80 \mathrm{~mm}$ till $-4.30 \mathrm{~mm}$ ). Semiquantitative scores of positive c-Fos-ir cells: -, negative; +/-, weak, but definite; +, mild; ++, moderate; +++, strong; N/A, brain structure not available in the mentioned bregma coordinates. 


\section{Basal Ganglia}

As shown in figures 8 (C) and (D), dlPAG DBS did not cause clear c-Fos expression in the global pallidus, but in the $\mathrm{CPu}$ moderate number c-Fos-ir cells expression was found as compared to rats of the control group.

\section{Other Brain Areas}

Moderate expression of c-Fos-ir cells was observed in the medial (MeA), basomedial (BMA), and anterior cortical (ACo) amygdaloid nuclei; while the basolateral (BLA) and central (CeA) nuclei of the amygdala only showed mild increase in the number of positive c-Fos-ir cells, in dlPAG-stimulated animals (Figs. 8E and F). As shown in figures 8 (A) and (B), mild neural activation was detected in the hippocampal regions of $\mathrm{CA} 1$ and dentate gyrus $(\mathrm{DG})$ but not in the hilus and $\mathrm{CA} 3$ regions. 


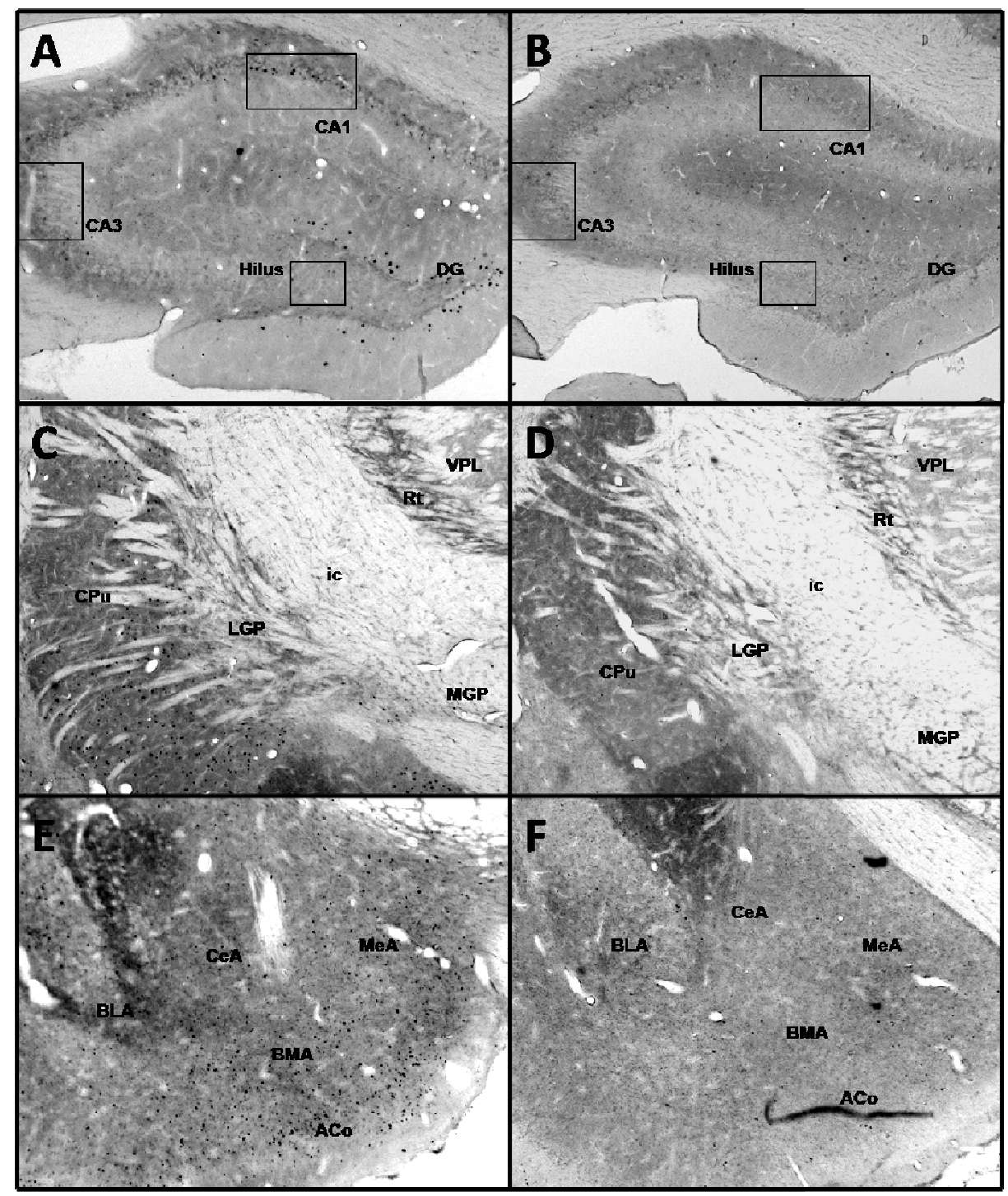

Figure 8. Representative photomicrographs of a $30 \mu \mathrm{m}$-thick coronal section from brain regions of the hippocampus areas (Figs. A \& B), basal ganglia structures (Figs. C \& D), and amygdaloid nuclei (Figs. E \& F) at the bregma level of $-3.14 \mathrm{~mm}$. Figs. A, C, and E show the c-Fos-ir cells in animals with the dIPAG DBS as compared to the control animals (Figs. B, D, and F). Abbreviations: CA1, CA3 (CA1, CA3 fields of hippocampus), Hilus (CA4 field of hippocampus), DG (dentate gyrus), CPu (caudate-putamen), cc (corpus callosum), LGP (lateral globus pallidus), MGP (medial globus pallidus), ic (interna capsule), Rt (reticular thalamic nucleus), VPL (ventral posterolateral thalamic nucleus), BLA (basolateral amygdaloid nucleus, anterior part), CeA (central amygdaloid nucleus), MeA (medial amygdaloid nucleus), BMA (basomedial amygdaloid nucleus), and ACo (anterior cortical amygdaloid nucleus). 


\section{Discussion}

In the present study, we have evaluated the pattern of neuronal activation in different forebrain regions induced by electrical stimulation of the dIPAG. This stimulation appears to activate regions located in the hypothalamus, amygdala, prefrontal cortex, and some related cortical areas. In addition, our results have revealed changes in neuronal activities in some specific parts of the thalamus and basal ganglia resulting from dIPAG DBS. This pattern of neuronal activation is in agreement with the twodimensional defence circuit as proposed by McNaughton \& Corr in controlling behaviour in response to threatening or novel stimuli (McNaughton and Corr 2004). In this twodimensional defence system, the circuitry for panic includes the PAG, hypothalamus, amygdala, anterior cingulate and prefrontal cortex (Fig. 9).

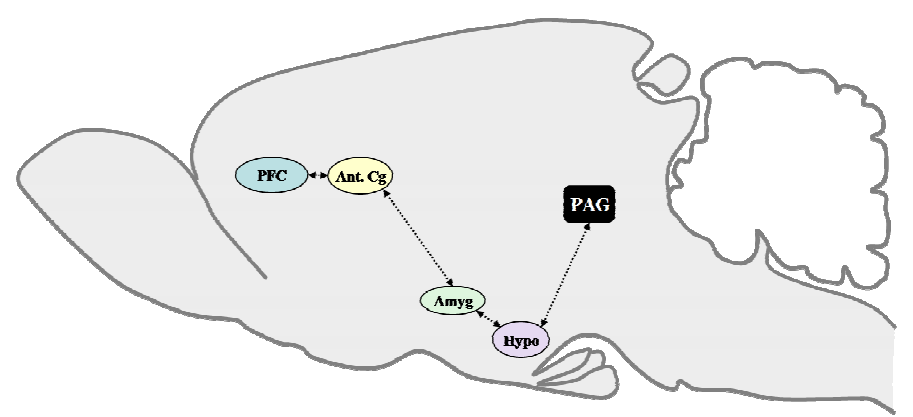

Figure 9. Schematic illustration of the forebrain upstream connections of the periaqueductal gray matter in defensive behaviour for escape or panic-like behaviour. Abbreviations: PAG: periaqueductal gray; Hypo: hypothalamus; Amyg: amygdala; Ant. $\mathrm{Cg}$ : anterior cingulate gyrus; and PFC: prefrontal cortex.

\section{Frontal Cortex}

In consistent with the current results, a series of retrograde studies have revealed that the projections to the PAG arise predominantly from the medial prefrontal cortex wall and a few selected orbital/anterior insular prefrontal cortex regions (Floyd et al 2000; Reep and Winans 1982). In addition, the injections of anterograde tracers into each PAGprojecting prefrontal region have also revealed distinct columnar patterns in the PAG. The medial prefrontal cortex projects densely to the dIPAG, whereas ventrolateral PAG received an exclusive robust input from the orbital and anterior insular areas and weaker input from the medial and dorsomedial prefrontal areas (Floyd et al 2000; Floyd et al 2001; Jasmin et al 2004). Besides, the dorsomedial prefrontal cortex was found to project robustly to the lateral PAG column which indicates that different types of defensive behaviour are controlled by different PAG columns (Gabbott 2003; Gabbott et al 2003; Jasmin et al 2004; Yasui et al 1991). 
There were some novel findings in the current study. For instance we have found c-Fos-ir cells mainly in the $5^{\text {th }}$ and $6^{\text {th }}$ cortical layers of the granular insular cortex (GI), dysgranular insular cortex (DI), and the posterior part of agranular insular cortex (AIP), but not the $1^{\text {st }}-4^{\text {th }}$ cortical layers. This is actually in line with the observation that cortical projecting neurons to subcortical areas are located in the deep layers 5 and 6 of the cortex (DeFelipe and Farinas 1992). The insular cortex is considered as the viscerosensory region processing afferent cardiovascular, cardiopulmonary, gastrointestinal, odour, gustatory, and other related sensory and pain information (Jasmin et al 2004; Ruggiero et al 1987; Saper 1982). This information is subsequently relayed to a variety of subcortical autonomic regions (ventral striatum-nucleus accumbens, basolateral amygdala, mediodorsal thalamus, lateral hypothalamus, parabrachial nucleus, dlPAG, ventral tegmental area, dorsal raphe, and medullary regions) and to orbital and medial prefrontal cortex regions (Gabbott et al 2003; Jasmin et al 2004).

In view of these results, the connection of the frontal cortex with subcortical regions and the PAG seems to be particularly important in the integration of cognitiveaffective information during the escape- or panic-like behaviour. The prelimbic and infralimbic cortices have a significant role in the expression of fear and cognitive functions (Corcoran and Quirk 2007; Radley et al 2006), and in learning and coping with threatening stimuli or environments (Rich and Shapiro 2007). Furthermore, the cingulate gyrus and insular cortex are connected with the hypothalamus and amygdala which appear to be involved in the autonomic functions such as regulating the blood pressure and heart rate during defensive behaviour (Allman et al 2001; Jasmin et al 2004).

\section{Hypothalamus}

The medial hypothalamic area, including the anterior hypothalamus, dorsomedial part of the ventromedial hypothalamus (VMHdm), and dorsal premammillary nucleus (PMd), which together form a defensive system (Canteras 2002; Canteras et al 2001), shows a strong activation to conditioned fear (e.g. cat odor, as well as a live cat) (Canteras et al 1997; Dielenberg et al 2001a; Dielenberg et al 2001b; Dielenberg and McGregor 2001). The bed nucleus of the stria terminalis, ventral part of the lateral septum, and PAG are also activated during cat odor exposure. Keay \& Bandler showed that the axons of the medial prefrontal cortex wall densely target the ventromedial hypothalamic nucleus and anterior hypothalamic area and terminate within the dlPAG (Canteras 2002; Keay and Bandler 2001; Vianna and Brăndao 2003). On the other hand, the orbital and anterior insular prefrontal cortex areas selectively target the lateral hypothalamus and project only to the vlPAG. As for the IPAG, the dorsomedial prefrontal cortex convexity and anterior cingulate cortex (area 24) firstly project to the dorsal hypothalamic areas and then send collaterals that terminate in the IPAG column. 


\section{Amygdala}

Recent data have shown that the amygdala and the PAG, together with the medial hypothalamus, constitute an integrated circuitry in the brain that commands defensive behaviour and elaborates aversive emotional and motivational states. The function of the amygdala would be to synthesize the various inputs from the environment and then signal the PAG according to the degree of threat presented to the organism (LeDoux 1994 ; LeDoux et al 1988; McNaughton and Corr 2004). Retrograde tracer experiments have demonstrated the subcortical structures such as the central nucleus and ventrolateral part of the basal nucleus of the amygdala having projections to the PAG and other midbrain structures (Gabbott et al 2003; Gabbott et al 2005; Gray and Magnuson 1992). Different parts of the midbrain are involved in mediating different measures of conditioned fear, such as the fear-potentiated startle and freezing, both of which are dependent of the amygdala. A study by Zhao \& Davis has shown that fear-potentiated startle in the rats is mediated by neurons in the deep layers of the superior colliculus/ deep mesencephalic nucleus of the rostral midbrain through the glutamate non-NMDA receptors whereas the dorsal or lateral PAG were responsible for freezing (Zhao and Davis 2004). Previous studies also suggested that unconditioned fear (cat odour) activated downstream pheromone-related structures, including the posteroventral part of the medial amygdala (Dielenberg and McGregor 2001; McGregor et al 2004). It is notable that the effects of medial amygdala lesions in rats reduced freezing/immobility in the cat odour exposure (Blanchard et al 2005; $\mathrm{Li}$ et al 2004). In addition, the VMH receives major input from areas involved in sensory processing, such as the bed nucleus of the stria terminalis and medial amygdala (Canteras et al 2001; Petrovich et al 2001). Involvement of these structures in defensive behaviour appears to mediate the responsivity to predatory threats which provides a fundamental understanding of the functional mapping with other brain structures.

\section{Conclusion}

Our results have shown that electrical stimulation of the dlPAG produced different patterns of neuronal activation in specific parts of the forebrain which are involved in panic- or fear-like behaviour. Interestingly, this pattern of activation matched the concept of the defence system by McNaughton and Corr related to rage, panic and fear. The present study provides evidence that other forebrain structures are also involved in these behaviours. 
Table 4. Abbreviations

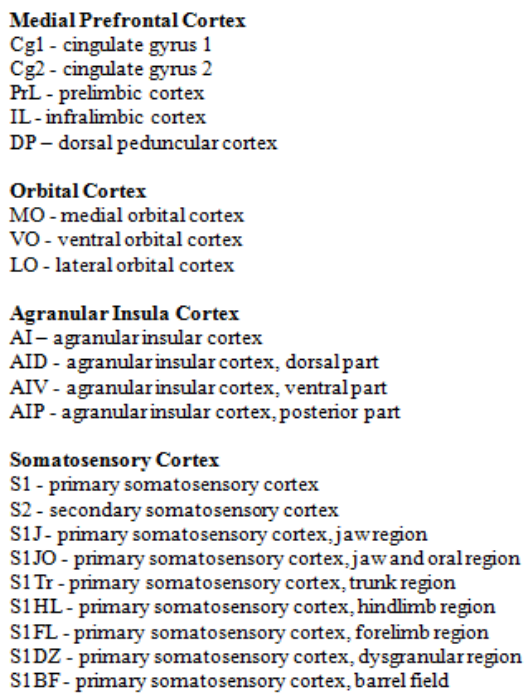

TC - tuber cinereum area
Olfactory Areas

AOM - anterior olfactory nucleus, medial part AOV - anterior olfactory nucleus, ventral part AOP - anterior olfactory nucleus, posterior part $\mathrm{Tu}$ - olfactory tubercle

TuDC - olfactory tubercle densocellular layer

TuPO - olfactory tubercle polymorph layer

TuPI- olfactory tubercle plexiform layer

Amygdala

$\mathrm{CeA}$ - central amygdaloid nucleus

BLA - basolateral amygdaloid nucleus

BMA - basomedial amygdaloid nucleus

MeA - medial amygdaloid nucleus

ACo - anterior cortical amygdaloid nucleus

LA - lateral amygdaloid nucleus

PLCo-posterolateral cortical amygdaloidnucleus

\section{Basal Ganglia}

$\mathrm{CPu}$ - caudate-putamen

LGP - lateral globus pallidus

MGP - medial globus pallidus

STN - subthalamic nucleus

ic - intema capsule

\section{Hippocampus}

DG - dentate gyrus

CA1 - CA1 field of hippocampus

$\mathrm{CA} 3$ - CA3 field of hippocampus

Hilus - CA4 field of hippocampus

Habenular

$\mathrm{MHb}$ - medial habenularnucleus

LHbM - lateral habenular nucleus, medial part

LHBL - lateral habenular nucleus, lateral part

\section{Thalamus}

Rt - reticular thalamic nucleus

VA - ventral anterior thalamic nucleus

VM - ventromedial anterior thalamic nucleus

VL - ventrolateral thalamic nucleus

VPL - ventral posterolateral thalamic nucleus

VPM - ventral posteromedial thalamic nucleus

CM - central medial thalamic nucleus

IMD - intermediadorsal thalamic nucleus

$\mathrm{AV}$ th - anterior ventral thalamic nucleus

MD - mediodorsal thalamic nucleus

$\mathrm{AD}$ - anterior dorsal thalamic nucleus

PT - paratenial thalamic nucleus

PC - paracentral thalamic nucleus

LDDM - laterodorsal thalamic nucleus, dorsomedial part LDDL - laterodorsal thalamic nucleus, dorsolateral part

LPMR - lateral posterior thalamic nucleus, mediorostral part

LPLR - lateral posterior thalamic nucleus, laterorostral part

DLG - dorsal lateral geniculate nucleus

Po - posterior thalamic nuclear group

PV - paraventricular thalamic nucleus

PVA - paraventricular thalamic nucleus, anterior part

PVP - paraventricular thalamic nucleus, posterior part

$\mathrm{Rh}$ - rhomboid thalamic nucleus

$\mathrm{Re}-$ reunions thalamic nucleus

Hypothalamus

LH-lateral hypothalamic area

AHC - anterior hypothalamic area, central part

AHP - anterior hypothalamic area, posterior part

VMH - ventromedial hypothalamic nucleus

DMD - dorsomedial hypothalamic nucleus, dorsal part

$\mathrm{Pe}$ - periventricular hypothalamic nucleus

$\mathrm{Pa}$-peraventricular hypothalamic nucleus

Arc - arcuate hypothalamic nucleus 


\section{Acknowledgement}

This research was supported by a grant from the FP6 Marie Curie Fellowship (MESTCT-2005-020589).

\section{References}

Allman JM, Hakeem A, Erwin JM, Nimchinsky E, Hof P (2001): The anterior cingulate cortex. The evolution of an interface between emotion and cognition. Ann N Y Acad Sci 935:107-117.

American-Psychiatric-Association (1994): Diagnostic and Statistical Manual of Mental Disorders. 4th Edition. Washington, DC: American Psychiatric Association.

Bandler R, Shipley MT (1994): Columnar organization in the midbrain periaqueductal gray: modules for emotional expression? Trends Neurosci 17:379-389.

Bittencourt AS, Nakamura-Palacios EM, Mauad H, Tufik S, Schenberg LC (2005): Organization of electrically and chemically evoked defensive behaviours within the deeper collicular layers as compared to the periaqueductal gray matter of the rat. Neuroscience 133:873-892.

Borelli KG, Ferreira-Netto C, Coimbra NC, Brăndao ML (2005): Fos-like immunoreactivity in the brain associated with freezing or escape induced by inhibition of either glutamic acid decarboxylase or GABAA receptors in the dorsal periaqueductal gray. Brain Res 1051:100-111.

Canteras NS (2002): The medial hypothalamic defensive system: hodological organization and functional implications. Pharmacol Biochem Behav 71:481-491.

Canteras NS, Chiavegatto S, Valle LE, Swanson LW (1997): Severe reduction of rat defensive behaviour to a predator by discrete hypothalamic chemical lesions. Brain Res Bull 44:297-305.

Canteras NS, Ribeiro-Barbosa ER, Comoli E (2001): Tracing from the dorsal premammillary nucleus prosencephalic systems involved in the organization of innate fear responses. Neurosci Biobehav Rev 25:661-668.

Cassano GB, Savino M (1993): Symptomatology of panic disorder: an attempt to define the panicagoraphobic spectrum phenomenology. In: SA Montgomery, Editor, The psychopharmacology of panic, Oxford University Press, New York:38-57.

Coimbra NC, De Oliveira R, Freitas RL, Ribeiro SJ, Borelli KG, Pacagnella RC, et al (2006): Neuroanatomical approaches of the tectum-reticular pathways and immunohistochemical evidence for serotonin-positive perikarya on neuronal substrates of the superior colliculus and periaqueductal gray matter involved in the elaboration of the defensive behaviour and fearinduced analgesia. Exp Neurol 197:93-112.

Corcoran KA, Quirk GJ (2007): Activity in prelimbic cortex is necessary for the expression of learned, but not innate, fears. $J$ Neurosci 27:840-844.

de Bortoli VC, Nogueira RL, Zangrossi H, Jr. (2006): Effects of fluoxetine and buspirone on the panicolytic-like response induced by the activation of 5-HT1A and 5-HT2A receptors in the rat dorsal periaqueductal gray. Psychopharmacology (Berl) 183:422-428.

De Oca BM, DeCola JP, Maren S, Fanselow MS (1998): Distinct regions of the periaqueductal gray are involved in the acquisition and expression of defensive responses. $J$ Neurosci 18:3426-3432.

Deakin JFW, Graeff FG (1991): 5-HT and mechanisms of defence. J Psychopharmacol:305-315.

DeFelipe J, Farinas I (1992): The pyramidal neuron of the cerebral cortex: morphological and chemical characteristics of the synaptic inputs. Prog Neurobiol 39:563-607.

Desbonnet L, Temel Y, Visser-Vandewalle V, Blokland A, Hornikx V, Steinbusch HW (2004): Premature responding following bilateral stimulation of the rat subthalamic nucleus is amplitude and frequency dependent. Brain Res 1008:198-204.

Dielenberg RA, Carrive P, McGregor IS (2001a): The cardiovascular and behavioural response to cat odor in rats: unconditioned and conditioned effects. Brain Res 897:228-237. 
Dielenberg RA, Hunt GE, McGregor IS (2001b): "When a rat smells a cat": the distribution of Fos immunoreactivity in rat brain following exposure to a predatory odor. Neuroscience 104:10851097.

Dielenberg RA, McGregor IS (2001): Defensive behaviour in rats towards predatory odors: a review. Neurosci Biobehav Rev 25:597-609.

Floyd NS, Price JL, Ferry AT, Keay KA, Bandler R (2000): Orbitomedial prefrontal cortical projections to distinct longitudinal columns of the periaqueductal gray in the rat. J Comp Neurol 422:556-578.

Floyd NS, Price JL, Ferry AT, Keay KA, Bandler R (2001): Orbitomedial prefrontal cortical projections to hypothalamus in the rat. J Comp Neurol 432:307-328.

Gabbott PL (2003): Radial organisation of neurons and dendrites in human cortical areas 25, 32, and 32'. Brain Res 992:298-304.

Gabbott PL, Warner TA, Jays PR, Bacon SJ (2003): Areal and synaptic interconnectivity of prelimbic (area 32), infralimbic (area 25) and insular cortices in the rat. Brain Res 993:59-71.

Gabbott PL, Warner TA, Jays PR, Salway P, Busby SJ (2005): Prefrontal cortex in the rat: projections to subcortical autonomic, motor, and limbic centers. J Comp Neurol 492:145-177.

Gray TS, Magnuson DJ (1992): Peptide immunoreactive neurons in the amygdala and the bed nucleus of the stria terminalis project to the midbrain central gray in the rat. Peptides 13:451-460.

Hogg S, Michan L, Jessa M (2006): Prediction of anti-panic properties of escitalopram in the dorsal periaqueductal grey model of panic anxiety. Neuropharmacology 51:141-145.

Hunsperger RW (1956): [Affective reaction from electric stimulation of brain stem in cats.]. Helv Physiol Pharmacol Acta 14:70-92.

Jasmin L, Burkey AR, Granato A, Ohara PT (2004): Rostral agranular insular cortex and pain areas of the central nervous system: a tract-tracing study in the rat. J Comp Neurol 468:425-440.

Keay KA, Bandler R (2001): Parallel circuits mediating distinct emotional coping reactions to different types of stress. Neurosci Biobehav Rev 25:669-678.

LeDoux JE (1994 ): The amygdala: Contributions to fear and stress. Seminal Neuroscience 6:231-237.

LeDoux JE, Iwata J, Cicchetti P, Reis DJ (1988): Different projections of the central amygdaloid nucleus mediate autonomic and behavioural correlates of conditioned fear. J Neurosci 8:2517-2529.

Lim LW, Blokland A, Visser-Vandewalle V, Vlamings R, Sesia T, Steinbusch H, et al (2008a): Highfrequency stimulation of the dorsolateral periaqueductal gray and ventromedial hypothalamus fails to inhibit panic-like behaviour. Behav Brain Res 193:197-203.

Lim LW, Temel Y, Visser-Vandewalle V, Steinbusch H, Schruers K, Hameleers R, et al (2008b): Effect of buspirone on the behavioural regulation of rats in low versus high anxiety conditions. Arzneimittelforschung 58:269-276.

Maren S, Quirk GJ (2004): Neuronal signalling of fear memory. Nat Rev Neurosci 5:844-852.

McGregor IS, Hargreaves GA, Apfelbach R, Hunt GE (2004): Neural correlates of cat odor-induced anxiety in rats: region-specific effects of the benzodiazepine midazolam. $J$ Neurosci 24:41344144.

McNaughton N, Corr PJ (2004): A two-dimensional neuropsychology of defense: fear/anxiety and defensive distance. Neurosci Biobehav Rev 28:285-305.

Mobbs D, Petrovic P, Marchant JL, Hassabis D, Weiskopf N, Seymour B, et al (2007): When fear is near: threat imminence elicits prefrontal-periaqueductal gray shifts in humans. Science 317:1079-1083.

Nashold BS, Jr., Wilson WP, Slaughter DG (1969): Sensations evoked by stimulation in the midbrain of man. J Neurosurg 30:14-24.

Nguyen HP, Kobbe P, Rahne H, Worpel T, Jager B, Stephan M, et al (2006): Behavioural abnormalities precede neuropathological markers in rats transgenic for Huntington's disease. Hum Mol Genet 15:3177-3194.

Paxinos G, Watson C (1998): The Rat Brain in Stereotaxic Coordinates. Academic Press, New York.

Petrovich GD, Canteras NS, Swanson LW (2001): Combinatorial amygdalar inputs to hippocampal domains and hypothalamic behaviour systems. Brain Res Brain Res Rev 38:247-289.

Radley JJ, Arias CM, Sawchenko PE (2006): Regional differentiation of the medial prefrontal cortex in regulating adaptive responses to acute emotional stress. J Neurosci 26:12967-12976.

Reep RL, Winans SS (1982): Efferent connections of dorsal and ventral agranular insular cortex in the hamster, Mesocricetus auratus. Neuroscience 7:2609-2635. 
Rich EL, Shapiro ML (2007): Prelimbic/infralimbic inactivation impairs memory for multiple task switches, but not flexible selection of familiar tasks. $J$ Neurosci 27:4747-4755.

Ruggiero DA, Mraovitch S, Granata AR, Anwar M, Reis DJ (1987): A role of insular cortex in cardiovascular function. J Comp Neurol 257:189-207.

Saper CB (1982): Convergence of autonomic and limbic connections in the insular cortex of the rat. $J$ Comp Neurol 210:163-173.

Schenberg LC, Vargas LC, Medeiros RL, Marques TA, Silva SR, Fraipont PT, S. (1998): Evaluation of the rat defense reaction as a model of panic attack in man: pharmacological and neuroendocrine evidence. . Int J Psychophys 127-128.

Temel Y, Boothman LJ, Blokland A, Magill PJ, Steinbusch HW, Visser-Vandewalle V, et al (2007): Inhibition of 5-HT neuron activity and induction of depressive-like behaviour by high-frequency stimulation of the subthalamic nucleus. Proc Natl Acad Sci U S A 104:17087-17092.

UFAW (1999): Handbook on the care and management of laboratory animals. (7th Ed.). London Blackwell Science Ltd.

Van Zutphen LFM, Baumans V, Beynen AC (2006): Principles of laboratory animal science (Revised Edition). Elsevier:21-32.

Vianna DM, Borelli KG, Ferreira-Netto C, Macedo CE, Brăndao ML (2003): Fos-like immunoreactive neurons following electrical stimulation of the dorsal periaqueductal gray at freezing and escape thresholds. Brain Res Bull 62:179-189.

Vianna DM, Brăndao ML (2003): Anatomical connections of the periaqueductal gray: specific neural substrates for different kinds of fear. Braz J Med Biol Res 36:557-566.

Yasui Y, Itoh K, Kaneko T, Shigemoto R, Mizuno N (1991): Topographical projections from the cerebral cortex to the nucleus of the solitary tract in the cat. Exp Brain Res 85:75-84.

Zhao Z, Davis M (2004): Fear-potentiated startle in rats is mediated by neurons in the deep layers of the superior colliculus/deep mesencephalic nucleus of the rostral midbrain through the glutamate nonNMDA receptors. $J$ Neurosci 24:10326-10334. 


\title{
CHEIAP)T[E]R 4H
}

\section{Effect of Buspirone on the behavioural regulation of Wistar rats in low versus high anxiety conditions}

\author{
Lee Wei Lim, Yasin Temel, Veerle Visser-Vandewalle, Harry Steinbusch, \\ Koen Schruers, Rob Hameleers, Gabriel Esquivel, Eric Griez, and Arjan Blokland
}

\begin{abstract}
Buspirone is reported to have anxiolytic effects in humans and is mostly described for mild anxiety. To further explore the effects of buspirone on different levels of anxiety, the effect of buspirone was evaluated in two different conditions of the open-field which were distinguished as low and high anxiety (enclosed and exposed open-field, respectively). Twenty-eight albino Wistar rats $(350-400 \mathrm{~g})$ were tested in two different arena settings, an enclosed and an exposed open-field. Fourteen animals were initially injected with $1 \mathrm{ml}$ saline while the others $\mathrm{n}=14$ received buspirone $3 \mathrm{mg} / \mathrm{kg}$. Our data showed clear differences in the two open field settings suggesting a higher anxiety level in the exposed open field. In addition, correlation analysis showed that both anxiety test measure different aspects of anxiety. Buspirone treatment reduced the behavioural activity in both the enclosed and exposed open-field which is generally interpreted as an anxiogenic effect. However, buspirone increased the time in the center areas and decreased the frequencies in the outer regions. These behavioural changes are generally seen as an anxiolytic effect. Correlation analysis showed that buspirone treatment disrupted the relation between indices of anxiety. These results showed that in an open field setting buspirone appears to have a dual effect. The reduced activity and increase in time spent in the center areas are indicative of both an anxiogenic and an anxiolytic effect, respectively. This was found in both open field settings, suggesting that the effects of buspirone are independent of the anxiety level.
\end{abstract}

Arzneimittel-Forschung (Drug Research) 2008;58(6):269-276 


\section{Introduction}

Buspirone (CAS number: 33386-08-2), a classic 5-HT-1A receptor partial agonist has been reported to have therapeutic role in clinical anxiety and possibly in mood disorders. Its mechanism of action is complex involving both the pre- and postsynaptic receptor sites. De Vry and Schreiber hypothesized that the anxiolytic effects of 5- $\mathrm{HT}_{1 \mathrm{~A}}$ partial agonists result predominantly from an interaction with presynaptic $5-\mathrm{HT}_{1 \mathrm{~A}}$ receptors, resulting in a decrease of hyperactive serotonergic neurotransmission (De Vry et al 2004).

In human studies, buspirone has been well established in the clinical practice, typically for generalized anxiety disorder while it is considered relatively ineffective for other anxiety conditions (Ninan 2004a). However, there are findings where this agent appeared to be less effective than benzodiazepines (Goldberg and Finnerty 1982; Lader and Scotto 1998). As the first alternative to the benzodiazepines, its efficacy level was reported to be effective only in mild anxiety with a slow onset of action (Sramek et al 2002). Several authors consider buspirone to be inferior and not as acceptable as benzodiazepines (Chessick et al 2006). It was also pointed out by some authors that patients who were treated with benzodiazepines were not satisfied when switching to buspirone (Goa and Ward 1986). Furthermore, several studies have shown conflicting results and whether buspirone is useful as first line treatment in general anxiety disorders still needs to be answered. In consideration of these clinical data, indicating that there is a degree of uncertainty regarding the efficacy of buspirone; one could conclude that buspirone is only effective in mild anxiety but not in more severe cases of anxiety.

Over the past decades, several animal models have been developed to investigate the neurobiological mechanisms underlying anxiety. The most widely used behavioural models for experimental anxiety include the open field tests (Blokland et al 2002; Klebaur and Bardo 1999), the elevated plus maze (Cruz et al 1994; Hogg 1996) and the zero maze test (Hranilovic et al 2005). Recently many other modifications of these models have been designed and proven to be bidirectional sensitive to stressful manipulation based on the animal emotional reactivity (Jacobson et al 2007; Kalueff and Tuohimaa 2004; Ring et al 2006).

In the open field procedure, the animal is usually placed in the center or the periphery of the apparatus. In such situation, rodents spontaneously prefer the periphery of the apparatus to the central parts of the open field. When the mice and rats explore or walk close to the walls, the behavioural is called thigmotaxis. The increased exploratory activity and/or increased exploration of the center of the open field versus the periphery are considered strong indices of decreased anxiety levels (Prut and Belzung 2003; Romeo et al 2003; Song et al 2003). The anxiogenic behaviour in the open field is triggered by two factors: individual testing (the animal is separated from its social group) and anxiogenic environment (as the arena is very large relative to the animal's breeding or 
natural environment). The influence of the latter two factors on the animals' behaviour is especially important in those species that show fear of open spaces or new environment. This is particularly for the case of rodents as they usually live in social groups and in small tunnels (Kessler et al 1998).

The exploratory behavioural of rats when they are placed in the open field arena has been generally considered as the classical paradigm to assess emotionality, timidity and also to measure the anxiety state of rats (Dember 1956; Hall 1934). This concept is widely accepted based on the rats' unfamiliarity with the new environment in which they displayed hyperactivity and typical thigmotaxic behavioural in the open field by moving more along the walls or corners of the arena (Schwarting et al 1993). The measurement of the animal's movement in different areas of an open field is essential to determine the exploratory behavioural especially during anxiolytic pharmacological challenge in this animal model (Arakawa 2006; Koob et al 2006).

However, studies showed that high and low levels of locomotor activity in the rat were well correlated with high and low responsivity, respectively, to the behavioural effect of psychotherapeutic drugs (Prut and Belzung 2003). Extensive pharmacological validation has revealed that open field behavioural is sensitive to the classical anxiolyticlike activity of benzodiazepines. Similarly, $5-\mathrm{HT}_{1 \mathrm{~A}}$ receptor agonists such as buspirone are active in the open field test (Hooks et al 1994).

Graeff suggested that the existing animal models do not satisfactorily discriminate between specific types of anxiety disorders according to current classification systems such as the DSM-IV e.g. generalized anxiety disorder, panic disorder, phobia and etc. (Graeff et al 1998). However, recent studies showed that different variants of existing laboratory models may mimic different degrees of anxiety, for instance low and high anxiety (Ennaceur et al 2006; Mallo et al 2007).

The purpose of our present investigation is to study the effect of buspirone versus saline injection on the animals' behaviour in two different conditions of the open field test. The two anxiogenic conditions used in this study are: (i) An enclosed open-field with dim light condition, assumed to represent a low anxiety (LA) paradigm (Blanchard et al 2001b; Treit and Fundytus 1988) and (ii) An exposed open-field with elevated platform which has no wall surrounding the arena 'without visible boundaries' (Ennaceur et al 2006) and being illuminated by fluorescent light, assumed to represent a high or severe anxiety (HA) condition. We hypothesized that buspirone would display anxiolytic activity in both the LA and HA conditions, in terms of a general increase in locomotor activity (total distance moved) and an increase in the duration spent in the unsafe areas of the open field settings. 


\section{Material and Methods}

\section{Subjects}

This study was approved by the Experimental Animal Commission of Maastricht University, the Netherlands. Twenty-eight male albino Wistar rats (Harlan, Horst, The Netherlands) with the weight $350-400 \mathrm{~g}$ were used in this study. The animals were housed individually in standard transparent polypropylene cages under controlled 12-h dark-light cycle with room temperature $20-22{ }^{\circ} \mathrm{C}$ and humidity $60-70 \%$. During the stay in their respective housing condition, food and water was given in free access and they were transferred to new cages once a week for cleaning purposes and renewing their food and water supply. All the animals were handled daily in order to habituate them to being picked up in order to reduce handling stress during behavioural testing.

\section{Apparatus}

The apparatus consisted of an enclosed open field, clear Plexiglas box with an open top and a dark floor (Fig. 1a). The apparatus was placed in a dimly lit room. The exposed open-field arena was covered by a wooden platform, which was placed on the top part of the enclosed open-field arena with an altitude $40 \mathrm{~cm}$ above the ground without any surrounding walls (Fig. 1b). The apparatus was placed in a brightly lit room. All testing (enclosed and exposed open field) was conducted in the same room and the apparatus was cleaned after each experimental procedure. The movements of each rat were recorded automatically using a camera and Ethovision tracking software (Ethovision $®$, Noldus Information Technology in Wageningen, the Netherlands). 

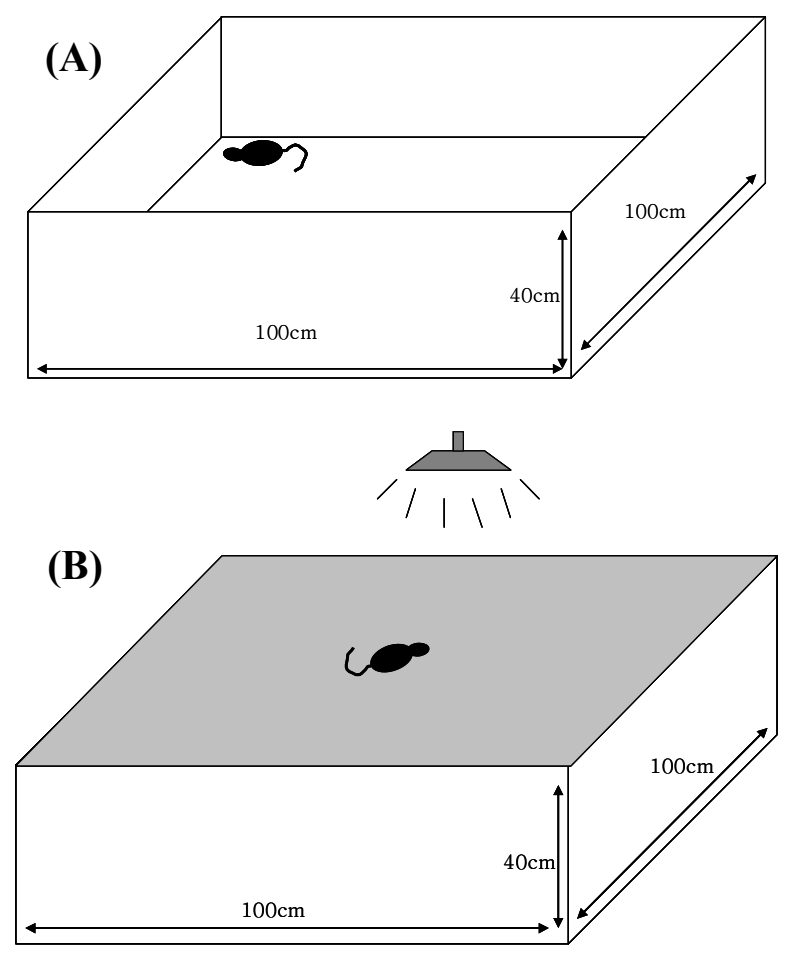

Figure 1: Schematic drawings (and dimensions in $\mathrm{cm}$ ) of the open field settings. A) Enclosed open-field and B) Exposed open field. The enclosed open field was located in a dimly lit room whereas the exposed open-field was located in a brightly lit room.

\section{Procedures}

An overview of the experiment is shown in Table 1. The animals were divided into four groups (each $n=7$ ). Two groups were treated with saline and the other two groups were treated with buspirone. Each group of animals (both the saline and buspirone group) was divided again into 2 sub-groups ( $n=7$, enclosed open field and $n=7$, exposed-elevated open field).

\begin{tabular}{|c|c|c|c|c|}
\hline Drug & $($ Each, $n=7)$ & Exposed open-field & \multirow{6}{*}{$\begin{array}{c}\text { One } \\
\text { week's } \\
\text { period } \\
\text { of rest }\end{array}$} & Enclosed open-field \\
\hline Saline & Group 1 & 2 sessions & & 2 sessions \\
\hline \multirow[t]{2}{*}{ Buspirone } & Group 1 & 2 sessions & & 2 sessions \\
\hline & & Enclosed open-field & & Exposed open-field \\
\hline Saline & Group 2 & 2 sessions & & 2 sessions \\
\hline Buspirone & Group 2 & 2 sessions & & 2 sessions \\
\hline
\end{tabular}

Table 1: Design of the experiment. 
Behavioural testing started after the rats were placed in the middle of the arena. A trial was stopped after $5 \mathrm{~min}$ and the rat was removed from the arena and put back in its home cage. This procedure was repeated and performed randomly on two successive days and two researchers were blind with respect to the conditions of testing. After one week of rest the animals were tested again, although in the other open field setting.

\section{Drug administration}

Saline and buspirone hydrochloride (TOCRIS Cookson Inc., Missouri, USA) was dissolved in saline solution and injected intraperitoneally $30 \mathrm{~min}$ before testing in a volume of $1 \mathrm{ml} / \mathrm{kg}$. We chose a dose of $3 \mathrm{mg} / \mathrm{kg}$ because this has previously been reported to affect anxiety-related behaviourals and no sedative effects (Grundmann et al 2006; Hashimoto et al 1992; Mendelson et al 1990), and may interfere with the parameters of the tests used in this study. A week before the actual experimental testing, all animals received 3 times of $1 \mathrm{ml}$ saline injection on alternate days to habituate to the injection procedure.

\section{Statistical analysis}

The enclosed and exposed open field arena was subdivided into 9 areas (see Fig. 2) and three different zones were defined (Blokland et al 2002): (i) corner zones (four squares each $25 \mathrm{~cm} \times 25 \mathrm{~cm}$ ), (ii) wall zones (four rectangles each $25 \mathrm{~cm} \times 50 \mathrm{~cm}$ ) and the (iii) center zone (one square $50 \mathrm{~cm} \times 50 \mathrm{~cm}$ ). The following measures were used for statistical analysis: (i) distance moved (for arena and different zones), (ii) time spent in each zone and (iii) frequency entry in the outer (combination of wall and corner zones) and inner (center zone) areas. The average of two days was calculated for statistical analysis. 


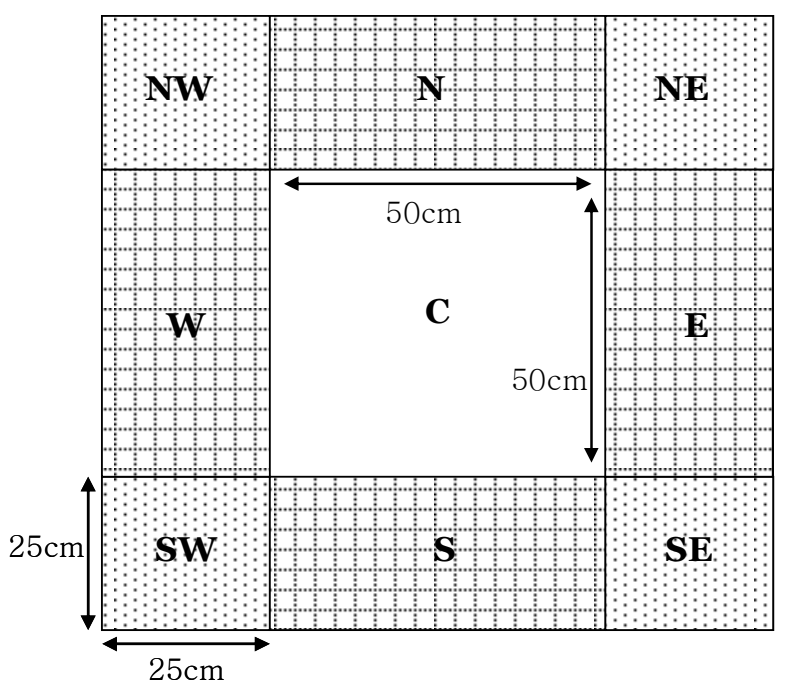

Figure 2: The surface of both open-fields was virtually divided into 9 zones. These were defined as: corner zones (consisting of the four corner zones), wall zones (consisting of the four wall zones), and the center zone.

The data were analyzed in a three-way Analysis of Variance (ANOVA) using Open-Field Type and Order (order of testing) as within subject factors and Treatment as a between-subjects factor. An LSD post hoc test was used to analyze group differences in more detail. To examine the relation between variables within a test and between different tests, Pearson correlation coefficients were calculated. All p-values $<0.05$ were considered significant. All data are presented as mean \pm S.E.M. 


\section{Results}

\section{Enclosed versus exposed open field}

Firstly, the order of testing did not appear to affect the behavioural in both tests (distance moved: $\mathrm{F}(1,13)=0.01$, ns; Time spent in different locations: all $\mathrm{F}$ ' $<<0.34$, ns). Consequently, we did not incorporate this factor in further analyses. To evaluate the differences of behaviour in the enclosed (LA) versus the exposed (HA) open field and the data of the saline treated animals were separately analyzed. This analysis revealed that the rats covered more distance in the enclosed open field or LA test as compared with the exposed open field or HA test $(F(1,13)=86.02, p<0.001$; see Fig. 3). The difference in distance moved was related to a decrease in the wall and corner areas ( $F$ 's $>47.80$, $\mathrm{p}<0.001$; see Fig. 4) whereas the distance traveled in the centre areas was for both types of open field was not affected $(\mathrm{F}(1,13)=0.37$, ns.). With respect to the time spent in the different areas of the open field, it was found that the rats spent less time in the corner of the HA tests as opposed to the LA $(\mathrm{F}(1,13)=17.84, \mathrm{p}<0.001)$ test. Whereas, in the HA tests, the rats spent more time in the wall and center areas as compared with the LA test $(F(1,13)=15.49, p<0.01$ and $F(1,13)=83.34, p<0.001$, respectively.

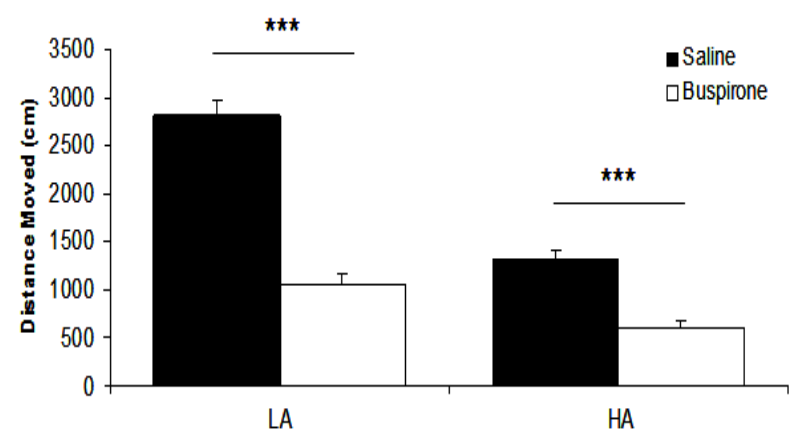

Figure 3: The effects of buspirone on the measure distance moved (fig. 3A) in both test conditions (LA and HA). Data represent mean (+SEM). 


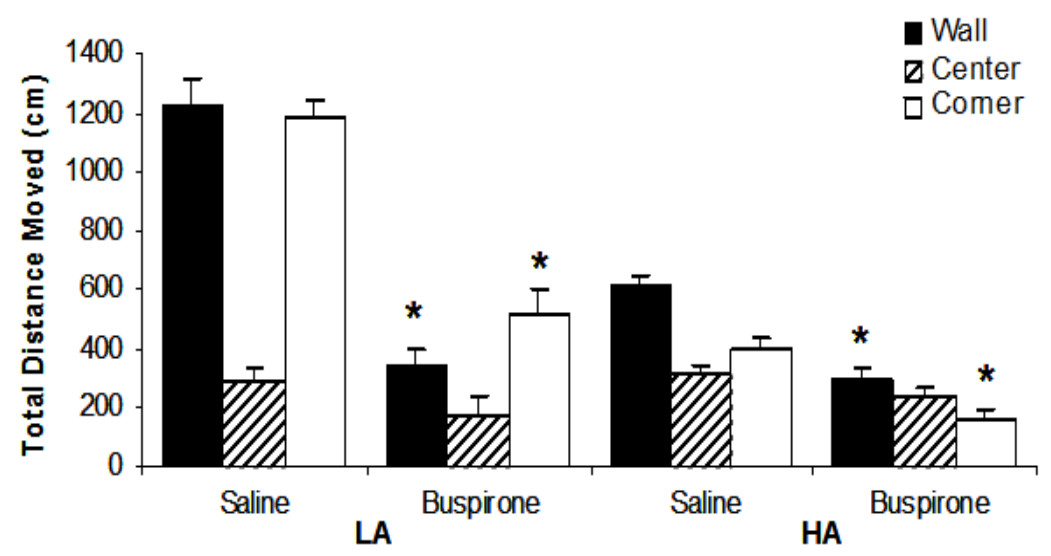

Figure 4: The effects of buspirone on the measure distance moved $(\mathrm{cm})$ in the different areas of the open-field in both test conditions (LA and HA). Data represent mean (+SEM). * Different from saline

\section{Effects of buspirone}

Since all main effects of order of testing did not reveal statistically significant effects (all $\mathrm{F}$ ' $\mathrm{s}<2.12$, ns.) this factor was excluded in further analyses. Buspirone treatment clearly reduced the activity of the animals both in the LA and the HA tests $(F(1,26)=96.93, p<0.001$; see Fig. 3$)$. The drug effects were greater in the LA when compared with the HA $(\mathrm{F}(1,26)=24.58, \mathrm{p}<0.001)$. This decrease in activity was related with a decrease in the wall and corner areas $(F(1,26)=85.73, p<0.001$ and $F(1,26)=66.63$, $\mathrm{p}<0.001$, respectively) whereas only a marginal drug effect was found for the activity in the centre zone $(\mathrm{F}(1,26)=3.58, \mathrm{p}<0.07$, ns.). The effects of buspirone on locomotor activity were greater in the LA than in the HA for the wall and corner $(F(1,26)=25.08$, $p<0.001$ and $F(1,26)=14.38, p<0.001$, respectively). On the other hand, the drug effect in the LA and the HA tests were comparable for the measure of distance moved in center areas $(F(1,26)=0.09$, ns. $)$.

A more complex picture emerged when analyzing the effects of buspirone treatment on the time spent of the rats in the different zones in both tests (see Fig. 5). The time spent of the rats in the wall zone was decreased in both tests $(F(1,26)=5.40, p<0.05)$. Although no Type by Drug interaction was found $(\mathrm{F}(1,26)=1.48$, ns.), post hoc analysis revealed that buspirone clearly reduced the time spent in the wall zone of the LA $(\mathrm{p}<0.001)$ test but not in the HA test. Besides, buspirone also significantly decreased the time spent in the corner squares of the HA test but not in the LA test (Type of task $x$ Treatment effect: $\mathrm{F}(1,26)=4.95, \mathrm{p}<0.05)$. This was confirmed by a post-hoc analysis showing that buspirone treatment had no effect in the corner squares of the LA test but only effective in the HA test. However, there was a main effect of treatment for the time spent in the centre squares $(F(1,26)=5.62, p<0.05)$, indicating that the time in the centre 
squares increased after buspirone treatment. Post hoc analysis showed that this increase was only significantly found in the HA test $(\mathrm{p}<0.02)$.

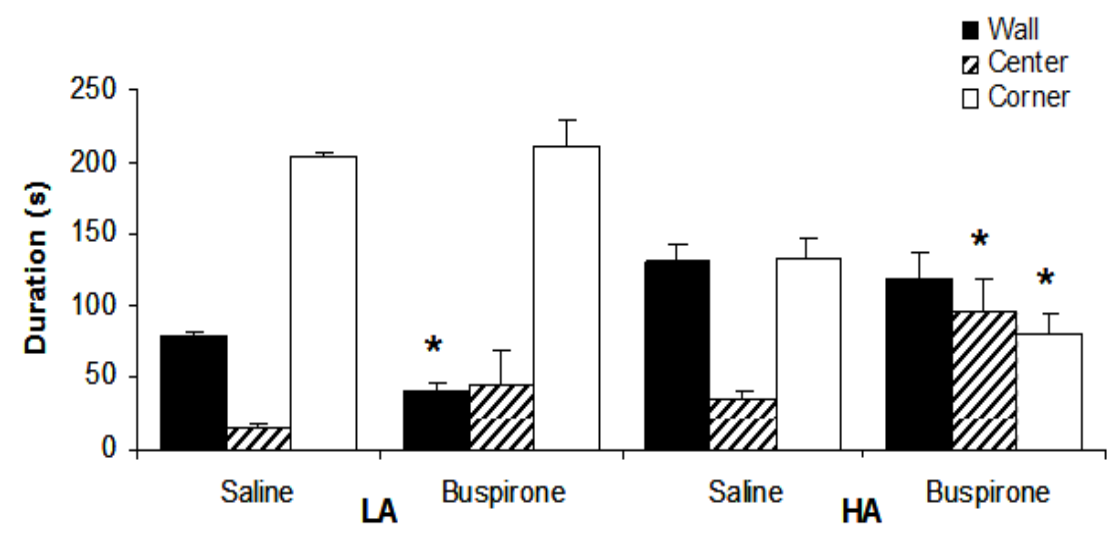

Figure 5: The effects of buspirone on the time spent (s) in the different areas of the open field in both test conditions (LA and HA). Data represent mean (+SEM). * Different from saline

\section{Measures of frequency entry}

Repeated measures ANOVA revealed significant differences within $(\mathrm{F}(1,26)=41.125, \mathrm{p}<0.0001)$ and between $(\mathrm{F}(1,26)=312.76, \mathrm{p}<0.0001)$ subjects tests, and interaction between Group, Test and Treatment $(F(1,26)=6.85, p<0.05$; see Fig. 6a and $6 \mathrm{~b})$. The effect of buspirone treatment significantly decreased the percentage of frequency entry at the outer areas in both the LA and HA tests, whereas the frequency entry of the inner areas was found insignificantly decreased. In the LA tests, a remarkable frequency entry was observed at the outer area than the inner area in both the saline and buspirone treated animals (see Fig. 6). Nevertheless, the HA tests also showed a similar effect of decreased frequency entry in both the outer and inner areas. The effect of buspirone treatment in the HA test showed more or less the same level of frequency entry in both the outer and inner areas as compared with saline which having only a slight decreased of frequency entry at the inner area than the outer area. Post hoc tests revealed significantly decrease of the frequency entry (2-tailed) at the outer areas after buspirone treatment in both the LA and HA tests $(\mathrm{P}<0.05)$. Besides, statistical analysis also showed a significant decrease of the frequency entry at the outer area of HA testing condition when compared with LA testing condition $(\mathrm{P}<0.05)$. 


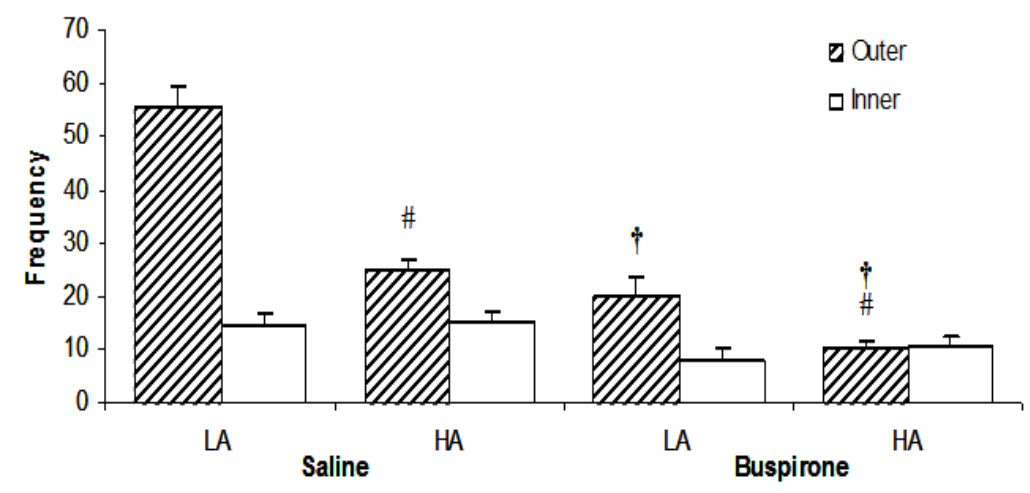

Figure 6: The effects of buspirone on the frequency entry into the outer and inner areas of the openfield (LA and HA tests). Data represent mean (+SEM). ${ }^{*}$ Different from outer area in the LA condition and ${ }^{\dagger}$ Different from outer area in the LA \& HA conditions of saline treatment.

\section{Correlations}

Correlations within and between tests between the different variables are shown in Table 2. When all animals were included in the analysis a mixed picture of correlations was found. Within test analysis showed that the time in centre areas was negatively correlated with the time in the wall and corner areas. The activity of the animals was correlated with the time spent in the different zones and was opposite in the LA and the HA test. Thus, distance moved in the LA was positively correlated with the time in the wall zone whereas the distance moved in the HA was positively correlated with the time in the corners and negatively correlated with the time in the centre zone. When analyzing the correlations between the same parameters in different tests revealed that the distance moved in both tests correlated positively. Time in the centre area was also correlated positively. No correlation was found for the time spent in the corner and wall zones.

The correlation matrix differed significantly when only analyzing the saline and buspirone treated animals (see Table $2 \mathrm{~B} / \mathrm{C}$ ). In the saline group a good correlation between the different measures was found in the LA test. In the HA test only the time in the corner correlated negatively in the time in the wall and centre zones. Remarkably, no correlations were observed between the (similar) measures in the different tasks. In the analysis for the buspirone group in the LA test only negative correlations were found between time in the centre and the time in the corner and wall areas. There were more correlations found in the HA test where the activity of the rats was positively correlated with the time in the wall areas and negatively correlated with the time in the centre zone. There were occasional correlations between the measures of the different tests. No correlations between the same measures were observed. 
A) All animals (saline and buspirone treated; $n=28$ )

\begin{tabular}{|l|c|c|c|c|c|c|c|c|}
\hline & \multicolumn{5}{|c|}{ LA open field test } & \multicolumn{4}{c|}{ HA open field test } \\
\hline & DM $_{\mathrm{LA}}$ & TICO $_{\mathrm{LA}}$ & TIWA & TICE $_{\mathrm{LA}}$ & DM $_{\mathrm{HA}}$ & TICO $_{\mathrm{HA}}$ & TIWA $_{\mathrm{HA}}$ & TICE $_{\mathrm{HA}}$ \\
\hline TICO $_{\mathrm{LA}}$ & -0.16 & -- & -- & -- & -- & -- & -- & -- \\
\hline TIWA $_{\mathrm{LA}}$ & $\mathbf{0 . 8 1}$ & 0.03 & -- & -- & -- & -- & -- & -- \\
\hline TICE $_{\mathrm{LA}}$ & -0.22 & $-\mathbf{0 . 9 0}$ & $-\mathbf{0 . 4 6}$ & -- & -- & -- & -- & -- \\
\hline $\mathrm{DM}_{\mathrm{HA}}$ & $\mathbf{0 . 7 5}$ & 0.14 & $\mathbf{0 . 6 1}$ & -0.38 & -- & -- & -- & -- \\
\hline TICO $_{\mathrm{HA}}$ & $\mathbf{0 . 4 8}$ & -0.02 & $\mathbf{0 . 4 6}$ & -0.20 & $\mathbf{0 . 5 3}$ & -- & -- & -- \\
\hline TIWA $_{\mathrm{HA}}$ & -0.06 & $\mathbf{0 . 6 2}$ & -0.06 & $\mathbf{- 0 . 5 2}$ & 0.16 & -0.25 & -- & -- \\
\hline TICE $_{\mathrm{HA}}$ & -0.36 & $\mathbf{0 . 4 2}$ & -0.32 & $\mathbf{0 . 5 1}$ & $-\mathbf{0 . 5 7}$ & $-\mathbf{0 . 6 7}$ & $-\mathbf{0 . 5 5}$ & -- \\
\hline
\end{tabular}

$D M$, distance moved; $T I C O$, time in corner; $T I W A$, time in wall; $T I C E$, time incentre; $L A$, low anxiety; HA, high anxiety.

B) Saline-treated animals $(\mathrm{n}=14)$

\begin{tabular}{|c|c|c|c|c|c|c|c|c|}
\hline & \multicolumn{4}{|c|}{ LA open field test } & \multicolumn{4}{|c|}{ HA open field test } \\
\hline & $\mathrm{DM}_{\mathrm{LA}}$ & $\mathrm{TICO}_{\mathrm{LA}}$ & TIWA $_{\text {LA }}$ & $\mathrm{TICE}_{\mathrm{LA}}$ & $\mathrm{DM}_{\mathrm{HA}}$ & $\mathrm{TICO}_{\mathrm{HA}}$ & TIWA $_{\mathrm{HA}}$ & $\mathrm{TICE}_{\mathrm{HA}}$ \\
\hline $\mathrm{TICO}_{\mathrm{LA}}$ & -0.70 & - & - & -- & - & - & - & - \\
\hline TIWA $_{\mathrm{LA}}$ & 0.61 & -0.95 & -- & -- & -- & -- & -- & -- \\
\hline $\mathrm{TICE}_{\mathrm{LA}}$ & 0.53 & -0.76 & 0.58 & - & - & - & - & -- \\
\hline$\overline{\mathrm{DM}_{\mathrm{HA}}}$ & 0.42 & -0.13 & 0.10 & 0.27 & - & -- & $\overline{--}$ & - \\
\hline $\mathrm{TICO}_{\mathrm{HA}}$ & 0.41 & -0.47 & 0.46 & 0.21 & 0.31 & -- & -- & -- \\
\hline TIWA $_{\mathrm{HA}}$ & -0.44 & 0.43 & -0.33 & -0.23 & -0.26 & -0.87 & - & - \\
\hline TICE $_{\mathrm{HA}}$ & -0.09 & 0.24 & -0.38 & -0.05 & -0.17 & -0.54 & 0.05 & -- \\
\hline
\end{tabular}

C) Buspirone-treated animals $(\mathrm{n}=14)$

\begin{tabular}{|c|c|c|c|c|c|c|c|c|}
\hline & \multicolumn{4}{|c|}{ LA open field test } & \multicolumn{4}{|c|}{ HA open field test } \\
\hline & $\mathrm{DM}_{\mathrm{LA}}$ & $\mathrm{TICO}_{\mathrm{LA}}$ & TIWA $_{\mathrm{LA}}$ & $\mathrm{TICE}_{\mathrm{LA}}$ & $\mathrm{DM}_{\mathrm{HA}}$ & $\mathrm{TICO}_{\mathrm{HA}}$ & TIWA $_{\mathrm{HA}}$ & TICE $_{\mathrm{HA}}$ \\
\hline$\overline{\mathrm{TICO}_{\mathrm{LA}}}$ & -0.04 & - & - & - & - & - & - & - \\
\hline TIWA $_{\text {LA }}$ & 0.48 & 0.43 & -- & -- & -- & - & -- & -- \\
\hline $\mathrm{TICE}_{\mathrm{LA}}$ & -0.09 & -0.98 & -0.61 & -- & -- & -- & -- & - \\
\hline $\mathrm{DM}_{\mathrm{HA}}$ & -0.19 & 0.66 & 0.02 & -0.59 & - & - & - & - \\
\hline $\mathrm{TICO}_{\mathrm{HA}}$ & -0.15 & 0.15 & -0.04 & -0.13 & 0.28 & - & - & -- \\
\hline TIWA $_{\mathrm{HA}}$ & -0.17 & 0.71 & -0.10 & -0.60 & 0.57 & -0.02 & -- & - \\
\hline TICE $_{\mathrm{HA}}$ & 0.22 & -0.58 & 0.16 & 0.48 & -0.60 & -0.67 & -0.72 & -- \\
\hline
\end{tabular}

Table 2: Pearson correlation coefficients between the different measures of the open field tests. Non-italic entries indicate correlations within the same test and italic entries indicate correlations between tests. Bold entries are statistical reliable correlations between two measures. 


\section{Discussion}

In this study, we investigated the effects of buspirone on the exploratory behaviour of rats in two different types of open-field settings. Buspirone treatment decreased animals' behavioural activity in both variants of the test, and tended to increase the time spent in the less safe areas. Surprisingly, these findings may suggest both an anxiogenic and anxiolytic effect of buspirone in the two test models.

In our laboratory, the enclosed open field test has frequently been used to measure strain differences and effects of treatment on anxiety. All these studies showed a very robust negative correlation between the time in the corner and the total distance moved (Blokland et al 2002; Prickaerts et al 1996; van der Staay and Blokland 1996; van der Staay et al 1990). Thus, a decrease in the exploratory behavioural is associated with an increase in time spent in the safe areas. This was replicated in the present study only in the enclosed open field (LA condition). In the exposed open field (HA condition), the correlation was not observed, supporting the idea that this test measures a different aspect of anxiety. Previous data have shown that these two variants of the open field test are models of different levels of anxiety (Ennaceur et al 2006). Our data support this notion whereby the exposed open field appears to induce a state of higher anxiety, as indicated by correlation analysis of indices of anxiety and an overall decrease in exploratory activity.

In the open field setting the wall and corner (outer areas) are safer than the inner areas (Crawley 1985; Prut and Belzung 2003). Regarding the time spent of the center area of the open-field, our results showed that rats were more sensitive to the anxiolytic effect of buspirone in the HA condition than the LA condition. In addition, our frequency data also clearly revealed that buspirone significantly decreased the number of entries into the outer areas suggesting an overall anxiolytic effect. The decreased duration spent at the corner area of HA rats and decreased duration spent at the wall area of LA rats support our assumption that buspirone has anxiolytic properties. On the other hand, buspirone treatment also decreased the behavioural activity both in the enclosed and exposed open-field suggesting an anxiogenic effect. Anxiogenic-like effects of buspirone in a plus-maze have been reported previously (Collinson and Dawson 1997; Dawson et al 1995). These results are consistent with our findings of a decreased distance moved in both variants of the open field.

The reduction of locomotor activity in both the enclosed and exposed open fields could be interpreted as a result of a sedative effect. However, in previous reports the dosage of buspirone commonly varied between $0.03 \mathrm{mg} / \mathrm{kg}$ and $60 \mathrm{mg} / \mathrm{kg}$. It is interesting to note that few studies demonstrated lower doses to possess any anxiolytic property. Some found small doses to be merely ineffective (Cervo et al 2000; Vaidya et al 2005; Wada and Fukuda 1991). We used a dose of $3 \mathrm{mg} / \mathrm{kg}$ of buspirone based on different behavioural pharmacological effects in different models (Ettenberg and Bernardi 2006; 
Grundmann et al 2007; Picazo and Fernandez-Guasti 1998; Warnick et al 2006). Also, behavioural and EEG studies have shown that buspirone does not produce sedative effect, motor deficits or memory impairments (Hashimoto et al 1992; Lerman et al 1986; Mattila et al 1982; Mendelson et al 1990; Newton et al 1982). The latter studies provide additional support that the decrease in behavioural activity in the open field settings is not likely to be interpreted in terms of a general sedation.

Clinical observations have suggested that buspirone might be less effective than the benzodiazepines in the management of anxiety. In practice, it is used primarily for relief of mild to moderate generalized anxiety disorder and nervous tension, and is not considered effective for other types of severe anxiety disorders. However, the results observed in our laboratory models strongly suggest that buspirone yielded anxiolytic effects in both the low and high anxiety condition (enclosed and exposed open field, respectively) with increased time spent in the center of the open field and decreased frequency entries in the outer areas. Alternative explanations of the experimental data, such as immobility due to anxiogenic effects, or a possible role of sedative effects, appear unlikely.

\section{Conclusion}

In conclusion, buspirone seems to have anxiolytic activity in two different settings (enclosed and exposed) of the open fields. Buspirone therefore appears to be effective in both moderate and severe anxiety. Contrarily to the impressions of many clinicians, it is suggested that buspirone may not only be useful in reducing mild anxiety but a severe anxiety as well. The present data along with other experimental data leave open the possibility of a dual effect of buspirone on anxiety. Mechanisms responsible for the reduction of locomotor activity and therefore increased time spent in the center areas will require further elucidation. Taken together the findings suggest a complex effect of buspirone in an unconditional anxiety test.

\section{Acknowledgement}

This research was supported by a grant from the FP6 Marie Curie Fellowship (MEST-CT-2005-020589). 


\section{References}

Arakawa H (2006): Changes in the pattern of exploratory behaviour are associated with the emergence of social dominance relationships in male rats. Dev Psychobiol 48:39-47.

Blanchard RJ, Yudko E, Dulloog L, Blanchard DC (2001): Defense changes in stress nonresponsive subordinate males in a visible burrow system. Physiol Behav 72:635-642.

Blokland A, Lieben C, Deutz NE (2002): Anxiogenic and depressive-like effects, but no cognitive deficits, after repeated moderate tryptophan depletion in the rat. J Psychopharmacol 16:39-49.

Cervo L, Munoz C, Bertaglia A, Samanin R (2000): Alnespirone and buspirone have anxiolytic-like effects in a conflict procedure in rats by stimulating 5-HT(1A) receptors. Behav Pharmacol 11:153-160.

Chessick CA, Allen MH, Thase M, Batista Miralha da Cunha AB, Kapczinski FF, de Lima MS, et al (2006): Azapirones for generalized anxiety disorder. Cochrane Database Syst Rev 3:CD006115.

Collinson N, Dawson GR (1997): On the elevated plus-maze the anxiolytic-like effects of the 5-HT(1A) agonist, 8-OH-DPAT, but not the anxiogenic-like effects of the 5-HT(1A) partial agonist, buspirone, are blocked by the 5-HT1A antagonist, WAY 100635. Psychopharmacology (Berl) 132:35-43.

Crawley JN (1985): Exploratory behaviour models of anxiety in mice. Neurosci Biobehav Rev 9:37-44.

Cruz AP, Frei F, Graeff FG (1994): Ethopharmacological analysis of rat behaviour on the elevated plusmaze. Pharmacol Biochem Behav 49:171-176.

Dawson GR, Crawford SP, Collinson N, Iversen SD, Tricklebank MD (1995): Evidence that the anxiolytic-like effects of chlordiazepoxide on the elevated plus maze are confounded by increases in locomotor activity. Psychopharmacology (Berl) 118:316-323.

De Vry J, Schreiber R, Melon C, Dalmus M, Jentzsch KR (2004): 5-HT1A receptors are differentially involved in the anxiolytic- and antidepressant-like effects of 8-OH-DPAT and fluoxetine in the rat. Eur Neuropsychopharmacol 14:487-495.

Dember WN (1956): Response by the rat to environmental change. J Comp Physiol Psychol 49:93-95.

Ennaceur A, Michalikova S, Chazot PL (2006): Models of anxiety: responses of rats to novelty in an open space and an enclosed space. Behav Brain Res 171:26-49.

Ettenberg A, Bernardi RE (2006): Anxiolytic-like actions of buspirone in a runway model of intravenous cocaine self-administration. Pharmacol Biochem Behav 85:393-399.

Goa KL, Ward A (1986): Buspirone. A preliminary review of its pharmacological properties and therapeutic efficacy as an anxiolytic. Drugs 32:114-129.

Goldberg HL, Finnerty R (1982): Comparison of buspirone in two separate studies. J Clin Psychiatry 43:87-91.

Graeff FG, Netto CF, Zangrossi H, Jr. (1998): The elevated T-maze as an experimental model of anxiety. Neurosci Biobehav Rev 23:237-246.

Grundmann O, Kelber O, Butterweck V (2006): Effects of St. John's wort extract and single constituents on stress-induced hyperthermia in mice. Planta Med 72:1366-1371.

Grundmann O, Nakajima J, Seo S, Butterweck V (2007): Anti-anxiety effects of Apocynum venetum L. in the elevated plus maze test. J Ethnopharmacol 110:406-411.

Hall C (1934): Emotional behaviour in the rat. I. Defecation and urination as measures of individual differences in emotionality. . J Comp Psychol 18:385-403.

Hashimoto T, Hamada C, Wada T, Fukuda N (1992): Comparative study on the behavioural and EEG changes induced by diazepam, buspirone and a novel anxioselective anxiolytic, DN-2327, in the cat. Neuropsychobiology 26:89-99.

Hogg S (1996): A review of the validity and variability of the elevated plus-maze as an animal model of anxiety. Pharmacol Biochem Behav 54:21-30.

Hooks MS, Jones GH, Juncos JL, Neill DB, Justice JB (1994): Individual differences in schedule-induced and conditioned behaviours. Behav Brain Res 60:199-209.

Hranilovic D, Cicin-Sain L, Bordukalo-Niksic T, Jernej B (2005): Rats with constitutionally upregulated/downregulated platelet 5HT transporter: differences in anxiety-related behaviour. Behav Brain Res 165:271-277.

112 
Jacobson LH, Bettler B, Kaupmann K, Cryan JF (2007): Behavioural evaluation of mice deficient in $\operatorname{GABA}(\mathrm{B}(1))$ receptor isoforms in tests of unconditioned anxiety. Psychopharmacology (Berl) 190:541-553.

Kalueff AV, Tuohimaa P (2004): Experimental modeling of anxiety and depression. Acta Neurobiol Exp (Wars) 64:439-448.

Kessler RC, Stang PE, Wittchen HU, Ustun TB, Roy-Burne PP, Walters EE (1998): Lifetime panicdepression comorbidity in the National Comorbidity Survey. Arch Gen Psychiatry 55:801-808.

Klebaur JE, Bardo MT (1999): The effects of anxiolytic drugs on novelty-induced place preference. Behav Brain Res 101:51-57.

Koob AO, Cirillo J, Babbs CF (2006): A novel open field activity detector to determine spatial and temporal movement of laboratory animals after injury and disease. $J$ Neurosci Methods 157:330336.

Lader M, Scotto JC (1998): A multicentre double-blind comparison of hydroxyzine, buspirone and placebo in patients with generalized anxiety disorder. Psychopharmacology (Berl) 139:402-406.

Lerman JA, Kaitin KI, Dement WC, Peroutka SJ (1986): The effects of buspirone on sleep in the rat. Neurosci Lett 72:64-68.

Mallo T, Alttoa A, Koiv K, Tonissaar M, Eller M, Harro J (2007): Rats with persistently low or high exploratory activity: behaviour in tests of anxiety and depression, and extracellular levels of dopamine. Behav Brain Res 177:269-281.

Mattila MJ, Aranko K, Seppala T (1982): Acute effects of buspirone and alcohol on psychomotor skills. $J$ Clin Psychiatry 43:56-61.

Mendelson WB, Martin JV, Rapoport DM (1990): Effects of buspirone on sleep and respiration. Am Rev Respir Dis 141:1527-1530.

Newton RE, Casten GP, Alms DR, Benes CO, Marunycz JD (1982): The side effect profile of buspirone in comparison to active controls and placebo. J Clin Psychiatry 43:100-102.

Ninan PM, S (2004): Buspirone and gepirone. In: Schatzberg AF, Nemeroff CB, editors. . Textbook of psychopharmcology 3rd ed Washington, DC: American Psychiatric Publishing:391-404.

Picazo O, Fernandez-Guasti A (1998): Antianxiety effects of diazepam and buspirone in rats under different hormonal status. Proc West Pharmacol Soc 41:205-206.

Prickaerts J, Raaijmakers W, Blokland A (1996): Effects of myocardial infarction and captopril therapy on anxiety-related behaviours in the rat. Physiol Behav 60:43-50.

Prut L, Belzung C (2003): The open field as a paradigm to measure the effects of drugs on anxiety-like behaviours: a review. Eur J Pharmacol 463:3-33.

Ring RH, Malberg JE, Potestio L, Ping J, Boikess S, Luo B, et al (2006): Anxiolytic-like activity of oxytocin in male mice: behavioural and autonomic evidence, therapeutic implications. Psychopharmacology (Berl) 185:218-225.

Romeo RD, Mueller A, Sisti HM, Ogawa S, McEwen BS, Brake WG (2003): Anxiety and fear behaviours in adult male and female C57BL/6 mice are modulated by maternal separation. Horm Behav 43:561-567.

Schwarting RK, Goldenberg R, Steiner H, Fornaguera J, Huston JP (1993): A video image analyzing system for open-field behaviour in the rat focusing on behavioural asymmetries. $J$ Neurosci Methods 49:199-210.

Song C, Li X, Leonard BE, Horrobin DF (2003): Effects of dietary n-3 or n-6 fatty acids on interleukin1beta-induced anxiety, stress, and inflammatory responses in rats. J Lipid Res 44:1984-1991.

Sramek JJ, Zarotsky V, Cutler NR (2002): Generalised anxiety disorder: treatment options. Drugs 62:1635-1648.

Treit D, Fundytus M (1988): Thigmotaxis as a test for anxiolytic activity in rats. Pharmacol Biochem Behav 31:959-962.

Vaidya AH, Rosenthal DI, Lang W, Crooke JJ, Benjamin D, Ilyin SE, et al (2005): Oral buspirone causes a shift in the dose-response curve between the elevated-plus maze and Vogel conflict tests in Long-Evans rats: relation of brain levels of buspirone and 1-PP to anxiolytic action. Methods Find Exp Clin Pharmacol 27:245-255.

van der Staay FJ, Blokland A (1996): Behavioural differences between outbred Wistar, inbred Fischer 344, brown Norway, and hybrid Fischer 344 x brown Norway rats. Physiol Behav 60:97-109. 
van der Staay FJ, Kerbusch S, Raaijmakers W (1990): Genetic correlations in validating emotionality. Behav Genet 20:51-62.

Wada T, Fukuda N (1991): Pharmacologic profile of a new anxiolytic, DN-2327: effect of Ro15-1788 and interaction with diazepam in rodents. Psychopharmacology (Berl) 103:314-322.

Warnick JE, Wicks RT, Sufka KJ (2006): Modeling anxiety-like states: pharmacological characterization of the chick separation stress paradigm. Behav Pharmacol 17:581-587. 


\title{
$\left(\mathrm{CH}[\mathrm{A}] \mathrm{P}^{\prime} \mathrm{T}\right] \mathrm{E} \mathbb{R} \overline{5}^{\prime}$
}

\section{High-frequency stimulation of the dorsolateral periaqueductal gray and ventromedial hypothalamus fails to inhibit panic-like behaviour}

Lee Wei Lim, Arjan Blokland, Veerle Visser-Vandewalle, Rinske Vlamings,
Thibaut Sesia, Harry Steinbusch, Koen Schruers, Eric Griez, and Yasin Temel

\begin{abstract}
Electrical stimulation of the dorsolateral periaqueductal gray (dlPAG) and one of its target structures, the ventromedial hypothalamus (VMH), produces a typical behaviour in rats consisting of vigorous running and jumping which is known as "escape behaviour". Escape behaviour in rodents closely mimics panic attacks in humans. Since electrical stimulation at higher frequencies generally inhibits the stimulated region, we tested in this study the hypothesis that deep brain stimulation (DBS) of the dIPAG and VMH at higher frequencies $(>100 \mathrm{~Hz}$ ) would not induce escape behaviour. More specifically, we evaluated whether experimental DBS could be used to inhibit panic-like behaviour. Rats underwent implantation of DBS-electrodes at the level of the dIPAG and VMH and the effects of various stimulation parameters were assessed. In addition, we studied the neural activation pattern resulting from DBS of the dIPAG and VMH using c-Fos immunohistochemistry. We found that stimulation amplitude is the most important stimulation parameter in the induction of escape behaviour. Remarkably, stimulation frequency $(1-300 \mathrm{~Hz})$ had no effect on stimulation-induced escape behaviour and therefore it was not possible to prevent the induction of escape behaviour with higher frequencies. The neuronal activation pattern resulting from dIPAG and VMH DBS was similar. These findings suggest that DBS of the dIPAG and VMH induces panic-related behaviours even at higher frequencies.
\end{abstract}

Behav Brain Res. 193 (2008) 197-203 


\section{Introduction}

The use of stimulation electrodes implanted in the brain to control severely disabling psychiatric and neurological conditions is an exciting and fast emerging area of clinical neuroscience (Perlmutter and Mink 2006; Schiff et al 2007; Wichmann and Delong 2006). Its popularity is directly related to its minimal invasiveness, reversibility (stimulation can be turned on and off), and adjustability (various combinations of stimulation parameters are possible). Currently, thousands of patients have been implanted with stimulating electrodes and especially in the field of psychiatric disorders new indications are evaluated. For instance, in case series, deep brain stimulation (DBS) has relieved symptoms in patients with treatment-resistant depression (Mayberg et al 2005) and obsessive-compulsive disorder (Abelson et al 2005; Nuttin et al 1999).

Before applying DBS for new indications in clinical psychiatry, it is preferred that the effects of DBS are evaluated systematically in animal models. In this respect, DBS could be considered to treat refractory panic and anxiety disorders. Panic disorder (PD) is one of the most frequently encountered anxiety disorder and one out of every seventy five people worldwide experiences panic attack (PA) once in their lives (NIH 1991 Sep 2527). Panic attacks are characterized by an acute moment of intense fear or psychologically distress with a sudden onset rapidly building to a peak level and are usually accompanied by somatic and psychological symptoms associated with a sense of impending danger and an urge to escape from the susceptible risk condition (Craske and Waters 2005; Griez and Schruers 1998; Klerman et al 1993). Panic disorder is recognized as a disabling condition and its treatment includes pharmacologic and behavioural therapies as well as combinations of these strategies (American-Psychiatric-Association. 2000; Barlow et al 2000; Goisman et al 1999). In some cases, patients do not respond to these treatments and experience a chronic course of disease burden, usually together with their families (Fleet et al 1996; Reiman et al 1984; Roy-Byrne et al 1999).

In preclinical experiments, electrical stimulation of the dorsolateral area of the Periaqueductal gray (PAG) and one of its target structures, the ventromedial hypothalamus (VMH), has been used to study the mechanism of PA. Electrical stimulation of these areas produces a typical behaviour consisting of vigorous running and jumping in rats (Brandao et al 1994; Jenck et al 1995; Jenck et al 1986; Schenberg et al 2001; Siegel et al 1997). This behaviour, also known as escape behaviour, is accompanied by strong emotional and autonomic activation (Bandler et al 1985a; Krieger and Graeff 1985; Schenberg et al 1990). Escape behaviour in rodents closely mimics PA in humans (Deakin 1998; Schenberg et al 2001). The neural circuit responsible for stimulation-induced escape behaviour has been partly identified. Several brain structures interconnected with the dIPAG have been reported to show changed neuronal activity due to electrical or chemical stimulation. For instance, electrical and chemical stimulation induced significant c-Fos expression in the amygdala, thalamus, and medial prefrontal cortex (prelimbic, infralimbic and cingulate areas) (Borelli et al 2005a; Ferreira-Netto et 
al 2005; Vianna et al 2003a). Another region that is strongly activated by dlPAG stimulation is the ventromedial hypothalamus (VMH) (de Oliveira et al 2000; FerreiraNetto et al 2005).

In previous experiments, several stimulation paradigms have been applied to manipulate the dIPAG and VMH, generally aiming to evoke escape behaviour (Bittencourt et al 2005; Jenck et al 1983; Jenck et al 1986; Sandner et al 1982). Therefore, only stimulation parameters inducing escape behaviour were investigated. Almost all studies focused on the stimulation intensity with a fixed frequency (usually 50-100 Hz) (de Almeida et al 2006; Schenberg et al 2002; Vargas and Schenberg 2001). The intensities of stimulation varied greatly among studies (Borelli et al 2004; Hassanain et al 2003; Martinez et al 2006; Siegel et al 1997). In this era in which electrical brain stimulation has become a widely applied technology in preclinical studies, a systematic analysis of effects of stimulation parameters on escape behaviour is needed using a stimulation setup similar to clinical DBS (Belujon et al 2007; Benazzouz et al 2004; Kringelbach et al 2007; Temel et al 2007). The effect of stimulation frequency is of particular importance, since this determines whether a brain region is activated or inhibited (Desbonnet et al 2004; Meissner et al 2007; Temel et al 2007). For instance, it has been demonstrated repeatedly that high frequency stimulation (HFS) inhibits the target by reducing its neuronal firing by a mechanism involving either a deporalization blockage, neurotransmitter depletion, and/or stimulation of presynaptic terminals with neurotransmitter release (Benazzouz et al 2004; Filali et al 2004; Lozano and Eltahawy 2004; Meissner et al 2005). In this study, we examined the behavioural and neuronal effects of dIPAG- and VMH DBS stimulation, and tested the hypothesis that HFS could be used to inhibit panic-like behaviour. Furthermore, the effect of stimulation parameters on neural activation patterns was examined in the forebrain using c-Fos immunohistochemistry. 


\section{Material and Methods}

\section{Subjects}

Subjects were Wistar male rats $(N=24,12$ weeks old, bred and housed at the Central Animal Facility of Maastricht University, Maastricht, the Netherlands). Rats had an average body weight of 300-350 g at the time of surgery. They were housed individually in standard cages on sawdust bedding in an air-conditioned room (about 20 ${ }^{\circ} \mathrm{C}$ ) under a 12/12-h reversed light/dark cycle. Food, standard laboratory chow (Hopefarms, Woerden, The Netherlands), and water were available ad libitum. All experimental procedures were approved by the Animal Experiments and Ethics Committee of Maastricht University.

\section{Experimental groups}

Rats were randomly assigned to one of three following experimental groups: A. Control $(n=6)$; B. dlPAG stimulation $(n=10)$; C. VMH stimulation $(n=8)$.

\section{Surgical procedure}

A detailed description of the surgical procedure and the electrodes has been provided earlier (Temel et al 2007; Temel et al 2005). In brief, the rats were anesthetized throughout the entire procedure using a combination of ketamine $(90 \mathrm{mg} / \mathrm{kg}$ s.c.) and xylazine (10 mg/kg s.c.). Rats were placed in a stereotactic apparatus (Stoelting, Wood Dale, USA; model 51653). After making a burr hole in the skull, rats of groups B and C received implantation of the electrodes at the level of the dlPAG (coordinates from Bregma: AP -7.6, ML 0.7, and $\mathrm{V}-4.8$, approached with a coronal angle of $10^{\circ}$ ) and $\mathrm{VMH}$ (coordinates from Bregma: AP -2.5 , ML 0.5, and V -9.5), respectively. A construction of one gold-plated needle-like electrode with an inner wire of a platinumiridium combination (Technomed, Beek, The Netherlands), with a tip diameter of $50 \mu \mathrm{m}$ and a shaft diameter of $250 \mu \mathrm{m}$, was employed in this experiment. The electrodes were fixed in position using dental cement (Heraeus Kulzer, Hanau, Germany). Rats had a oneweek recovery period.

\section{Behavioural evaluation}

Rats were evaluated in an open field (OF) test. For more details of this test please see Hameleers et al. (Hameleers et al 2007). In summary, rats were placed in the arena and were connected with an external stimulator through externalized leads. The stimulation started approximately one minute after the rat was placed in the OF arena. The behaviour of the rats was videotaped (Ethovision ${ }^{\circledR}$, Noldus Information Technology, Wageningen, the Netherlands). We observed three different types of behaviour during the 
experimental procedure, consisting of 'no effect', 'freezing' behaviour characterized by piloerection, micturition/defaecation, and immobility, and 'escape behaviour' characterized by rigorous and aimlessly running. The stimulation procedures and behavioural analysis were evaluated by two researchers.

\section{Deep brain stimulation}

For DBS we used a variety of stimulation amplitudes (1-650 $\mu \mathrm{A})$, and stimulation frequencies $(1-300 \mathrm{~Hz})$ at a quasi-random fashion. The pulse width was set at $100 \mu \mathrm{s}$ since in previous experiments variation in pulse width did not influence behavioural performance (Desbonnet et al 2004). A World Precision Instruments digital stimulator (DS8000, WPI, Berlin, Germany) and a stimulus isolator (DLS100, WPI, Berlin, Germany) were used to deliver the stimuli. Real time verification of the parameters applied during stimulation was obtained using a digital oscilloscope (Agilent 54622D oscilloscope, Agilent Technologies, Amstelveen, the Netherlands).

The electrical stimulation was performed with gradual increase of the current amplitude. At each step, stimulation duration was $15 \mathrm{sec}$ followed by a stimulation off period of $45 \mathrm{~s}$. The stimulation frequency was set at $50 \mathrm{~Hz}$, and pulse width at $0.1 \mathrm{~ms}$. Behavioural changes during this procedure were observed by two researchers. Freezing behaviour was consistently characterized by immobility (without body movement) accompanied by two distinctive symptoms of increased alertness (head scanning) and piloerection. After cessation of stimulation, freezing disappeared and animals began to move again.

\section{Histological processing}

Two hours after the final electrical stimulation procedure, rats were perfused transcardially with Tyrode $(0.1 \mathrm{M})$ and fixative containing $4 \%$ paraformaldehyde, $15 \%$ picric acid and $0.05 \%$ glutaraldehyde in $0.1 \mathrm{M}$ phosphate buffer ( $\mathrm{pH} 7.6)$. Brains were removed and post-fixed for $2 \mathrm{~h}$ followed by overnight immersion in 10\%, 20\%, and 30\% sucrose at $4{ }^{\circ} \mathrm{C}$. Brain tissue was then quickly frozen with $\mathrm{CO}_{2}$ and stored at $-80{ }^{\circ} \mathrm{C}$. Subsequently, the prefrontal regions of the brains were cut serially on a cryostat into 30 $\mu \mathrm{m}$ frontal sections and again stored at $-80{ }^{\circ} \mathrm{C}$. C-Fos immunohistochemistry was carried out by using an anti-c-Fos rabbit polyclonal antibody (Santa Cruz Biotechnology Inc., Santa Cruz, CA, USA) (diluted 1:20 000 in $0.1 \%$ Bovine Serum Albumin and Tris Buffered Solution-Triton (TBS-T) solution).

After overnight incubation at room temperature on a constant shaker, sections were rinsed with TBS-T, Tris Buffered Solution (TBS), and TBS-T and incubated with the secondary antibody (diluted 1: 400 in biotinylated donkey anti-rabbit biotine; Jackson Immunoresearch Laboratories Inc., Westgrove, USA) for ninety minutes. Subsequently, 
the sections were incubated with an avidin-biotin-peroxidase complex (diluted 1:800, Elite ABC-kit, Vectastatin; Burlingame, USA) for two hours. In between steps, sections were washed with TBS and TBS-T. To visualize the immune complex of Horse Radish Peroxide reaction product, sections were incubated with 3,3'-diaminobenzidine tetrahydrochloride $(\mathrm{DAB}) /$ Nickel Chloride $\left(\mathrm{NiCL}_{2}\right)$ solution $(5 \mathrm{ml}$ DAB solution, $5 \mathrm{ml}$ Tris/HCl, $50 \mu \mathrm{l} \mathrm{NiCL}$, and $3.35 \mu l$ hydrogen peroxide). This reaction was stopped after 10 minutes by rinsing thoroughly all the sections with TBS. All sections were then mounted on gelatin-coated glasses. After dehydrating, all sections were cover-slipped with Pertex (HistolabProducts ab, Goteborg, Sweden). Additionally, one other series of sections per animal was stained with standard hematoxylin-eosin (Merck, Darmstadt, Germany) to evaluate the localization of the electrode tips.

\section{Semi-quantitative evaluation of c-Fos immunoreactive cells}

Systematic cell counts were performed of c-Fos immunoreactive (c-Fos-ir) cells in the prelimbic (PrL), infralimbic (IL), cingulate ( $\mathrm{Cg} 1)$ and motor (M2) cortices. Photographs of the areas of interest were taken at $4 \mathrm{X}$ magnification using an Olympus DP70 camera connected to an Olympus AX70 bright-field microscope (analySIS; Imaging System, Münster, Germany). Our quantification method was similar to a previously reported method, with minor modifications (Lamprea et al 2002). Four sections from each animal were selected for quantification. The boundaries of the areas of interest were delineated and measured. The same light intensity and threshold conditions were employed for all sections. The counting of the numbers of c-Fos-ir cells was performed using the conventional image analysis program 'Image J' (version 1.38, NIH, USA). A cell was counted as c-Fos-ir if its density was $75 \%$ higher than the background density. In addition, artifacts in the sections were excluded from analysis to ensure the accuracy of measurements.

In this study, this method of quantification was preferred to a stereological analysis which is laborious, since the differences were clear and therefore data about relative differences were sufficient for our purposes.

\section{Statistical analysis}

Data are presented as mean \pm S.E.M and were analyzed using Analysis of Variance (ANOVA). Data of c-Fos-ir cell counts are expressed as number of c-Fos-ir cells $/ \mathrm{mm}^{2}$. An LSD post hoc test was used to analyze group differences in more detail. Pvalues lower than 0.05 were considered significant. 


\section{Results}

\section{Histological evaluation of the electrode localization}

Electrode tips were located at the level of the dIPAG in 8 rats of group B, and in 5 rats of group $\mathrm{C}$ electrodes were located in the $\mathrm{VMH}$. In two rats of group $\mathrm{B}$ and 3 rats of group $\mathrm{C}$, the electrodes were misplaced and these rats were excluded from analysis. The localization of the electrode tip in the PAG and VMH are illustrated in Figure 1. Based on the evaluation of the hematoxylin and eosin staining, no neuronal damage was observed except for the electrode trajectory.

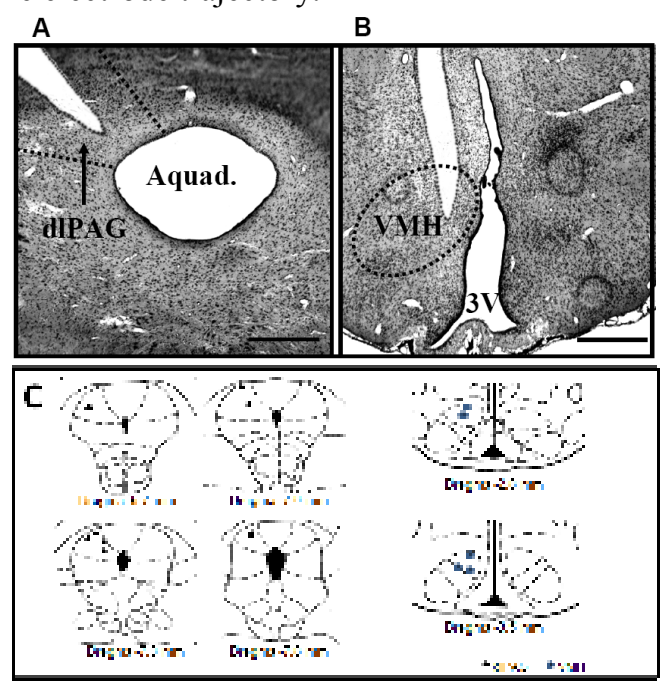

Figure 1: Representative low-power photomicrographs of a $30 \mu \mathrm{m}$-thick frontal section from the brain of a rat subjected to stereotactic implantation of concentric bipolar electrode to stimulate the dIPAG (Fig. A, scale bar $=250 \mu \mathrm{m}$ ) and VMH (Fig. B, scale bar $=500 \mu \mathrm{m}$ ) is shown. Fig. C, Schematic representation of the electrode sites in the dIPAG and VMH according to the Paxinos and Watson atlas, respectively. The symbol $(\mathbf{\Delta})$ indicates the electrode localization in the dIPAG and $(\bullet)$ in the VMH. Abbreviation: Aquad. $=$ aquaduct of Sylvius, $3 \mathrm{~V}=$ third ventricle. 


\section{Behavioural Evaluation}

\section{Effect of stimulation parameters}

The intensity of the electrical current applied to the dlPAG and VMH of the animals was based on the lowest threshold to induce escape behaviour. The current amplitudes necessary for inducing freezing behaviour and escape behaviour differed significantly between rats with dlPAG DBS and VMH DBS (F's $>351.13$; P's $<0.00$ ). The current intensity applied to the dIPAG and VMH DBS to induce freezing behaviour was $78.57 \pm 4.04 \mu \mathrm{A}$ and $540.00 \pm 29.15 \mu \mathrm{A}$, respectively, while the current intensity to evoke escape behaviour was $85.71 \pm 13.36 \mu \mathrm{A}$ and $590.00 \pm 29.15 \mu \mathrm{A}$, respectively (Figure 2). After confirming the current amplitudes necessary to evoke escape behaviour, we evaluated the effect of stimulation frequency. We found that each stimulation frequency applied resulted in escape behaviour (Table 1).
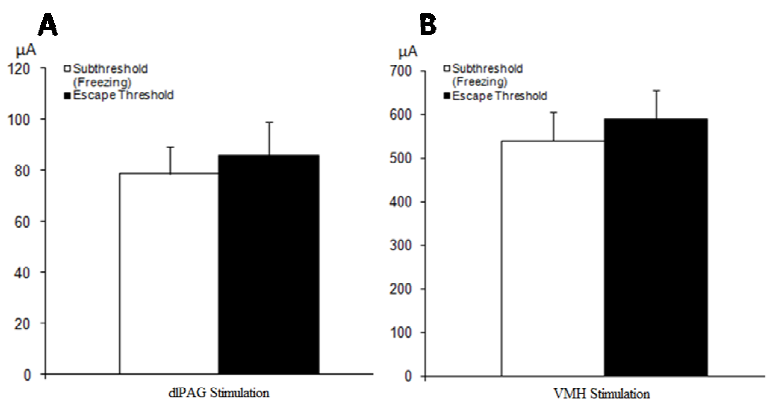

Figure 2: This figure shows the current amplitudes $(\mu \mathrm{A})$ necessary to induce freezinglike behaviour and escape reaction. Data represent means ( \pm SEM) of dIPAG (Fig A) and VMH stimulation (Fig. B) groups. 


\section{Effect of repeated stimulation}

Rats that showed escape behaviour in the previous session, showed no escape behaviour when they were stimulated again at their escape threshold on the second day. However, after a longer period of recovery (seven days), rats again showed escape behaviour when stimulating at their escape threshold. Furthermore, the rats which showed escape behaviour due to stimulation, showed freezing behaviour when they were placed in the OF arena the next day (Figure 3).

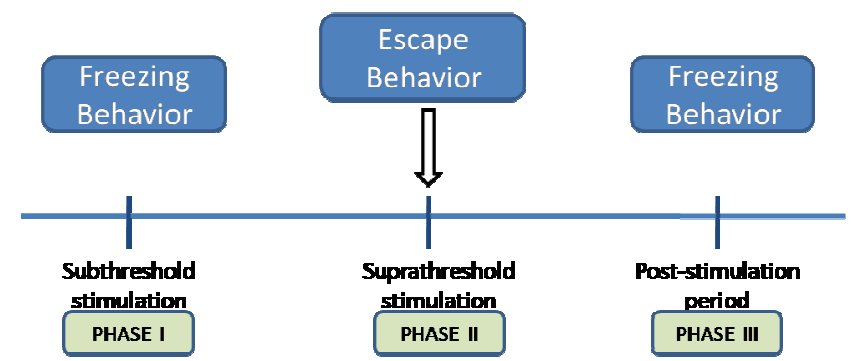

Figure 3: Behavioural effects of sub-threshold stimulation (phase I), suprathreshold stimulation (phase II) and post-stimulation period (phase III). We found that stimulation below the escape-threshold induced freezing behaviour. In addition, rats showed freezing behaviour when they were placed in OF arena one day after the stimulation experiment.

\begin{tabular}{|c|c|c|c|c|c|c|c|c|c|c|c|c|c|c|}
\hline \multirow{3}{*}{ 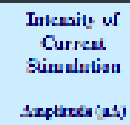 } & \multicolumn{7}{|c|}{ Dorsolateral Perizqueductal Gray } & \multicolumn{7}{|c|}{ Ventromedial Ilypothalamus } \\
\hline & \multicolumn{4}{|c|}{$1 .+\mathrm{S}(\mathrm{H} \times)$} & \multicolumn{3}{|c|}{$\left.\mathrm{HHSi}_{2}\right)$} & \multicolumn{4}{|c|}{$\mathrm{I} . \mathrm{K} \times(\mathrm{H} / \mathrm{a}$} & \multicolumn{3}{|c|}{$\mathrm{H}+\mathrm{S}\left(\mathrm{H} \mathrm{x}^{\prime}\right)$} \\
\hline & $I$ & 5 & 10 & 50 & 200 & $\$ 50$ & 300 & $I$ & 5 & $\Delta \theta$ & 50 & 100 & 150 & 300 \\
\hline $0.25-74 \mu \mathrm{A}$ & $\mathbf{F}$ & I & $\mathbf{F}$ & $\mathrm{T}$ & $\mathbf{F}$ & $\mathrm{I}$ & $\mathbf{F}$ & $\mathrm{NI}$ & NI & $\mathrm{sI}$ & $\mathrm{SI}$ & $\mathrm{NI}$ & $\mathrm{NL}$ & $\mathrm{NE}$ \\
\hline $75 \pi 4$ & ED & ID & ED & ID & ED & ID & ED & $\mathrm{NI}$ & NI & $\mathrm{NI}$ & $\mathrm{SI}$ & $\mathrm{NI}$ & $\mathrm{NI}$ & $\mathrm{NI}$ \\
\hline $7 n w_{\mu-1}$ & K.K & H.E & K. H & H.E & K. K & H.E & $\mathbf{K K}$ & $\mathrm{vt}$ & Ar: & $\mathrm{vt}$ & $\mathrm{ve}$ & NF: & $\mathrm{vH}$ & $\mathrm{Ar}:$ \\
\hline $200 \pi 4$ & ED & ID & ED & ID & ED & ID & ED & $\mathrm{NI}$ & NI & $\mathrm{SI}$ & $\mathrm{NI}$ & $\mathrm{NL}$ & $\mathrm{NI}$ & NI \\
\hline$s i N_{\mu-1}$ & K. K & H.E & K.K & H.E & K. K & H.E & K.K & $r$ & $F$ & $\mathrm{r}$ & $\mathrm{k}$ & $r$ & $r$ & $F$ \\
\hline 500 几1 & ED & ID & ED & ID & ED & ID & ED & ID & ED & EI & ID & EI & ID & ED \\
\hline$K\left(W W_{\mu-1}\right.$ & K. $\mathrm{K}$ & H.E & K. K & H.E & KK & H.E & EKH & H.E & E. H & K. H & H.E & K. K & H.E & K. K \\
\hline $6.5 N_{\mu-1}$ & ED & ID & ED & ID & ED & ID & ED & ID & ED & EI & ID & EI & ID & ED \\
\hline
\end{tabular}

Table 1: This table shows the effect of stimulation parameters on behaviour. A variety of stimulation parameters consisting of different current amplitudes $(1-650 \mu \mathrm{A})$ and stimulation frequencies (1-300 Hz) were used. The pulse width was set at $100 \mu \mathrm{s}$. Abbreviations: 'LFS' Low-frequency stimulation, 'HFS' - High-frequency stimulation, 'F'- Freezing response, 'EB'- Escape behaviour, and 'NE'- No effect. 


\section{Evaluation of c-Fos-ir cells}

Since numbers of c-Fos-ir cells in the ipsilateral and contralateral regions were not significantly different ( $\mathrm{P}$ 's $>0.05$ ), we pooled these data. DBS of the dIPAG and VMH significantly increased the number of c-Fos-ir cells in the $\operatorname{PrL}(\mathrm{F}$ 's $>53.96, \mathrm{P}<0.00)$, IL (F's $>90.85, \mathrm{P}<0.00)$, M2 (F's $>77.93, \mathrm{P}<0.00)$ and $\mathrm{Cg} 1$ (F's $>95.24, \mathrm{P}<0.00)$ regions as compared to control animals. In all regions, VMH DBS resulted in higher numbers of c-Fos-ir cells as compared to dlPAG DBS (F's $>14.28, \mathrm{P}<0.05$ ) (Figures 4 and 5).

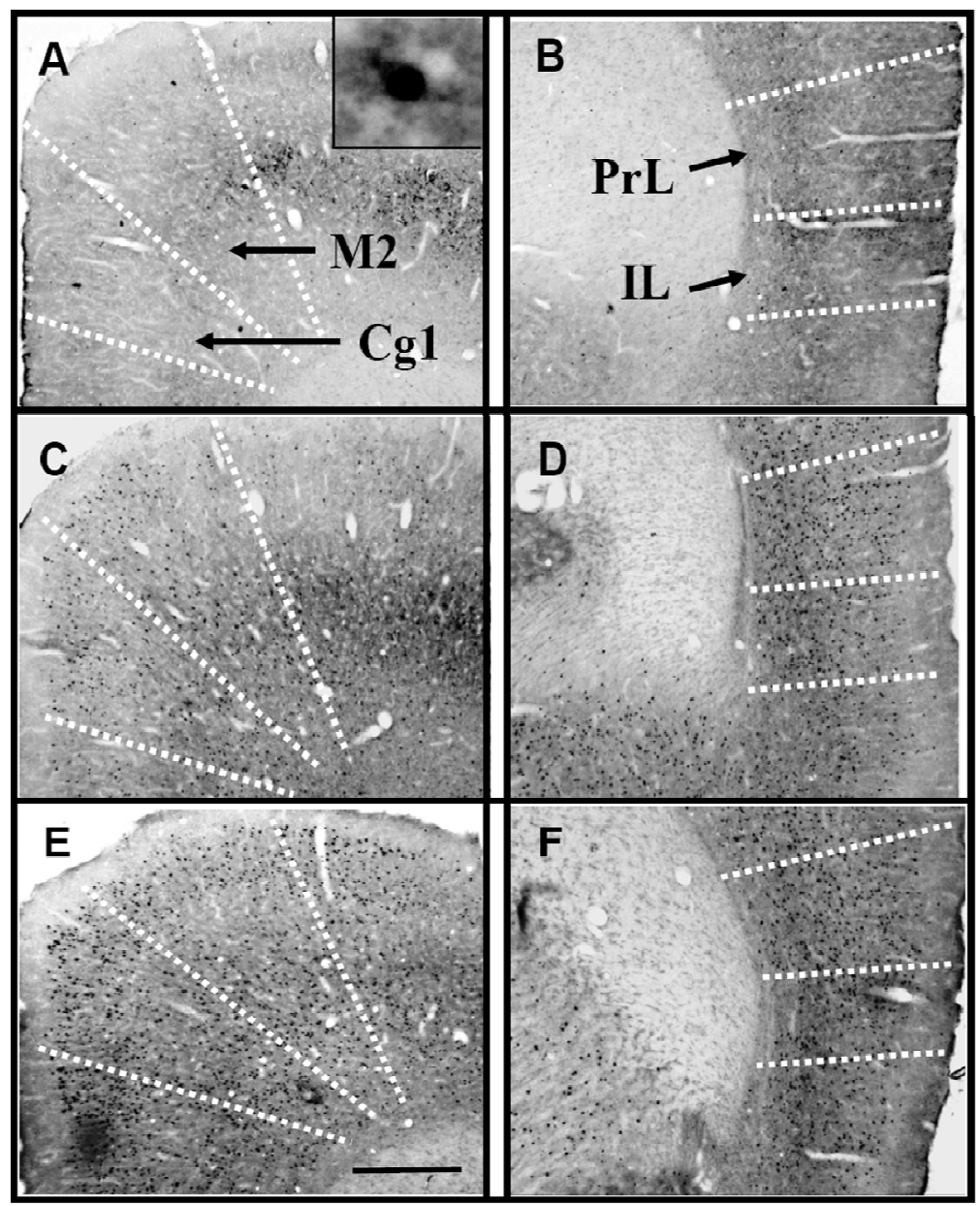

Figure 4: Representative low-power photomicrographs of $30 \mu \mathrm{m}$-thick frontal sections from the brain of a control rat (Figs. A and B), a rat subjected to stereotactic implantation of concentric bipolar electrode to stimulate the dlPAG (Figs. C and D) and VMH (Figs. E and F). Figs A, C, and E at bregma level: $2.20 \mathrm{~mm}$ show the level of the $\mathrm{Cg} 1$ (Cingulate gyrus 1) and M2 (Motor cortex 2), and Figs. B, D, and F at bregma level: $2.20 \mathrm{~mm}$ show the level of PrL (Prelimbic cortex), and IL (Infralimbic cortex). The small dark dots represent c-Fos-ir cells. The inset in A shows a representative high-power photomicrograph of a c-Fos-ir cell. Scale bar $=500 \mu \mathrm{m}$. 


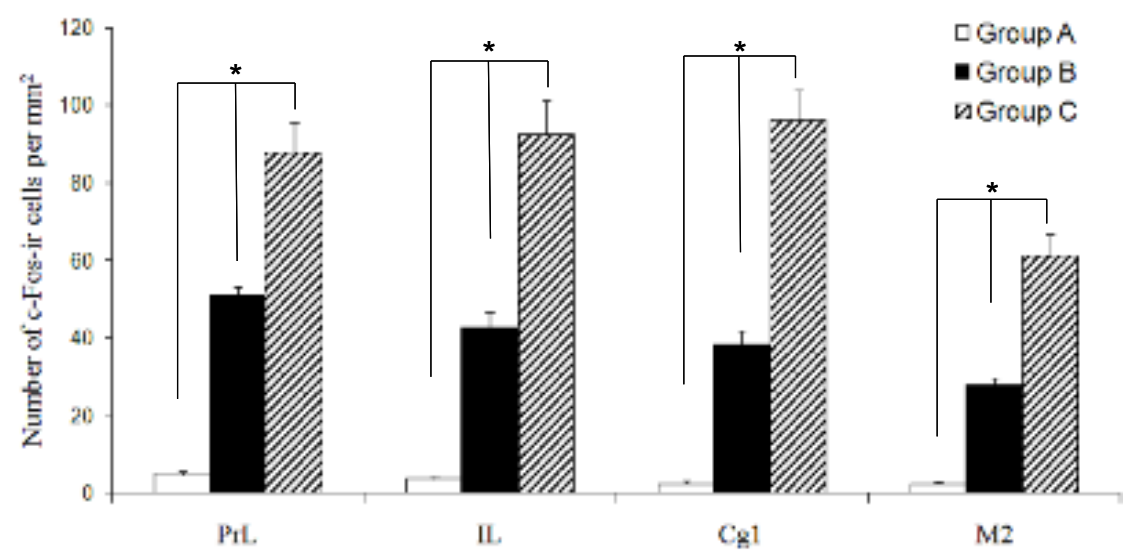

Figure 5: Grouped data of c-Fos-ir cells per $\mathrm{mm}^{2}$. Data represents means \pm S.E.M. of groups A (control), B (PAG stimulation) and C (VMH stimulation). Abbreviations: PrL: prelimbic cortex; IL: infralimbic cortex; $\mathrm{Cg} 1$ : cingulate gyrus 1; and M2: motor cortex 2. * indicates significant difference between groups $(\mathrm{P}<0.05)$.

\section{Discussion}

Electrical stimulation of the dIPAG and VMH produced a typical behaviour consisting of vigorous running and jumping in rat, referred as escape behaviour. This behaviour in rodents has been considered a phenomenon closely mimicking PA in humans (Deakin 1998; Schenberg et al 2001). Our results have revealed that the most important stimulation parameter for this behaviour is the stimulation amplitude. For each subject, a minimum amount of stimulation amplitude (escape-threshold) was necessary to induce escape behaviour. Interestingly, substantially higher amplitudes were required with VMH DBS. In addition, VMH DBS resulted in higher levels of neuronal activation (ie. more c-Fos ir cells) in the prefrontal areas associated with panic-reactions, which could be related to these high stimulation intensities.

The key finding of this study is that it was not possible to prevent the induction of escape behaviour by PAG and VMH DBS. We have applied a wide range of frequencies which all induced escape behaviour. Even with $300 \mathrm{~Hz}$ stimulation with a thresholdamplitude, rats showed escape behaviour. These findings suggest that both dIPAG and VMH are not sensitive for high frequency stimulation in the context of escape behaviour. This is in contrast with findings in animal models of Parkinson's disease, Huntington's disease or depression (Benazzouz et al 2004; Meissner et al 2005; Temel et al 2007; Temel et al 2006). In these models, low frequency stimulation usually deteriorated the condition, whereas HFS was effective in reducing the symptoms. However, an important similarity is the acute effect of dIPAG and VMH DBS on behaviour. 
We observed two types of behaviour. Sub-threshold stimulation resulted in freezing behaviour and stimulations at the threshold or above induced escape behaviour. McNaughton and Corr (2004) have introduced the concept of two-dimensional defensive behaviour, categorizing behavioural reactions into avoidable and unavoidable threats such as the escape behaviour and panic-like freezing behaviour (McNaughton and Corr 2004). The first dimension describes the two systems of defensive behaviour associated particularly with the PAG and hypothalamus in controlling defensive avoidance (fear) and defensive approach (anxiety). The second dimension illustrates an important hierarchical organization of defensive behaviour. A particular finding in this study, is that rats showed freezing behaviour when they were placed in the OF arena on the next day after a stimulation session. However, when the recovery period was extended, animals returned did not show this behaviour and reacted normally. This finding could be indicative of a fear-conditioning effect with subsequent extinction.

The results of c-Fos immunohistochemistry further establishes the involvement of the medial prefrontal cortex in the integration of cognitive-affective information in response to emotional stress (Radley et al 2006). More specifically, the $\mathrm{Cg} 1$ plays a role in autonomic functions, such as regulating blood pressure and heart rate (Allman et al 2001). Further, the PrL, and IL cortices appear to be directly involved in cognitive functions, fear expression (Corcoran and Quirk 2007), and in learning and coping with changing contingencies in new tasks or familiar environments (Rich and Shapiro 2007). We have also evaluated the c-Fos expression in the motor cortex, especially in the M2 area, to confirm the neuronal substrate of high motor activity associated with escape behaviour. In line with our expectation we found high levels of c-Fos-ir cells in the cortical motor areas. In all regions, VMH DBS resulted in more c-Fos-ir cells as compared to dIPAG DBS. One possible explanation could be the higher amplitudes used with VMH DBS which have influenced neighboring circuits and regions. Another explanation is that the effects of DBS of the VMH are mediated via the dlPAG. This explanation would corroborate the hierarchical neural levels in the two-dimensional defense system (see Fig. 6) (McNaughton and Corr 2004). Blanchard \& Blanchard also described a similar hierarchy of defensive behaviour (Blanchard and Blanchard 1989a; Blanchard and Blanchard 1990) which was related to the neural hierarchy in the mechanism of defense as proposed by Deakin (Deakin 1991c) and Graeff (Graeff 1994). These theories explained the involvement of different levels of neuroanatomical structures (e.g. septo-hippocampal system, amygdala and hypothalamus) and neurotransmitters (e.g. acetylcholine, serotonin) in facilitating defensive behaviour related to rage and panic, respectively. Conceptually, the PAG has long been known as the primitive defensive structure commanding fight and flight reaction and accordingly higher current amplitudes were necessary with VMH DBS to influence the dIPAG in order to induce such defensive response. Nevertheless, the results obtained with c-Fos immunohistochemistry should be interpreted carefully, since c-Fos is only a general marker of neuronal activity. Consequently, the c-Fos experssion may reflect direct and indirect effects, and excitation and inhibition. 


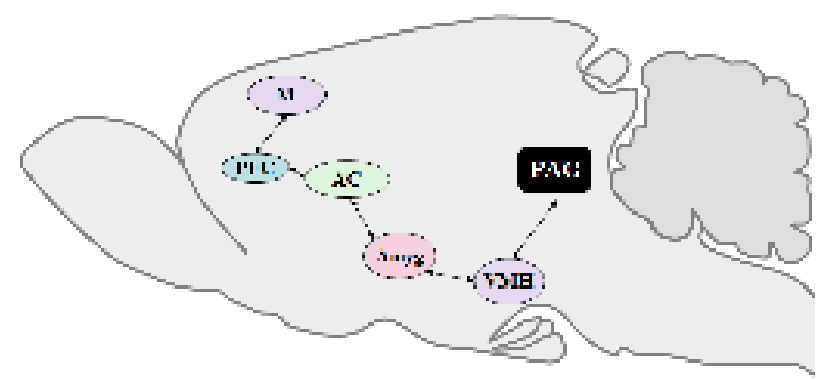

Figure 6: Schematic illustration of the upstream connections of the periaqueductal gray matter in defensive behaviour based on McNaughton and Corr's two-dimensional defense system (McNaughton and Corr 2004). Abbreviations: PAG: periaqueductal gray, VMH: ventromedial hypothalamus, Amyg: amygdala, AC: anterior cingulate gyrus, PFC: prefrontal cortex, and M: motor cortex.

\section{Conclusion}

In conclusion, the main finding of the present study is that both low- and high frequency stimulation of the dIPAG and VMH DBS induced escape behaviour. In addition, different current amplitudes produced different behaviours consisting of freezing and escape. Furthermore, we found simple fear-conditioning with subsequent extinction in the post-stimulation period.

\section{Acknowledgement}

The authors are grateful to Mr. Rob Hameleers, Ms. Ingeborg van Kroonenburgh, and Ms. Lan Xie for their technical assistance. This research was supported by a grant from the FP6 Marie Curie Fellowship (MEST-CT-2005-020589). 


\section{References}

Abelson JL, Curtis GC, Sagher O, Albucher RC, Harrigan M, Taylor SF, et al (2005): Deep brain stimulation for refractory obsessive-compulsive disorder. Biol Psychiatry 57:510-516.

Allman JM, Hakeem A, Erwin JM, Nimchinsky E, Hof P (2001): The anterior cingulate cortex. The evolution of an interface between emotion and cognition. Ann N Y Acad Sci 935:107-117.

American-Psychiatric-Association. (2000): Diagnostic and statistical manual of mental disorders. 4th ed., text revision. Washington, D.C.: American Psychiatric Association.

Bandler R, Depaulis A, Vergnes M (1985): Identification of midbrain neurones mediating defensive behaviour in the rat by microinjections of excitatory amino acids. Behav Brain Res 15:107-119.

Barlow DH, Gorman JM, Shear MK, Woods SW (2000): Cognitive-behavioural therapy, imipramine, or their combination for panic disorder: A randomized controlled trial. Jama 283:2529-2536.

Belujon P, Bezard E, Taupignon A, Bioulac B, Benazzouz A (2007): Noradrenergic modulation of subthalamic nucleus activity: behavioural and electrophysiological evidence in intact and 6hydroxydopamine-lesioned rats. $J$ Neurosci 27:9595-9606.

Benazzouz A, Tai CH, Meissner W, Bioulac B, Bezard E, Gross C (2004): High-frequency stimulation of both zona incerta and subthalamic nucleus induces a similar normalization of basal ganglia metabolic activity in experimental parkinsonism. Faseb $J$ 18:528-530.

Bittencourt AS, Nakamura-Palacios EM, Mauad H, Tufik S, Schenberg LC (2005): Organization of electrically and chemically evoked defensive behaviours within the deeper collicular layers as compared to the periaqueductal gray matter of the rat. Neuroscience 133:873-892.

Blanchard RJ, Blanchard DC (1989): Attack and defense in rodents as ethoexperimental models for the study of emotion. Prog Neuropsychopharmacol Biol Psychiatry 13 Suppl:S3-14.

Blanchard RJ, Blanchard DC (1990): In: McNaughton N, Andrews G, editors. An ethoexperimental analysis of defense, fear and anxiety. Anxiety. Dunedin: Otago University Press:124-133.

Borelli KG, Ferreira-Netto C, Coimbra NC, Brandao ML (2005): Fos-like immunoreactivity in the brain associated with freezing or escape induced by inhibition of either glutamic acid decarboxylase or GABAA receptors in the dorsal periaqueductal gray. Brain Res 1051:100-111.

Borelli KG, Nobre MJ, Brandao ML, Coimbra NC (2004): Effects of acute and chronic fluoxetine and diazepam on freezing behaviour induced by electrical stimulation of dorsolateral and lateral columns of the periaqueductal gray matter. Pharmacol Biochem Behav 77:557-566.

Brandao ML, Cardoso SH, Melo LL, Motta V, Coimbra NC (1994): Neural substrate of defensive behaviour in the midbrain tectum. Neurosci Biobehav Rev 18:339-346.

Corcoran KA, Quirk GJ (2007): Activity in prelimbic cortex is necessary for the expression of learned, but not innate, fears. J Neurosci 27:840-844.

Craske MG, Waters AM (2005): Panic disorder, phobias, and generalized anxiety disorder. Annu Rev Clin Psychol 1:197-225.

de Almeida LP, Ramos PL, Pandossio JE, Landeira-Fernandez J, Zangrossi H, Jr., Nogueira RL (2006): Prior electrical stimulation of dorsal periaqueductal grey matter or deep layers of the superior colliculus sensitizes rats to anxiety-like behaviours in the elevated T-maze test. Behav Brain Res 170:175-181.

de Oliveira RW, Del Bel EA, Guimaraes FS (2000): Behavioural and c-fos expression changes induced by nitric oxide donors microinjected into the dorsal periaqueductal gray. Brain Res Bull 51:457-464.

Deakin JF (1998): The role of serotonin in panic, anxiety and depression. Int Clin Psychopharmacol 13 Suppl 4:S1-5.

Deakin JFWGF (1991): 5-HT and mechanism of defence. J Psychopharmacol 5:305-315.

Desbonnet L, Temel Y, Visser-Vandewalle V, Blokland A, Hornikx V, Steinbusch HW (2004): Premature responding following bilateral stimulation of the rat subthalamic nucleus is amplitude and frequency dependent. Brain Res 1008:198-204.

Ferreira-Netto C, Borelli KG, Brandao ML (2005): Neural segregation of Fos-protein distribution in the brain following freezing and escape behaviours induced by injections of either glutamate or NMDA into the dorsal periaqueductal gray of rats. Brain Res 1031:151-163. 
Filali M, Hutchison WD, Palter VN, Lozano AM, Dostrovsky JO (2004): Stimulation-induced inhibition of neuronal firing in human subthalamic nucleus. Exp Brain Res 156:274-281.

Fleet RP, Dupuis G, Marchand A, Burelle D, Arsenault A, Beitman BD (1996): Panic disorder in emergency department chest pain patients: prevalence, comorbidity, suicidal ideation, and physician recognition. Am J Med 101:371-380.

Goisman RM, Warshaw MG, Keller MB (1999): Psychosocial treatment prescriptions for generalized anxiety disorder, panic disorder, and social phobia, 1991-1996. Am J Psychiatry 156:1819-1821.

Graeff FG (1994): Neuroanatomy and neurotransmitter regulation of defensive behaviours and related emotions in mammals. Braz J Med Biol Res 27:811-829.

Griez E, Schruers K (1998): Experimental pathophysiology of panic. J Psychosom Res 45:493-503.

Hameleers R, Blokland A, Steinbusch HW, Visser-Vandewalle V, Temel Y (2007): Hypomobility after DOI administration can be reversed by subthalamic nucleus deep brain stimulation. Behav Brain Res 185:65-67.

Hassanain M, Bhatt S, Siegel A (2003): Differential modulation of feline defensive rage behaviour in the medial hypothalamus by 5-HT1A and 5-HT2 receptors. Brain Res 981:201-209.

Jenck F, Moreau JL, Martin JR (1995): Dorsal periaqueductal gray-induced aversion as a simulation of panic anxiety: elements of face and predictive validity. Psychiatry Res 57:181-191.

Jenck F, Schmitt P, Karli P (1983): Morphine applied to the mesencephalic central gray suppresses brain stimulation induced escape. Pharmacol Biochem Behav 19:301-308.

Jenck F, Schmitt P, Karli P (1986): Morphine injected into the periaqueductal gray attenuates brain stimulation-induced effects: an intensity discrimination study. Brain Res 378:274-284.

Klerman GL, Hirschfeld RMA, Weissman MM (1993): Panic Anxiety and Its Treatments: Report of the World Psychiatric Association Presidential Educational Program Task Force. American Psychiatric Association:pp 44.

Krieger JE, Graeff FG (1985): Defensive behaviour and hypertension induced by glutamate in the midbrain central gray of the rat. Braz J Med Biol Res 18:61-67.

Kringelbach ML, Jenkinson N, Owen SL, Aziz TZ (2007): Translational principles of deep brain stimulation. Nat Rev Neurosci 8:623-635.

Lamprea MR, Cardenas FP, Vianna DM, Castilho VM, Cruz-Morales SE, Brandao ML (2002): The distribution of fos immunoreactivity in rat brain following freezing and escape responses elicited by electrical stimulation of the inferior colliculus. Brain Res 950:186-194.

Lozano AM, Eltahawy H (2004): How does DBS work? Suppl Clin Neurophysiol 57:733-736.

Martinez RC, de Oliveira AR, Brandao ML (2006): Conditioned and unconditioned fear organized in the periaqueductal gray are differentially sensitive to injections of muscimol into amygdaloid nuclei. Neurobiol Learn Mem 85:58-65.

Mayberg HS, Lozano AM, Voon V, McNeely HE, Seminowicz D, Hamani C, et al (2005): Deep brain stimulation for treatment-resistant depression. Neuron 45:651-660.

McNaughton N, Corr PJ (2004): A two-dimensional neuropsychology of defense: fear/anxiety and defensive distance. Neurosci Biobehav Rev 28:285-305.

Meissner W, Guigoni C, Cirilli L, Garret M, Bioulac BH, Gross CE, et al (2007): Impact of chronic subthalamic high-frequency stimulation on metabolic basal ganglia activity: a 2-deoxyglucose uptake and cytochrome oxidase mRNA study in a macaque model of Parkinson's disease. Eur J Neurosci 25:1492-1500.

Meissner W, Leblois A, Hansel D, Bioulac B, Gross CE, Benazzouz A, et al (2005): Subthalamic high frequency stimulation resets subthalamic firing and reduces abnormal oscillations. Brain 128:2372-2382.

NIH NIoH (1991 Sep 25-27): Treatment of Panic Disorder. NIH Consens Statement 9(2):1-24.

Nuttin B, Cosyns P, Demeulemeester H, Gybels J, Meyerson B (1999): Electrical stimulation in anterior limbs of internal capsules in patients with obsessive-compulsive disorder. Lancet 354:1526.

Perlmutter JS, Mink JW (2006): Deep brain stimulation. Annu Rev Neurosci 29:229-257.

Radley JJ, Arias CM, Sawchenko PE (2006): Regional differentiation of the medial prefrontal cortex in regulating adaptive responses to acute emotional stress. J Neurosci 26:12967-12976.

Reiman EM, Raichle ME, Butler FK, Herscovitch P, Robins E (1984): A focal brain abnormality in panic disorder, a severe form of anxiety. Nature 310:683-685. 
Rich EL, Shapiro ML (2007): Prelimbic/infralimbic inactivation impairs memory for multiple task switches, but not flexible selection of familiar tasks. J Neurosci 27:4747-4755.

Roy-Byrne PP, Stein MB, Russo J, Mercier E, Thomas R, McQuaid J, et al (1999): Panic disorder in the primary care setting: comorbidity, disability, service utilization, and treatment. J Clin Psychiatry 60:492-499; quiz 500.

Sandner G, Schmitt P, Karli P (1982): Effect of medial hypothalamic stimulation inducing both escape and approach on unit activity in rat mesencephalon. Physiol Behav 29:269-274.

Schenberg LC, Bittencourt AS, Sudre EC, Vargas LC (2001): Modeling panic attacks. Neurosci Biobehav Rev 25:647-659.

Schenberg LC, Capucho LB, Vatanabe RO, Vargas LC (2002): Acute effects of clomipramine and fluoxetine on dorsal periaqueductal grey-evoked unconditioned defensive behaviours of the rat. Psychopharmacology (Berl) 159:138-144.

Schenberg LC, Costa MB, Borges PC, Castro MF (1990): Logistic analysis of the defense reaction induced by electrical stimulation of the rat mesencephalic tectum. Neurosci Biobehav Rev 14:473479.

Schiff ND, Giacino JT, Kalmar K, Victor JD, Baker K, Gerber M, et al (2007): Behavioural improvements with thalamic stimulation after severe traumatic brain injury. Nature 448:600-603.

Siegel A, Schubert KL, Shaikh MB (1997): Neurotransmitters regulating defensive rage behaviour in the cat. Neurosci Biobehav Rev 21:733-742.

Temel Y, Boothman LJ, Blokland A, Magill PJ, Steinbusch HW, Visser-Vandewalle V, et al (2007): Inhibition of 5-HT neuron activity and induction of depressive-like behaviour by high-frequency stimulation of the subthalamic nucleus. Proc Natl Acad Sci U S A 104:17087-17092.

Temel Y, Cao C, Vlamings R, Blokland A, Ozen H, Steinbusch HW, et al (2006): Motor and cognitive improvement by deep brain stimulation in a transgenic rat model of Huntington's disease. Neurosci Lett 406:138-141.

Temel Y, Visser-Vandewalle V, Aendekerk B, Rutten B, Tan S, Scholtissen B, et al (2005): Acute and separate modulation of motor and cognitive performance in parkinsonian rats by bilateral stimulation of the subthalamic nucleus. Exp Neurol 193:43-52.

Vargas LC, Schenberg LC (2001): Long-term effects of clomipramine and fluoxetine on dorsal periaqueductal grey-evoked innate defensive behaviours of the rat. Psychopharmacology (Berl) 155:260-268.

Vianna DM, Borelli KG, Ferreira-Netto C, Macedo CE, Brandao ML (2003): Fos-like immunoreactive neurons following electrical stimulation of the dorsal periaqueductal gray at freezing and escape thresholds. Brain Res Bull 62:179-189.

Wichmann T, Delong MR (2006): Deep brain stimulation for neurologic and neuropsychiatric disorders. Neuron 52:197-204. 


\title{
Buspirone induced acute and chronic changes of neural activation in the periaqueductal gray of rats
}

\author{
Lee Wei Lim, Yasin Temel, Thibaut Sesia, Rinske Vlamings, \\ Veerle Visser-Vandewalle, Harry Steinbusch, and Arjan Blokland
}

\begin{abstract}
5-Hydroxytryptamine ${ }_{1 \mathrm{~A}}\left(5-\mathrm{HT}_{1 \mathrm{~A}}\right)$ modulation within the midbrain periaqueductal gray (PAG) is closely associated with anxiety- or panic-like behaviour. Several findings have demonstrated that the properties of buspirone (a 5-HT $\mathrm{HA}_{1 \mathrm{~A}}$ partial agonist) would function as either anxiolytic or panicolytic in both clinical and laboratory animal research. In this study, we have investigated the neuronal activity occurring within the different regions of the PAG induced by buspirone treatment. Twenty-eight albino Wistar rats (350-400g) were injected with either acute or chronic saline/buspirone (each, $n=7$ ), respectively. Our results show that buspirone treatment reduced locomotor activity, body weight and fecal boli, particularly in the chronic buspirone group. Two-way ANOVA revealed a significant decrease of c-Fos-ir cells expression in all regions of the rostral PAG after both acute- and chronic buspirone (AB and $\mathrm{CB}$, respectively) treatment. However, no effects on c-Fos-ir were detected in the caudal IPAG and vlPAG in both the $\mathrm{AB}$ and $\mathrm{CB}$ groups, and in the dIPAG of the $\mathrm{CB}$ group. Interestingly, c-Fos-ir cells in the dmPAG column were reduced consistently in both the rostral and caudal PAG in both AB and $\mathrm{CB}$ groups. Besides, in all regions the number of c-Fos-ir cells was higher in the $\mathrm{AB}$ than in the $\mathrm{CB}$ group with exception of the rostral IPAG. In conclusion, the main anxiolytic effect of buspirone was specifically localized in all regions of the rostral PAG and in the caudal dmPAG. However, the caudal dlPAG, IPAG and vlPAG were found to be ineffective to buspirone treatment, probably due to their distinctive function in mediating higher level of anxiety in defensive behaviour. This indicates that the longitudinal anatomical structure of the PAG possesses a different level of receptor sensitivity of 5-HT $\mathrm{HT}_{1 \mathrm{~A}}$ in the pathophysiology of anxiety and panic disorder.
\end{abstract}

Neuroscience 155 (2008) 164-173 


\section{Introduction}

Buspirone, a 5-Hydroxytryptamine $\mathrm{AA}_{\mathrm{A}}\left(5-\mathrm{HT}_{1 \mathrm{~A}}\right)$ partial agonist, is an efficacious anxiolytic drug in the treatment of clinically generalized anxiety disorder (GAD) (Jacobson et al 2007), and ineffective for severe anxiety (Ninan 2004b; Sramek et al 2002), and panic disorder (PD) (Charney et al 1986; Sheehan et al 1990). The most common side effects, which occur approximately in $10 \%$ of the patients, are drowsiness, and headache. Occasionally, patients may complain of fatigue, nervousness, insomnia, and light-headedness. Nevertheless, the main advantage of buspirone as compared with the typical benzodiazepine anxiolytic is that it does not produce addiction, withdrawal syndrome, or mental confusion (Gorman 2003). Most clinical data have shown that the anxiolytic activity begins from one to three weeks after starting the therapy and that single doses are not very effective (Goldberg 1979). However, in the laboratory animal studies, buspirone was found to be effective in both the acute- and chronic treatment conditions, as well as the anxiolytic effects in the mild and severe anxiety conditions during the open-field tests (Clement et al 1996; Cole and Rodgers 1993; Lim et al 2008f; Liu et al 2004). Some authors even consider that the chronic nature of GAD is severe and debilitating which requires a long-term treatment and therefore buspirone seems to be more adapted to such therapeutic approach (Boulenger 1995; Brawman-Mintzer 2001).

The experimental evidence of $5-\mathrm{HT}_{1 \mathrm{~A}}$ modulation in defensive behaviour within the midbrain periaqueductal gray (PAG) is closely related with $\mathrm{PD}$ and anxiety-like behaviour (Beckett and Marsden 1997; de Bortoli et al 2006; Graeff 2004). In line with the clinical findings, buspirone showed no effects on the 'escape behaviour', a defensive behaviour which is generally known as the 'panic-like' reaction in the experimental animal models (Connor and Davidson 1998; Den Boer and Slaap 1998; Poltronieri et al 2003). Interestingly, in some preclinical studies the administration of 5- $\mathrm{HT}_{1 \mathrm{~A}}$ agonist into the dorsal PAG have been shown to inhibit such escape reaction during the electrical stimulation which is generally considered not relevant in the clinical practice (de Bortoli et al 2006; Nogueira and Graeff 1995). On the contrary, several investigations have also demonstrated that the administration of buspirone was even possible to induce panic attacks as reported in the clinical studies (Lechin et al 2002; Norman and Judd 1989; Pols et al 1989). Such contradictory findings have stirred considerable excitement over this unsolved puzzle in the inhibitory or excitatory mechanism for "panic-like" behaviour. However, it is still a matter of investigation whether buspirone may have a relevant role in the regulation of defensive responses in association with anxiety disorder.

There is empirical evidence showing that the different regions of the PAG play some specific roles in the modulation of anxiety and defensive behaviour. In particular, the dorsolateral PAG (dlPAG) and lateral PAG (IPAG) are involved mainly in the facilitation of panic-like behaviour, a behaviour known as escape or flight reaction (Borelli et al 2004; Vianna et al 2003a). In contrast to the stimulation of dPAG or IPAG, the ventrolateral PAG (vlPAG) stimulation produced passive reactions of 
quiescence/immobility, decreased vigilance and hyporeactivity with hypotension and bradycardia, not responding to any external environmental stimuli (Keay and Bandler 2001; McNaughton and Corr 2004). The similar effects of hypotensive responses without significant heart rate changes were also observed during the stimulation in the dorsomedial PAG (dmPAG) (Pajolla and de Aguiar Correa 2004; Pajolla et al 2005). Thus, excitation of the vlPAG region elicits anxiety-like reaction characterized by freezing behaviour. It has been proposed that the vlPAG is exclusively involved in the passive emotional coping reaction during the inescapable events such as muscle and visceral pain. Such events have been shown to consistently evoke c-Fos expression in the vlPAG column selectively (Clement et al 1996; Keay et al 1994).

Besides, the active emotional coping which responsible for the confrontational defensive reaction (fight and flight) when an animal is facing the stress or threat, activates either the dIPAG or IPAG columns (Keay and Bandler 2001). Thus, the different somatic and autonomic reactions with respect to either active or passive emotional coping in the different columns of the PAG, has provided an appropriate defensive strategy to any arising threats and levels of anxiety. Furthermore, various behavioural animal studies have indicated that either the administration of anxiolytic or anxiogenic drug alter the number of c-Fos immunoreactivity (c-Fos-ir) expression in the different regions of the PAG (Netto and Guimaraes 2004; Singewald and Sharp 2000). Therefore, morphological and anatomical studies of the neuronal activation in the PAG are necessary to evaluate the fundamental changes resulting from these anxiolytic drugs before proceeding further into its complexity.

It is known that c-Fos expression is an accepted marker for the neural activation based on its function in regulating the immediate early transcription of genes (Malkani and Rosen 2000; Muller et al 1983). In this study, we investigated the effects of acute and chronic buspirone treatment using this c-Fos marker to study the differential pattern of neural activation particularly focused on the different regions of the PAG. 


\section{Material and methods}

\section{Subjects}

Twenty-eight male albino Wistar rats (Harlan, Horst, The Netherlands) weighing approximately $350-400 \mathrm{~g}$ were used in this study. They were housed individually in the standard transparent polypropylene cages on sawdust bedding in an air-ventilated room under a 12/12-h reversed light/dark cycle with the room temperature $20-22{ }^{\circ} \mathrm{C}$ and humidity $60-70 \%$. Food, standard laboratory chow (Hopefarms, Woerden, the Netherlands) and acidified water were available ad libitum. The home cages of the animals were changed once a week as well as their food and water supply. All the animals were handled daily in order to habituate them to being picked up in order to reduce handling stress during the injection procedure. The experimental protocol and procedures were approved by the Animal Experiments and Ethics Committee of Maastricht University, the Netherlands.

\section{Experimental groups}

Animals were divided randomly into the following four experimental groups: Acute saline (AS, $n=7)$, Acute buspirone $(A B, n=7)$, Chronic saline (CS, $n=7)$, and Chronic buspirone $(\mathrm{CB}, \mathrm{n}=7)$. The rats with acute treatment received only one time injection, whereas the rats in the chronic treatment group were injected continuously for twenty one days with either saline or buspirone hydrochloride, respectively.

\section{Drug administration}

Buspirone hydrochloride (TOCRIS Cookson Inc., Missouri, USA) was dissolved in saline solution and injected subcutaneously. We used a dose of $3 \mathrm{mg} / \mathrm{kg}$ because this has previously been reported to influence anxiety-related behaviour and produce no sedative effects (Clement et al 1996; Hashimoto et al 1992; Lim et al 2008f; Ninan 2004b). A week before the actual experimental injection, all animals received 3 times of $1 \mathrm{ml}$ saline injection on alternate days to habituate the animals to the injection procedure. Chronic treatment with saline and buspirone consisted of 21 daily routine injections. The acute treatment with saline or buspirone (one time injection) was performed at day 21 , so that all animals achieved the same age/body weight at the end of the experimental stage. 


\section{Behavioural analysis}

Behavioural observation of the mobility of rats started after the injection with either saline or buspirone. Once the rats were placed back into their individual home cages $(20 \times 25 \times 45 \mathrm{~cm})$, their mobility was measured by two independent researchers, of which one was blind to the treatment condition. The immobility was operationally interpreted as the total absence of body movement and it was scored through a timesample procedure. Firstly, the activity was rated every $1 \mathrm{~min}$ for the total of $10 \mathrm{~min}$, and then subsequently every $10 \mathrm{~min}$ till the end of $180 \mathrm{~min}$. The mobility of the rat was defined as simultaneous present of movement such as grooming and walking within the home-cage. The measurement of rat's behaviour was conducted in the usual dim-light condition with no interference of objects such as videotapes recording and procedural manipulation. One researcher was blind with respect to the experimental condition during the behavioural observation.

This procedure was repeated and performed randomly on five successive days (day 1 , day 5 , day 10 , day 15 , and day 20 ). Additionally, the body weight of all rats was measured one week before treatment started, and also during the 3 weeks chronic treatment. After the injection on day 14, the fecal boli of all animals were collected from the cage and weighted accordingly.

\section{Histological processing}

Two hours after the final procedure of injection, rats were perfused transcardially with Tyrode $(0.1 \mathrm{M})$ and fixative containing $4 \%$ paraformaldehyde, $15 \%$ picric acid and $0.05 \%$ glutaraldehyde in $0.1 \mathrm{M}$ phosphate buffer $(\mathrm{pH} 7.6)$. Brains were removed and post-fixed for $2 \mathrm{~h}$ followed by overnight immersion in $10 \%, 20 \%$ and $30 \%$ sucrose at $4{ }^{\circ} \mathrm{C}$. Brain tissue was then quickly frozen with $\mathrm{CO}_{2}$ and stored at $-80{ }^{\circ} \mathrm{C}$. Subsequently, the prefrontal regions of the brains were cut serially on a cryostat (MICROM HM 520, Neuss, Germany) into $30 \mu \mathrm{m}$ frontal sections and again stored at $-80^{\circ} \mathrm{C}$.

\section{c-Fos protein immunohistochemisty}

c-Fos immunohistochemistry was carried out by using anti-cFos, rabbit polyclonal $\operatorname{lgG}$ (diluted 1:20,000 in 0.1\% Bovine Serum Albumin (BSA) and Tris Buffered SolutionTriton (TBS-T) solution; Santa Cruz Biotechnology Inc., Santa Cruz, CA) as primary antibody for an overnight incubation at room temperature on a constant shaker. Next, after the rinsing steps with TBS-T, Tris Buffered Solution (TBS), and TBS-T; all the sections were incubated with the secondary antibody (diluted 1: 400 in biotinylated donkey anti-rabbit biotine; Jackson Immunoresearch Laboratories Inc., Westgrove, USA) for one hour and subsequently the sections were incubated with an avidin-biotin- 
peroxidase complex (diluted 1:800 in Elite ABC-kit, Vectastatin; Burlingame, USA) for two hours. In between steps, sections were washed with TBS and TBS-T. To visualize the immune complex of Horse Radish Peroxide (HRP) reaction product, the sections were incubated with 3,3'-diaminobenzidine tetrahydrochloride (DAB)/ Nickel Chloride $\left(\mathrm{NiCL}_{2}\right)$ solution $\left(5 \mathrm{ml} \mathrm{DAB}\right.$ solution, $5 \mathrm{ml}$ Tris $/ \mathrm{HCl}, 50 \mu \mathrm{NiCL} \mathrm{N}_{2}$, and $3.35 \mu 1$ hydrogen peroxide $\left.\left(\mathrm{H}_{2} \mathrm{O}_{2}\right)\right)$. This reaction was stopped within the duration of 10 minutes by rinsing thoroughly all the sections with TBS. Finally sections were then rinsed, dehydrated, and cover-slipped.

\section{Quantitative evaluation of c-Fos immunoreactive cells}

Systematic cell counts of c-Fos immunoreactive (c-Fos-ir) cells were performed in two separate parts of the PAG: A. Rostral PAG (dmPAG, dlPAG, and IPAG; Bregma $6.04 \mathrm{~mm},-6.30 \mathrm{~mm},-6.72 \mathrm{~mm},-6.80 \mathrm{~mm}$, and $-7.30 \mathrm{~mm}$ ) and B. Caudal PAG (dmPAG, dlPAG, IPAG, and vlPAG; Bregma $-7.64 \mathrm{~mm},-7.80 \mathrm{~mm},-8.00 \mathrm{~mm},-8.30 \mathrm{~mm}$, and $8.72 \mathrm{~mm}$ ) parts, respectively. Photographs of the areas of interest were taken at $4 \mathrm{X}$ magnification using an Olympus DP70 camera connected to an Olympus AX70 brightfield microscope (analySIS; Imaging System, Münster, Germany). Our quantification method was similar to a previously reported method, with minor modifications (Lamprea et al 2002; Lim et al 2008b). Four sections from each of the rostral $(n=4)$ and caudal $(n=4)$ PAG in each animal ( $\mathrm{n}=6$ in each group) were selected for quantification. The boundaries of the areas of interest were delineated and measured. The same light intensity and threshold conditions were employed for all sections. The counting of the numbers of cFos-ir cells was performed using the conventional image analysis program 'Image J' (version 1.38, NIH, USA). A cell was counted as c-Fos-ir if its density was $75 \%$ higher than the background density. In addition, artifacts in the sections were excluded from analysis to ensure the accuracy of measurements. Since we observed marked differences between groups, we preferred the present method of quantification instead of a stereological method.

\section{Statistical analysis}

All data are presented as means \pm S.E.M and were analyzed using a two-way Analysis of Variance (ANOVA) using Treatment (saline vs. buspirone) and Duration of treatment (acute and chronic) as between-subject factors. All statistical analyses were performed with SPSS 13.0 version for Windows. Data of c-Fos-ir cell counts are expressed as number of c-Fos-ir cells per $\mathrm{mm}^{2}$. An LSD post hoc test was used to analyze group differences in more detail. P-values lower than 0.05 were considered significant. 


\section{Results}

\section{Behavioural evaluation}

After injection, rats in the buspirone injected groups were more immobile in their home cages as compared to the control groups (Day 1, F(3,24)=2064.094, $\mathrm{p}<0.001$; Day 5, $\mathrm{F}(3,24)=41040.353, \mathrm{p}<0.001 ;$ Day $10, \mathrm{~F}(3,24)=4320.288, \mathrm{p}<0.001 ;$ Day 15, $\mathrm{F}(3,24)=4109.152, \mathrm{p}<0.001$; Day $20, \mathrm{~F}(3,24)=3823.978, \mathrm{p}<0.001)$. The rats with acute treatment of buspirone were immobile for a period of 3 to 20 minutes, whereas the duration of immobility in the chronically treated rats lasted 3-80 minutes on the fifth day of injection (See Fig 1). However, on days 10, 15 and 20 the immobility of CB rats lasted 3-100 minutes. Some rats began to show slight activity after 100 minutes of injection, and the mobility was returned to normal after approximately 130 minutes.

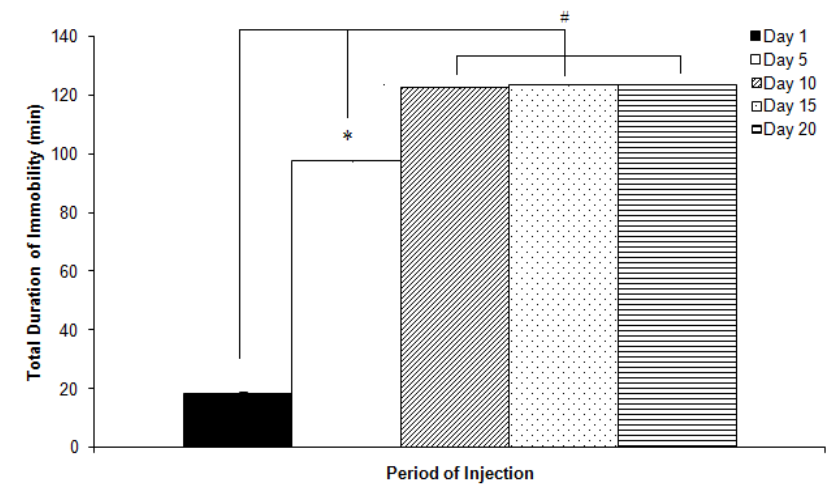

Figure 1: The graph represents the duration of immobility of rats during the period of injection on the day 1 of acute treatment; and day 5, day 10, day 15, and day 20 of chronic treatment conditions. The animals with acute and chronic saline treatment demonstrated no immobility throughout the entire experiment. Data are presented as means \pm S.E.M. * indicates significant difference as compared to the day 1 of acute treatment, \# indicates significant difference of day 10, day 15 and day 20 in comparison to day 5 and day 1 , respectively $(\mathrm{P}<0.05)$.

Additionally, the body weight of all rats was measured continuously on week 1, week 2, week 3, and week 4. No significant effect on weight change was found in all groups in week $1(\mathrm{~F}(3,19)=0.314$, n.s. $)$ and week $2(\mathrm{~F}(3,19)=0.914$, n.s. $)$. However, the body weight was lower in the CB group in week $3(\mathrm{~F}(3,19)=6.693, \mathrm{p}<0.001)$ and week 4 $(F(3,19)=5.709, p<0.001)$ (See Fig 3). Interestingly, in line with loss of body weight in the $\mathrm{CB}$ rats, the fecal mass production of the $\mathrm{CB}$ group also showed a significant decrease in week 3 as compared to the other groups $(F(3,27)=36.696, p<0.001$; see Figure 2). 


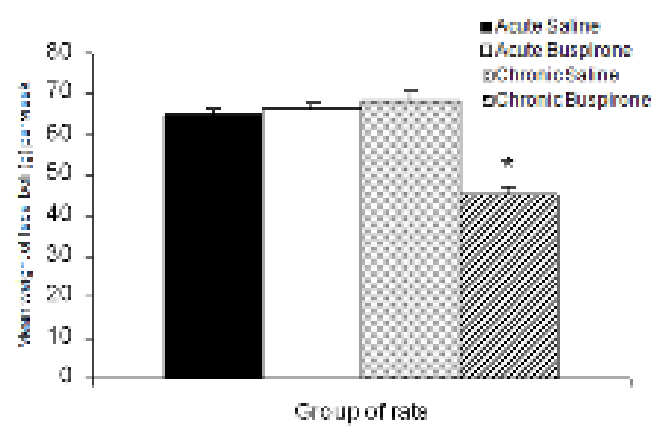

Figure 2: The effect of acute and chronic buspirone treatment in comparison to saline treated animals. The total mean weight of fecal boli (per week) was measured on the Day 14 of injection during the experimental procedure within the animal home cages. Data are presented as means \pm S.E.M. * indicates significant difference as compared to the saline injected groups, acute and chronic treatment, respectively $(\mathrm{P}<0.05)$.

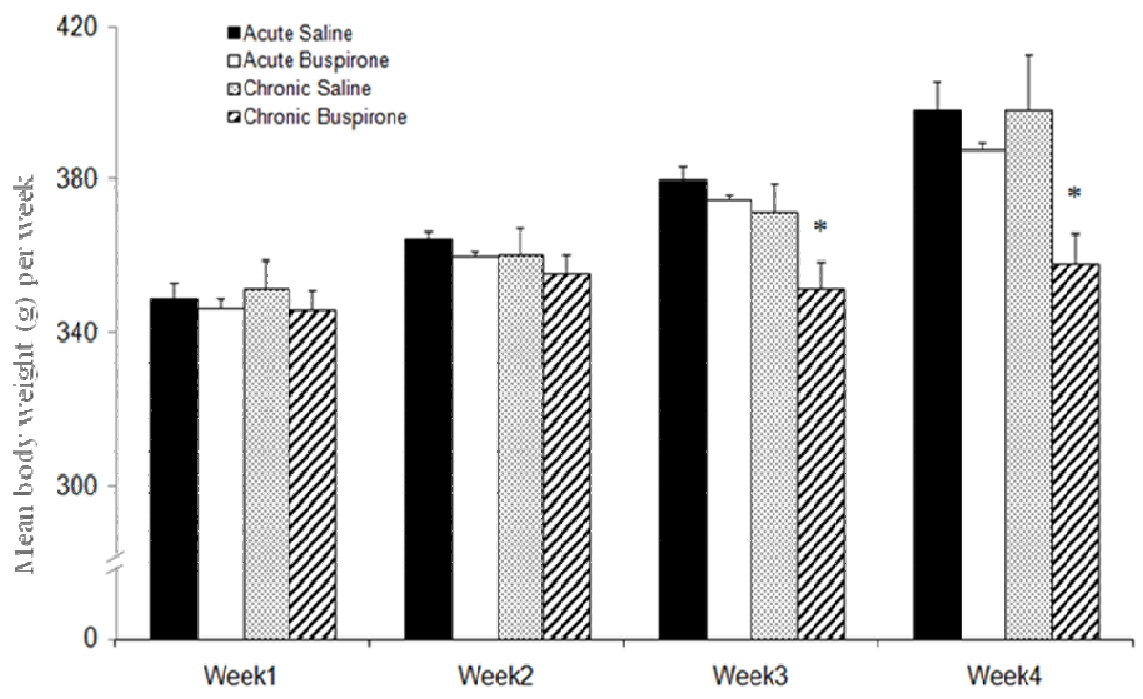

Figure 3: The graph shows the mean body weight (g) of animals during the acute and chronic buspirone and saline treatments. Data are presented as means \pm S.E.M. * indicates significant difference as compared to the saline injected groups, acute and chronic treatment, respectively $(\mathrm{P}<$ $0.05)$. 


\section{Evaluation of c-Fos-ir cells}

Two-way ANOVA showed a significant difference between groups in all regions of the rostral PAG, dmPAG $(\mathrm{F}(3,15)=66.855, \mathrm{P}<0.001)$, dlPAG $(\mathrm{F}(3,15)=34.408$, $\mathrm{p}<0.001)$, and $\operatorname{PAG}(\mathrm{F}(3,15)=285.207, \mathrm{P}<0.001)$. In the caudal PAG, a significant difference between groups was found in the dmPAG $(\mathrm{F}(3,15)=189.591, \mathrm{P}<0.001)$, dIPAG $(\mathrm{F}(3,15)=8.244, \mathrm{p}<0.001)$, IPAG $(\mathrm{F}(3,15)=4.524, \mathrm{P}<0.001)$, and $\mathrm{vlPAG}(\mathrm{F}(3,15)=66.992$, $\mathrm{P}<0.001)$. Post-hoc analysis revealed significantly decrease of c-Fos-ir cells expression in the entire region of the rostral PAG of both the $\mathrm{AB}$ and $\mathrm{CB}$ treated rats. In the caudal PAG, a significant decrease in the number of c-Fos-ir cells was found in the dmPAG region of both the $A B$ and $C B$ groups, as well as in the dIPAG of $A B$ group but not the CB group. No significant effect was detected in the caudal IPAG and vlPAG of both the $\mathrm{AB}$ and $\mathrm{CB}$ groups. Interestingly, a consistent effect on the decrease of c-Fos-ir cells expression was significantly found at the dmPAG column in both the rostral and caudal $\mathrm{PAG}$ of $\mathrm{AB}$ and $\mathrm{CB}$ groups, respectively. The acute treatment conditions of AS resulted in higher number of c-Fos-ir cells as compared to CS treated condition, except for the rostral IPAG.

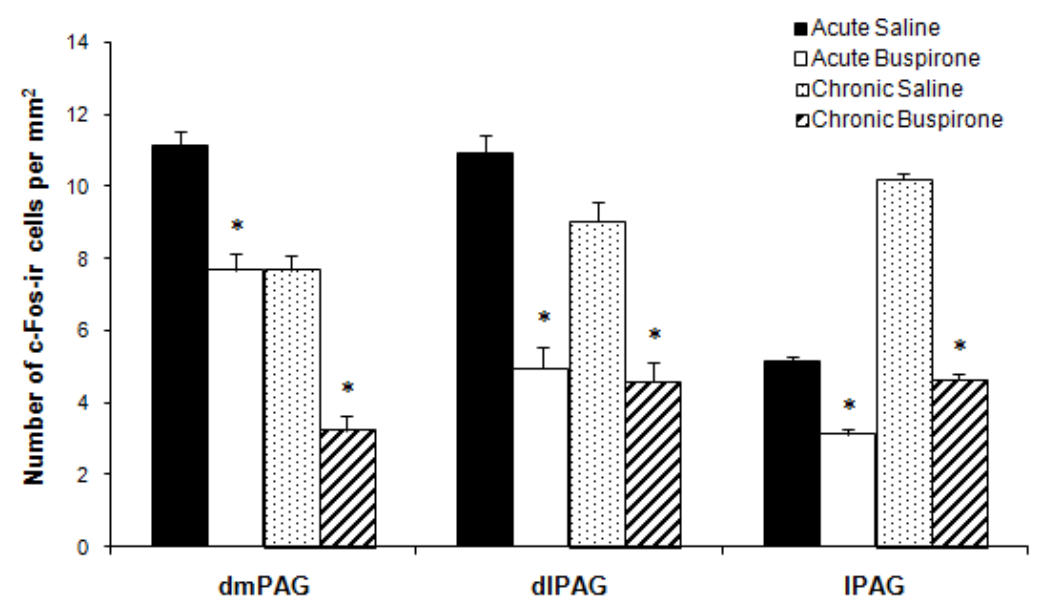

Figure 4: Grouped data of c-Fos-ir cells per $\mathrm{mm}^{2}$ in the rostral PAG region. Data represent means \pm S.E.M. of groups A (acute saline), B (acute buspirone), C (chronic saline) and D (chronic buspirone). Abbreviations: dmPAG: dorsomedial periaqueductal gray; dIPAG: dorsolateral periaqueductal gray; and IPAG: lateral periaqueductal gray. * indicates significant difference as compared to the saline injected groups, acute or chronic treatment, respectively $(\mathrm{P}<0.05)$. 


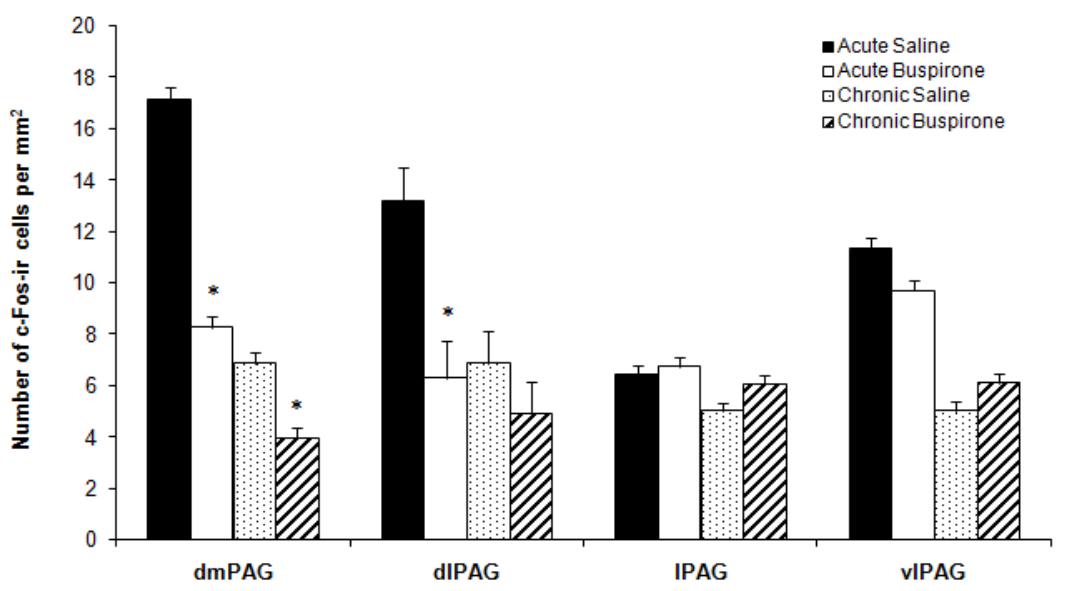

Figure 5: Grouped data of c-Fos-ir cells per $\mathrm{mm}^{2}$ in the caudal PAG region. Data represents means \pm S.E.M. of groups A (acute saline), B (acute buspirone), C (chronic saline) and D (chronic buspirone). Abbreviations: dmPAG: dorsomedial periaqueductal gray; dIPAG: dorsolateral periaqueductal gray; IPAG: lateral periaqueductal gray, and vlPAG: ventrolateral periaqueductal gray. * indicates significant difference as compared to the saline injected groups, acute or chronic treatment, respectively $(\mathrm{P}<0.05)$.

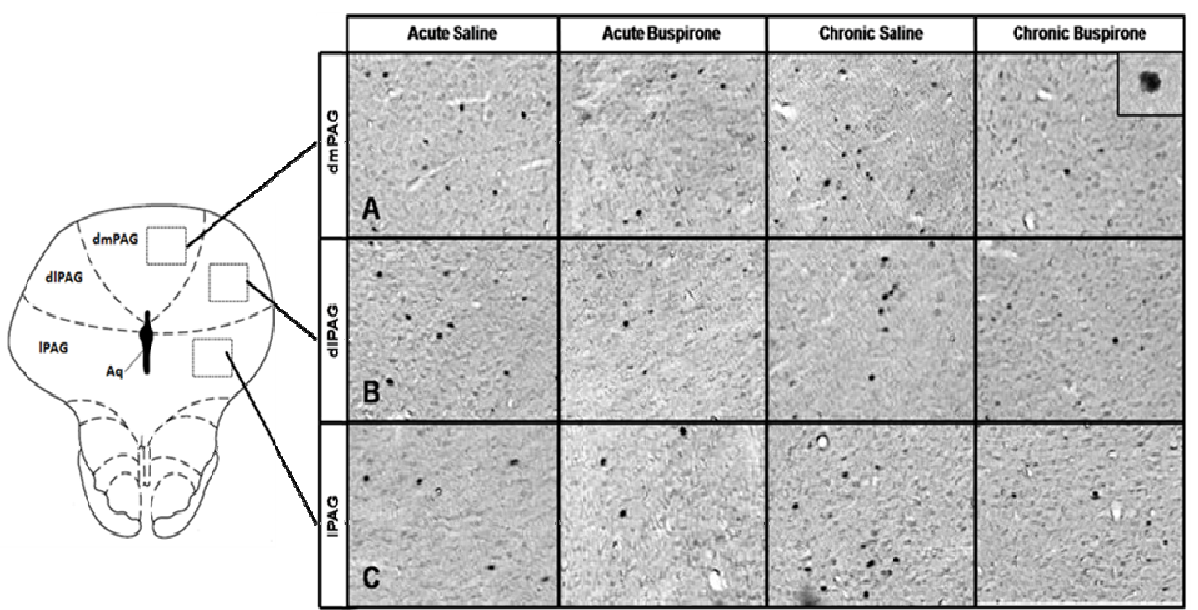

Figure 6: Schematic drawing of the rostral PAG regions based on the Atlas of the rat brain by Paxinos and Watson $\left(4^{\text {th }}\right.$ Edition, 1998, Academic Press Inc, California, USA). Boxed areas are shown in the high-magnification photomicrographs of Fig. 6 (A, B, C). Representative high-power photomicrographs of a $30 \mu \mathrm{m}$-thick section from the brain of the rostral PAG regions, see fig.6 (A): dmPAG, (B): dlPAG, and (C) IPAG. Abbreviation: $\mathrm{Aq}=$ Aquaduct, $\mathrm{dmPAG}=$ dorsomedial periaqueductal gray, $\mathrm{d} I \mathrm{PAG}=$ dorsolateral periaqueductal gray, and $\mathrm{PAG}=$ lateral periaqueductal gray. The small dark dots represent c-Fos-ir cells at $4 \mathrm{X}$ magnification power. The inset in A shows a representative high-power photomicrograph of a c-Fos-ir cell at 100X magnification. 


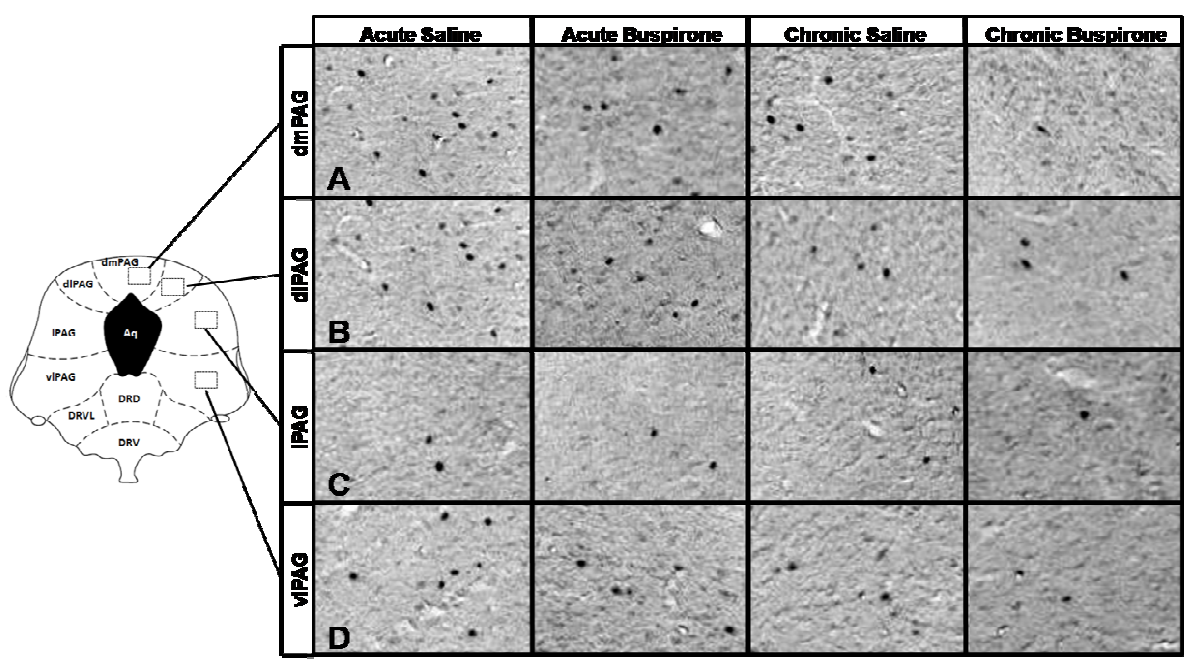

Figure 7: Schematic drawing of the caudal PAG regions based on the Atlas of the rat brain by Paxinos and Watson $\left(4^{\text {th }}\right.$ Edition, 1998, Academic Press Inc, California, USA). Boxed areas are shown in the high-magnification photomicrographs of Fig. 7 (A, B, C, D). Representative high-power photomicrographs of a $30 \mu \mathrm{m}$-thick section from the brain of the caudal PAG regions, see fig.7 (A): dmPAG, (B): dlPAG, (C) IPAG, and (D) vlPAG. Abbreviation: dmPAG= dorsomedial periaqueductal gray, $\mathrm{dl} P A G=$ dorsolateral periaqueductal gray, $1 \mathrm{PAG}=$ lateral periaqueductal gray, $\mathrm{vl} \mathrm{PAG}=$ ventrolateral $\mathrm{PAG}, \mathrm{Aq}=$ Aquaduct, $\mathrm{DRD}=$ dorsal raphe dorsal, $\mathrm{DRV}=$ dorsal raphe ventral, and $\mathrm{DRVL}=$ dorsal raphe ventrolateral. The small dark dots represent c-Fos-ir cells at $4 \mathrm{X}$ magnification power. 


\section{Discussion}

The main objective of this experiment was to evaluate the neuronal activity occurring within the different regions of the PAG after acute and chronic treatment of buspirone. Besides, we have also measured the effects of these treatments on behavioural mobility. It was found that the treatment with buspirone decreased behavioural activity particularly in the CB group which showed a significant longer duration of immobility as compared with the other groups. Additionally, the reduction of body weight was clearly observed in the $\mathrm{CB}$ rats as measured on the second and third week of chronic treatment. The latter group also showed a decrease in the total weight of fecal boli production on the second week of treatment. Two-way ANOVA revealed a significant decrease in the number of c-Fos-ir cells in all regions of the rostral PAG, and in the dorsal regions of the caudal PAG. It has to be noted that buspirone treatment did not affect the number of cFos-ir cells in the caudal IPAG and vlPAG regions of both AB and CB groups, as well as the dlPAG of the CB group. Accordingly, the most consistent effect of buspirone on cFos expression was found in the dmPAG column in both the rostral and caudal part of the PAG. The differential pattern of c-Fos-ir expression in the different regions of the PAG after buspirone treatment may indicate that the longitudinal anatomical structure of the PAG possesses a different level of receptor sensitivity towards $5-\mathrm{HT}_{1 \mathrm{~A}}$ mechanism in the pathophysiology of anxiety and panic disorder.

\section{Behavioural effects of buspirone treatment}

The effects of locomotor activity suppression in the acute- and chronicallybuspirone treated rats suggest that the pharmacological interaction of $5-\mathrm{HT}_{1 \mathrm{~A}}$ does not only induce a complex mechanism of action on neurotransmitters, but also involve in the modulation of anxiety disorder (de Bortoli et al 2006). The immobility of rats in the home cages is usually interpreted as a result of sedative effect which may possibly reflect the dopamine D2 antagonism-induced sedation or locomotor suppressant induced by alpha-2 adrenoceptor antagonist action (Collinson and Dawson 1997). However, comparative studies on the behavioural and EEG changes have confirmed that buspirone with the dosage varied between 10-20 mg does not produce any sedative effect, motor disturbance and memory impairments (Lerman et al 1986; Mattila et al 1982; Newton et al 1982). For instance, buspirone was reported to reduce both the REM (rapid eye movement) sleep and non-REM latency when compared to those sedative anxiolytic agents, e.g. diazepam which increased the non-REM sleep and caused severe motor disturbance (Hashimoto et al 1992; Mendelson et al 1990). Considering these effects, Grundmann et al. also showed that a single injection of $10 \mathrm{mg} / \mathrm{kg}$ buspirone treatment did not produce any significant overt behavioural change or motor dysfunction in the elevated pluz-maze and open field test, indicating that the observed effects were not due to sedation (Grundmann et al 2006; Grundmann et al 2007). The latter studies support the hypothesis that buspirone with dosages as used in this experiment produced no sedative properties unlike 
benzodiazepines. On the other hand, Collinson and Dawson showed that buspirone increased substantially the production of glucocorticoid hormone which eventually suppressed the locomotor activity as induced by alpha-2 adrenoceptor antagonist action (Collinson and Dawson 1997). In view of this, one study had demonstrated that the locomotor suppressant effect of buspirone after 1 hour but not 4 hours was correlated significantly with glucocorticoid production suggesting that the acute glucocorticoidreleasing effect of buspirone initially suppressed locomotor activity and thereby masking the anxiolytic action of the compound (McNaughton et al 1996). However, the present study had revealed more specifically the exact time frame of such immobility activity in both the acute and chronic treatment. It has been reported that the immobility with the reduction of locomotor activity could be the result of an anxiogenic effect, but at the same time the authors also found evidence for an anxiolytic effect (Clement et al 1996; Lim et al 2008f). Taken together these behavioural findings concerning the dual effects of buspirone, a complex mechanism of 5-HT $\mathrm{HA}_{1 \mathrm{~A}}$ interaction might probably take place within the different regions of PAG for the modulation of anxiety disorder that eventually affects the emotional response and autonomic nervous system.

\section{Reduction of body weight and fecal boli}

In human studies, buspirone has been well established typically in the treatment of GAD. In consideration of the side effects, buspirone does not induce any sedation or cognitive dysfunction as compared to other anxiolytic compounds such as the benzodiazepines. However, other adverse effects such as vertigo, headaches, anorexia, and nausea, have been frequently encountered in patients after buspirone administration (Goldberg 1979; Goldberg and Finnerty 1979; Gorman 2003). Interestingly, it has been reported previously that after chronic buspirone treatment, the body weight was significantly reduced (Andersen et al 2005; Larsson et al 1990; Schechter et al 1990). In contrast, some studies have also demonstrated that buspirone did not cause any increase or decrease of the average body weight (Eison 1986; Okazawa et al 1999), while one study even showed the effect of weight gain (Goudie and Leathley 1991). Nevertheless, there are a number of mechanisms involved such as the genetic and environmental factors or drug interaction to play a role for the alteration of body weight. Thus, the reduction of the mean weight on body mass and fecal boli in the CB group, one could possibly explain that the side effects (ie. nausea and anorexia) were probably due to the decreased appetite and gastrointestinal disturbances.

\section{Effects of c-Fos-ir expression on acute and chronic saline treatment}

Interestingly, the number of c-Fos-ir cells in the AS condition was found to be significantly higher than the CS treated condition even though all the rats had received 3 injections prior to the experiment. The pattern of c-Fos-ir cells expression in this condition could not be possibly explained by the experimental stress as it was 
demonstrated in a previous study that a single restraint or injection would induce stresslike behaviour but not in the repeated injection procedure due to the habituation effects (Fernandes et al 2002; Melia et al 1994). Nevertheless, the procedural stress manipulation cannot be ruled out as the leading factor for such pattern of c-Fos-ir expression. In this respect, our assumption is that the animals might require a longer period in order to achieve its habituation effects as it was observed in the case of chronic conditions. Another possible explanation could be that the PAG is sensitive to the procedural injection since the PAG has been generally known to be involved in the regulation of fear and anxiety. Our finding show that the PAG is activated differently in the acute and chronic saline conditions which might suggest a modulatory role of 5-HT1A in the fear and anxiety condition.

\section{Effects of buspirone on the rostral and caudal periaqueductal gray}

The major finding in this study was that the number of c-Fos-ir cells was significantly reduced in all regions of the rostral PAG, whereas the caudal PAG showed a rather complex picture of c-Fos-ir cells expression in its different regions. It has been proposed that different areas of the PAG play a different role in mediating defensive behaviour during an aversive or stressful situation. We know from electrical or chemical stimulation studies, that dIPAG stimulation evokes a typical response known as defensive behaviour which is closely related to panic and anxiety like behaviour (Bandler and Keay 1996; Borelli et al 2005a; Brandao et al 1994; Brandao et al 1982). This panic-like behaviour was further investigated in our laboratory and a simple fear-conditioning effect with anxiety-like behaviour was found during the post-stimulation period in the caudal dlPAG of electrical stimulated animals ( $\mathrm{Lim}$ et al 2008b). Additionally, there are data showing that the dIPAG and IPAG are involved mainly in the facilitation of panic-like behaviour (Borelli et al 2004; Vianna et al 2003a), whereas the vlPAG stimulation produced freezing- or fear-like behaviour (Keay and Bandler 2001; McNaughton and Corr 2004). In recent years, most clinical and preclinical studies have indicated that buspirone is only used for mild anxiety (e.g. GAD) and it is considered ineffective for other anxiety conditions (e.g. panic disorder) (Connor and Davidson 1998; Ninan 2004b). Accordingly, the present study has demonstrated no significant effect of c-Fos-ir expression in the caudal dIPAG, IPAG, and vlPAG regions, which is in line with the clinical findings that buspirone was effective only in mild anxiety (i.e GAD) and not for the severe anxiety such as fear and panic disorder. Therefore, buspirone plays no significant role in preventing the spontaneous occurrence of panic attacks. Furthermore, it has been shown that intra-dorsal-PAG injection of buspirone produced no effect on escape reaction (de Bortoli et al 2006) whereas a panicolytic compound such as $5-\mathrm{HT}_{1 \mathrm{~A}}$ receptor agonists 8-OH-DPAT and BAY-R-1532 decreased the aversive behaviour induced by the stimulation of the same structure (Nogueira and Graeff 1995). It is therefore possible that the caudal dIPAG, IPAG and vlPAG are mainly responsible for intense and aversive behaviours such as panic-like reaction, whereas the rostral PAG is involved more in the regulation of mild anxiety-like behaviour. 


\section{Effects of buspirone on the dorsomedial periaqueductal gray}

Several experimental findings have demonstrated that the $5-\mathrm{HT}_{1 \mathrm{~A}}$ receptors in the PAG are involved in anxiety and panic disorder (Graeff 2004; Nogueira and Graeff 1995; Pobbe and Zangrossi 2005; Zanoveli et al 2005). However, the specific role played by the different regions of the PAG in the regulation of anxiety is still poorly understood, though it has been the focus of interest for decades. A recent study with microinjection of ovian corticotropin-releasing factor (oCRF, a nonspecific CRF receptor agonist that produces anxiogenic-like effects) into the dmPAG, dIPAG, and IPAG showed that a difference effect of columnar specificity for the oCRF in the PAG was obtained using the exploratory behavioural of rats in the elevated plus-maze (EPM) test (Borelli and Brandao 2008). It was found that the oCRF intra-dmPAG reduced entries and time spent in the open arms and decreased end-arm exploration and head-dipping. On the other hand, the oCRF intra-dIPAG and IPAG produced no effect on the exploratory behavioural of the animals in the EPM. Besides, Fontanesi et al., have observed the increase of c-Fos-ir expression in the $\mathrm{dPAG}$ of rats during the withdrawal period of prolonged treatment with diazepam which lead to a withdrawal syndrome characterized by increased level of anxiety (Fontanesi et al 2007). Since our findings have revealed that a consistent effect was obtained in the dorsomedial column of both the rostral and caudal PAG in acute and chronic buspirone treated animals, it is most likely the anxiolytic effect is mainly localised in the dmPAG.

\section{Effects of buspirone on the dorsolateral periaqueductal gray}

Many studies have shown that neural activation within the different regions of the PAG (i.e. high levels of c-Fos-ir expression) was related either to the experimental anxiogenic testing condition or the administration of anxiogenic drugs to the animals (Netto and Guimaraes 2004; Singewald and Sharp 2000; Zienowicz et al 2007). One study showed that the administration of anxiogenic drugs, for instance the $\mathrm{m}$ chlorophenyl piperazine (mCPP; non-selective 5-hydroxytryptamine 5-HT2C receptor agonist), carboxy-terminal tetrapeptide of cholecystokinin (CCK4; CCKB agonist), and yohimbine ( $\alpha 2$-adrenoceptor antagonist) increased the number of c-Fos-ir cells in the rostral dIPAG regions but not the caudal dIPAG (Singewald and Sharp 2000). However, the present study of buspirone treatment showed that the decrease in the number of c-Fosir cells of the PAG which also supports the hypothesis that the pharmacological property of buspirone is anxiolytic. Moreover, the present study revealed that buspirone decreased the number of c-Fos-ir cells in the rostral dIPAG and caudal dIPAG in the AB group but not the caudal dIPAG in the CB group. This suggests that the rostral dIPAG plays a role in anxiety, while the caudal dIPAG showed somehow rather complex or no effect in the regulation of anxiety. One possible explanation is that buspirone appears to play a dual role in the regulation of anxiety either as anxiolytic or anxiogenic within the different brain regions. Such result of dual effect was also reported in many studies across different experimental paradigms and animal models (Graeff 2002). Another possibility 
would be the complexity of mechanism of action between the pharmacological properties of buspirone along with different regions of the PAG as it was well established that the different anatomical column of the PAG possesses different and specific functional role in the regulation of defensive behaviour including the panic- and anxiety-like response (Borelli and Brandao 2008; LeDoux et al 1988; Vianna et al 2003a).

\section{Role of periaqueductal gray $5-H T_{1 A}$ receptors in anxiety}

To our knowledge, the PAG contains a large quantity of 5-HT-ir nerve terminals that originate from the 5-HT containing cells bodies located in the dorsal raphe nucleus (Beitz et al 1986; Clements et al 1985; Lovick et al 2000). The obtained results from different studies on electrophysiological and autoradiographical mapping of 5-HT receptors have demonstrated that the PAG is relatively rich in 5- $\mathrm{HT}_{1 \mathrm{~A}}, 5-\mathrm{HT}_{1 \mathrm{~B}}, 5-\mathrm{HT}_{2 \mathrm{~A}}$, and other receptor subtypes (Brandao et al 1991; Pazos and Palacios 1985; Pompeiano et al 1992). Of interest for the 5- $\mathrm{HT}_{1 \mathrm{~A}}$ receptor, the receptor-binding data have shown that $>65 \%$ of neurons within the PAG regions were highly responsive to $5-\mathrm{HT}_{1 \mathrm{~A}}$ agonists (Behbehani et al 1993). Nogueira and Graeff have shown that the microinjections of 5$\mathrm{HT}_{1 \mathrm{~A}}$ receptor agonist, 8-OH-DPAT and BAY-R-1532 into the dPAG decreased remarkably the escape reaction (Nogueira and Graeff 1995). It was also reported that the activation of both the $5-\mathrm{HT}_{1 \mathrm{~A}}$ and $5-\mathrm{HT}_{2 \mathrm{~A}}$ receptors within the $\mathrm{dPAG}$ inhibited the escape reaction when rats were exposed to the open arms of an anxiety test (Zanoveli et al 2003). On the other hand, a contradictory result was found on the chronic administration of buspirone, a compound non-effective for PD, which did not inhibit the escape reaction as compared to those of clinically effective panicolytic drugs such as the selective serotonin reuptake inhibitor (SSRI) imipramine and fluoxetine (de Bortoli et al 2006; Poltronieri et al 2003). Thus, the differential effects of $5-\mathrm{HT}_{1 \mathrm{~A}}$ agonists as either anxiolytic or panicolytic actions in the PAG suggest that the increase of 5-HT level within the PAG plays a role on either the anti-aversive or -anxiety or both actions (Behbehani et al 1993; Nogueira and Graeff 1991). In addition, the interaction of 5-HT $1 \mathrm{~A}$ with other receptor subtypes or neurotransmitters (e.g. $5-\mathrm{HT}_{2 \mathrm{~A}}, \mathrm{GABAergic}$ interneurons) at the cellular level could also possibly influence the PAG neuronal activity involving the mechanism of panicolytic or anxiolytic action (Conn and Sanders-Bush 1987; Griffiths and Lovick 2002). Taken together, these studies along with our findings may explain the relative importance of $5-\mathrm{HT}_{1 \mathrm{~A}}$ agonists on the regulation of panic and anxiety disorders in the different regions of the PAG. 


\section{Conclusion}

In conclusion, the present findings demonstrated that stimulation of $5-\mathrm{HT}_{1 \mathrm{~A}}$ receptors induced different neuronal activation pattern in the different regions of the PAG in both the acute- and chronic buspirone treatment. In view of these results, the main effect of anxiolytic action was specifically localized in all regions of the rostral PAG and in the caudal dmPAG. However, the caudal dIPAG, IPAG and vlPAG were found to be ineffective to buspirone treatment, probably due to their distinctive function in mediating higher level of anxiety in defensive behaviour. This indicates that the longitudinal anatomical structure of the PAG possesses a different level of receptor sensitivity of 5$\mathrm{HT}_{1 \mathrm{~A}}$ in the pathophysiology of anxiety and panic disorder.

\section{Acknowledgement}

This research was supported by a grant from the FP6 Marie Curie Fellowship (MEST-CT-2005-020589).

\section{References}

Andersen TH, Bech P, Larsen NE (2005): Switching patients from olanzapine or risperidone to a combination treatment using perphenazine plus buspirone: evaluation of antipsychotic efficacy and side-effects, including extrapyramidal effects and weight loss. Nord J Psychiatry 59:205-208.

Bandler R, Keay KA (1996): Columnar organization in the midbrain periaqueductal gray and the integration of emotional expression. Prog Brain Res 107:285-300.

Beckett S, Marsden CA (1997): The effect of central and systemic injection of the 5-HT1A receptor agonist 8-OHDPAT and the 5-HT1A receptor antagonist WAY100635 on periaqueductal greyinduced defence behaviour. J Psychopharmacol 11:35-40.

Behbehani MM, Liu H, Jiang M, Pun RY, Shipley MT (1993): Activation of serotonin1A receptors inhibits midbrain periaqueductal gray neurons of the rat. Brain Res 612:56-60.

Beitz AJ, Clements JR, Mullett MA, Ecklund LJ (1986): Differential origin of brainstem serotoninergic projections to the midbrain periaqueductal gray and superior colliculus of the rat. $J$ Comp Neurol 250:498-509.

Borelli KG, Brandao ML (2008): Effects of ovine CRF injections into the dorsomedial, dorsolateral and lateral columns of the periaqueductal gray: a functional role for the dorsomedial column. Horm Behav 53:40-50.

Borelli KG, Ferreira-Netto C, Coimbra NC, Brandao ML (2005): Fos-like immunoreactivity in the brain associated with freezing or escape induced by inhibition of either glutamic acid decarboxylase or GABAA receptors in the dorsal periaqueductal gray. Brain Res 1051:100-111.

Borelli KG, Nobre MJ, Brandao ML, Coimbra NC (2004): Effects of acute and chronic fluoxetine and diazepam on freezing behaviour induced by electrical stimulation of dorsolateral and lateral columns of the periaqueductal gray matter. Pharmacol Biochem Behav 77:557-566. 
Boulenger JP (1995): Treatment of generalized anxiety: new pharmacologic approaches]. Encephale 21:459-466.

Brandao ML, Cardoso SH, Melo LL, Motta V, Coimbra NC (1994): Neural substrate of defensive behaviour in the midbrain tectum. Neurosci Biobehav Rev 18:339-346.

Brandao ML, de Aguiar JC, Graeff FG (1982): GABA mediation of the anti-aversive action of minor tranquilizers. Pharmacol Biochem Behav 16:397-402.

Brandao ML, Lopez-Garcia JA, Graeff FG, Roberts MH (1991): Electrophysiological evidence for excitatory 5-HT2 and depressant 5-HT1A receptors on neurones of the rat midbrain tectum. Brain Res 556:259-266.

Brawman-Mintzer O (2001): Pharmacologic treatment of generalized anxiety disorder. Psychiatr Clin North Am 24:119-137.

Charney DS, Woods SW, Goodman WK, Rifkin B, Kinch M, Aiken B, et al (1986): Drug treatment of panic disorder: the comparative efficacy of imipramine, alprazolam, and trazodone. $J$ Clin Psychiatry 47:580-586.

Clement CI, Keay KA, Owler BK, Bandler R (1996): Common patterns of increased and decreased fos expression in midbrain and pons evoked by noxious deep somatic and noxious visceral manipulations in the rat. $J$ Comp Neurol 366:495-515.

Clements JR, Beitz AJ, Fletcher TF, Mullett MA (1985): Immunocytochemical localization of serotonin in the rat periaqueductal gray: a quantitative light and electron microscopic study. J Comp Neurol 236:60-70.

Cole JC, Rodgers RJ (1993): Ethological evaluation of the effects of acute and chronic buspirone treatment in the murine elevated plus-maze test: comparison with haloperidol Psychopharmacology (Berl) 114:288-296.

Collinson N, Dawson GR (1997): On the elevated plus-maze the anxiolytic-like effects of the 5-HT(1A) agonist, 8-OH-DPAT, but not the anxiogenic-like effects of the 5-HT(1A) partial agonist, buspirone, are blocked by the 5-HT1A antagonist, WAY 100635. Psychopharmacology (Berl) 132:35-43.

Conn PJ, Sanders-Bush E (1987): Central serotonin receptors: effector systems, physiological roles and regulation. Psychopharmacology (Berl) 92:267-277.

Connor KM, Davidson JR (1998): Generalized anxiety disorder: neurobiological and pharmacotherapeutic perspectives. Biol Psychiatry 44:1286-1294.

de Bortoli VC, Nogueira RL, Zangrossi H, Jr. (2006): Effects of fluoxetine and buspirone on the panicolytic-like response induced by the activation of 5-HT1A and 5-HT2A receptors in the rat dorsal periaqueductal gray. Psychopharmacology (Berl) 183:422-428.

Den Boer JA, Slaap BR (1998): Review of current treatment in panic disorder. Int Clin Psychopharmacol 13 Suppl. 4 pp. S25-S30.

Eison MS (1986): Lack of withdrawal signs of dependence following cessation of treatment or Ro15,1788 administration to rats chronically treated with buspirone. Neuropsychobiology 16:15-18.

Fernandes GA, Perks P, Cox NK, Lightman SL, Ingram CD, Shanks N (2002): Habituation and crosssensitization of stress-induced hypothalamic-pituitary-adrenal activity: effect of lesions in the paraventricular nucleus of the thalamus or bed nuclei of the stria terminalis. $J$ Neuroendocrinol 14:593-602.

Fontanesi LB, Ferreira R, Cabral A, Castilho VM, Brandao ML, Nobre MJ (2007): Brainstem areas activated by diazepam withdrawal as measured by Fos-protein immunoreactivity in rats. Brain Res 1166:35-46.

Goldberg HL (1979): Buspirone--a new antianxiety agent not chemically related to any presently marketed drugs [proceedings]. Psychopharmacol Bull 15:90-92.

Goldberg HL, Finnerty RJ (1979): The comparative efficacy of buspirone and diazepam in the treatment of anxiety. Am J Psychiatry 136:1184-1187.

Gorman JM (2003): Treating generalized anxiety disorder. J Clin Psychiatry 64 Suppl 2:24-29.

Goudie AJ, Leathley MJ (1991): Effects of the 5HT(1A) agonist anxiolytic gepirone on benzodiazepine withdrawal signs in rats. Behav Pharmacol 2:461-469.

Graeff FG (2002): On serotonin and experimental anxiety. Psychopharmacology (Berl) 163:467-476.

Graeff FG (2004): Serotonin, the periaqueductal gray and panic. Neurosci Biobehav Rev 28:239-259. 
Griffiths JL, Lovick TA (2002): Co-localization of 5-HT 2A -receptor- and GABA-immunoreactivity in neurones in the periaqueductal grey matter of the rat. Neurosci Lett 326:151-154.

Grundmann O, Kelber O, Butterweck V (2006): Effects of St. John's wort extract and single constituents on stress-induced hyperthermia in mice. Planta Med 72:1366-1371.

Grundmann O, Nakajima J, Seo S, Butterweck V (2007): Anti-anxiety effects of Apocynum venetum L. in the elevated plus maze test. J Ethnopharmacol 110:406-411.

Hashimoto T, Hamada C, Wada T, Fukuda N (1992): Comparative study on the behavioural and EEG changes induced by diazepam, buspirone and a novel anxioselective anxiolytic, DN-2327, in the cat. Neuropsychobiology 26:89-99.

Jacobson LH, Bettler B, Kaupmann K, Cryan JF (2007): Behavioural evaluation of mice deficient in GABA(B(1)) receptor isoforms in tests of unconditioned anxiety. Psychopharmacology (Berl) 190:541-553.

Keay KA, Bandler R (2001): Parallel circuits mediating distinct emotional coping reactions to different types of stress. Neurosci Biobehav Rev 25:669-678.

Keay KA, Clement CI, Owler B, Depaulis A, Bandler R (1994): Convergence of deep somatic and visceral nociceptive information onto a discrete ventrolateral midbrain periaqueductal gray region. Neuroscience 61:727-732.

Lamprea MR, Cardenas FP, Vianna DM, Castilho VM, Cruz-Morales SE, Brandao ML (2002): The distribution of fos immunoreactivity in rat brain following freezing and escape responses elicited by electrical stimulation of the inferior colliculus. Brain Res 950:186-194.

Larsson LG, Renyi L, Ross SB, Svensson B, Angeby-Moller K (1990): Different effects on the responses of functional pre- and postsynaptic 5-HT1A receptors by repeated treatment of rats with the 5HT1A receptor agonist 8-OH-DPAT. Neuropharmacology 29:86-91.

Lechin F, van der Dijs B, Lechin ME (2002): Neurocircuitry and Neuroautonomic Disorders. Reviews and Therapeutic Strategies, Karger Basel:pp 54-56.

LeDoux JE, Iwata J, Cicchetti P, Reis DJ (1988): Different projections of the central amygdaloid nucleus mediate autonomic and behavioural correlates of conditioned fear. J Neurosci 8:2517-2529.

Lerman JA, Kaitin KI, Dement WC, Peroutka SJ (1986): The effects of buspirone on sleep in the rat. Neurosci Lett 72:64-68.

Lim LW, Blokland A, Visser-Vandewalle V, Vlamings R, Sesia T, Steinbusch HWM, et al (2008a): Highfrequency stimulation of the dorsolateral periaqueductal gray and ventromedial hypothalamus fails to inhibit panic-like behaviour. Behav Brain Res:(In press).

Lim LW, Temel Y, Visser-Vandewalle V, Steinbusch HWM, Schruers K, Hameleers R, et al (2008b): Effect of Buspirone on the behavioural regulation of rats in low versus high anxiety conditions. Arzneimittel-Forschung/ Drug Research:(In Press).

Liu YP, Wilkinson LS, Robbins TW (2004): Effects of acute and chronic buspirone on impulsive choice and efflux of 5-HT and dopamine in hippocampus, nucleus accumbens and prefrontal cortex. Psychopharmacology (Berl) 173:175-185.

Lovick TA, Parry DM, Stezhka VV, Lumb BM (2000): Serotonergic transmission in the periaqueductal gray matter in relation to aversive behaviour: morphological evidence for direct modulatory effects on identified output neurons. Neuroscience 95:763-772.

Malkani S, Rosen JB (2000): Specific induction of early growth response gene 1 in the lateral nucleus of the amygdala following contextual fear conditioning in rats. Neuroscience 97:693-702.

Mattila MJ, Aranko K, Seppala T (1982): Acute effects of buspirone and alcohol on psychomotor skills. $J$ Clin Psychiatry 43:56-61.

McNaughton N, Corr PJ (2004): A two-dimensional neuropsychology of defense: fear/anxiety and defensive distance. Neurosci Biobehav Rev 28:285-305.

McNaughton N, Panickar KS, Logan B (1996): The pituitary-adrenal axis and the different behavioural effects of buspirone and chlordiazepoxide. Pharmacol Biochem Behav 54:51-56.

Melia KR, Ryabinin AE, Schroeder R, Bloom FE, Wilson MC (1994): Induction and habituation of immediate early gene expression in rat brain by acute and repeated restraint stress. J Neurosci 14:5929-5938.

Mendelson WB, Martin JV, Rapoport DM (1990): Effects of buspirone on sleep and respiration. Am Rev Respir Dis 141:1527-1530. 
Muller R, Tremblay JM, Adamson ED, Verma IM (1983): Tissue and cell type-specific expression of two human c-onc genes. Nature 304:454-456.

Netto CF, Guimaraes FS (2004): Anxiogenic effect of cholecystokinin in the dorsal periaqueductal gray. Neuropsychopharmacology 29:101-107.

Newton RE, Casten GP, Alms DR, Benes CO, Marunycz JD (1982): The side effect profile of buspirone in comparison to active controls and placebo. J Clin Psychiatry 43:100-102.

Ninan PMS (2004): Buspirone and gepirone. In: Schatzberg AF, Nemeroff CB, editors. Textbook of psychopharmcology 3rd ed Washington, DC. . American Psychiatric Publishing:391-404.

Nogueira RL, Graeff FG (1991): 5-HT mediation of the antiaversive effect of isamoltane injected into the dorsal periaqueductal grey. Behav Pharmacol 2:73-77.

Nogueira RL, Graeff FG (1995): Role of 5-HT receptor subtypes in the modulation of dorsal periaqueductal gray generated aversion. Pharmacol Biochem Behav 52:1-6.

Norman TR, Judd FK (1989): Panic attacks, buspirone, and serotonin function. Lancet 2:615.

Okazawa H, Yamane F, Blier P, Diksic M (1999): Effects of acute and chronic administration of the serotonin1A agonist buspirone on serotonin synthesis in the rat brain. $J$ Neurochem 72:2022-2031.

Pajolla GP, de Aguiar Correa FM (2004): Cardiovascular responses to the injection of L-glutamate in the lateral hypothalamus of unanesthetized or anesthetized rats. Auton Neurosci 116:19-29.

Pajolla GP, Tavares RF, Pelosi GG, Correa FM (2005): Involvement of the periaqueductal gray in the hypotensive response evoked by L-glutamate microinjection in the lateral hypothalamus of unanesthetized rats. Auton Neurosci 122:84-93.

Pazos A, Palacios JM (1985): Quantitative autoradiographic mapping of serotonin receptors in the rat brain. I. Serotonin-1 receptors. Brain Res 346:205-230.

Pobbe RL, Zangrossi H, Jr. (2005): 5-HT(1A) and 5-HT(2A) receptors in the rat dorsal periaqueductal gray mediate the antipanic-like effect induced by the stimulation of serotonergic neurons in the dorsal raphe nucleus. Psychopharmacology (Berl) 183:314-321.

Pols HJ, Griez E, Zandbergen J (1989): Does buspirone have anxiogenic properties? Lancet 2:682-683.

Poltronieri SC, Zangrossi H, Jr., de Barros Viana M (2003): Antipanic-like effect of serotonin reuptake inhibitors in the elevated T-maze. Behav Brain Res 147:185-192.

Pompeiano M, Palacios JM, Mengod G (1992): Distribution and cellular localization of mRNA coding for 5-HT1A receptor in the rat brain: correlation with receptor binding. $J$ Neurosci 12:440-453.

Schechter LE, Bolanos FJ, Gozlan H, Lanfumey L, Haj-Dahmane S, Laporte AM, et al (1990): Alterations of central serotoninergic and dopaminergic neurotransmission in rats chronically treated with ipsapirone: biochemical and electrophysiological studies. J Pharmacol Exp Ther 255:1335-1347.

Sheehan DV, Raj AB, Sheehan KH, Soto S (1990): Is buspirone effective for panic disorder? J Clin Psychopharmacol 10:3-11.

Singewald N, Sharp T (2000): Neuroanatomical targets of anxiogenic drugs in the hindbrain as revealed by Fos immunocytochemistry. Neuroscience 98:759-770.

Sramek JJ, Zarotsky V, Cutler NR (2002): Generalised anxiety disorder: treatment options. Drugs 62:1635-1648.

Vianna DM, Borelli KG, Ferreira-Netto C, Macedo CE, Brandao ML (2003): Fos-like immunoreactive neurons following electrical stimulation of the dorsal periaqueductal gray at freezing and escape thresholds. Brain Res Bull 62:179-189.

Zanoveli JM, Nogueira RL, Zangrossi H, Jr. (2003): Serotonin in the dorsal periaqueductal gray modulates inhibitory avoidance and one-way escape behaviours in the elevated T-maze. Eur $J$ Pharmacol 473:153-161.

Zanoveli JM, Nogueira RL, Zangrossi H, Jr. (2005): Chronic imipramine treatment sensitizes 5-HT1A and 5-HT 2 A receptors in the dorsal periaqueductal gray matter: evidence from the elevated T-maze test of anxiety. Behav Pharmacol 16:543-552.

Zienowicz M, Wislowska-Stanek A, Lehner M, Taracha E, Skorzewska A, Bidzinski A, et al (2007): Fluoxetine attenuates the effects of pentylenetetrazol on rat freezing behaviour and c-Fos expression in the dorsomedial periaqueductal gray. Neurosci Lett 414:252-256. 
154 


\title{
Electrical stimulation of the dorsolateral periaqueductal gray evokes escape response followed by fear behaviour in rats: Reversal by SSRI treatment
}

\author{
Lee Wei Lim, Arjan Blokland, Sonny Tan, Rinske Vlamings, Thibaut Sesia, \\ Veerle Visser-Vandewalle, Koen Schruers, Harry Steinbusch, and Yasin Temel
}

\begin{abstract}
Electrical stimulation of the dorsolateral periaqueductal gray (dlPAG) has been shown to induce escape and freezing responses which mimic the panic- and fear-like behaviour. In the present study, we tested the hypothesis whether the freezing behaviour could be attenuated by acute and chronic administration of escitalopram and buspirone. Additionally, the levels of blood corticosterone were measured in the different experimental conditions. Our results demonstrated that escitalopram treatment was effective in attenuating the stimulation induced fear when compared to buspirone and saline treated animals after acute and chronic treatment. The stimulation amplitudes to evoke escape behaviour were significantly higher after chronic buspirone and escitalopram treatment. The levels of blood corticosterone were increased after stimulation and the open-field testing conditions when compared to the baseline level. In conclusion, the current study shows that the escape reaction generated intrinsically within the dIPAG was followed by freezing behaviour $12 \mathrm{~h}$ later. This fear-like behaviour was reversed by escitalopram treatment while buspirone or vehicle treated groups did not attenuate fear behaviour. Our data also confirm the elevation of blood corticosterone level during the panic and fear-like behaviour. Future research of fear should be focused on the underlying neural mechanism within the dlPAG.
\end{abstract}

(Submitted) 


\section{Introduction}

Fear is an emotional activation of defensive behavioural system that protects an organism from potentially threatening stimuli. The behavioural response to such threats can be either innate (unconditioned) or learned (conditioned) (Blanchard and Blanchard 1972; Klemenhagen et al 2006; Stiedl et al 2000). Innate fear depends on stimuli that naturally evoke fear when animals are exposed to a novel place (Blanchard et al 1991) or natural predators (Montgomery 1955; Montgomery and Monkman 1955). While learned fear is a form of Pavlovian conditioning when an animal is trained to associate a neutral stimulus (tone, light) with an external aversive stimulus, usually an electric foot-shock (Brown et al 1951; Davis et al 1993), noxious thermal stimuli (Finn et al 2006; Harris and Westbrook 1994) or predatory odor (Blanchard et al 1990; Dielenberg et al 1999). In this respect, the most frequently used animal models of fear-conditioning have a common behavioural phenotype as the exhibition of freezing response with high levels of immobility and vigilant scanning of the environment (Bandler and Shipley 1994; Carrive 1993). Despite these animal models were generally used to investigate the underlying mechanisms of fear memory acquisition and consolidation (Dayan et al 2000; Schiller et al 2008), the neural substrate that responsible for the origin of fear expression in the brain is still poorly understood. In other words, the acquisition of fear involves a complex neural circuitry and neurochemistry in the overall integration of fearful impulses from the higher levels of fear circuit in the thalamic and amygdaloid nuclei complex relays to the lower levels (i.e., at hypothalamic and mesencephalic levels; see (LeDoux 1993; LeDoux 1995; Panksepp 1998).

Recently, electrical stimulation of the midbrain dorsal periaqueductal gray (PAG) induces defensive behaviour and a wealth of evidence also suggesting that it plays an important role for the generation of fear and anxiety (Bandler and Shipley 1994; Lovick et al 2000). Interestingly and unexpectedly, we have observed a similar behaviour in rats who had received electrical stimulation of the dorsolateral periaqueductal gray (dlPAG). Immediately after the onset of stimulation rats show vigorous running and jumping in the open-field arena (Lim et al 2008a; Lim et al 2008b). This behaviour is known as escape behaviour and is generally accepted as a model for panic attacks (Graeff 1990; Schenberg et al 2001). When the stimulated rats were placed in the same open-field arena after $12 \mathrm{~h}$ of escape behaviour, they became immobile and showed head scanning, indicative of fear. Here, we have investigated this phenomenon more in detail. We hypothesized that electrical stimulation of the dIPAG (unconditioned stimulus, US) would induce such kind of innate fear response after evoking escape behaviour in an enclosed open-field environment (conditioned stimulus, CS).

In the first part of the present study, we recorded the behaviour of the subjects after having received dIPAG stimulation with parameters evoking fear behaviour in the open-field arena. Subsequently, the effects of acute and chronic escitalopram treatment on fear behaviour were tested in the same group of animals. We expected that this 
selective serotonin reuptake inhibitor (SSRI) would attenuate the fear response induced by dIPAG stimulation based on its efficacy in the treatment of panic disorders (APA 1998; Hogg et al 2006; Hollander and Simeon 2003). Another group of animals was treated with buspirone, again tested after a single-dose and chronic treatment. Buspirone, a classical $5-\mathrm{HT}_{1 \mathrm{~A}}$ receptor agonist, is effective in the treatment of generalized anxiety disorder but not for other severe anxiety (Ninan 2004). Therefore, we reasoned that buspirone would not be effective in reducing dIPAG stimulation-induced fear response. This pharmacological approach was used to further characterize the behavioural phenotype induced by dIPAG stimulation. Finally, corticosterone levels were measured at different phases of the experiment to examine the relation between the behavioural changes and treatment effects. The present study would allow us to further elucidate the intrinsic properties of dIPAG as a substrate for the expression of fear responses, and the modulation by 5 -HT treatment.

\section{Material and Methods}

\section{Subjects}

Subjects were male albino Wistar rats $(N=40,12$ weeks old $)$, bred and housed at the Central Animal Facility of Maastricht University (Maastricht, the Netherlands). Rats had an average body weight of 300-350 g at the time of surgery. They were housed individually in standard cages on sawdust bedding in an air-conditioned room (about 20 ${ }^{\circ} \mathrm{C}$ ) under a 12/12-h reversed light/dark cycle. Food, standard laboratory chow (Hopefarms, Woerden, the Netherlands), and water were available ad libitum. This study was approved by the Animal Experiments and Ethics Committee of Maastricht University.

\section{Experimental groups}

Rats were randomly divided into the following six experimental groups: A. dIPAG stimulation and treatment with saline (STIM-SAL, n=7); B. dIPAG stimulation and treatment with buspirone (STIM-BUSP, $n=7$ ); C. dIPAG stimulation and treatment with escitalopram (STIM-ESCIT n=7); D. dIPAG sham surgery and saline treatment (SHAMSAL, $n=6$ ); E. dlPAG sham surgery and buspirone treatment (SHAM-BUSP, $n=6$ ); and $F$. dIPAG sham surgery and escitalopram treatment (SHAM-ESCIT, $n=7$ ). 
A flowchart of the experiment is shown in figure 1. All animals were handled daily in order to habituate them to being picked up and reduce stress during behavioural testing.

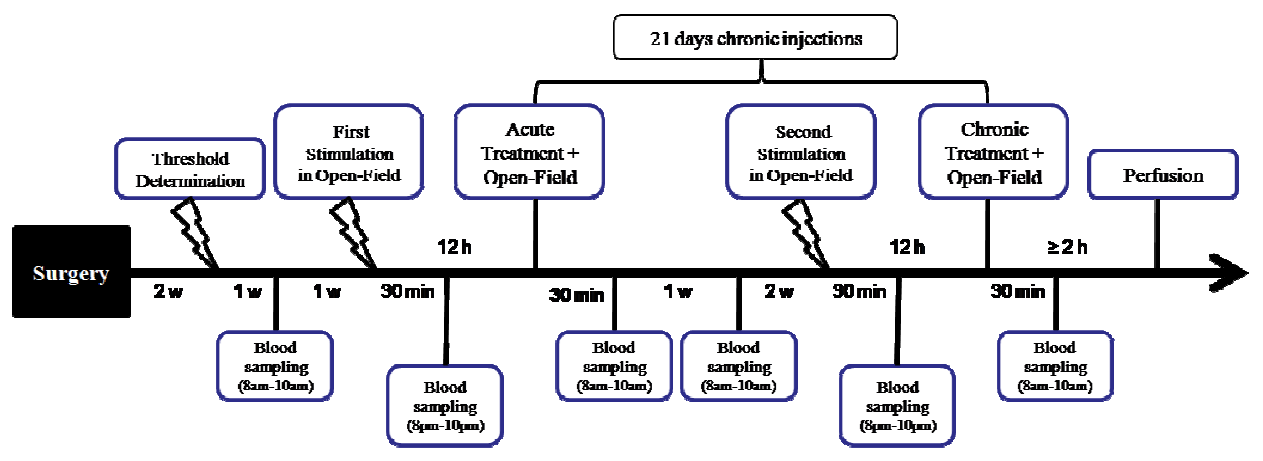

Figure 1. Design of the experimental procedures.

\section{Surgical procedures}

A detailed description of the surgical procedure has been reported previously (Temel et al 2007). In brief, the rats were anesthetized throughout the entire procedure using a combination of ketamine $(90 \mathrm{mg} / \mathrm{kg})$ and xylazine $(10 \mathrm{mg} / \mathrm{kg})$ injected subcutaneously (s.c.). Rats were placed in a stereotactic apparatus (Stoelting, Wood Dale, USA; model 51653). After making a burr hole in the skull, rats received implantation of the electrode at the level of the dIPAG (coordinates from Bregma: anteroposterior, -7.6; mediolateral, +0.7 ; and ventral, -4.8 ; approached with a coronal angle of $10^{\circ}$ ). A construction of one gold-plated needle-like electrode with an inner wire of a platinumiridium combination (Technomed, Beek, the Netherlands) with a tip diameter of $50 \mu \mathrm{m}$ and a shaft diameter of $250 \mu \mathrm{m}$, was employed in this experiment. The electrodes were fixed in position using dental cement (Heraeus Kulzer, Hanau, Germany). After the operation, rats were injected with Temgesic $(0.1 \mathrm{mg} / \mathrm{kg}$, s.c. $)$ and allowed to recover for two weeks.

\section{Electrical dlPAG Stimulation}

All animals in the dIPAG stimulation group underwent a stimulation session in their home cages to determine the level of the escape threshold. The stimulation amplitudes were gradually increased till the escape behaviour (ie. rigorously running with aimless direction) was observed ( $\mathrm{Lim}$ et al 2008a). The stimulation duration was $15 \mathrm{~s}$ followed by a stimulation-off period of $45 \mathrm{~s}$. After this the cable was removed. The stimulation frequency was set at $50 \mathrm{~Hz}$, and pulse width at $0.1 \mathrm{~ms}$ based on previous experience (Lim et al 2008a). Animals which required stimulation amplitudes above 100 $\mu \mathrm{A}$ were discarded from analysis. Remarkably, when rats were stimulated for the second time in the open field (see Fig. 1), rats from the STIM BUS and STIM ESCIT groups did 
not show an escape response at the amplitude as determined at the first stimulation session. The amplitudes were increased in a stepwise manner until an escape response was observed. This stepwise increase was achieved within 1-2 $\mathrm{min}$ in the open field. A World Precision Instruments (WPI) digital stimulator (DS8000, WPI, Berlin, Germany) and a stimulus isolator (DLS100, WPI, Berlin, Germany) were used to deliver the stimuli. Real time verification of the parameters applied during stimulation was obtained using a digital oscilloscope (Agilent 54622D oscilloscope, Agilent Technologies, Amstelveen, the Netherlands). After the threshold determination session, all rats were given a recovery period of two weeks. The sham animals were similarly connected to the stimulator but no current was delivered to the dIPAG.

\section{Drug administration}

Escitalopram oxalate (ESCIT) (H. Lundbeck A/S, Copenhagen, Denmark) and Buspirone hydrochloride (BUSP) (TOCRIS, Cookson Inc., Missouri, USA) were freshly prepared and dissolved in saline $0.9 \% \mathrm{NaCl}$ (Braun, Melsungen, Germany). ESCIT (10 $\mathrm{mg} / \mathrm{kg}$ ) and BUSP $(3 \mathrm{mg} / \mathrm{kg}$ ) were injected (s.c. in a volume of $1 \mathrm{ml} / \mathrm{kg}$ ) $60 \mathrm{~min}$ and 120 min before behavioural testing, respectively. These doses were chosen based on previous experimental studies. A week before the actual experimental testing, all animals received $1 \mathrm{ml}$ saline injection 3 times on alternating days in order to habituate to the injection procedure. A single-dose acute treatment was performed before the open-field experiment. After recording the behaviour and collecting blood samples, the subjects entered into the chronic experiment. They received 21 daily injections of either ESCIT, BUSP, or SAL.

\section{Behavioural testing}

The apparatus consisted of an enclosed open-field (square: $100 \mathrm{~cm} \times 100 \mathrm{~cm}$, and height: $40 \mathrm{~cm}$ ), clear Plexiglas box with an open top and a dark floor (Lim et al 2008d). All open-field testing was conducted in the same room in a dimly lit condition from 08:00 till 10:00 $\mathrm{h}$. On the first day of stimulation in the open field, rats were placed in the open-field arena and connected with the external stimulator through externalized leads. The electrical stimulation was performed based on the previously determined escape threshold level and started $1 \mathrm{~min}$ after the rat was placed in the open-field arena. Once the escape reaction was evoked, the cable connected to the rat was detached and the animal was left in the open-field for approximately $30 \mathrm{~s}$. 
Next day, after $12 \mathrm{~h}$ of escape behaviour rats were placed again in the open-field. The behaviour of each rat was recorded using an automated system consisting of a camera connected to a computer with the Ethovision tracking software (Ethovision, Noldus Information Technology, Wageningen, the Netherlands). At the time of open field testing the researchers were blind with respect to treatment and stimulation conditions. A trial was stopped after $5 \mathrm{~min}$ and the rat was removed from the arena. Of note, behaviour was not analyzed during the first open field test since the escape response after STIM was assumed not to produce open field data that could be interpreted in a reliable manner.

\section{Blood sampling and corticosterone radioimmunoassay}

Blood sample collections were taken at different time points (see Fig 1). All rat tail blood samples were withdrawn and directly put into heparinized blood collection tubes (Microvette, CB300, Sarstedt, Germany) in a cold ice box. Blood samples were centrifuged at $3000 \mathrm{rpm}$ for $5 \mathrm{~min}$ at $4^{\circ} \mathrm{C}$ and the supernatant was thereafter stored at $-80^{\circ} \mathrm{C}$ until analysis. $50 \mu \mathrm{l}$ of plasma was extracted with $3 \mathrm{ml}$ dichloromethane and vortexed for one minute in order to determine the concentration of plasma corticosterone. The corticosterone was then measured directly on $1 \mathrm{ml}$ dried dichloromethane and extracted for radioimmunoassay using corticosterone- ${ }^{125} \mathrm{I}$. The radioimmunological reaction was performed overnight at $4^{\circ} \mathrm{C}$, after which a secondary antibody system was used to separate bound and unbound steroid. The entire procedure has been described in detail previously (Sulon et al 1978; Van den Hove et al 2006).

\section{Histological processing}

After the final experiment, rats were under generalized anesthesia with Nembutal $(75 \mathrm{mg} / \mathrm{kg})$ and perfused transcardially with Tyrode $(0.1 \mathrm{M})$ and fixative solution containing $4 \%$ paraformaldehyde, $15 \%$ picric acid and $0.05 \%$ glutaraldehyde in $0.1 \mathrm{M}$ phosphate buffer ( $\mathrm{pH}$ 7.6). The rat brains have been post-fixed for 2 hours in the same fixative used for perfusion. Hereafter, the brains were cryprotected by overnights sucrose treatment at $4{ }^{\circ} \mathrm{C}$. Brain tissue was then quickly frozen with $\mathrm{CO}_{2}$ and stored at $-80{ }^{\circ} \mathrm{C}$. Subsequently, the brains were cut serially on a cryostat into $30 \mu \mathrm{m}$ frontal sections and again stored at $-80{ }^{\circ} \mathrm{C}$. The sections were stained with standard hematoxylin-eosin (Merck, Darmstadt, Germany) to examine the localization of the electrode tips.

\section{Statistical analysis}

All data are presented as mean \pm S.E.M and were analyzed using two-way ANOVA using Treatment and Stimulation as between-subjects factors. A Duncan post hoc test was used to analyze group differences in more detail. Pearson correlation 
coefficients were calculated to examine the relation between variables within a test and between different tests of corticosterone and behavioural open-field data. All p-values < 0.05 were considered significant.

\section{Results}

\section{Histological evaluation of the electrode localization}

In all rats, except for four, the electrode tips were located within the dlPAG. One rat in group STIM-SAL and STIM-ESCIT, two rats in SHAM-ESCIT, electrodes were placed outside the dIPAG. The required current to induce an escape reaction in the rats of STIM-SAL and STIM-ESCIT was $>100 \mu \mathrm{A}$ and they were discarded from analysis. The final group sizes were six animals per group for SHAM-SAL, SHAM-BUSP, STIM-SAL, STIM-ESCIT and seven animals for groups STIM-BUSP, and SHAM-ESCIT.

The localization of the electrode tip in the dIPAG is illustrated in Fig. 2. Except for the electrode trajectory, we observed no additional tissue damage due to repeated stimulation.

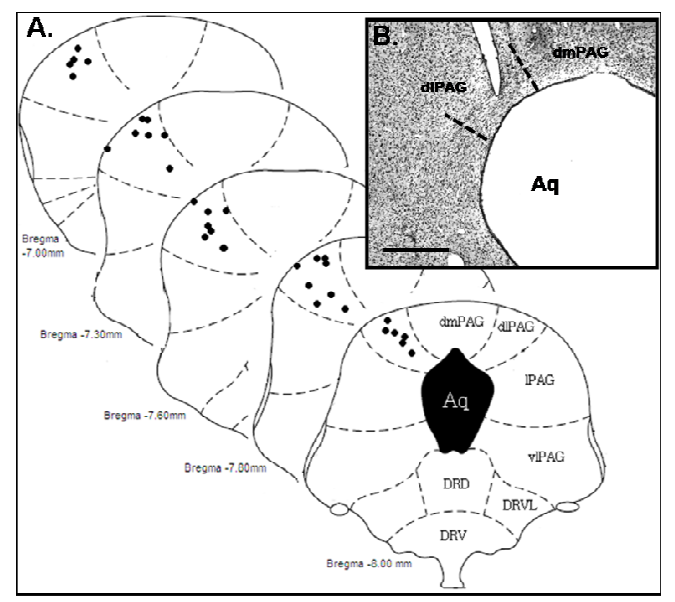

Figure 2. Representative low-power photomicrographs of a $30 \mu \mathrm{m}$-thick coronal section from the brain of a rat subjected to stereotactic implantation of concentric bipolar electrode to stimulate the dlPAG (Fig. 2B, scale bar $=250 \mu \mathrm{m}$ ) is shown. Fig. 2A, schematic representation of the electrode sites in the dIPAG according to the Paxinos and Watson atlas, respectively. The symbol (•) indicates the electrode localization in the dIPAG. Abbreviation: Aq = aqueduct of Sylvius; dIPAG $=$ dorsolateral periaqueductal gray; $\mathrm{dmPAG}=$ dorsomedial periaqueductal gray; $\mathrm{PAG}=$ lateral periaqueductal gray; vlPAG = ventrolateral periaqueductal gray; DRD = dorsal raphe nucleus, dorsal part; DRVL $=$ dorsal raphe nucleus, ventrolateral part; and DRV = dorsal raphe nucleus, ventral part. 


\section{Threshold dlPAG stimulation}

The intensity of stimulation current applied to the dlPAG of the animals was based on the lowest threshold to induce escape behaviour. There were no group differences before acute treatment $(F(2,17)=0.02$, n.s.; see Fig. 3). The stimulation amplitudes to evoke escape behaviour were significantly higher for the second phase for animals in STIM-BUSP and STIM-ESCIT group $(\mathrm{F}(2,17)=26.07, \mathrm{p}<0.001)$.

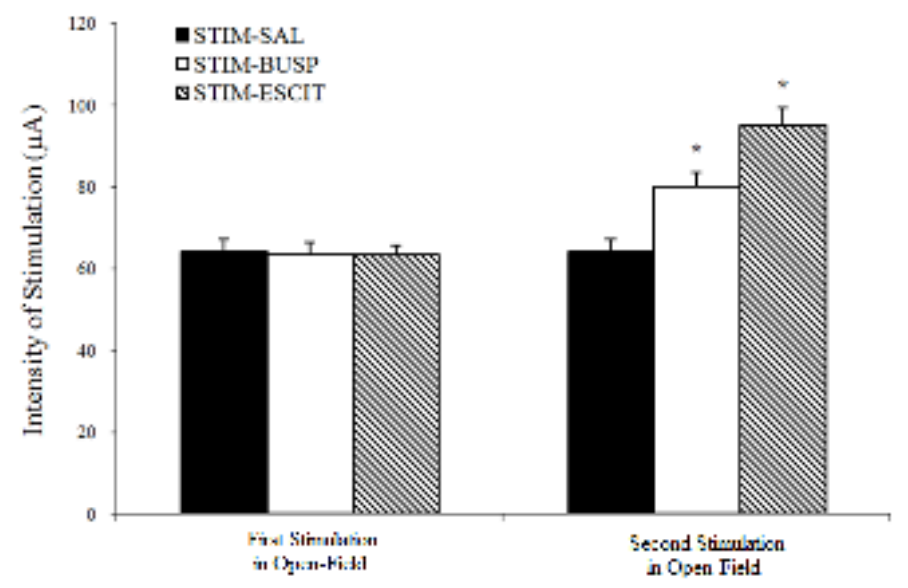

Figure 3. This figure shows the current amplitudes $(\mu \mathrm{A})$ necessary to induce escape reaction. Data represent means \pm S.E.M. of dlPAG group. Indication: * Significant difference from the STIM-SAL group during the stimulation phase II.

\section{Open field behaviour after dlPAG stimulation}

The open field behaviour was comparable in the acute and chronic phases of the study (Treatment, Stimulation and all interactions with Time, for the distance moved, time in corner and mean velocity: all F's $<1.45$ n.s.). However, there was an overall increase in the time the rats spent in the corner areas in the chronic phase (Time: $\mathrm{F}(1,31)=11.38, \mathrm{p}<0.01)$, which was independent of stimulation or treatment conditions (all F's $<1.45$ n.s.).

Twelve hours after dIPAG stimulation the rats were put in the same open field, and the behaviour of the animals was scored. STIM rats showed a significant reduction in distance moved and mean velocity and an increased time spent in corner areas as compared to the SHAM animals (all F's $>4.67, \mathrm{p}<0.05$; see Fig. 4). Acute treatment attenuated these effects (all F's $>3.54, \mathrm{p}<0.05$; and a marginal Treatment by Stimulation interaction: all F's $>2.88, \mathrm{p}<0.07$ ). Post hoc analysis of treatment effects in the STIM groups revealed that only ESCIT attenuated the effects of dIPAG stimulation on all three open field measures. 

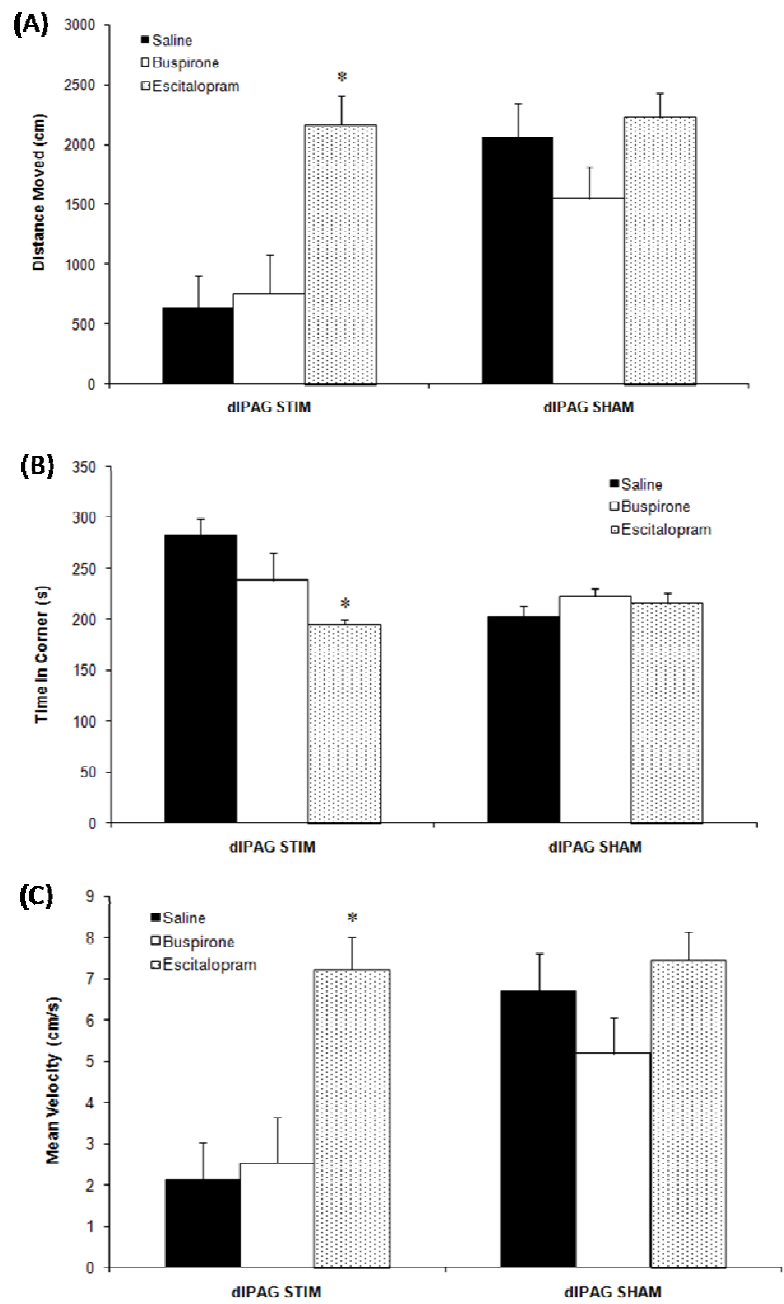

Figure 4. A set of bar graphs showing the behavioural data of acute treatment with saline, buspirone, and escitalopram for the dIPAG stimulation, and dIPAG sham rats. The data of distance moved (Fig. 4A), time spent in the corner zones (Fig. 4B), and mean velocity (Fig. 4C) in the open-field are expressed as means \pm S.E.M. Indication: * Significant difference from the STIM-SAL and STIM-BUSP.

After chronic treatment, the animals were stimulated to induce an escape response for the second time in the open-field. Later, they were again tested in the open-field after $12 \mathrm{~h}$ of escape reaction. Similar to the acute treatment, STIM rats showed a significant reduction in distance moved and mean velocity and an increased time spent in corner areas as compared to the SHAM animals (all F's $>10.58, \mathrm{p}<0.01$ ). There was no indication of treatment effects (all F's $>2.06$, n.s.). However, there were marginal Treatment by Stimulation effects for all three open field measures (all F's $>2.91, \mathrm{p}<0.07$ ). Post hoc analysis of treatment effects in the STIM group revealed that only ESCIT 
attenuated the effects of dlPAG stimulation on all three open field measures (Fig. 4). No effects of treatment was found in the SHAM group (Treatment: all F's $<1.13$, n.s.).
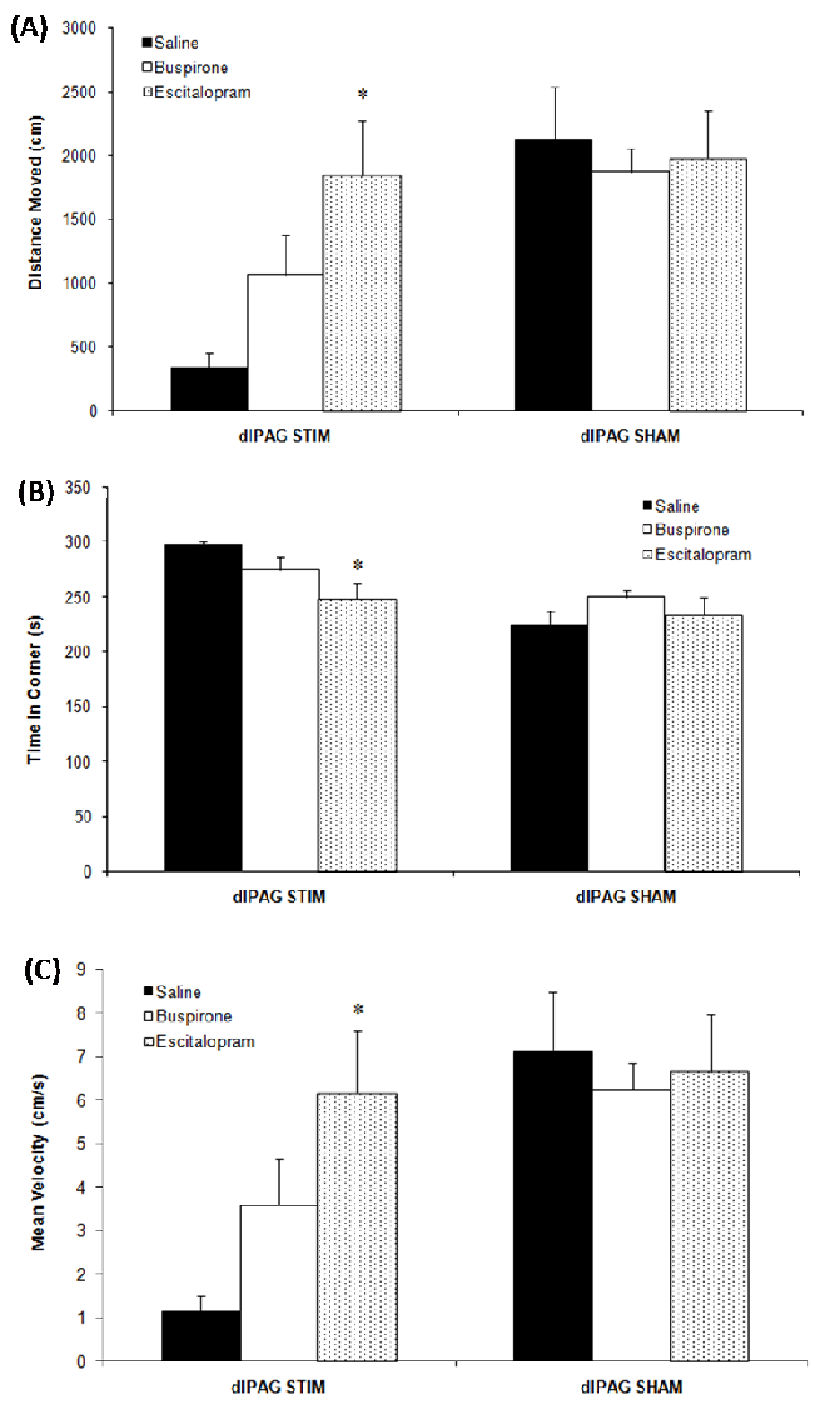

Figure 5. A set of bar graphs showing the behavioural data of chronic treatment with saline, buspirone, and escitalopram for the dIPAG DBS, and dIPAG sham rats. The data of distance moved (Fig. 5A), time spent in the corner zones (Fig. 5B), and mean velocity (Fig. 5C) in the open-field are expressed as means \pm S.E.M. Indication: * Significant difference from the STIM-SAL. 


\section{Effects of dlPAG stimulation on blood corticosterone level}

Corticosterone levels were similar in the pre- (baseline) and post open-field periods (Time: $\mathrm{F}(1,15)=2.65$, ns). Comparison of STIM-SAL and SHAM-SAL groups showed that STIM increased corticosterone levels after open field testing in the acute $(t(10)=8.00, p<0.01)$ and chronic treatment condition $(t(10=3.73, p<0.01$; see Figure 6 A/B). One-way ANOVA showed that there was treatment effect in the SHAM animals, acutely $(\mathrm{F}(2,17)=4.44, \mathrm{p}<0.05)$ and marginally after chronic treatment $(\mathrm{F}(2,17)=3.34$, $\mathrm{p}<0.07)$. Post hoc analysis showed that after acute BUSP treatment corticosterone levels were increased. After chronic treatment both BUSP and ESCIT increased the corticosterone levels after the rats were placed in the open field.

Thirty minutes after the rats were stimulated corticosterone levels were higher as compared to base line levels (see Fig. 6A). However, there were no differences between the treatment groups at the first time and second time the rats were stimulated ( $\mathrm{F}$ 's $<1.71$, ns.). After acute treatment the corticosterone response was less pronounced in the STIMESCIT group as compared to the other STIM groups $(F(2,17)=6.96, p<0.01)$. Chronic treatment also affected the corticosterone response $(F(2,17)=9.67, p<0.01)$, but now the post hoc analysis revealed that BUSP treatment increased the response and the STIMESCIT did not differ from the STIM-SAL group.

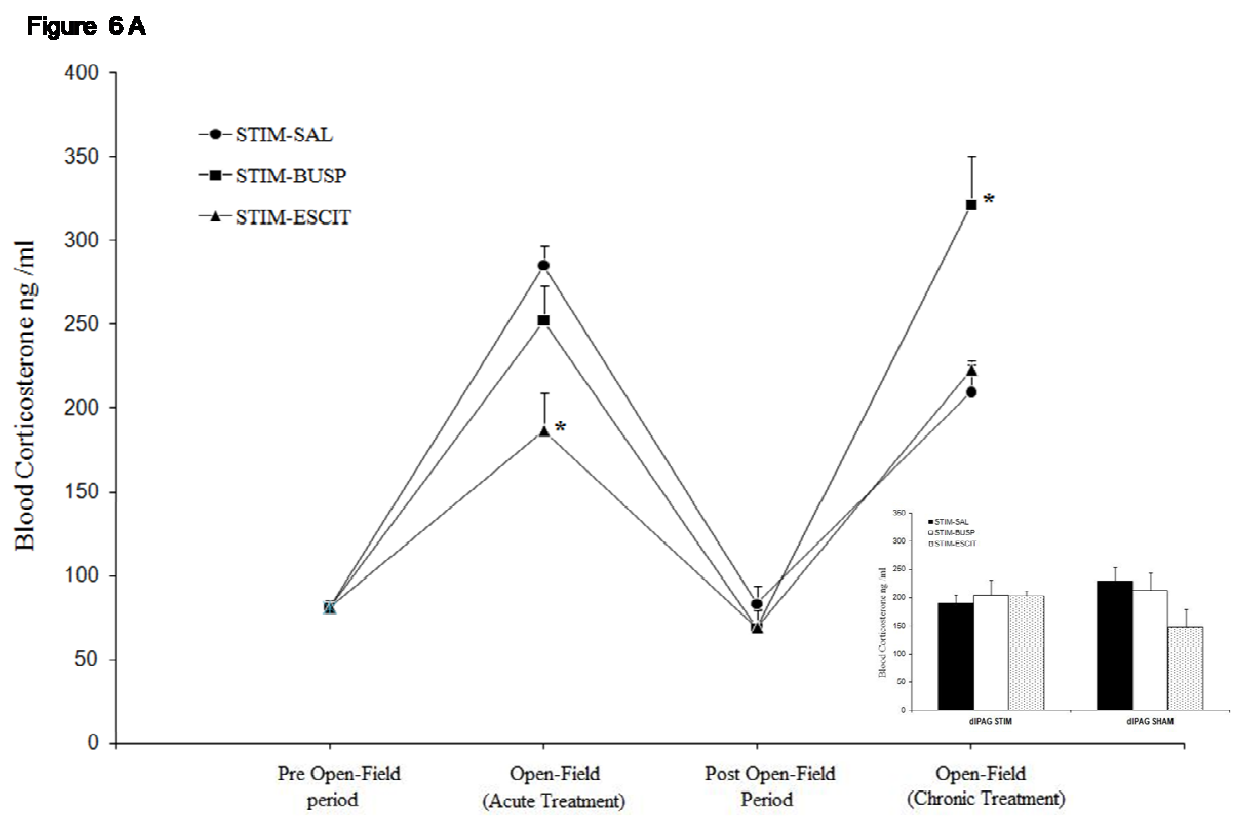




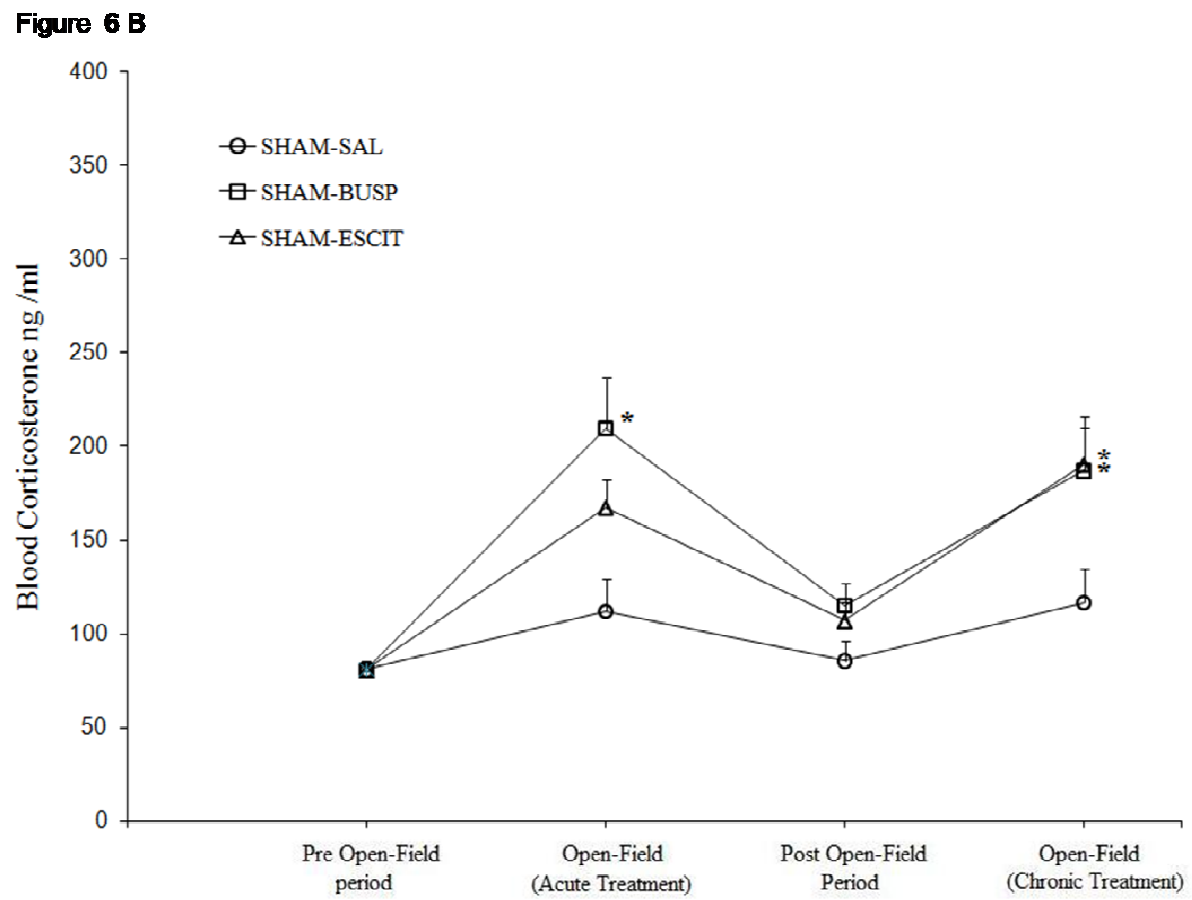

Figure 6 (A) and 6 (B). The chart of lines with markers showing the plasma level of blood corticosterone $(\mathrm{ng} / \mathrm{ml})$ for the dIPAG stimulation, and dIPAG sham rats. The data are expressed as means \pm S.E.M demonstrating the condition during the pre open-field period, stimulation phase I, open-field testing with acute treatment, post open-field period, stimulation phase II, and openfield testing with chronic treatment. The inset in 6 (A) shows the levels of blood corticosterone during the first and second stimulation periods in the open-field conditions. Indication: - STIMSAL; $\boldsymbol{\square}$ STIM-BUSP; $\boldsymbol{\wedge}$ STIM-ESCIT; $\mathbf{O}$ SHAM-SAL; $\boldsymbol{\square}$ SHAM-BUSP; and $\boldsymbol{\Delta}$ SHAMESCIT. * Significant difference from the STIM- or SHAM-SAL group.

\section{Correlation between corticosterone level and open-field behavioural effects}

The correlation between the behavioural measures and the corticosterone levels (taken 30 min after open-field behaviour) are presented in figures 7, 8, and Table 1 . When all animals were included in the analysis, significant correlations were found between the corticosterone level and the open-field behaviour $\left(\mathrm{r}_{p}>.50\right)$. In table 1, within test analysis showed that the corticosterone level was negatively correlated with the distance moved and mean velocity; and positively correlated with the time spent in corner zone of the open-field in both acute and chronic testing conditions. Additionally, the time spent in the corner zone of the rats was found to be negatively correlated with the distance moved and mean velocity in the open-field (see Table 1). Figure 7A shows that the pattern of correlations for distance moved and corticosterone of STIM-SAL and STIM-BUSP were concentrated in the region with little distance moved and high 
corticosterone levels (upper right area). On the other hand, a shift to the lower right area (more distance moved and lower coricosterone levels) was observed in the SHAM groups and the STIM ESCIT group with almost no overlap between these set of groups. A similar picture emerged for the relation between time spent in the corner areas and corticosterone, although the shift was from upper right to lower left side of the figure (see Figure 7B). After chronic treatment the correlations were comparable although the correlations were somewhat lower (See Figures 8A/B and Table 1).

(A)

\begin{tabular}{|l|c|c|c|c|}
\hline \multicolumn{5}{|c|}{ Open-Field (Acute Treatment) } \\
\hline & Corticosterone & Distance moved & Mean Velocity & Time in corner \\
\hline Corticosterone & - & - & - & - \\
\hline Distance moved & $-0.72 * *$ & - & - & - \\
\hline Mean velocity & $-0.73^{* *}$ & $1.00^{* *}$ & - & - \\
\hline Time in corner & $0.50^{* *}$ & $-0.71^{* *}$ & $-0.71^{* *}$ & - \\
\hline
\end{tabular}

(B)

\begin{tabular}{|l|c|c|c|c|}
\hline \multicolumn{5}{|c|}{ Open-Field (Chronic Treatment) } \\
\hline & Corticosterone & Distance moved & Mean Velocity & Time in corner \\
\hline Corticosterone & - & - & - & - \\
\hline Distance moved & $-0.33 *$ & - & - & - \\
\hline Mean velocity & $-0.33 *$ & $1.00 * *$ & - & - \\
\hline Time in corner & $0.40 *$ & $-0.90 * *$ & $-0.90 * *$ & - \\
\hline
\end{tabular}

** Correlation is significant at the 0.01 level ( 2 -tailed)

* Correlation is significant at the 0.05 level (2-tailed)

Table 1: Pearson correlation coefficients between the levels of blood corticosterone and the different measures of the open-field in both the acute (Table 1A), and chronic (Table 1B) treatments. Indication: ** Correlation is significant at the 0.01 level (2-tailed), * Correlation is significant at the 0.05 level (2tailed). 

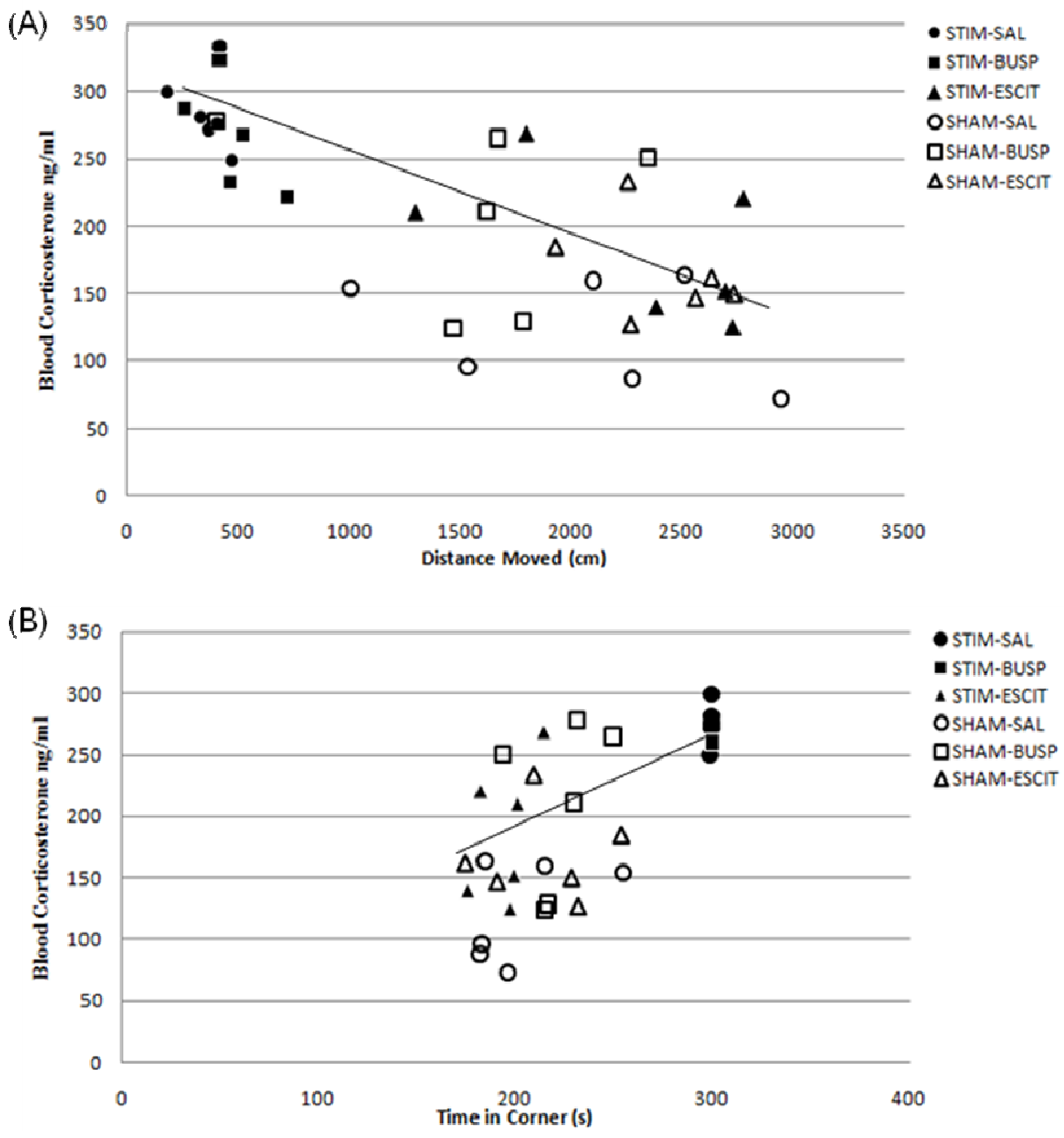

Figure 7: Pearson correlation coefficients between the levels of blood corticosterone and the distanced moved (Fig. 7 A) and the time spent in the corner zone (Fig. 7 B) of the open-field

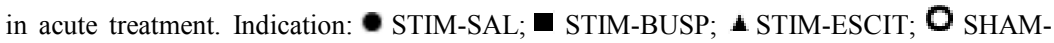
SAL; $\boldsymbol{\square}$ SHAM-BUSP; and $\boldsymbol{\Delta}$ SHAM-ESCIT. 

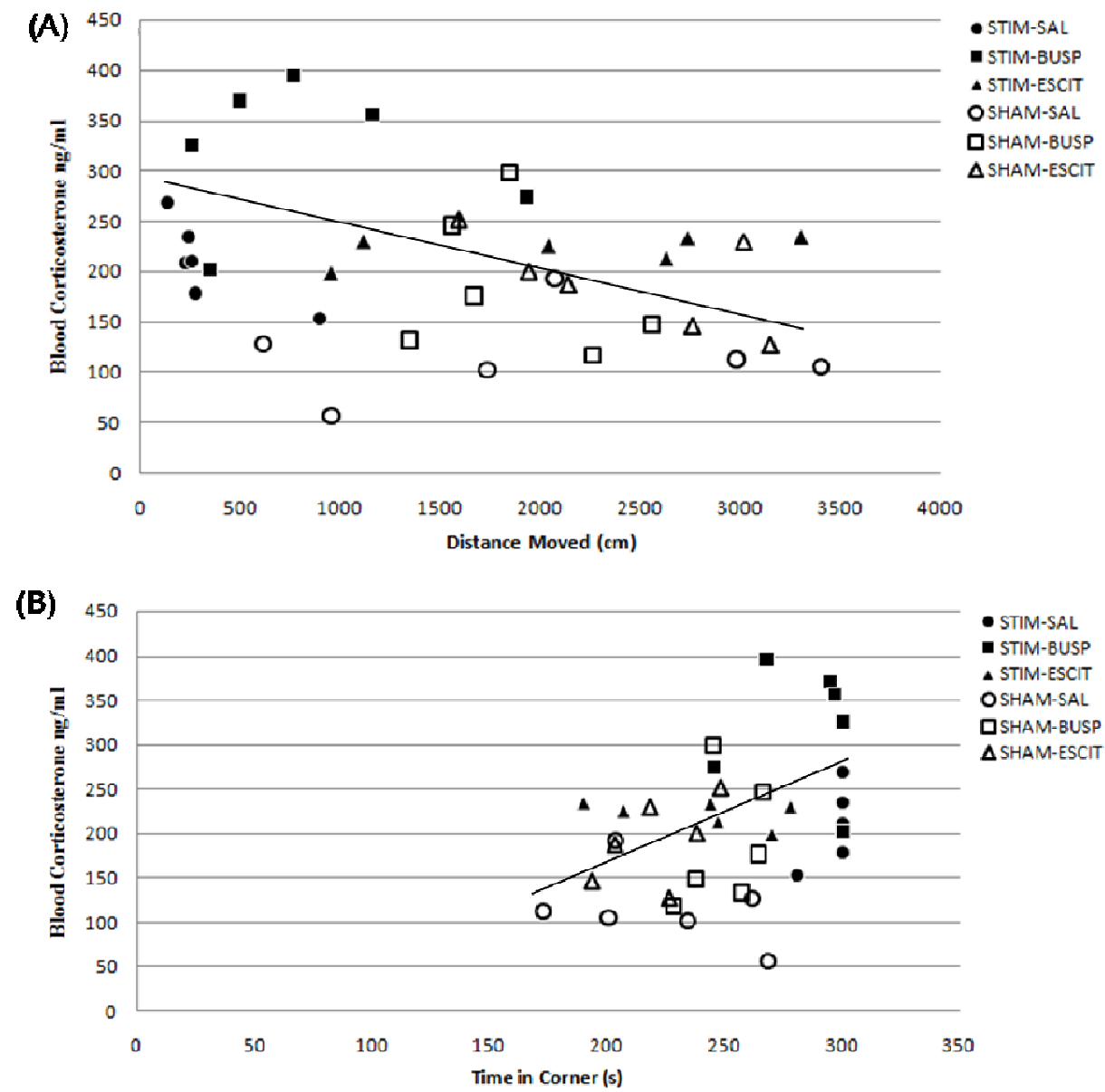

Figure 8: Pearson correlation coefficients between the levels of blood corticosterone and the distanced moved (Fig. 8 A) and the time spent in the corner zone (Fig. 8 B) of the open-field in chronic treatment. Indication: - STIM-SAL; - STIM-BUSP; $\triangle$ STIM-ESCIT; 0 SHAM-SAL; $\boldsymbol{\square}$ SHAM-BUSP; and $\boldsymbol{\Delta}$ SHAM-ESCIT. 


\section{Discussion}

In this study, electrical stimulation of the dIPAG evoked escape reactions subsequently followed by freezing response when animals were placed back to the openfield $12 \mathrm{~h}$ later. These findings indicate that dIPAG stimulation induces long lasting (at least $12 \mathrm{~h}$ ) fear which is probably associated with the open field context. Further, it was shown that escitalopram, but not buspirone, treatment was effective in attenuating the freezing behaviour in both the acute and chronic treatment condition. Interestingly, the stimulation amplitudes to evoke escape behaviour were increased after chronic treatment with ESCIT and BUSP. Further, the present study shows that dIPAG stimulation elevated blood corticosterone levels which were associated with changes in open field behaviour. Altogether these data indicate that dIPAG stimulation induced behavioural and physiological changes which could even be observed $12 \mathrm{~h}$ after stimulation. These findings suggest that dlPAG stimulation not only induces escape behaviour but that stimulation also leads to fear conditioning. Since there are no other stimuli than the context during dIPAG stimulation, the observed freezing behaviour in the open field context is considered to model internal generated fear.

It could be argued that the freezing behaviour observed $12 \mathrm{~h}$ after stimulation could be regarded as generalized fear after stimulation. However, before the rats were tested in the open field no freezing was observed in the home cage. The rats showed a normal behavioural repertoire in their home cage and the freezing behaviour was observed as soon as they were placed in the open field. In the present study we did not test whether the fear was also expressed in another context. Previous data have shown that fear induced by dIPAG stimulation generalizes to other contexts (Vianna et al 2001). It should be noted that in this latter study relative small boxes were used in which the context was modified. To what extend this dIPAG stimulation induced fear generalizes to other contexts needs to be investigated in further studies.

\section{Effects of treatment}

The electrophysiological and microdialysis studies have demonstrated that the somatodendritic 5- $\mathrm{HT}_{1 \mathrm{~A}}$ receptors become desensitized after prolonged administration of SSRIs (Dawson et al 2000; Hamon et al 1990; Invernizzi et al 1994). The therapeutic effect of ESCIT as antidepressant and panicolytic drug can be achieved either via the stimulation of 5- $\mathrm{HT}_{1 \mathrm{~A}}$ receptors indirectly through increased availability of synaptic 5-HT or possibly mediated by activation of 5- $\mathrm{HT}_{1 \mathrm{~A}}$ receptors (De Vry 1995). The behavioural effect observed herein after fear conditioning exposure was in accordance with previous reports showing the panicolytic properties of ESCIT in the electrical stimulated dorsal PAG (Hogg et al 2006). The latter authors reported that ESCIT significantly reduced the escape behaviour and fear-like sensation indicating the potential therapeutic efficacy for fear and panic disorders. Based on these findings, it was hypothesized that the activation 
of 5-HT $\mathrm{HA}_{1 \mathrm{~A}}$ receptors in dlPAG produces inhibitory of aversive responses, an anti-aversive effects (Brandao et al 1991). Furthermore, Graeff also suggested that the increase of 5HT availability within the midbrain decreases the magnitude of anxiety (Graeff 2004). In agreement with previous studies, the present study of ESCIT treatment did not only increase the aversive threshold response but also attenuate the freezing or fear-like behaviour in the open-field environment.

In addition, our study shows that the current intensity for the escape threshold was remarkably increased in the groups of STIM-BUSP and STIM-ESCIT. This data replicated previous studies on the reduction of aversive response when animals were subjected to the dorsal PAG stimulation using anti-panic agents such as alprazolam, clonazepam, zimelidine, (Jenck et al 1990; Jenck et al 1995) escitalopram, fluoxetine, paroxetine and the benzodiazepine (Hogg et al 2006). It was proposed that the antiaversive effects were obtained by increasing the extracellular synaptic availability of serotonin in the brain (Jenck et al 1995; Schutz et al 1985) as well as through the activation of 5-HT $2 \mathrm{c}$ receptors (Jenck et al 1998). However, the present study showed that buspirone was able to increase the aversive threshold for escape reaction but not reducing the freezing behaviour in the open-field testing. One possible explanation could be the complexity of mechanism of action of BUSP in the different regions of the PAG. In this respect, our previous findings have revealed that BUSP induced different patterns of cFos immunoreactivity in the rostral and caudal dIPAG, which suggest that the rostral dlPAG plays a role for anxiety while the caudal dlPAG is more towards aversive behaviour such as panic-like behaviour (Lim et al 2008c).

The morphological property of PAG is considerably rich in 5-HT immunoreactive nerve terminals that originated mainly from the serotonin-containing neuron in the dorsal raphe nucleus (Beitz et al 1986; Lovick et al 2000). Many studies on the 5-HT $\mathrm{HA}_{1 \mathrm{~A}}$ receptor subtype have indicated that this subsystem plays an important role in the modulation of fear conditioning (Ceglia et al 2004; Pobbe and Zangrossi 2005; Quartermain et al 1993). Recent findings on the 5- $\mathrm{HT}_{1 \mathrm{~A}}$ receptor subtype have indicated that this structure is highly involved in the modulatory function underlying generalized anxiety disorder and defensive behaviour (Argyropoulos et al 2004; Quartermain et al 1993). Furthermore, our previous results have shown that BUSP treatment induced a different pattern of neuronal activation in the different $\mathrm{PAG}$ region, indicating a different level of receptor sensitivity of $5-\mathrm{HT}_{\mathrm{IA}}$ in the pathophysiology of anxiety and panic disorder. (Lim et al 2008c).

It has been established that BUSP is clinically known to be effective only for mild anxiety (e.g. generalized anxiety disorder) but not for severe anxiety (e.g. panic disorder) condition (Ninan 2004). Previous experimental evidences have also demonstrated no effects on the escape behaviour, a panic-like reaction in the dIPAG stimulated animals (Connor and Davidson 1998; Poltronieri et al 2003). However, some contradictory results showed that the administration of $5-\mathrm{HT}_{1 \mathrm{~A}}$ agonist into the dorsal PAG was possible to inhibit this escape reaction during the electrical stimulation of this structure (de Bortoli et 
al 2006; Nogueira and Graeff 1995). It is of interest to note that the present study of BUSP treatment produced no effects on the conditioned fear in the open-field testing but it increased the intensity of stimulation of escape reaction after chronic treatment. On the other hand, there seemed to be a trend that after chronic treatment BUSP showed some beneficial effects. It could be argued that longer treatment periods are required to obtain an effect of BUSP treatment in this model.

\section{Corticosterone and defensive behaviour}

In consideration of the stress hormone, corticosterone/cortisol is thought to be an important neuroendocrinological hormone for stress response and defensive behaviour. There are some controversial issues concerning the involvement of stress hormones for panic attacks (PAs) in which the hypothalamic-pituitary-adrenal (HPA) axis was not activated during the naturally occurring PAs and in the experimental induced panic-like attacks by selective panicogenic agents such as lactate and carbon dioxide (Graeff and Del-Ben 2008; Schenberg et al 2001). However, several contradictory findings have demonstrated that the plasma cortisol level was elevated in the naturally occurring PAs, as well as in the experimental studies with $35 \% \mathrm{CO}_{2}$ inhalation, or administration of pharmacological agents with $\alpha_{2}$-adrenergic antagonist yohimbine, the serotonergic agents 1-(m-chlorophenyl) piperazine (mCPP) and fenfluramine (Argyropoulos et al 2002; Davidson 2000; Nutt and Ballenger 2003; van Duinen et al 2005). PAs are generally regarded as severe traumatic stressors, nevertheless other findings of naturally occurring PAs show no marked elevation of cortisol or adreno-cortico-tropin hormone (ACTH) though (McNally and Lukach 1992). Further, recent studies with $35 \% \mathrm{CO}_{2}$ challenge and pharmacological substances (m-CKK, yohimbine, caffeine) showed that the HPA axis was activated in these experimental panic-like responses (Charney et al 1987; Graeff et al 2005; van Duinen et al 2005; van Duinen et al 2007).

The present data show that corticosterone levels were increased after dIPAG stimulation and after open field testing in the STIM animals. Also, an increase of the corticosterone levels was found after acute and chronic ESCIT and BUSP treatment in the open field testing of sham animals. Previous studies have demonstrated that HPA activation was associated with a $5-\mathrm{HT}_{1 \mathrm{~A}}$ agonistic function by increasing the plasma corticosterone levels in order for the animal to cope with this stressful/fearful condition (McAllister-Williams et al 2001; Takao et al 1997; Tsuji et al 2001; Young et al 1994). Thus, the elevation of corticosterone level by BUSP and SSRIs treatment in the present study was in agreement with previous observations (Bundgaard et al 2007; Lorens and Van de Kar 1987; Matheson et al 1988). Nevertheless, in STIM animals a reduction of corticosterone level was observed after ESCIT treatment (as opposed to BUSP) when compared to STIM-SAL animals in the open field. Yet, these animals still showed a considerably high level of corticosterone as compared to the SHAM-SAL group. 
In this study, it is important to note that, the levels of corticosterone did not mimic the behavioural effects as observed in the open field testing of both the acute and chronic treatment. It could be anticipated that the attenuation of fear-like response in the open field testing would lead to a reduction of corticosterone level. However, the results obtained in this study were not the one we expected. One possible explanation could be that the administration of SSRI activates the HPA axis through the post-synaptic 5-HT receptors in the paraventricular nucleus of the hypothalamus, which results in adrenocorticotropin release at the pituitary levels (Dinan 1996; Fuller et al 1996). At the same time, SSRI treatment also enhances the serotonergic activity by increasing the extracellular 5-HT levels in the central nervous system (Hjorth et al 2000; Pineyro and Blier 1999). Therefore, our data show for the first time that SSRI treatment produces phobiolytic activity with elevation of corticosterone level during the open field testing in the animal model of internal fear generated by dIPAG stimulation.

\section{Neural mechanism of fear}

Recent evidence indicated that the amygdala is a center where convergence of various types of fearful sensations and perceptions that animals experienced. The amygdala-PAG connection provides an essential defensive behavioural system in the overall integration of fearful information. Previous studies demonstrated that the lateral amygdaloid nucleus (LA) connects directly to the central amygdaloid nucleus (CA), which projects its axons downward via the ventral amygdalofugal pathway, through the anterior and medial hypothalamus, and finally down to the lower reaches of the PAG (LeDoux 1994; LeDoux 1995; Swanson and Petrovich 1998). In this study, the electrical stimulation was used as an unconditioned fear stimulus (US) generated within the dIPAG in an enclosed open-field environment (as condition stimulus, CS). During stimulation, rats immediately displayed spontaneous flight response and this condition was considered as intense forms of fear/panic. As such, the CS cue was generated and fearful information of the open-field environment arrived at the thalamic nuclei, and later through a direct thalamic-amygdaloid connection, where information was conveyed to the LA (see Figs. 9A and 9B). This pathway is known as the primitive mechanism of defense or "low-road" in the defensive behavioural system as described previously by LeDoux in which a fearresponse is activated in animals. During this moment, CS and US information converge onto the LA where plasticity was formed to mediate the process of acquisition of fear learning. Therefore, $12 \mathrm{~h}$ later after the stimulation rats exhibited freezing behaviour when they were placed back into the same open-field environment. Interestingly, Vianna et al showed that electrical stimulation of the dIPAG produced no freezing behaviour in the same/different context environment $24 \mathrm{~h}$ later (Vianna et al 2001). However, the present study demonstrated that freezing behaviour was observed after $12 \mathrm{~h}$ of escape reaction when rats were tested again in the same open field condition. This suggests that fear conditioning generated within the dlPAG was confined to a specific time frame which followed by subsequent extinction. 

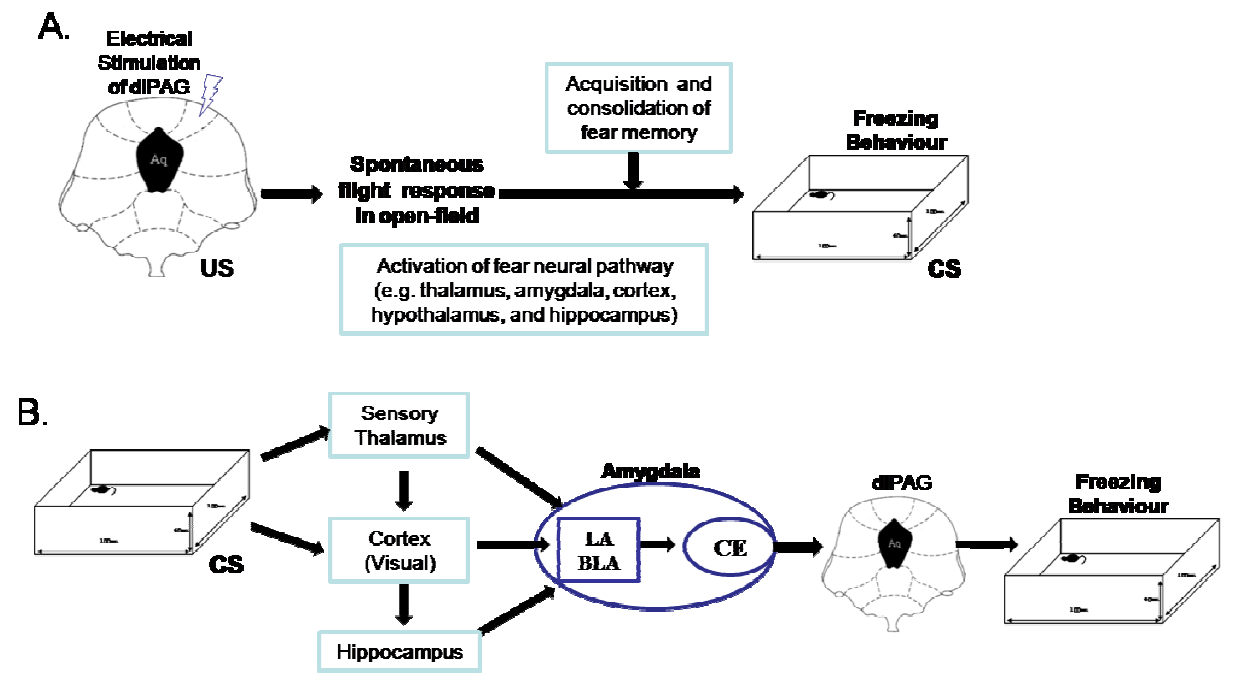

Figure 9 (A) and (B): Illustration of freezing behaviour in the open-field after the induction of escape behaviour by electrical stimulation of the dIPAG - a substrate for the expression of fear.

In conclusion, the current study shows that the freezing behaviour generated intrinsically within the dlPAG was confined to a specific time frame after the induction of escape behaviour. This fear-like response was attenuated by ESCIT treatment while BUSP was not effective. Interestingly, the stimulation amplitudes to evoke escape behaviour were significantly higher for animals chronically treated with buspirone and escitalopram. Further, our data also confirm the activation of the HPA axis during the panic and fear-like behaviour. Future research of fear should be focused on the underlying neural substrate of fear generated by dIPAG stimulation.

\section{Acknowledgement}

The authors are thankful to $\mathrm{H}$. Lundbeck A/S for the donation of Escitalopram Oxalate. This research was supported by a grant from the FP6 Marie Curie Fellowship (MEST-CT-2005-020589). 


\section{References}

APA (1998): Practice guidelines for the treatment of patients with panic disorder. Am $J$ Psychiatry:155:151-134.

Argyropoulos SV, Bailey JE, Hood SD, Kendrick AH, Rich AS, Laszlo G, et al (2002): Inhalation of 35\% $\mathrm{CO}(2)$ results in activation of the HPA axis in healthy volunteers. Psychoneuroendocrinology 27:715-729.

Argyropoulos SV, Hood SD, Adrover M, Bell CJ, Rich AS, Nash JR, et al (2004): Tryptophan depletion reverses the therapeutic effect of selective serotonin reuptake inhibitors in social anxiety disorder. Biol Psychiatry 56:503-509.

Bandler R, Shipley MT (1994): Columnar organization in the midbrain periaqueductal gray: modules for emotional expression? Trends Neurosci 17:379-389.

Beitz AJ, Clements JR, Mullett MA, Ecklund LJ (1986): Differential origin of brainstem serotoninergic projections to the midbrain periaqueductal gray and superior colliculus of the rat. J Comp Neurol 250:498-509.

Blanchard DC, Blanchard RJ (1972): Innate and conditioned reactions to threat in rats with amygdaloid lesions. J Comp Physiol Psychol 81:281-290.

Blanchard RJ, Blanchard DC, Agullana R, Weiss SM (1991): Twenty-two kHz alarm cries to presentation of a predator, by laboratory rats living in visible burrow systems. Physiol Behav 50:967-972.

Blanchard RJ, Blanchard DC, Weiss SM, Meyer S (1990): The effects of ethanol and diazepam on reactions to predatory odors. Pharmacol Biochem Behav 35:775-780.

Brandao ML, Lopez-Garcia JA, Graeff FG, Roberts MH (1991): Electrophysiological evidence for excitatory 5-HT2 and depressant 5-HT1A receptors on neurones of the rat midbrain tectum. Brain Res 556:259-266.

Brown JS, Kalish HI, Farber IE (1951): Conditioned fear as revealed by magnitude of startle response to an auditory stimulus. $J$ Exp Psychol 41:317-328.

Bundgaard C, Larsen F, Jorgensen M, Mork A (2007): Pharmacokinetic/pharmacodynamic feedback modelling of the functional corticosterone response in rats after acute treatment with escitalopram. Basic Clin Pharmacol Toxicol 100:182-189.

Carrive P (1993): The periaqueductal gray and defensive behaviour: functional representation and neuronal organization. Behav Brain Res 58:27-47.

Ceglia I, Acconcia S, Fracasso C, Colovic M, Caccia S, Invernizzi RW (2004): Effects of chronic treatment with escitalopram or citalopram on extracellular 5-HT in the prefrontal cortex of rats: role of 5-HT1A receptors. Br J Pharmacol 142:469-478.

Charney DS, Woods SW, Goodman WK, Heninger GR (1987): Neurobiological mechanisms of panic anxiety: biochemical and behavioural correlates of yohimbine-induced panic attacks. $A m J$ Psychiatry 144:1030-1036.

Connor KM, Davidson JR (1998): Generalized anxiety disorder: neurobiological and pharmacotherapeutic perspectives. Biol Psychiatry 44:1286-1294.

Davidson RJ (2000): Anxiety, Depression, and Emotion: anxiety, Depression Sas C. Oxford University Press:77-78.

Davis M, Falls WA, Campeau S, Kim M (1993): Fear-potentiated startle: a neural and pharmacological analysis. Behav Brain Res 58:175-198.

Dawson LA, Nguyen HQ, Smith DI, Schechter LE (2000): Effects of chronic fluoxetine treatment in the presence and absence of (+/-)pindolol: a microdialysis study. Br J Pharmacol 130:797-804.

Dayan P, Kakade S, Montague PR (2000): Learning and selective attention. Nat Neurosci 3 Suppl:12181223.

de Bortoli VC, Nogueira RL, Zangrossi H, Jr. (2006): Effects of fluoxetine and buspirone on the panicolytic-like response induced by the activation of 5-HT1A and 5-HT2A receptors in the rat dorsal periaqueductal gray. Psychopharmacology (Berl) 183:422-428.

De Vry J (1995): 5-HT1A receptor agonists: recent developments and controversial issues. Psychopharmacology (Berl) 121:1-26. 
Dielenberg RA, Arnold JC, McGregor IS (1999): Low-dose midazolam attenuates predatory odor avoidance in rats. Pharmacol Biochem Behav 62:197-201.

Dinan TG (1996): Serotonin and the regulation of hypothalamic-pituitary-adrenal axis function. Life Sci 58:1683-1694.

Finn DP, Jhaveri MD, Beckett SR, Madjd A, Kendall DA, Marsden CA, et al (2006): Behavioural, central monoaminergic and hypothalamo-pituitary-adrenal axis correlates of fear-conditioned analgesia in rats. Neuroscience 138:1309-1317.

Fuller RW, Perry KW, Hemrick-Luecke SK, Engleman E (1996): Serum corticosterone increases reflect enhanced uptake inhibitor-induced elevation of extracellular 5-hydroxytryptamine in rat hypothalamus. $J$ Pharm Pharmacol 48:68-70.

Graeff FG (1990): Brain defense systems and anxiety. In: Roth M, Burrows GD, Noyes R (eds) Handbook of Anxiety. The neurobiology of anxiety. Elsevier, Amsterdam:307-354.

Graeff FG (2004): Serotonin, the periaqueductal gray and panic. Neurosci Biobehav Rev 28:239-259.

Graeff FG, Del-Ben CM (2008): Neurobiology of panic disorder: From animal models to brain neuroimaging. Neurosci Biobehav Rev.

Graeff FG, Garcia-Leal C, Del-Ben CM, Guimaraes FS (2005): Does the panic attack activate the hypothalamic-pituitary-adrenal axis? An Acad Bras Cienc 77:477-491.

Hamon M, Gozlan H, el Mestikawy S, Emerit MB, Bolanos F, Schechter L (1990): The central 5-HT1A receptors: pharmacological, biochemical, functional, and regulatory properties. Ann N Y Acad Sci 600:114-129; discussion 129-131.

Harris JA, Westbrook RF (1994): Effects of midazolam and naloxone in rats tested for sensitivity/reactivity to formalin pain in a familiar, novel or aversively conditioned environment. Psychopharmacology (Berl) 115:65-72.

Hjorth S, Bengtsson HJ, Kullberg A, Carlzon D, Peilot H, Auerbach SB (2000): Serotonin autoreceptor function and antidepressant drug action. $J$ Psychopharmacol 14:177-185.

Hogg S, Michan L, Jessa M (2006): Prediction of anti-panic properties of escitalopram in the dorsal periaqueductal grey model of panic anxiety. Neuropharmacology 51:141-145.

Hollander E, Simeon D (2003): Anxiety disorders. In Textbook of Clinical Psychiatry. American Psychiatric Publishing, Washington, DC 4th Ed:543-565.

Invernizzi R, Bramante M, Samanin R (1994): Chronic treatment with citalopram facilitates the effect of a challenge dose on cortical serotonin output: role of presynaptic 5-HT1A receptors. Eur $J$ Pharmacol 260:243-246.

Jenck F, Broekkamp CL, Van Delft AM (1990): The effect of antidepressants on aversive periaqueductal gray stimulation in rats. Eur J Pharmacol 177:201-204.

Jenck F, Moreau JL, Berendsen HH, Boes M, Broekkamp CL, Martin JR, et al (1998): Antiaversive effects of $5 \mathrm{HT} 2 \mathrm{C}$ receptor agonists and fluoxetine in a model of panic-like anxiety in rats. Eur Neuropsychopharmacol 8:161-168.

Jenck F, Moreau JL, Martin JR (1995): Dorsal periaqueductal gray-induced aversion as a simulation of panic anxiety: elements of face and predictive validity. Psychiatry Res 57:181-191.

Klemenhagen KC, Gordon JA, David DJ, Hen R, Gross CT (2006): Increased fear response to contextual cues in mice lacking the 5-HT1A receptor. Neuropsychopharmacology 31:101-111.

LeDoux JE (1993): Emotional networks in the brain. In Handbook of emotions (M. Lewis \&J. M. Haviland, eds.) New York: Guilford Press:109-118.

LeDoux JE (1994): Emotion, memory and the brain. Sci Am 270:50-57.

LeDoux JE (1995): Emotion: clues from the brain. Annu Rev Psychol 46:209-235.

Lim LW, Blokland A, Visser-Vandewalle V, Vlamings R, Sesia T, Steinbusch H, et al (2008a): Highfrequency stimulation of the dorsolateral periaqueductal gray and ventromedial hypothalamus fails to inhibit panic-like behaviour. Behav Brain Res 193:197-203.

Lim LW, Temel Y, Blokland A, Visser-Vandewalle V, Steinbusch H (2008b): Fos immunoreactivity in the rat forebrain induced by electrical stimulation of the dorsolateral periaqueductal gray matter. $J$ Chem Neuroanat (In press).

Lim LW, Temel Y, Sesia T, Vlamings R, Visser-Vandewalle V, Steinbusch HW, et al (2008c): Buspirone induced acute and chronic changes of neural activation in the periaqueductal gray of rats. Neuroscience 155:164-173. 
Lim LW, Temel Y, Visser-Vandewalle V, Steinbusch H, Schruers K, Hameleers R, et al (2008d): Effect of buspirone on the behavioural regulation of rats in low versus high anxiety conditions. Arzneimittelforschung 58:269-276.

Lorens SA, Van de Kar LD (1987): Differential effects of serotonin (5-HT1A and 5-HT2) agonists and antagonists on renin and corticosterone secretion. Neuroendocrinology 45:305-310.

Lovick TA, Parry DM, Stezhka VV, Lumb BM (2000): Serotonergic transmission in the periaqueductal gray matter in relation to aversive behaviour: morphological evidence for direct modulatory effects on identified output neurons. Neuroscience 95:763-772.

Matheson GK, Gage D, White G, Dixon V, Gipson D (1988): A comparison of the effects of buspirone and diazepam on plasma corticosterone levels in rat. Neuropharmacology 27:823-830.

McAllister-Williams RH, Anderson AJ, Young AH (2001): Corticosterone selectively attenuates 8-OHDPAT-mediated hypothermia in mice. Int J Neuropsychopharmacol 4:1-8.

McNally RJ, Lukach BM (1992): Are panic attacks traumatic stressors? Am J Psychiatry 149:824-826.

Montgomery KC (1955): The relation between fear induced by novel stimulation and exploratory behaviour. J Comp Physiol Psychol 48:254-260.

Montgomery KC, Monkman JA (1955): The relation between fear and exploratory behaviour. J Comp Physiol Psychol 48:132-136.

Ninan PMS (2004): Buspirone and gepirone. In: Schatzberg AF, Nemeroff CB, editors. Textbook of psychopharmcology 3rd ed Washington, DC. . American Psychiatric Publishing:391-404.

Nogueira RL, Graeff FG (1995): Role of 5-HT receptor subtypes in the modulation of dorsal periaqueductal gray generated aversion. Pharmacol Biochem Behav 52:1-6.

Nutt DJ, Ballenger JC (2003): Anxiety Disorders. Blackwell Publishing:280-281.

Panksepp J (1998): Affective Neuroscience: The foundations of human and animal emotions. Oxford University Press:206-222.

Pineyro G, Blier P (1999): Autoregulation of serotonin neurons: role in antidepressant drug action. Pharmacol Rev 51:533-591.

Pobbe RL, Zangrossi H, Jr. (2005): 5-HT(1A) and 5-HT(2A) receptors in the rat dorsal periaqueductal gray mediate the antipanic-like effect induced by the stimulation of serotonergic neurons in the dorsal raphe nucleus. Psychopharmacology (Berl) 183:314-321.

Poltronieri SC, Zangrossi H, Jr., de Barros Viana M (2003): Antipanic-like effect of serotonin reuptake inhibitors in the elevated T-maze. Behav Brain Res 147:185-192.

Quartermain D, Clemente J, Shemer A (1993): 5-HT1A agonists disrupt memory of fear conditioning in mice. Biol Psychiatry 33:247-254.

Schenberg LC, Bittencourt AS, Sudre EC, Vargas LC (2001): Modeling panic attacks. Neurosci Biobehav Rev 25:647-659.

Schiller D, Cain CK, Curley NG, Schwartz JS, Stern SA, Ledoux JE, et al (2008): Evidence for recovery of fear following immediate extinction in rats and humans. Learn Mem 15:394-402.

Schutz MT, de Aguiar JC, Graeff FG (1985): Anti-aversive role of serotonin in the dorsal periaqueductal grey matter. Psychopharmacology (Berl) 85:340-345.

Stiedl O, Misane I, Spiess J, Ogren SO (2000): Involvement of the 5-HT1A receptors in classical fear conditioning in C57BL/6J mice. J Neurosci 20:8515-8527.

Sulon J, Demey-Ponsart L, Beauduin P, Sodoyez JC (1978): Radioimmunoassay of corticosterone, cortisol and cortisone: their application to human cord and maternal plasma. J Steroid Biochem 9:671-676.

Swanson LW, Petrovich GD (1998): What is the amygdala? Trends Neurosci 21:323-331.

Takao K, Nagatani T, Kitamura Y, Yamawaki S (1997): Effects of corticosterone on 5-HT1A and 5-HT2 receptor binding and on the receptor-mediated behavioural responses of rats. Eur J Pharmacol 333:123-128.

Temel Y, Boothman LJ, Blokland A, Magill PJ, Steinbusch HW, Visser-Vandewalle V, et al (2007): Inhibition of 5-HT neuron activity and induction of depressive-like behaviour by high-frequency stimulation of the subthalamic nucleus. Proc Natl Acad Sci U S A 104:17087-17092.

Tsuji M, Takeda H, Matsumiya T (2001): Protective effects of 5-HT1A receptor agonists against emotional changes produced by stress stimuli are related to their neuroendocrine effects. $\mathrm{Br} \mathrm{J}$ Pharmacol 134:585-595. 
Van den Hove DL, Steinbusch HW, Bruschettini M, Gazzolo D, Frulio R, Scheepens A, et al (2006): Prenatal stress reduces S100B in the neonatal rat hippocampus. Neuroreport 17:1077-1080.

van Duinen MA, Schruers KR, Maes M, Griez EJ (2005): CO2 challenge results in hypothalamicpituitary-adrenal activation in healthy volunteers. $J$ Psychopharmacol 19:243-247.

van Duinen MA, Schruers KR, Maes M, Griez EJ (2007): CO2 challenge induced HPA axis activation in panic. Int J Neuropsychopharmacol 10:797-804.

Vianna DM, Landeira-Fernandez J, Brandao ML (2001): Dorsolateral and ventral regions of the periaqueductal gray matter are involved in distinct types of fear. Neurosci Biobehav Rev 25:711719.

Young AH, Goodwin GM, Dick H, Fink G (1994): Effects of glucocorticoids on 5-HT1A presynaptic function in the mouse. Psychopharmacology (Berl) 114:360-364. 


\section{CIHIA PP'TIEIR \&}

\section{CONCLUSION}




\section{Conclusion}

In the present study, we first tested the hypothesis whether electrical stimulation of the dIPAG at higher frequencies $(>100 \mathrm{~Hz})$ would prevent rats showing escape or paniclike behaviour in the open-field arena. Secondly, we hypothesized that SSRI treatment would attenuate the fear-like behaviour after escape reaction of dIPAG stimulation during the post-stimulation periods. Furthermore, we also investigated the modulatory role and treatment effects of buspirone in the different regions of the PAG and different settings of the open-field arenas. Altogether, the experimental data presented in this thesis are concluded as follows.

Chapter 2: The PAG is composed of different anatomical columns with functional differentiation. The PAG is considered a key structure to coordinate behaviour in response to threatening stimuli. It has been demonstrated that stimulation of this area in rats initiate different defensive behaviours such as fight, flight and freeze in response to aversive external and internal stimuli. Besides, it also eliminates the perception of pain by stimulation which is called stimulation produced analgesia. Several physiological changes have been observed in the alteration of blood circulation, respiration, pain perception, autonomic movement and postural adjustment with complex behaviour during and after the stimulation or lesions of the PAG. In addition, the PAG also modulates several biological functions such as reproductive or sexual behaviour, maternal behaviour, vocalization, anxiety, cardiovascular, and respiratory activities

Chapter 3: The integration of cognitive-affective information for defensive behaviour involves different neuroanatomical structures. We found that electrical stimulation of the dIPAG produced different patterns of neuronal activation in specific parts of the forebrain which are involved in panic- or fear-like behaviour. Importantly, the range of neuroanatomical structures (e.g. cortical areas, septo-hippocampal system, amygdala and hypothalamus) and neurotransmitters (e.g. acetylcholine, serotonin) matched the two-dimensional defense system of McNaughton and Corr.

Chapter 4: To further investigate the effects of buspirone, two different conditions of the open-field were used which were the enclosed and exposed open-fields (distinguished as low and high anxiety). Our results showed that buspirone has an anxiolytic action in these two open-field settings suggesting that buspirone may not only be useful in reducing mild anxiety but also severe anxiety as well. However, in clinical practice buspirone is typically used for mild anxiety such as generalized anxiety disorder and not for other severe anxiety conditions. Besides, the reduced activity and increase time spent in the center areas of the open-field setting are indicative of both an anxiogenic and anxiolytic effect, respectively. This data appears to show a dual effect of buspirone on anxiety. 
Chapter 5: It was demonstrated that electrical stimulation of the dIPAG and VMH at higher-frequencies $(>100 \mathrm{~Hz})$ was not able to prevent the induction of escape behaviour. The intensity of stimulation amplitude turned out to be the most important stimulation parameter for evoking escape behaviour. Furthermore, we also observed that the neuronal activation pattern in the medial prefrontal cortex resulting from dlPAG and VMH stimulation was similar. These findings suggest that electrical stimulation of the dIPAG and VMH induces panic-related behaviours even at higher frequencies.

Chapter 6: In this study, it was shown that the modulatory roles of 5-HT $1 \mathrm{~A}$ receptors induced different neuronal activation patterns in the different regions of the PAG in both the acute and chronic buspirone treatment conditions. In view of these results, the main effect of anxiolytic action was specifically localized in all regions of the rostral and caudal dmPAG. However, the caudal dlPAG, IPAG and vIPAG were found to be ineffective to buspirone treatment, probably due to their distinctive function in mediating higher level of anxiety in defensive behaviour. This indicates that the longitudinal anatomical structure of the PAG possesses a different level of receptor sensitivity of 5-HT ${ }_{1 \mathrm{~A}}$ in the pathophysiology of anxiety and panic disorder.

Chapter 7: Here, we have shown that the escape reaction generated intrinsically within the dIPAG was followed by freezing behaviour on the next day. This fear-like response was attenuated by escitalopram treatment while buspirone or vehicle treated groups showed no effect. Interestingly, the stimulation amplitudes to evoke escape behaviour were significantly higher for animals chronically treated with buspirone and escitalopram. In addition, our data also confirm the activation of the HPA axis during the panic and fear-like behaviour after dIPAG stimulation.

The results obtained from these experiments as outlined in this thesis show that the dlPAG plays an important role in defensive behaviour. The electrical stimulation of the dlPAG shows a similar fearful emotional activation in both animals and humans. Thus, the use electrical stimulation of the PAG as an animal model of neuropsychiatric disorders is a promising tool which can be used in the development of novel therapies. In addition, our findings also suggest the combination of drugs and neurostimulatory therapies in the management of experimental models of pathological fear. The question whether neurostimulatory therapies can be used in the treatment of pathological fear remains not fully answered. From this study, we can state that this is not possible using the PAG as target. However, these new clues from an old concept can lead us to find the optimal target. 


\section{Acknowledgement}

Everything in thanksgiving and glory to God in the highest!

The completion of this substantial work is the result of the collaborative efforts of numerous people that share a common philosophy in which scientific discoveries make a difference in the lives of people. My first sincere gratitude and appreciation is owed to my academic supervisors Prof. Dr. Harry Steinbusch, Prof. Dr. Veerle Visser-Vandewalle, Dr. Yasin Temel, and Dr. Arjan Blokland who endured months of reading and revising the unusually long drafts of my manuscripts which finally assembled into this book.

I would like to express my sincere appreciation to Prof. Dr. Harry Steinbusch, for giving me an opportunity to work on this challenging topic and providing me continuous guidance, and support throughout this period of scientific research. Thank you once again for the eighteen months appointment as a Marie Curie Fellow to carry out this study.

My acknowledgements of gratitude would also be mentioned to Prof. Dr. Veerle Visser-Vandewalle, for your inspiration, guidance, and careful perusal of this thesis. Thank you for your invaluable comments and critiques on the improvement of this work.

Dr. Yasin Temel and Dr. Arjan Blokland: My heartfelt gratitude for your sustained and substantial contribution to my intellectual progress as well as your meticulous examination over all my scientific publications and development. Thank you for your endurance, uncomplaining, and motivating over this period of my PhD course at the Maastricht University, the Netherlands. Yasin: I will always keep this in my mind that "good science good laugh"; and Arjan: you have said this to me "To boldly go beyond where no man has gone before". Additionally, I am also grateful to Halime Celik, for your kind understanding and hospitality that every time (especially in the evening) I come to your house and take too much of your personal time with your husband.

The acknowledgements would not be complete without thanking my colleague (as well as my sub-family members) of the experimental neurosurgery. Dr. Sonny Tan, Thibaut Sesia, Rinske Vlamings, Dr. Marcus Janssen, Ingeborg van Kroonenburgh and Dr. Lieke Noblesse, and Ali Jahanshahianvar: Thank you for your unconditional supports and helps not only for my research works but also for our excellent and wonderful relationship. I really appreciate everything you have done for me and my gratitude to all of you is too marvelous for words! Rinske and Ingeborg, thank you once again for being my 'Paranimfen' in organizing this event a successful. Besides, I would like to thank Rob Hameleers, Dr. Ramazan Kozan, Dr. Ahmad Hilmi Kaya, Xie Lan, Maki Matsui, Dr. Nazan Aydin, Dr. Leonidas Chouliaras, Vincent Buithuis, Jan-Dirk Vermeij, Mujzgan Aziz Mohammadi for your contribution in creating an ideal and interactive environment of science in this experimental neurosurgery group. 
Most of all, I would like to thank my colleague and friends who work in the department of neuroscience for maintaining a well administered research environment. Here, my heartfelt gratitude to Dr. Govert Hoogland, Dr. Fred van Leeuwen, Dr. Jan De Vente, Dr. Danilo Gavilanes, Dr. Kim Rijkers, Dr. Veronique Moers-Hornikx, Dr. Jos Prickaerts, Dr. Daniel van den Hove, Dr. Kris Rutten, Dr. Mario Losen, Dr. Pilar Martinez, Dr. Ralf Schneider, Dr. Gunther Kenis, Dr. Ronald Deumens, Dr. Bart Joosten, Dr. Sofie Janssen, Dr. Joost van Der Brook, Wiel Honig, Dr. Lukas Ricker, Dr. Evi Lemmens, Dr. Tatyana Strekalova, Dr. Nicole Senden, Anja de Bruin, Ivona Brasnjevic, Marijke Lemmens, Eveline Strackx, Annerieke Sierksma, Imke van Kooten, Natalia Kholod, Chiara Mencarelli, Marisela, Martinez-Claros, Alejandro Gomez, Eva van Donkelaar, Olga Reneerkens, Marko Phernambucq, Jochen De Vry, Kathleen Vrolix, Michiel Truin, Robby Jaken, Anne Gabriel, Frank Dennissen, Dr. Pawel Kreczmanski, Dr. Mu Myint, Dr. Bart Biallosterski, Eva Bollen, Dr. Jean Maurice Cijntje, Dr. Sajjad Rahnama'i, Jodi Pawluski, Peter Molenaar, and others. A special thank is also extended to Hellen Steinbusch, Marjanne Markerink, Denise Hermes, Jorike Endert, and Marjan Philippens for your excellent coordination and histological/technical support in the laboratory. My sincere gratitude is also owed to MarieTherese Moers, Anouk Hamers, Akke Spauwen, Mirese Willems, Sandra Habets for your wonderful secretary works in the department, as well as Ankie Hochstenbach, Laurent Louwies, Martie Wanders, and Marko van Hertrooy for your financial and administration coordination.

Dear Prof. Dr. Eric Griez and Dr. Koen Schruers, I feel greatly indebted to both of you for giving me an opportunity and gateway to scientific research and your intellectual guidance on my master course in affective neuroscience. My sincere appreciation would also be mentioned to Leni Noteborn, Dr. Gabriel Esquivel, Dr. Marlies van Duinen, Lies Goossens, Valentina Niccolai for your encouragement and invaluable supports.

A word of thank-you would also be expressed to Job Gerver, Ellen Derks, Bianca Buligescu, Henry Espinoza, Mok Hao Yen, Mok Wen Mei, Xiao Yen, She-King, Chuong Kiu, Dr. Ding Cheng Hoe, Prof. Dr. Oleg Volkodav, Prof. Dr. Andrei Sakhaltuev, as well as all my Thai and Chinese community in the Netherlands, for your marvelous friendship and supports.

On a more personal note, I would like to thank all my family members especially my wife Lorraine Leung, adopted dad Ong Soon Chye, uncle David Ling Kong Kong, aunt Agnes Lim, grandmas, step-parents Yong Saw Min and Wong Hea Eng, and everyone for your unconditional love, supports, care, and constant encouragement.

Besides, I would like to express my sincere gratitude to Simon Drobig and his family, for their immeasurable help and care. My gratitude is also owed to the Maastricht Christian Chinese Church members and several officers of the Salvation Army (Major and Mrs. John Umasanthiram, Major Kamala, Major and Mrs. Lim Teck Fung, Major Chelvee, Mr. and Mrs. Eddie Choong, Ms. Elaine Wong, Envoy Enrol Duck-Chong) for their care, love, powerful prayers, and spiritual supports. Major John, I will always remember your word that, "discipline makes a man"; and Major Lim, you have told me "do not forget God, when you have achieved the goal in your life". Today, all your advice accomplished its purpose. 
A special thank is extended to the board of evaluation committee (Prof. Dr. J.J. van Overbeeke, Prof. Dr. J.S.H. Vles, Prof. Dr. M. De Baets, Dr. K. Schruers), and the corona of my dissertation defense (Prof. Dr. E. Beuls, Prof. Dr. A. Benazzouz, and Dr. P. Magill) for asking insightful questions and providing useful comments on the presentation of this scientific report.

Finally, I wish to thank the members of the general public who attended this special occasion of my $\mathrm{PhD}$ oral dissertation defense. All deserve my deepest heartfelt gratitude. Without you, this work would not have been possible.

$\widetilde{\mathbb{U}}_{\text {he LORD is my shepherd, I shall not be in want. }}$

He makes me lie down in green pastures,

He leads me beside quiet waters, He restores my soul.

He guides me in paths of righteousness for His name's sake.

Even though I walk through the valley of the shadow of death,

I will fear no evil, for you are with me;

Your rod and your staff, they comfort me.

You prepare a table before me in the presence of my enemies.

You anoint my head with oil; my cup overflows.

Surely goodness and love will follow me all the days of my life,

And I will dwell in the house of the LORD forever.

Psalms 23: 1-6

耶和华是我的牧者, 我必不致缺乏。

他使我躺卧在青草地上, 领我至可安歇的水边。

他使我的灵魂苏醒, 为自己的名引导我走义路。

我虽然行过死荫的幽谷, 也不怕遭害, 因为你与我同在;

你的仗, 你的竿, 都安慰我。

在我敌人面前, 你为我摆设宴席。

你用油膏了我的头, 且使我的福杯满溢。

我一生一世必有恩惠慈爱随着我,

我且要住在耶和华的殿中, 直到永远。

诗篇 23: 1-6 
Research and Thesis Sponsorship
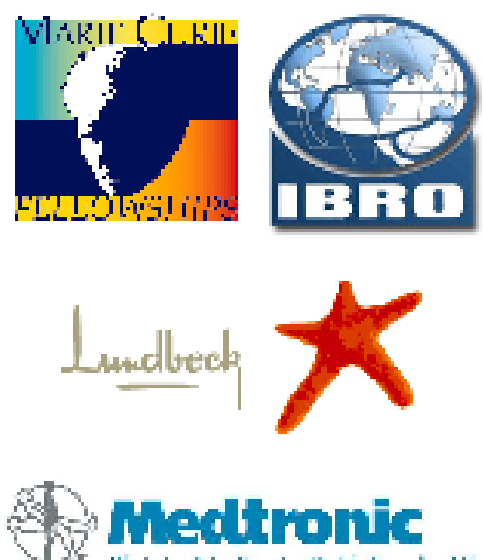

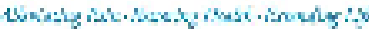

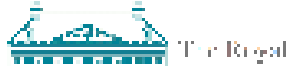

ing listh

iirifi

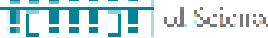

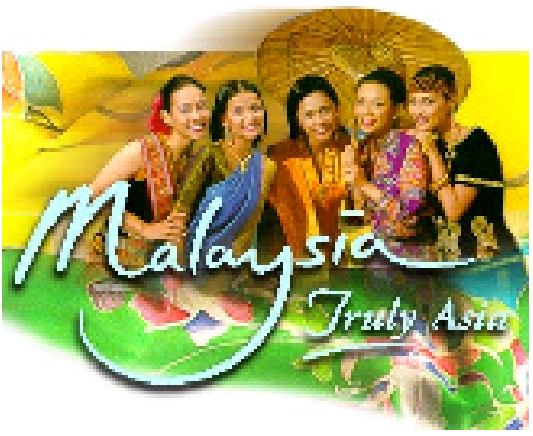

http://www.tourism.gov.my/ 


\section{BIOGRAPHY}

Lee Wei (Anthony) Lim was born in 1980 in Malaysia. After the completion of his secondary school education in 1998, he chose to pursue medicine in Belgorod State Medical University, Russia, and Crimean State Medical University, Ukraine with the support of his adopted father, Mr. Ong Soon Chye. He obtained his medical degree in June 2005, unlike so many of his contemporaries he did not return immediately to Malaysia for his medical practice, instead he went to the Netherlands, Maastricht University for a master degree in affective neuroscience. Firstly, he worked as a research assistant at Vijverdal Academic Anxiety Center under the supervision of Prof. Dr. Eric Griez and Dr. Koen Schruers; and later at the Maastricht University Medical Center and School for Mental Health and Neurosciences in the departments of neurosurgery and neuroscience under the guidance of Prof. Dr. Harry Steinbusch, Prof. Dr. Veerle VisserVandewalle, Dr. Yasin Temel and Dr. Arjan Blokland. Two years later in July 2007, he obtained his master degree. And in May 2007 he was officially appointed as a Marie Curie Fellow to carry out his $\mathrm{PhD}$ study in neuroscience. In recognition of his motivation for scientific research, he received several awards for instance the "Dutch Education Learning at Top level Award" (DELTA) and the "International Brain Research Organization" (IBRO) grant. After the accomplishment of his $\mathrm{PhD}$ project in 2008, he was awarded the "Kootstra Talent Fellowship" to continue his scientific career in the arena of translational neuroscience. Along this pathway, he met his beautiful and intriguing wife, Lorraine Leung, in the Netherlands. 
192 


\section{List of Publications}

\section{International Peer-Reviewed Journals}

1. LW Lim, VI Molchanov, OV Volkodav. Iatrogenic Traumatic Brain Injury: Penetration of Kirschner's Knitting Needle into the Middle Cranial Cavity. J Craniofac Surg. 2007 May; 18 (3):674-9.

2. LW Lim, Y Temel, T Sesia, R Vlamings, V Visser-Vandewalle, H Steinbusch, A Blokland. Buspirone induced acute and chronic changes of neural activation in the periaqueductal gray of rats. Neuroscience. 2008 Jul 31;155(1):164-173.

3. LW Lim, A Blokland, V Visser-Vandewalle, R Vlamings, T Sesia, H Steinbusch, K Schruers, E Griez, Y Temel. High-frequency stimulation of the dorsolateral periaqueductal gray and ventromedial hypothalamus fails to inhibit the panic-like behaviour. Behav Brain Res. 193 (2008) 197-203.

4. LW Lim, Y Temel, V Visser-Vandewalle, H Steinbusch, K Schruers, R Hameleers, G Esquivel, E Griez, A Blokland. Effect of Buspirone on the Behavioural regulation of rats in low versus high anxiety conditions. Arzneimittel-Forschung/ Drug Research. 2008;58(6):269-276.

5. AH Kaya, R Vlamings, S Tan, P Magill, LW Lim, H Steinbusch, V Visser-Vandewalle, T Sharp, Y Temel. Increased electrical and metabolic activity in the dorsal raphe nucleus of Parkinsonian rats. Brain Res. 2008 Jul 24;1221:93-7.

6. T Sesia, Y Temel, LW Lim, A Blokland, HWM Steinbusch, V Visser-Vandewalle. Deep brain stimulation of the nucleus accumbens core and shell: opposite effects on impulsive action. Exp. Neurol. 214 (2008) 135-129.

7. Y Temel, S Tan, R Vlamings, T Sesia, LW Lim, V Visser-Vandewalle, C Baunez. (2008) Cognitive and limbic effects of deep brain stimulation in preclinical studies. Frontiers in Bioscience 14, 1891-1901.

8. LW Lim, OV Volkodav. (2009) Germinal Matrix Hemorrhage of Prematurity: Treatment Approaches and Outcomes in a Single Institutional Review in the Ukraine. Pediatr Neurosurg 2009;45:132-140.

9. LW Lim, Y Temel, V Visser-Vandewalle, A Blokland, H Steinbusch. (2009) Fos immunoreactivity in the rat forebrain induced by electrical deep brain stimulation of the periaqueductal gray. J Chem Neuroanat. (In press)

\section{Submitted}

1. LW Lim, A Blokland, Y Temel. (2009) The Periaqueductal Gray: from longitudinal column to defensive Behaviour.

2. LW Lim, A Blokland, S Tan, R Vlamings, T Sesia, V Visser-Vandewalle, K Schruers, H Steinbusch, Y Temel. (2009) Electrical stimulation of the dorsolateral periaqueductal gray evokes escape response followed by fear behaviour in rats: reversal by SSRI treatment. 
3. S Tan, LW Lim, R Vlamings, T Sesia, Janssen M, V Visser-Vandewalle, H Steinbusch, Y Temel. (2009) Experimental deep brain stimulation in animal models.

4. LW Lim, A Jahanshahianvar, A Blokland, H Steinbusch, V Visser-Vandewalle, Y Temel. (2009) Buspirone induces 5-HT changes in the nuclei of dorsal raphe of rats.

5. VMP Moers-Hornikx, T Sesia, K Basar, LW Lim, G Hoogland, HWM Steinbusch, DAWD Gavilanes, Y Temel, JSH. Vles (2009) Cerebellar nuclei are involved in impulsive behaviour. Beh. Brain Res.

6. VMP Moers-Hornikx, LW Lim*, TT Kaplan, Hoogland G, Steinbusch H, Temel Y, JH Vles (2009) Cerebellar nuclei are involved in panic-like behaviour. Brain Research

\section{Chapters in International Peer-Reviewed Books}

1. T Sesia, S Tan, R Vlamings, LW Lim, V Visser-Vandewalle, Y Temel. (2008) Basal Ganglia and Behaviour: Behavioural effects of deep brain stimulation in experimental neuropsychiatry. International Basal Ganglia Society (IBAGS)

\section{Abstracts Publication}

1. LW Lim, OV Volkodof, M Zemliansky, S Zinchenko, D Abdul Razzaq (2005) Intracranial Hemorrhages in Premature Newborn. Volume 252, Supplement 2/June, Journal of Neurology 252 [Suppl 2]: II 51, DOI 10.1007 /s00415-005-2002-6. Child Neurology P177, ENS, Vienna, Austria.

2. LW Lim, D Abdul Razzaq, M Fathimath (2005) The modification of Pterional Access. Abstract Journal of $77^{\text {th }}$ Crimean Scientific Practical Conference and $1^{\text {st }}$ Winter Meeting of International Medical Student Symposium of European Medical Student Association, Crimea, Ukraine.

3. LW Lim, M Fathimath, D Abdul Razzaq (2005) Emergency care in isolated and combined cranio-cerebral trauma. Abstract Journal of $77^{\text {th }}$ Crimean Scientific Practical Conference and $1^{\text {st }}$ Winter Meeting of International Medical Student Symposium of European Medical Student Association, Crimea, Ukraine (Oral Presentation)

4. LW Lim, VI Molchanov, OV Volkodav (2007) Iatrogenic Traumatic Brain Injury: Penetration of Kirschner's Knitting Needle into the Middle Cranial Cavity. British Neurosci. Assoc. Abstr., vol 19, P62.03, ISSN 1345-8301, Harrogate, UK.

5. LW Lim, VI Molchanov, SW Lam, OV Volkodav (2007) Germinal Matrix Hemorrhage of Prematurity: Treatment Approaches and Outcomes in a single Institutional Review in the Ukraine. British Neurosci. Assoc. Abstr., vol 19, P60.09, ISSN 1345-8301, Harrogate, UK.

6. LW Lim, VI Molchanov, OV Volkodav (2007) Complication Outcome and Clinical Evaluation for the Isolated and Combined Craniocerebral Trauma. British Neurosci. Assoc. Abstr., vol 19, P62.02, ISSN 1345-8301, Harrogate, UK.

7. LW Lim, Y Temel, R Hameleers, K Schruers, V Visser-Vandewalle, H Steinbusch, E Griez, A Blokland. (2007) The effect of Buspirone on the performance in enclosed and exposed open 
field. British Neurosci. Assoc. Abstr., vol 19, P64.03, ISSN 1345-8301, Harrogate, UK.

8. LW Lim, Y Temel, R Hameleers, T Sesia, R Vlamings, K Schruers, H Steinbusch, A Blokland, E Griez, V Visser-Vandewalle (2007) The Escape Behaviour induced by Electrical Brain Stimulation of the dorsolateral Periaqueductal Gray and Ventromedial Hypothalamus. British Neurosci. Assoc. Abstr., vol 19, P64.02, ISSN 1345-8301, Harrogate, UK.

9. T Sesia, Y Temel, K Basar, R Vlamings, LW Lim, A Blokland, HWM Steinbusch, V VisserVandewalle (2007) Effect of electrical brain stimulation of the reticular thalamic nucleus on reaction time performance. $6^{\text {th }}$ Institute's Day of Brain \& Behaviour Research, Maastricht, the Netherlands.

10. T Sesia, Y Temel, K Basar, R Vlamings, LW Lim, J Prickaerts, A Blokland, HWM Steinbusch, V Visser-Vandewalle (2007) Differential effects of high frequency stimulation of the ventrolateral and mediodorsal thalamic nucleus on impulsive action. $9^{\text {th }}$ Triennial Meeting of the International Basal Ganglia Society, Egmond aan Zee, the Netherlands.

11. S Tan, C Baunez, R Vlamings, T Sesia, LW Lim, S Lardeux, V Visser-Vandewalle, Y Temel (2007) Cognitive and limbic effects of deep brain stimulation in preclinical studies. $11^{\text {th }}$ European Graduate School of Neuroscience (EURON) Ph.D Student Day, Université Catholique de Louvain, Brussels, Belgium.

12. I van Kroonenburgh, LW Lim, V Visser-Vandewalle, HWM Steinbusch, A Blokland, Y Temel (2008) Deep brain stimulation of the periaqueductal gray induces panic-like Behaviour. Abstract Journal of 2008 MMSRC Meeting, Maastricht, the Netherlands.

13. LW Lim, A Blokland, V Visser-Vandewalle, R Vlamings, T Sesia, H Steinbusch, K Schruers, E Griez, Y Temel. High-frequency stimulation of the dorsolateral periaqueductal gray and ventromedial hypothalamus fails to inhibit panic-like behaviour. Acta Neurochir. The European Journal of Neurosurgery (2008) 150:978. The XVIII Congress of the European Society of Stereotactic and Functional Neurosurgery (ESSFN), Rimini, Italy.

14. AH Kaya, R Vlamings, S Tan, LW Lim, P Magill, H Steinbusch, V Visser-Vandewalle, T Sharp, Y Temel. Increased electrical and metabolic activity in the dorsal raphe nucleus of Parkinsonian rats. Acta Neurochir. The European Journal of Neurosurgery (2008) 150:958. The XVIII Congress of the European Society of Stereotactic and Functional Neurosurgery (ESSFN), Rimini, Italy.

15. T Sesia, Y Temel, LW Lim, HWM Steinbusch, V Visser-Vandewalle, A Blokland (2008) Deep brain stimulation of the nucleus accumbens core and shell: opposite effects on impulsive behaviour. Acta Neurochir. The European Journal of Neurosurgery (2008) 150:977. The XVIII Congress of the European Society of Stereotactic and Functional Neurosurgery (ESSFN), Rimini, Italy. 


\section{Committee Members in the Oral Defense}

1. Prof. Dr. J. J. van Overbeeke

2. Prof. Dr. H. W. M. Steinbusch

3. Prof. Dr. V. Visser-Vandewalle

4. Prof. Dr. J. S. H. Vles

5. Prof. Dr. M. De Baets

6. Prof. Dr. E. Beuls

7. Prof. Dr. A. Benazzouz (Bordeaux, France)

8. Dr. P. Magill (Oxford, UK)

9. Dr. K. Schruers

10. Dr. Y. Temel

11. Dr. A. Blokland 